\title{
USE OF APATITE FOR CHEMICAL STABILIZATION OF SUBSURFACE CONTAMINANTS
}

\section{FINAL REPORT}

Work Performed Under Contract:

DE-AC26-01NT41306

Submitted by:

Materials and Chemistry Laboratory, Inc.

East Tennessee Technology Park, Building K-1006

2010 Highway 58, Suite 1000

Oak Ridge, Tennessee 37830-1702

Principal Investigator:

Dr. William D. Bostick

Telephone Number: (865) 574-6827

Fax Number: (865) 576-8558

Contributors:

Dr. R.J. Stevenson, L.A. Harris, D. Peery, J.R. Hall, J.L. Shoemaker, R.J. Jarabek, and E.B. Munday

Submitted to:

U.S. Department of Energy

National Energy Technology Laboratory

COR: Richard Bush

May 2003 


\section{DISCLAIMER}

"This report was prepared as an account of work sponsored by an agency of the United States Government. Neither the United States Government nor any agency thereof, nor any of their employees, makes any warranty, express or implied, or assumes any legal liability or responsibility for the accuracy, completeness, or usefulness of any information, apparatus, product, or process disclosed, or represents that its use would not infringe privately owned rights. Reference herein to any specific commercial product, process, or service by trade name, trademark, manufacturer, or otherwise does not necessarily constitute or imply its endorsement, recommendation, or favoring by the United States Government or any agency thereof. The views and opinions of authors expressed herein do not necessarily state or reflect those of the United States Government or any agency thereof." 


\section{CONTENTS}

LIST OF FIGURES

LIST OF TABLES

1. EXECUTIVE SUMMARY

2. INTRODUCTION

3. EXPERIMENTAL

4. RESULTS AND DISCUSSION

4.1 Raw Materials Characterization

4.1.1 Apatite II ${ }^{\mathrm{TM}}$ : Whole Bone

4.1.2 Sieve Analysis

4.1.3 Bulk Density (Wet and Dry)

4.1.4 Estimate of Residual Organic Matter

4.1.5 Preparation of A Bone Char Product

4.1.6 Synthetic Hydroxyapatite

4.1.7 X-Ray Diffraction (XRD)

4.1.8 Solubility Estimates for Biogenic Apatite

4.1.8.1 Dissolution of Biogenic Apatite: Stirred Tank Reactor

4.2 Establishing Conditions for Batch Testing with Use of ${ }^{233} \mathrm{U}$ Isotope

4.2.1 Temporal Effects of Batch Contact

4.2.2 Effect of Apatite Particle Size

4.2.3 Effect of Soluble P, Organic Matter, and Active Microbes on the Long-Term Uptake of Soluble U

4.3 Batch Tests: Survey of Amenable Metals (Single Metal Experiments)

4.3.1 Antimony, as $\mathrm{Sb}(\mathrm{III})$

4.3.2 Arsenic, as $\operatorname{As}(\mathrm{V})$

4.3.3 Barium, as $\mathrm{Ba}(\mathrm{II})$

4.3.4 Cadmium, as Cd(II)

4.3.5 Chromium, as $\mathrm{Cr}(\mathrm{VI})$

4.3.6 Copper, as $\mathrm{Cu}(\mathrm{II})$

4.3.7 Iron, as $\mathrm{Fe}(\mathrm{II})$

4.3.8 Lead, as $\mathrm{Pb}(\mathrm{II})$

4.3.9 Manganese, as $\mathrm{Mn}(\mathrm{II})$

4.3.10 Mercury, as $\mathrm{Hg}(\mathrm{II})$

4.3.11 Molybdenum, as Mo(VI)

4.3.12 Nickel, as Ni(II)

4.3.13 Selenium, as Se(IV)

4.3.14 Strontium, as $\mathrm{Sr}(\mathrm{II})$

4.3.15 Technetium-99, as Tc(VII)

4.3.16 Thorium, as Th(IV)

4.3.17 Uranium, as U(VI)

4.3.18 Vanadium, as $\mathrm{V}(\mathrm{V})$

4.3.19 Zinc, as $\mathrm{Zn}(\mathrm{II})$

4.3.20 Summary and Comparison of Single Metal Batch Test Results

\begin{tabular}{|l}
\hline Page \\
\hline V \\
\hline VIII \\
\hline 1 \\
\hline 4 \\
\hline 11 \\
\hline 20 \\
\hline 20 \\
\hline 20 \\
\hline 21 \\
\hline 22 \\
\hline 23 \\
\hline 23 \\
\hline 24 \\
\hline 25 \\
\hline 27 \\
\hline 28 \\
\hline 35 \\
\hline 35 \\
\hline 36 \\
\hline 37 \\
\hline 41 \\
\hline 42 \\
\hline 44 \\
\hline 47 \\
\hline 49 \\
\hline 52 \\
\hline 54 \\
\hline 57 \\
\hline 64 \\
\hline 69 \\
\hline 71 \\
\hline 76 \\
\hline 78 \\
\hline 80 \\
\hline 83 \\
\hline 87 \\
\hline 90 \\
\hline 94 \\
\hline 96 \\
\hline 99 \\
\hline
\end{tabular}


CONTENTS (cont.)

4.4 Batch Tests: Experimental Design (Multi-Metal Experiments; Project Task 1.2.5)

4.5 Treatability Demonstration: Use of APA-C to Treat Wastewater

4.6 Leachability Tests for Solid Phase Apatite Residuals

4.6.1 TCLP of Metal-Exposed Apatite (Project Task 1.2.4)

4.6.2 Bioaccessibility Testing of Metal-Exposed Apatite

4.6.2.1 BA Testing for Raw Apatite

4.6.2.2 BA Testing on Exposed Dry Apatite (EDA)

4.6.2.3 BA Testing on Treatability Study Sample (02-0071)

4.7 Soil Column Studies (Project Task 1.3)

4.7.1 Description of Soils Used

4.7.2 Apatite Amendment

4.7.3 Soil Column Tests

4.7.3.1 Preliminary Testing: Spiked Synthetic Groundwater Fed to "Clean" Soil

4.7.3.2 Spiked Synthetic Groundwater Fed to "Clean" Soil

4.7.3.3 "Clean" Aqueous Feed to Contaminated Soil ("Series 31")

4.7.4 Characterization of Soil Samples from Column Studies

4.7.4.1 Characterization of the Microbial Populations Induced in Apatite-Amended Soil Column 31.3

4.7.4.2 Examination of Soil Samples from "Series 57" Soil Columns

4.7.4.2.1 Exposed Soil Mineralogy (“Series 57”)

4.7.4.2.2 Spatial distribution of Select Metals Within Exposed Soil ("Series 57”)

4.7.4.2.3 Summary of data for migration of contaminants in soil

4.7.4.3 Selective extraction of metal contaminants in soil column composites

4.7.4.3.1 Introduction

4.7.4.3.2 Results

4.7.4.3.2.1 Sequential Extraction of Calcium $(\mathrm{Ca})$

4.7.4.3.2.2 Sequential Extraction of Phosphorous $(\mathrm{P})$

4.7.4.3.2.3 Sequential Extraction of Arsenic (As)

4.7.4.3.2.4 Sequential Extraction of Uranium (U)

4.7.4.3.2.5 Sequential Extraction of Cadmium $(\mathrm{Cd})$

4.7.4.3.2.6 Sequential Extraction of Mercury (Hg)

4.7.4.4 Summary for Sequential Extraction Results

5.0 Conclusions

6.0 References and Bibliography

7.0 List of Acronyms and Abbreviations

Appendix A-1

Appendix A-2

Appendix A-3

Appendix A-4

\begin{tabular}{|l}
\hline Page \\
\hline 101 \\
\hline 104 \\
\hline 107 \\
\hline 107 \\
\hline 108 \\
\hline 109 \\
\hline 109 \\
\hline 110 \\
\hline 111 \\
\hline 111 \\
\hline 114 \\
\hline 115 \\
\hline 116 \\
\hline 125 \\
\hline 129 \\
\hline 139 \\
\hline 139 \\
\hline 140 \\
\hline 140 \\
\hline 141 \\
\hline 145 \\
\hline 146 \\
\hline 146 \\
\hline 148 \\
\hline 148 \\
\hline 150 \\
\hline 152 \\
\hline 153 \\
\hline 156 \\
\hline 159 \\
\hline 160 \\
\hline 162 \\
\hline 167 \\
\hline 180 \\
\hline 183 \\
\hline 184 \\
\hline 186 \\
\hline
\end{tabular}




\section{LIST OF FIGURES}

1. The Apatite Mineral Group

2. Stirred tank reactor, configured to maintain anoxic conditions.

3. Theoretical lognormal mass distribution function for dry-sieved Apatite II (sample MCL 01-0263)

4. XRD diffractograms for synthetic hydroxyapatite (HAP, MCLinc sample \#01-0297) and fish bone apatite (MCLinc sample \#01-0263).

5. Computed Phosphate species distribution Diagram as a Function of Solution $\mathrm{pH}$ Value.

6. Redox status of anoxic slurry of Apatite II in synthetic groundwater.

7. Removal of Uranium from ${ }^{233}$ U-traced Synthetic Groundwater as a function of Partlicle 37 Size.

8. Removal of soluble U-233 from clean syn-BYBY (no initial P or biological activity).

9. Removal of soluble U-233 from "inoculated" syn-BYBY (pre-equilibrated with nonsterile APA to provide initial $\mathrm{P}$ and biological activity).

10. Sorption of $\mathrm{Sb}(\mathrm{III})$ on Raw Apatite.

11. Sorption of $\mathrm{Sb}(\mathrm{III})$ to Raw Apatite II.

12. Sorption of As(V) on Raw Apatite, fitted to a linearized Freundlich isotherm.

13. Sorption isotherm for $\mathrm{As}(\mathrm{V})$ partitioning between solution and solid phases.

14. Figure Ba-1.

15. Sorption of Barium to Raw Apatite II.

16. Sorption of Cd(II) on Raw Apatite.

17. Sorption of Cadmium to Raw Apatite II.

18. Initial concentration data (Co) are for series A in Table $\mathrm{Cr}-1$.

19. Sorption of $\mathrm{Cu}(\mathrm{II})$ on Raw Apatite.

20. Sorption of $\mathrm{Cu}(\mathrm{II})$ to Raw Apatite II, presented as a linear isotherm.

21. Interaction between Fe(II) and Apatite under Anoxic Conditions: Part 1

22. Interaction between Fe(II) and Apatite under Anoxic Conditions: Part II

23. Concentrations of Soluble $\mathrm{Pb}(\mathrm{Oc}$ : no exposure to Apatite; Ce: after exposure to Apatite), Sorted by Test Series (See Table Pb-1).

24. Concentration of $\mathrm{Pb}(\mathrm{II})$ in Serial Dilutions of Stock Solutions using( $\diamond)$ DI-water and

(匹) Synthetic Groundwater (syn-BYBY).

25. Sorption of $\mathrm{Pb}(\mathrm{II})$ on Raw Apatite. Experimental results are fitted to a linearized Freundlich isotherm Eq.4).

26. Sorption of $\mathrm{Pb}(\mathrm{II})$ to Raw Apatite II, presented as a linear isotherm.

27. Sorption of $\mathrm{Mn}(\mathrm{II})$ on Raw Apatite.

28. Sorption of Mn(II) to Raw Apatite II, presented as a linear isotherm.

29. Sorption of $\mathrm{Hg}(\mathrm{II})$ on Raw Apatite.

30. Sorption of $\mathrm{Hg}(\mathrm{II})$ to Raw Apatite II, presented as a linear isotherm.

31. Sorption of $\mathrm{Hg}(\mathrm{II})$ to Raw Apatite II (APA-II) and Calcined Apatite (Apa-C)

32. Concentrationos of Soluble $\mathrm{Hg}$ (Co: Series A, no exposure to Apatite C; Ce: Series B after exposure to Apatite), Sorted by Test Series.

33. Sorption of Mo(VI), as Molybdate, on Raw Apatite.

34. Sorption of Molybienum (as Molybdate) to Raw Apatite II.

35. Sorption of Ni(II) on Raw Apatite.

40

40

43

43

46

46

48

48

50

51




\section{LIST OF FIGURES (cont.)}

\begin{tabular}{|c|c|}
\hline & Page \\
\hline 36. Sorption of Ni(II) to Raw Apatite II. & 79 \\
\hline 37. Removal of soluble Se, added as selenous acid, by Raw Apatite. & 81 \\
\hline 38. Sorption of Selenium (Added as Selenous Acid) to Raw Apatite II. & 82 \\
\hline 39. Sorption of Sr(II) on Raw Apatite. & 84 \\
\hline 40. Sorption of Strontium to Raw Apatite II. & 85 \\
\hline $\begin{array}{l}\text { 41. (Scan 02-0126-01: Scanning Electron Microscopy with Energy-Dispersive X-ray } \\
\text { Spectroscopy (SEM-EDS) for Th-rich calcium phosphate solid phase formed by } \\
\text { contact of thorium nitrate solution and Apatite II). }\end{array}$ & 89 \\
\hline 42. SEM Back-Scattered Electron Image of Apatite from Column Study. & 91 \\
\hline 43. Sorption of V(V) on Raw Apatite. & 95 \\
\hline 44. Sorption of Vanadium to Raw Apatite II. & 95 \\
\hline 45. Sorption of $\mathrm{Zn}(\mathrm{II})$ to Raw Apatite II, presented as a Freundlich Sorption Isotherm. & 97 \\
\hline 46. Sorption isotherm for $\mathrm{Zn}$ (II) partitioning between solution and solid phases. & 98 \\
\hline $\begin{array}{l}\text { 47. Distritbution Coefficient }(\mathrm{Kd}, \mathrm{mL} / \mathrm{g}) \text { For Select Metals On Apatite II As a Function of } \\
\text { Equilibrium Concentration in Solution Phase }(\mathrm{Ce}, \mathrm{g} / \mathrm{mL}) \text {. }\end{array}$ & 100 \\
\hline $\begin{array}{l}\text { 48. A comparison of computed solid-phase distribution (Kd) vs. the corresponding } \\
\text { equilibrium solution phase metal concentration }(\mathrm{Ce}) \text { for mercury in the Single-Metal } \\
\text { Experiment (SME) and the Multi-Metal Experiment (MME). }\end{array}$ & 102 \\
\hline $\begin{array}{l}\text { 49. A comparison of computed solid-phase distribution coefficient (Kd) vs. the } \\
\text { corresponding equilibrium solution phase metal concentration (Ce) for cadmium in the } \\
\text { Single-Metals Experiment (SME) and the Multi-Metal Experiement (MME). }\end{array}$ & 103 \\
\hline $\begin{array}{l}\text { 50. Removal of Soluble Uranium from Synthetic BYBY Water with use of Bone Char } \\
\text { Products. }\end{array}$ & 106 \\
\hline 51. Theoretical Lognormal Mass Distribution for Dried Soil Grains. & 114 \\
\hline 52. Theoretical Lognormal Particle Mass Distribution for Select Apatite Products & 115 \\
\hline 53. Illustration of Soil Column Elution. & 116 \\
\hline 54. Total Iron (Fe) in Series 12 Soil Column Eluates. & 118 \\
\hline 55. Total Uranium (U) in "Series 12" Soil Column Eluates. & 120 \\
\hline 56. Elution of Select Metals from Soil Column 12-1 (control, with no Apatite Added). & 122 \\
\hline $\begin{array}{l}\text { 57. Elution of Select Metals from Soil Column 12-4 (Soil Amended with } \sim 5 \mathrm{wt} \% \\
\text { Elutriated Apatite). }\end{array}$ & 123 \\
\hline $\begin{array}{l}\text { 58. Breakthrough of } \mathrm{U} \text { and } \mathrm{Cd} \text { in the eluate from Soil Column 57-1 (no Apatite } \\
\text { amendment). }\end{array}$ & 126 \\
\hline 59. Mercury in Aqueous Solution (Feed and Column Eluate Samples). & 127 \\
\hline 60. Arsenic Concentration in Soil Column Series 57 Eluate. & 128 \\
\hline $\begin{array}{l}\text { 61. Raw Apatite II is added to dry blended soil } 00-0656 \text {, and then the blend is subjecte to } \\
\text { TCLP protocol. }\end{array}$ & 130 \\
\hline 62. Elution of U from Column 31-1 (No Apatite Amendment). & 131 \\
\hline 63. Cumulative elution of U from "Series 31" Soil Columns. & 132 \\
\hline 64. Elution of Mn from Soil Column Series 31. & 133 \\
\hline 65. Elution of P from "Series 31" Soil Columns. & 134 \\
\hline 66. Cumulative Elution of Total Phosphorous (p) from Soil Columns. & 135 \\
\hline 67. Elemental composition of solids from Column 31-4. & 136 \\
\hline
\end{tabular}




\section{LIST OF FIGURES (cont.)}

\begin{tabular}{l|l}
\hline & Page \\
\hline $\begin{array}{l}\text { 68. Morphology of Fine Solids that had been previously concentrated by centrifugation of } \\
\text { Column 31-4, eluate fraction 56C. }\end{array}$ & 137 \\
\hline 69. Spatial distribution of As in Segments from Exposed Soil Columns. & 142 \\
\hline 70. Spatial distribution of Cd in Segments from Exposed Soil Columns. & 143 \\
\hline
\end{tabular}

71. Spatial distribution of $\mathrm{Hg}$ in Segments from Exposed Soil Columns.

144

72. Spatial distribution of U in Segments from Exposed Soil Columns.

73. Partitioning of Extractable Ca in Exposed Soil Composites.

145

74. Partitioning of Extractable P in Soil Composites.

149

75. Partitioning of Extractable As in Exposed Soil Composites.

151

76. Partitioning of Extractable U in Exposed Soil Composites.

152

77. Partitioning of Extractable $\mathrm{Cd}$ in Exposed Soil Composites. 155

78. Partitioning of Extractable Hg in Exposed Soil Composites.

158




\section{LIST OF TABLES}

\begin{tabular}{l|l}
\hline & \\
\hline 1. Metal Contaminants of Concern: Reported Frequency of Occurrence in Soil and \\
Groundwater at Contaminated Sites
\end{tabular}

2. Select Groundwater Proxy Compositions

3. Lognormal Mass Distribution for Dry Sieved Apatite II (MCL 01-0263)

4. Select Physical Properties of Apatite

5. Solubility Products for Select Mineral Phases, Derived from the MINTEQ Database.

6. Solubility of Synthetic Hydroxyapatite (Reported Literature Values).

7. Dissolution of Elutriated Apatite II in Synthetic Groundwater $\left(\mathrm{T} \sim 23^{\circ}\right)$.

8. Short-Term (16-h) Release of Soluble Phosphate and Calcium Ions from Apatite by Leach with Deionized Water.

9. Removal of Soluble Uranium $\left(\mathrm{C}_{\mathrm{o}}=464 \mu \mathrm{g}-\mathrm{U} / \mathrm{L}\right)$ from Synthetic Groundwater.

10. Raw Apatite (APA) Contacted 56-h with M Sb(III) (from antimony potassium tartrate, $\left.\mathrm{C}_{8} \mathrm{H}_{4} \mathrm{~K}_{2} \mathrm{O}_{12} \mathrm{Sb}_{2} \cdot 3 \mathrm{H}_{2} \mathrm{O}\right)$ in Synthetic Groundwater Matrix

11. Raw Apatite (APA) Contacted 52-h with As (V) (from Sodium Arsenate) in Synthetic Groundwater

12. Raw Apatite (APA) Contacted 52-h with $\mathrm{M}=\mathrm{Ba}$ (II) (from barium chloride, $\mathrm{BaCl}_{2} \cdot 2 \mathrm{H}_{2} \mathrm{O}$ ) in Synthetic Groundwater Matrix

13. Raw Apatite (APA) Contacted 52-h with $\mathrm{M}=\mathrm{Cd}$ (II) (from cadmium nitrate) in Synthetic Groundwater Matrix

14. Raw Apatite (APA) Contacted 52-h with $\mathrm{M}=\mathrm{Cr}(\mathrm{VI})$ (from potassium dichromate) in Synthetic Groundwater Matrix

15. Raw Apatite (APA) Contacted 52-h with $\mathrm{M}=\mathrm{Cu}$ (II) (from cupric chloride in synthetic Groundwater Matrix

16. Interaction of Fe(II) and Apatite (APA) in 1-L Synthetic Groundwater Under Anoxic Conditions: Part 1

17. Interaction of $\mathrm{Fe}(\mathrm{II})$ and Apatite (APA) in 1-L Synthetic Groundwater Under Anoxic Conditions: Part II

18. Computed Data for Experiment 1042-25-7B (Apatite II ${ }^{\mathrm{tm}}$ plus $\mathrm{Fe}^{2+} ; 20$-h Contact; $\mathrm{pH}=63$; Solution Filtered at $0.45-\mu \mathrm{m})$

19. Raw Apatite (APA) Contacted 52-h with $\mathrm{M}=\mathrm{Pb}$ (II) (from lead nitrate) in Synthetic Groundwater Matrix

20. Raw Apatite (APA) Contacted 52-h with $\mathrm{M}=\mathrm{Pb}$ (II) (from lead nitrate) in DI-Water Matrix

21. Raw Apatite (APA) Contacted 52-h with $\mathrm{M}=\mathrm{Mn}$ (II) (from manganese sulfate) in Synthetic Groundwater Matrix

22. Raw Apatite (APA) Contacted 52-h with $\mathrm{M}=\mathrm{Hg}$ (II) (from mercuric sulfate) in Synthetic Groundwater Matrix

23. Calcined Apatite (APA-C) Contacted 52-h with $\mathrm{M}=\mathrm{Hg}(\mathrm{II})$ (from lead nitrate) in DI-Water Matrix

24. Raw Apatite (APA) Contacted 52-h with $\mathrm{M}=\mathrm{Mo}$ (VI) (from sodium molybdate, $\left.\mathrm{Na}_{2} \mathrm{MoO}_{4} \cdot 2 \mathrm{H}_{2} \mathrm{O}\right)$ in Synthetic Groundwater Matrix

25. Raw Apatite (APA) Contacted 52-h with $\mathrm{M}=\mathrm{Ni}$ (II) from nickel acetate) in synthetic Groundwater Matrix

26. Raw Apatite (APA) Contacted 52-h with $\mathrm{M}=\mathrm{Se}$ (IV) (from selenous acid, $\mathrm{H}_{2} \mathrm{SeO}_{3}$ ) in Synthetic Groundwater Matrix 
LIST OF TABLES (cont.)

\begin{tabular}{|c|c|}
\hline & Page \\
\hline $\begin{array}{l}\text { 27. Raw Apatite (APA) Contacted 52-h with } \mathrm{M}=\mathrm{Sr} \text { (II) (from strontium nitrate) in Synthetic } \\
\text { Groundwater Matrix }\end{array}$ & 84 \\
\hline 28. Removal of Soluble Tc-99 by Select Media (22-h Phase Contact) & 86 \\
\hline 29. Thorium Solution Activities After Contact with Apatite C-400 (16-h at L/S = 76, w/w) & 88 \\
\hline $\begin{array}{l}\text { 30. Raw Apatite (APA) Contacted 52-h with } \mathrm{M}=\mathrm{U}(\mathrm{VI}) \text { (from uranyl nitrate) in Synthetic } \\
\text { Groundwater Matrix }\end{array}$ & 92 \\
\hline $\begin{array}{l}\text { 31. Raw Apatite (APA) Contacted 52-h with } \mathrm{M}=\mathrm{V}(\mathrm{V}) \text { (from sodium vanadate, }\left(\mathrm{Na}_{3} \mathrm{VO}_{4} \cdot 6 \mathrm{H}_{2} \mathrm{O}\right) \\
\text { in Synthetic Groundwater Matrix }\end{array}$ & 94 \\
\hline 32. Raw Apatite (APA) Contacted 52-h with Zn(II) (from zinc sulfate) in Synthetic Groundwater & 96 \\
\hline 33. Batch-Treatment of a Wastewater Sample from Paducah Gaseous Diffusion Plant & 105 \\
\hline $\begin{array}{l}\text { 34. Overall Removal of Select Contaminants from PGDP Wastewater with Use of Acid-Washed } \\
\text { Coal (AWC) and Apatite II Char (APA-C) }\end{array}$ & 107 \\
\hline 35. TCLP Extraction of Exposed Dry Apatite-II (EDA) from Short-Term Exposure Study & 107 \\
\hline $\begin{array}{l}\text { 36. TCLP Extraction of Used Apatite-C from Long-Term FIU Treatability Study (MCL ID 02- } \\
\text { 0071) }\end{array}$ & 108 \\
\hline 37. Bioaccessibility Extraction of As-Received Raw Fishbone Apatite (Sample 01-0263) & 109 \\
\hline 38. BA Extraction of Apatite-II (EDA) "Bulk" from Short-Term Metal Exposure Study & 110 \\
\hline $\begin{array}{l}\text { 39. BA Extraction of Used Apatite-C from Long-Term FIU Treatability Study (Sample 02-0071, } \\
\text { "fines" fraction) }\end{array}$ & 110 \\
\hline 40. Select Physical Properties for Reference Soil 00-0656 (Used in Soil Column Series 31) & 112 \\
\hline 41. Estimate of Major Constituents in Soil Samples by X-Ray Fluorescence (XRF) & 113 \\
\hline 42. Select Properties of Apatite Products Used in Soil Columns & 115 \\
\hline 43. Effect of Added Apatite on the TCLP Lea & 129 \\
\hline
\end{tabular}




\subsection{EXECUTIVE SUMMARY}

Groundwater at many Federal and civilian industrial sites is often contaminated with toxic metals at levels that present a potential concern to regulatory agencies. The U.S. Department of Energy (DOE) has some unique problems associated with radionuclides (primarily uranium), but metal contaminants most likely drive risk-based cleanup decisions, from the perspective of human health, in groundwater at DOE and U.S. Environmental Protection Agency (EPA) Superfund Sites include lead ( $\mathrm{Pb}$ ), arsenic (As), cadmium $(\mathrm{Cd})$, chromium $(\mathrm{Cr})$, mercury $(\mathrm{Hg})$, zinc $(\mathrm{Zn})$, selenium $(\mathrm{Se})$, antimony $(\mathrm{Sb})$, copper $(\mathrm{Cu})$ and nickel $(\mathrm{Ni})$. Thus, the regulatory "drivers" for toxic metals in contaminated soils/groundwaters are very comparable for Federal and civilian industrial sites, and most sites have more than one metal above regulatory action limits. Thus improving the performance of remedial technologies for metal-contaminated groundwater will have "dual use" (Federal and civilian) benefit.

Contaminants distributed within the soil matrix typically represent the source term for partitioning into the groundwater systems. Excavation of the contaminated source, for compliant disposal or ex-situ treatment, is usually a large-scale and very expensive undertaking. An attractive alternative is $i n$-situ immobilization of contaminants within the original soil so that contaminants of concern do not continue to migrate at levels above regulatory concern into previously clean areas. One particularly effective means to accomplish this is with use of "Phosphate-Induced Metals Stabilization," a patented (US Patent \#6,217,775, held by PIMS-NW) soil remediation approach utilizing biogenic apatite (a calcium phosphate mineral, supplied in the form of fish bone). Apatite II ${ }^{\mathrm{TM}}$ works by providing phosphate ion to the solution phase to precipitate metal phosphate solids, and inducing the precipitation of metals into other phases such as carbonates, oxides, and hydroxides. The material also induces adsorption onto existing surfaces, where localized high phosphate ion activity can exceed the metal phosphate solubility product to yield highly insoluble crystalline phases that deposit directly onto the existing apatite substrate. Nanocrystals in the Apatite II structure provide sites to nucleate the metal precipitates. Toxic metal ions may replace the calcium, and toxic oxyanions may replace phosphate or carbonate in the apatite substrate structure.

We performed a series of batch-tests to assess which of the typical priority metals were removed from a synthetic groundwater solution by contact with apatite solids. The project-defined success criterion was achieving a conditional distribution coefficient, $\mathrm{K}_{\mathrm{d}}$, of $\sim 1,000 \mathrm{~mL} / \mathrm{g}$, which projects to retarding the migration of a contaminant plume by a factor of approximately 1,000 -fold. In our investigations, the affinity for priority cationic contaminants on Apatite II follows the approximate series (ranked by decreasing magnitude of the contaminant distribution coefficient, $\mathrm{Kd}$, at lowest solution phase residual concentration evaluated):

$$
\mathrm{UO}_{2}{ }^{+2}>\mathrm{Pb}^{+2} \geq \mathrm{Th}^{+4}>\mathrm{Cd}^{+2}>\mathrm{Mn}^{+2} \sim \mathrm{Zn}^{+2}>\mathrm{Cu}^{+2} \sim \mathrm{SbO}^{+} \sim \mathrm{Hg}^{+2}>\mathrm{Ni}^{+2}>\mathrm{Sr}^{+2}>\mathrm{Ba}^{+2}
$$


The metals in the progression up to and including $\mathrm{Hg}$, were able to meet the success criterion. Removal of contaminant oxyanions to pre-existing apatite phase in short-term batch tests was less successful; the approximate order of preference for sorption is:

$$
\mathrm{VO}_{4}{ }^{-3}>\mathrm{MoO}_{4}{ }^{-2}>\mathrm{SeO}_{3}{ }^{-2}>\mathrm{AsO}_{4}{ }^{-3}>\mathrm{CrO}_{4}{ }^{-2}>\mathrm{TcO}_{4}{ }^{-}
$$

None of the oxyanions tested met the proposed success criterion of $\mathrm{K}_{\mathrm{d}} \geq 1,000 \mathrm{~mL} / \mathrm{g}$ in the range of contaminant concentrations studied, but several (e.g., $\mathrm{VO}_{4}{ }^{-3}$ and $\mathrm{SeO}_{3}{ }^{-2}$ ) evidenced distinctly nonlinear sorption isotherms, with projected relatively strong sorption for low levels of soluble contaminant.

The batch tests demonstrated that biogenic apatite has the potential to strongly bind many of the high priority metal contaminants. The affinity for $U$ is especially strong; uranium appears to initially sorb to the apatite surface, rather than undergoing homogeneous precipitation from solution phase as an insoluble phosphate salt. At high U loading on apatite (several wt\%), phase transitions are noted, with formation of highly insoluble crystalline minerals of the autunite group $\left(\mathrm{M}\left(\mathrm{UO}_{2}\right)_{2}\left(\mathrm{PO}_{4}\right)_{2} \cdot \mathrm{nH}_{2} \mathrm{O}\right)$. We performed testing of biogenic apatite laden with select metals $(\mathrm{U}, \mathrm{Cd}, \mathrm{Pb}, \mathrm{Hg})$. These metals did not leach from the apatite host at concentrations above the criteria defined in the Toxicity Characteristic Leaching Procedure (TCLP). However, testing against a proposed Bioaccessibility Test protocol indicates that the apatite host is unstable at $\mathrm{pH} 1.5$, dissolving the matrix and releasing the majority of bound metal.

Ground apatite could be applied to soil as a metal stabilization agent by, e.g., in-situ soil mixing with the use of hollow-stem auger equipment. We evaluated the utility of such an approach by preparing soil columns comprised of native soil (control sample) and also soil mixed with ground apatite at a dosage of $\sim 5 \mathrm{wt} \%$. Two series of tests were performed: (a) elution of metals from contaminated soil by "clean' groundwater proxy, and (b) elution of select toxic metals fed to "clean" soil. In the absence of added apatite, uranyl and mercuric ions are relatively mobile in soil. But retention of these metals is greatly enhanced by apatite amendment, as evidenced by the lack of these species in the eluent from the amended soil, and also the progression profile of these metals within the exposed soil, as compared to the corresponding data for the control (untreated) soil. Cadmium and arsenic are more strongly retained in the soil matrix, with $\mathrm{Cd}$ more strongly retained in the amended soil, and arsenate somewhat more strongly retained in the control. The similarities between phosphate and arsenate, and the resulting competition for available binding sites, are the likely cause for slightly diminished retention of arsenate ion in the amended soil. In general, apatite amendment decreases the exchangeable fraction for toxic cations in soil, transforming the metals into more leach-resistant phases.

Raw ground apatite product contains considerable extraneous organic matter (as estimated by loss on ignition). Much of this less-dense extraneous material may be removed by washing the apatite product under running water (i.e., by elutrifying the solids). The extraneous organic matter may create nuisance odor in certain above ground applications of apatite technology. In the subsurface, raw apatite is a nutrient source (phosphate ion, an essential nutrient, from the slow dissolution of apatite phase, and 
nitrogen and carbon from the extraneous matter). Thus, apatite has the potential to be a beneficial adjunct to bioremediation. When soil amended with raw apatite (a nutrient source) becomes flooded with water, limiting the diffusion of air into the soil pore volume, anerobic bacteria may proliferate. Under these conditions, certain reducible metals, such as iron and manganese, become more soluble, and have the potential to combine with phosphate ion (from dissolution of apatite phase) to form fine particulate. This fine (colloidal) particulate has a tendency to agglomerate, however it also has the potential to migrate through the soil pores to some extent. 


\subsection{INTRODUCTION}

Cost-effective means are needed by the DOE and industry to minimize the migration of toxic heavy metals into previously clean areas or the leaching of these metals into groundwater. Approximately 75\% of EPA Superfund sites for which Records of Decision have been signed contain metals as contaminants of concern (COC) (Evanko and Dzombak, 1997). The DOE has some unique problems with radionuclides, but the frequency of occurrence for other contaminants of concern are very similar for the other agencies listed in Table $\mathbf{1 .}$

Table 1. Metal Contaminants of Concern: Reported Frequency of Occurrence in Soil and Groundwater at Contaminated Sites

\begin{tabular}{clll}
\hline Rank & $\begin{array}{l}\text { EPA Superfund } \\
\text { Sites (1) }\end{array}$ & $\begin{array}{l}\text { U.S. Department of Energy } \\
\text { (DOE) Sites (2) }\end{array}$ & $\begin{array}{l}\text { U.S. Department of } \\
\text { Defense (DOD) Sites (2) }\end{array}$ \\
\hline 1 & Lead $(\mathrm{Pb})$ & Radionuclides & Lead (Pb) \\
2 & Chromium (Cr) & Chromium (Cr) & Arsenic (As) \\
3 & Arsenic (As) & Lead (Pb) & Manganese (Mn) \\
4 & Zinc ( $\mathrm{Zn})$ & Mercury (Hg) & Cadmium (Cd) \\
5 & Cadmium $(\mathrm{Cd})$ & Cadmium (Cd) & Chromium (Cr) \\
6 & Copper $(\mathrm{Cu})$ & Arsenic (As) & Antimony (Sb) \\
7 & Mercury (Hg) & Barium (Ba) & Nickel (Ni) \\
\hline
\end{tabular}

(1) Evanko, C.R.; Dzombak, D.A. (1997), "Remediation of Metals-Contaminated Soils and Groundwater," Technical Evaluation Report TE-97-01, prepared for GWRTAC.

(2) Oelrich, I. (1998), "Environmental Contamination at Department of Defense and Energy Sites," presented at the First Workshop on Heavy Metal Contaminants in Water (Butte, MT, 1998).

From Table 1, it is obvious that many of the same toxic metals occur at levels of regulatory concern at both Federal and Industrial contaminated sites. Of the radionuclide contaminants occurring at DOE sites, uranium is the most ubiquitous. Morrison (2001) writes:

"More than 150 million tons of uranium mill tailings has been removed from 22 former uranium ore-processing sites in the United States. Remediation of groundwater at these sites is mandated by Congress and is being conducted by the U.S. Department of Energy (DOE) Uranium Mill Tailings Remedial Action (UMTRA) Ground Water Project. The U.S. Environmental Protection Agency (EPA) promulgated a groundwater concentration limit of $30 \mathrm{pCi} / \mathrm{L}$ (approximately $44 \mu \mathrm{g} / \mathrm{L}$ ) for $\mathrm{U}$ to ensure protection of human health and the environment near these sites... At many of these former ore processing sites, $U$ has entered the groundwater system resulting in contamination of more than 10 billion gallons of groundwater... In addition to tailings sites, $\mathrm{U}$ has been reported in groundwater at 12 of 18 major DOE facilities because of contamination from the weapons production cycle." 
Contaminants distributed within the soil matrix typically represent the source term for partitioning into the groundwater systems. Conventional technologies for the remediation of contaminated soil include source term reduction by: (1) the simple physical excavation of contaminated soil to be stored or placed in a controlled landfill at another location and replacement of the original soil with "borrowed" clean soil, or (2) extraction of the contaminant(s) from the soil matrix (e.g., in-situ or ex-situ soil washing, soil flushing, electrokinetic mobilization, etc.), with subsequent treatment or disposition of the contaminated extractant solution. An attractive alternative is in-situ immobilization of contaminants within the original soil so that contaminants of concern do not continue to migrate at levels above regulatory concern into previously clean areas. This approach is generally cost-effective, and is particularly applicable to controlled access active Federal facilities or closure sites with institutional controls, where the objective may be to prevent or minimize off-site migration of contaminant into public lands or groundwater systems. Changing a metal's molecular species by in-situ immobilization may reduce its water solubility, bioavailability, and potential toxicity to humans and the environment. However, the total concentration of the metals in the contaminated material may not necessarily change. Regulatory acceptance of the in-situ stabilization approach is favored by demonstrating that the modified form(s) of the contaminant do actually have greatly reduced mobility and toxicity, as evidenced by (e.g.), selective extraction procedures.

Many heavy metals from Table 1 form relatively insoluble phosphate compounds, including (but not limited to): lead $(\mathrm{Pb})$, cadmium $(\mathrm{Cd})$, zinc $(\mathrm{Zn})$, copper $(\mathrm{Cu})$, and radionuclides such as uranium $(\mathrm{U})$, and other actinide group metals. Thus the use of phosphate amendment for in-situ metal stabilization is an attractive treatment option. Use of apatite (calcium phosphate) mineral phases provides a persistent release of relatively low levels of phosphate ion over a period of time (perhaps several years). In contrast, the metal stabilizing effect for the use of soluble phosphate and other precursors may be relatively ephemeral and inefficient. However, many forms of apatite materials (e.g., mined phosphate rock) are only moderately reactive, due to their being recystallized, having extensive pre-existing substitution with fluoride ion and/or heavy metals, or having little microporosity or carbonate in their structure.

A particularly effective form of apatite for use in metal stabilization is Apatite II $^{\mathrm{TM}}$, a fishbone product patented by UFA Ventures (now PIMS-NW; US Patent \#6,217,775). Apatite II works by providing phosphate ion to the solution phase to precipitate metal phosphate solids, and inducing the precipitation of metals into other phases such as carbonates, oxides, and hydroxides. The material also induces adsorption onto existing surfaces, where localized high phosphate ion activity can exceed the metal phosphate solubility product to yield highly insoluble crystalline phases that deposit directly onto the existing apatite substrate. Nanocrystals in the Apatite II structure provide sites to nucleate the metal precipitates. Toxic metal ions may replace the calcium, and toxic oxyanions may replace phosphate or carbonate in the apatite substrate structure (see Figure 1). 


\section{$\mathrm{Ca}_{10}\left(\mathrm{PO}_{4}\right)_{6}(\mathrm{OH})_{2} \bullet \mathrm{nH}_{2} \mathrm{O}$ \\ | | I_Substitution by F, Cl, $\mathrm{CO}_{3}$ \\ I_Substitution by $\mathrm{CO}_{3}$, XOy $(\mathrm{X}=$ As, V, etc. $)$ \\ I_Substitution by $\mathrm{Pb}, \mathrm{U}, \mathrm{Zn}, \mathrm{Cd}, \mathrm{Th}, \mathrm{Sr}$, and many other Metals}

Figure 1. The Apatite Mineral Group

The National Energy Technology Laboratory (NETL) has funded a project (Use of Apatite for Chemical Stabilization of Subsurface Contaminants; NETL Contract DEAC26-01NT41306) to assess the applicability of biogenic apatite (a calcium phosphate mineral phase found in bone tissue) for sub-surface chemical fixation (in-situ stabilization) of select metal contaminants of interest. The apatite phase has a limited solubility in water, dissolving slowly to maintain a low activity of phosphate ion, which is available to react with dissolved metals. In addition, the apatite solid surface acts as a sorptive phase and promotes nucleation and precipitation of other metal phosphate phases.

In the Management Plan prepared for this project (MCL-614-TP), the following potential deployment issues were identified for research and resolution:

- Particle size. The particle size distribution of crushed bone will affect the specific surface area available for sorption or apatite dissolution phenomena.

- Organic matter. Since the Apatite II product is of biogenic origin (fish bone), it will be useful to determine the amount of residual organic matter, which may affect the stimulation of biological activity induced by the media after emplacement. Adventitious biological activity may be beneficial in some applications, such as the treatment of groundwater containing organic contaminants and select nutrients (e.g., nitrate ion). However, nitrogenous residue in extraneous matter may contribute to nuisance odor when material is stored or used above-ground.

- Crystallinity. An amorphous apatite material will be less stable than a highly crystalline material, and thus it will dissolve more rapidly to provide reactive phosphate to the solution phase. On the other hand, some degree crystallinity within the apatite solid phase is desirable to initiate sorption of contaminants and nucleation of precipitate phases at the reactive surface.

This report provides data to help address these issues. Batch-testing under a consistent set of conditions was used to assess the general applicability of apatite for the treatment of metal contaminants. In an initial phase of investigation, we used soluble uranium, a priority contaminant for DOE (Morrison et al., 2001), as a model compound to assess the effect of material properties and phase contact variables on the uptake of metals by apatite. After the testing parameters were established, batch tests were similarly performed for a number of priority metals, including those presented in Table 1. 
In order to compare the relative effectiveness of apatite solid phase for the removal of different soluble contaminants, or the removal of a given contaminant under variable test conditions, we compute a conditional distribution (or partition) coefficient, $\mathrm{K}_{\mathrm{d}}$, using the relationship:

$$
\mathrm{K}_{\mathrm{d}}=\mathrm{S} / \mathrm{C}_{\mathrm{e}}
$$

where $\mathrm{S}=$ mass of contaminant "sorbed" at equilibrium per mass of sorbent, and $\mathrm{C}_{\mathrm{e}}=$ equilibrium concentration of soluble contaminant in the aqueous phase.

If $\mathrm{C}$ is given in $\mathrm{g} / \mathrm{mL}$, then $\mathrm{K}_{\mathrm{d}}$ has the units $\mathrm{mL} / \mathrm{g}$. The value of $\mathrm{K}_{\mathrm{d}}$ obtained from equilibrium batch testing can be used to roughly estimate the packed bed capacity or retardation factor, $\mathrm{R}_{\mathrm{f}}$ (i.e., reactor breakthrough, in cumulative bed pore volumes passed), with the caveat that solute mass transport and reaction kinetics significantly affect the performance of actual dynamic flow reactors (Relyea, 1982):

where

$$
\mathrm{R}_{\mathrm{f}}=\left[1+\mathrm{K}_{\mathrm{d}}\left(\rho_{\mathrm{b}} / \theta\right)\right]
$$

$\mathrm{R}_{\mathrm{f}}=$ Maximum number of bed pore volumes that can be treated before breakthrough,

$\mathrm{K}_{\mathrm{d}}=$ Conditional contaminant distribution coefficient $(\mathrm{mL} / \mathrm{g})$, determined from the sorption isotherm,

$\rho_{\mathrm{b}}=$ Packed bed density $(\mathrm{g} / \mathrm{mL})$,

$\theta=\quad$ Total void fraction of the packed bed.

The retardation factor $\left(\mathrm{R}_{\mathrm{f}}\right)$ is a parameter often used in safety assessment models for waste repositories, to quantify the capability of a geologic medium to act as a barrier to radionuclide migration (Relyea, 1982). This parameter relates the migration rate of the contaminant solute to the rate of advection of the groundwater; a relatively large value for $\mathrm{R}_{\mathrm{f}}$ indicates that the contaminant has been immobilized to a great extent. For Eqn (2) to be strictly valid, the value of $K_{d}$ must be derived from a linear isotherm, or else (for nonlinear sorption isotherms, in which the observed value for $\mathrm{K}_{\mathrm{d}}$ is a function of concentration) it must be the empirical value of the $\mathrm{K}_{\mathrm{d}}$ determined at a solute equilibrium concentration equal to the solute concentration at the influent to the packed bed.

Nonlinear sorption often may be described by a Freundlich isotherm of the form:

$$
\mathrm{S}=\mathrm{K}_{\mathrm{F}} \mathrm{C}_{\mathrm{e}}{ }^{\mathrm{n}}
$$

Where $\mathrm{S}$ and $\mathrm{C}_{\mathrm{e}}$ may have the same meaning as in Eq. (1), and $\mathrm{K}_{\mathrm{F}}$ and $\mathrm{n}$ are empirically determined fit parameters (derived from regression analysis of the linear form of the expression, Eq. 4).

$$
\log \mathrm{S}=\log \mathrm{K}_{\mathrm{F}}+\mathrm{n} \log \mathrm{C}_{\mathrm{e}}
$$


Equation (1) is equivalent to the expression for a simple linear sorption isotherm, but $\mathrm{K}_{\mathrm{d}}$ may not be a true "constant" for removal mechanisms that do not involve limited surface binding sites; an example of the latter is reactive precipitation, which can ideally involve the deposition of many layers of precipitate on the reactive metal surface.

For the most realistic prediction of contaminant migration potential, it is essential that partition coefficients $\left(\mathrm{K}_{\mathrm{d}}\right)$ be measured at relevant site-specific conditions (USEPA, 1999). The conditional value for $\mathrm{K}_{\mathrm{d}}$ is sensitive to the equilibrium solution $\mathrm{pH}$ value and the solution temperature. Uptake of the contaminant of interest may be diminished by the presence of interfering ions that can affect the solid phase (by competition for the same binding sites on the sorbent, or by altering the surface properties, e.g., by nonspecific deposition), or that react with the solute (to form soluble complexes with the contaminant of interest or alter its net ionic charge distribution). For additional discussion on the geochemical utility of distribution ratios obtained by short-term batch method, see ASTM D 4319-93 and EPA 402-R-99-004B.

For apatite-based media, the mechanisms for removal of heavy metal from solution can be complex, and the term "sorption" is used loosely to describe the deposition of metal ions from solution to coexisting apatite structures (Chen et al., 1997). The parameter $\mathrm{K}_{\mathrm{d}}$, computed from equation (1) (or the equivalent value computed with use of the parameters in equation (3)), is used here simply as a figure of merit for comparing the performance of different media and contaminant solutes in a given water composition under defined laboratory testing conditions. A large value for $\mathrm{K}_{\mathrm{d}}$ indicates a high degree of contaminant removal from the solution phase (i.e., a favored partitioning to the solid phase). In the "Test Plan for Use of Apatite for Chemical Stabilization of Subsurface Contaminants,"(MCL-614-TP) a $\mathrm{K}_{\mathrm{d}}$ value of $\geq 1,000 \mathrm{~mL} / \mathrm{g}$ for a given contaminant is suggested as a success criterion for effective metal removal.

Select metals that were found to approach or exceed this success criterion during single metal batch testing were combined and batch testing was performed under an experimental design to determine whether there were interactions among the metals. In our experimental design, uranyl ion $\left(\mathrm{UO}_{2}{ }^{2+}\right)$ is selected as one of the priority metals for testing. Others selected were $\mathrm{Cd}^{2+}, \mathrm{Hg}^{2+}$, and $\mathrm{Pb}^{2+}$. One type of possible interaction would be competition among the metals for binding sites on the apatite surface. Another possible interaction would be synergistic co-precipitation of mixed metal phosphate phases. Many of the latter occur in nature (see Figure 1). For example, the autunite and meta-autunite group of minerals are comprised of $\sim 40$ species (Dana and Dana, 1997) of the general form:

$$
\mathrm{M}\left(\mathrm{UO}_{2}\right)_{2}\left(\mathrm{PO}_{4}\right)_{2} \bullet \mathrm{nH}_{2} \mathrm{O}
$$

In the mineral autunite, $\mathrm{M}$ in Eqn. (5) is $\mathrm{Ca}^{2+}$, but many other cations may substitute into the autunite structure. Analogously to substitutions in apatite structure (Figure 1), select oxyanions (e.g., arsenate, $\mathrm{AsO}_{4}{ }^{3-}$ ) may also substitute for the phosphate ion. 
The solid phase isolated from the multi-metal Experimental Design testing is evaluated by variety of analytical procedures. The solids are examined by x-ray diffraction (q.v.), to determine whether any new crystalline phases may be identified at the metal loading achieved in the experiment. The potential mobility of metal contaminants stabilized on apatite phase is assessed with use of the EPA Toxicity Characteristic Leaching Procedure (TCLP) Test. (This test was originally developed to evaluate the potential leachability of an improperly disposed hazardous waste). The potential bioavailability of metal contaminants stabilized on apatite phase is evaluated by the in vitro bioaccessibility extraction procedure developed by Ruby and co-workers' (SOP 110499), using their well-tested synthetic gastric juice cocktail approved by EPA Region 8 .

Short-term batch testing is a rapid means to screen for the applicability of the apatite technology. However, by its nature, it does not reflect the field conditions of a slow percolation of groundwater through the soil, nor does it assess relatively slow approaches to equilibrium. Soil column testing requires lengthy exposure to a continuous influx of water, but it is the closest approximation to field conditions, encompassing a variety of diffusive and chemical interaction processes, and is the preferred means to determine contaminant loading and total system performance.

A series of soil column experiments were conducted, assessing the effect of various apatite product amendments, added to soil at a nominal $5-\mathrm{wt} \%$. Two types of tests were conducted: (1) exposure of an authentic contaminated soil to "clean" synthetic groundwater, and (2) exposure of "clean" soil to synthetic groundwater that had been supplemented with select metal contaminants. The apatite amendments were selected to represent a range of particle sizes and residual organic matter. In some of the soil column experiments, the columns flooded (i.e., they became saturated and accumulated a film of free liquid, which limited the diffusion of oxygen into the soil pores); for soil columns amended with raw apatite having elevated residual organic matter, this resulted in anaerobic conditions, and the proliferation of anaerobic microbial activity. Eluates collected from the soil columns were analyzed for $\mathrm{Ca}$ and $\mathrm{P}$ (from the dissolution of apatite phase) and for the contaminant metals of interest.

In many cases, the contaminants of interest did not break through the soil columns during the relatively brief testing interval. Soil from the final column test series was examined in detail. This experiment, designated "Series 57", represented an infusion of select metals into a "clean" soil matrix, with and without apatite amendment. The soils from the columns (control and apatite-amended) were extruded, and then divided into segments, representing different lengths along the column. Portions of material from each segment were combined to form a composite material. Measurement of the metal loading in the discrete longitudinal segments of the soil column allows one to estimate the extent of metal migration, and hence the retention of metal in the soil. The TCLP and Bioaccessibilty protocols tested leaching of metal from samples of soil composite. 
In an attempt to more clearly ascertain the nature of the metal binding in the soil, the composite samples were examined by a sequential extraction procedure, in which the soil is exposed to a series of lixivant solutions, increasing in their extractive aggressiveness. This testing methodology recognizes that total soil metal inventory is of limited use in understanding bioavailability or metal mobility, and that it is more useful to estimate the amount of metal present in different solid-phase forms. A large number of permutations of lixivants have been proposed (McLean and Bledsoe, 1992), in an attempt to categorize metals into several operationally defined geochemical fractions, such as soluble and readily exchangeable, and more strongly sorbed metals associated with carbonates, organic matter, and/or iron and manganese oxides. For our evaluation, we selected the sequence of extractions recommended by Tessler et al. (1979), which is substantially equivalent to the recommendations of Phillips and Chapple (1995). Minimal association in the more mobile "exchangeable" category evidences enhanced stabilization of metal in soil, as does a greater proportion of metal associated with the more refractory "residual" category (i.e., the inventory of residual metal in soil remaining after the sequence of selective extractions have been performed).

Collectively, the data presented in this report support the use of apatite for the stabilization of subsurface contaminants. Apatite is demonstrated to have a strong affinity for most of the priority cationic metals listed in Table 1, although the sorptives removal of anionic forms of some metals (e.g., arsenate, selenate and chromate) does not meet the project-defined success criterion. The ability to remove soluble forms of uranium and thorium (priority radionuclides for many DOE sites) is especially notable. 


\subsection{EXPERIMENTAL}

Biogenic Apatite (APA) Products. Raw fish bone products were supplied by PIMSNW, Inc. (formerly UFA Venture), Richland, WA 99352, who hold US Patent $\# 6,217,775$ for the application to metal stabilization. Elutriated apatite fines are the dense solid residual for ground raw apatite that has been selectively cleansed of lessdense extraneous matter by floatation in a stream of upflowing water. Apatite char (APA-C) is biogenic apatite that has been thermally processed to destroy organic matter.

Synthetic Hydroxyapatite (syn-HAP). We prepared our synthetic hydroxyapatite material (MCL 01-0297) after the procedure described by Leyva et al., 2001. A stoichiometric amount of calcium nitrate solution (prepared by the neutralization of lime slurry by nitric acid) was slowly added (with stirring) to a warm $\left(\sim 60-80{ }^{\circ} \mathrm{C}\right)$ solution of $\mathrm{Na}_{2} \mathrm{HPO}_{4}$. Periodically, $\mathrm{NaOH}$ solution was added to maintain a $\mathrm{pH}$ value $\geq 10$. The slurry was allowed to slowly cool and the finely divided solids settled out overnight. The slurry was exposed to the open atmosphere, so it is possible that some carbon dioxide may have been absorbed to form carbonate ion, which can partially substitute for phosphate ion in the precipitated apatite phase. Repetitively allowing the solids to settle under gravity, decanting the supernate and replacing it with DI-water washed the solids from residual soluble salts and removed some fines. Finally, the solids were collected by vacuum filtration, rinsed well with DI-water, and the filtercake was subsequently dried at $110^{\circ} \mathrm{C}$. The aggregates of dried solids were de-lumped by gentle crushing with use of a mortar and pestle.

Mass-based particle size distribution estimates are made by sifting solids through a series of standard testing sieves of successively smaller mesh size (ASTM E-11 specification), and determining the weight fraction of material retained on each sieve (Herdon,1953). The mass- vs. -size range data is fitted to a theoretical distribution function (Mackay and Paterson, 1984).

Total organic matter in a sample is estimated by a loss-on-ignition (LOI) method (Method of Ben-Dor \& Banin, 1989, as described in Nelson \& Sommers, 1996). Asreceived material is placed in a tared ceramic crucible, and dried at $\sim 105^{\circ} \mathrm{C}$ for 1 -h. After gravimetric determination of the moisture content (calculated from weight loss at $105^{\circ} \mathrm{C}$ ), the dried material was held at $400{ }^{\circ} \mathrm{C}$ for 16 - to 24 -h with use of a Thermodyne Type 1400 muffle furnace to complete oxidation of organic matter. After each heating step, the crucible and contents were cooled to ambient temperature in a desiccator filled with Drierite, and then the net weight of material is determined. The LOI content of the sample is calculated as

$$
\text { LOI, } \%=100 \times\left[(\text { Weight })_{105 \mathrm{C}}-(\text { Weight })_{400 \mathrm{C}}\right] /(\text { Weight })_{105 \mathrm{C}}
$$


Bulk density $\left(\rho_{b}, \mathrm{~g} / \mathrm{cm}^{3}\right)$ for dry apatite solids is measured as a tamp density; a known mass of dry material $(\mathrm{g})$ is placed in a graduated cylinder, and the cylinder and contents are gently tamped against a hard surface 50-times, then the interface volume $\left(\mathrm{cm}^{3}\right)$ is measured.

The total void fraction $(\theta)$ of wet solids in a packed bed column is estimated by suspending a known mass of dry solids in distilled water, and then allowing the slurry to sediment in a graduated cylinder. The slurry is tamped, and excess water is carefully removed to the solid interface at the top of the column. The net mass and volume of the settled solids and water is measured. The void fraction is then estimated as the mass of water added (net total column mass less dry solids added) divided by the total column volume in $\mathrm{cm}^{3}$.

Synthetic Groundwater Surrogate is patterned to represent the BYBY groundwater composition found at the Y-12 National Security Complex (Bostick et al., 2000). The surrogate is prepared by the addition, per liter of deionized water, of the following chemicals: $\mathrm{MgSO}_{4} \bullet 7 \mathrm{H}_{2} \mathrm{O}, 61.1 \mathrm{mg} ; \mathrm{CaCl}_{2}, 31 \mathrm{mg} ; \mathrm{Ca}(\mathrm{OH})_{2}, 72 \mathrm{mg} ; \mathrm{NaHCO}_{3}, 45 \mathrm{mg}$; and $\mathrm{K}_{2} \mathrm{CO}_{3} \bullet 1.5 \mathrm{H}_{2} \mathrm{O}, 15.2 \mathrm{mg}$. Calcium ion is solubilized, and $\mathrm{pH}$ adjusted, by sparging the solution overnight with a gas mixture containing $\mathrm{CO}_{2}$. The $\mathrm{pH}$ after sparging is initially $\sim 6$, but gradually increases to $>7$ after several days of storage, as the solution equilibrates with ambient air. The nominal composition for synthetic Y-12 BYBY water is given in Table 2 (bolded data); also given for comparison purposes are select other groundwater proxies that have been used for treatability study or thermodynamic modeling purposes. The bicarbonate alkalinity of the BYBY surrogate solution $(\sim 3.2$ $\mathrm{mmol} / \mathrm{L}$ as bicarbonate) is typical of many groundwater compositions (Villalobos et al., 2001), and favors the solubilization of hexavalent uranium (uranyl ion) as a neutral or anionic carbonate complex (Farrell et al., 1999; Meinrath et al., 1996). On the other hand, the sulfate and carbonate levels in the surrogate water may limit the solubility of certain metals such as lead, etc.

For the synthetic BYBYwater composition illustrated in Table 1, the solution becomes saturated ${ }^{-}$with respect to calcite $\left(\mathrm{CaCO}_{3}\right)$ phase as the $\mathrm{pH}$ is raised above a value of $\sim 7$; thus, treatment media that cause the local $\mathrm{pH}$ value to become slightly alkaline may experience deposition of calcite, which can interfere with surface-mediated metal removal. Thus, the synthetic groundwater matrix is a much more realistic "challenge" to toxic metal ion treatment than would be (e.g.) a tap- or distilled water matrix.

\footnotetext{
${ }^{1}$ As calculated by SMEWW Method 2330: Calcium Carbonate Saturation.
} 
Table 2. Select Groundwater Proxy Compositions

\begin{tabular}{|c|c|c|c|c|c|c|}
\hline Property & Unit & $\begin{array}{c}\text { Global } \\
\text { Average } \\
\text { for } \\
\text { River } \\
\text { Water } \\
\text { (1) }\end{array}$ & $\begin{array}{c}\text { Simulated } \\
\text { Y-12 } \\
\text { BYBY } \\
\text { Water } \\
\text { (2) }\end{array}$ & $\begin{array}{c}\text { Simulated } \\
\text { ORNL } \\
\text { Corehole } \\
8 \text { Seep } \\
\text { Water } \\
\text { (3) }\end{array}$ & $\begin{array}{c}\text { Simulated } \\
\text { Hanford } \\
\text { Groundwater } \\
\text { (4) }\end{array}$ & $\begin{array}{c}\text { Simulated } \\
\text { Rocky Flats } \\
\text { Groundwater } \\
\text { (5) }\end{array}$ \\
\hline \multicolumn{7}{|l|}{$\begin{array}{c}\text { Major } \\
\text { Cations }\end{array}$} \\
\hline $\mathrm{Ca}^{+2}$ & $\mathrm{mg} / \mathrm{L}$ & 15 & 50 & 39 & 14.4 & 160 \\
\hline $\mathrm{K}^{+}$ & $\mathrm{mg} / \mathrm{L}$ & 2.3 & 7 & 1 & - & 3.6 \\
\hline $\mathrm{Mg}^{+2}$ & $\mathrm{mg} / \mathrm{L}$ & 4.1 & 6 & 8 & 4.4 & 44 \\
\hline $\mathrm{Na}^{+}$ & $\mathrm{mg} / \mathrm{L}$ & 6.3 & 12 & 8 & 4 & 140 \\
\hline \multicolumn{7}{|l|}{$\begin{array}{l}\text { Major } \\
\text { Anions }\end{array}$} \\
\hline $\mathrm{Cl}^{-}$ & $\mathrm{mg} / \mathrm{L}$ & 7.8 & 20 & 9.5 & & 85 \\
\hline $\mathrm{NO}_{3}^{-}$ & $\mathrm{mg} / \mathrm{L}$ & 1 & - & 5.3 & 9.9 & 8 \\
\hline $\mathrm{SO}_{4}{ }^{-2}$ & $\mathrm{mg} / \mathrm{L}$ & 11 & 24 & 21 & 15 & 590 \\
\hline $\mathrm{PO}_{4}^{-3}$ & $\mathrm{mg} / \mathrm{L}$ & 0.077 & - & 2.1 & - & \\
\hline \multicolumn{7}{|l|}{ Other } \\
\hline $\mathrm{H}_{4} \mathrm{SiO}_{4}$ & $\mathrm{mg} / \mathrm{L}$ & 20.8 & & 10.6 & & \\
\hline $\mathrm{pH}$ & SU & 6.7 & $6-7$ & $7.5-8.5$ & 8.2 & 8.1 \\
\hline Eh & $\begin{array}{c}\mathrm{mV} \text { vs } \\
\text { SHE }\end{array}$ & & $\begin{array}{l}+628 \text { (at } \\
\text { pH }=6)\end{array}$ & & & \\
\hline Hardness & $\begin{array}{c}\mathrm{mg} / \mathrm{L} \\
\mathrm{as} \\
\mathrm{CaCO}_{3}\end{array}$ & 54 & 150 & 130 & 54 & 581 \\
\hline $\begin{array}{c}\text { Alkalinity } \\
\text { (total) }\end{array}$ & $\begin{array}{c}\mathrm{mg} / \mathrm{L} \\
\text { as } \\
\mathrm{CaCO}_{3}\end{array}$ & 95 & 160 & & 88 & 295 \\
\hline
\end{tabular}

(1) Values cited in Table 5.1 of report EPA 402-R-99-004B; these data were used in geochemical models as a proxy for the composition of a "typical" shallow groundwater. (http://www.epa.gov/radiation/docs/kdreport/vol2/chapter5.pdf)

(2) Bostick et al. (2000). The authentic BYBY water contains elevated levels of $\mathrm{Cu}$, $\mathrm{Pb}, \mathrm{Mn}, \mathrm{U}$, and other contaminants of concern (Report Y/ER-285).

(3) Corehole 8 Seep is the principle contributor to the Oak Ridge National Laboratory (ORNL) process Waste Treatment Plant (PWTP). This seep water contains elevated levels of ${ }^{233} \mathrm{U},{ }^{90} \mathrm{Sr}$ and other radionuclides. Typical data for PWTP feed is cited in Report ORNL-TM/13689, et seq.

(4) Moody et al. (1996), Report BHI-00864. Inorganic contaminants of concern in Hanford soil and water (N-Springs area) include $\mathrm{U},{ }^{90} \mathrm{Sr}, \mathrm{As}, \mathrm{Cd}, \mathrm{Pb}$, and $\mathrm{Se}$.

(5) Anderson et al. (1998), WERC Report. 


\section{Batch Equilibration Testing}

Relatively short-term batch phase contact tests are used to survey which candidate priority metals in solution are amenable to treatment with apatite media. In a typical batch test, small amounts of dried solids ( $\sim 0.1$ to $0.2 \mathrm{~g})$ were contacted with $\sim 20 \mathrm{~mL}$ of solution phase for a defined interval of time by tumbling the slurry in sealed containers at 30 RPM with use of a rotary agitation device (TCLP extraction apparatus, Model 374012-BRE, Associated Design \& Mfg. Co., Alexandria VA). After equilibration, the phases are separated with use of a disposable syringe fitted with either a $0.2-\mu \mathrm{m}$ or $0.45-\mu \mathrm{m}$ filter membrane (Acrodisc), and the filtrate is analyzed for soluble constituent. Since batch-testing is performed at a relatively small solid-to-liquid ratio, it cannot reproduce the enhanced mass transfer conditions prevalent in (e.g.) a flow-through fixed bed situation (Relyea, 1982). Thus, any apparent kinetic effects observed in batch-testing may only be compared as relative values under the defined experimental conditions.

\section{Stirred Tank Reactor}

A limited number of tests (apatite dissolution, reactions with ferrous iron) were performed in an instrumented gas-purged stirred tank reactor (Figure 2). In this system, phase contact is enhanced by the combination of gas purge and mechanical stirring. The gases selected for the purge may be used to limit exposure to oxygen and to maintain a targeted $\mathrm{pH}$ range. The apparatus consists of a three-neck 1-L round bottom flask, with feed-through for purge gas; $\mathrm{pH}$ probe; oxidation-reduction potential (ORP) electrode; sampling syringe; and gas vent. In order to study reactions under anoxic conditions, the gas purge is conditioned by first bubbling the gas though a solution containing $\sim 1.3 \mathrm{~g}(\sim$ $23 \mathrm{mmol}$ ) Fe(II), to humidify the gas mixture and to strip any residual oxygen (Cui and Spahiu,1992). The performances of the $\mathrm{pH}$ probe (Corning PN 1746531) and the ORP probe (Orion combination $\mathrm{Pt} / \mathrm{Ag} / \mathrm{AgCl}$ electrode) ${ }^{2}$ were verified against standard buffer solution and Light's solution (VWR PN VW3872-2), respectively, before and after reaction vessel use. These transducer signals were recorded with use of Orion Model 701A digital Ionalyzers. The gas vent purges below water to minimize back diffusion of air. The vessel is filled with 1 - $\mathrm{L}$ of gas- purged synthetic BYBY groundwater (initial $\mathrm{pH}$ value $\sim 6.0$; total alkalinity $\sim 130 \mathrm{mg} / \mathrm{L}$, as $\mathrm{CaCO}_{3}$ ).

\footnotetext{
${ }^{2} \mathrm{The} \mathrm{Ag} / \mathrm{AgCl}$ electrode is filled with $4 \mathrm{M} \mathrm{KCl}$ saturated with $\mathrm{AgCl}$ to give a measured potential for Light's solution of $(+475 \pm 10) \mathrm{mV}$, or a corrected reference potential of $+675 \mathrm{mV}$ vs. the Standard Hydrogen Electrode (SHE) at $25^{\circ} \mathrm{C}$; see Standard Methods for the Examination of Water and Wastewater, $18^{\text {th }}$ Ed., Table 2580:II.
} 


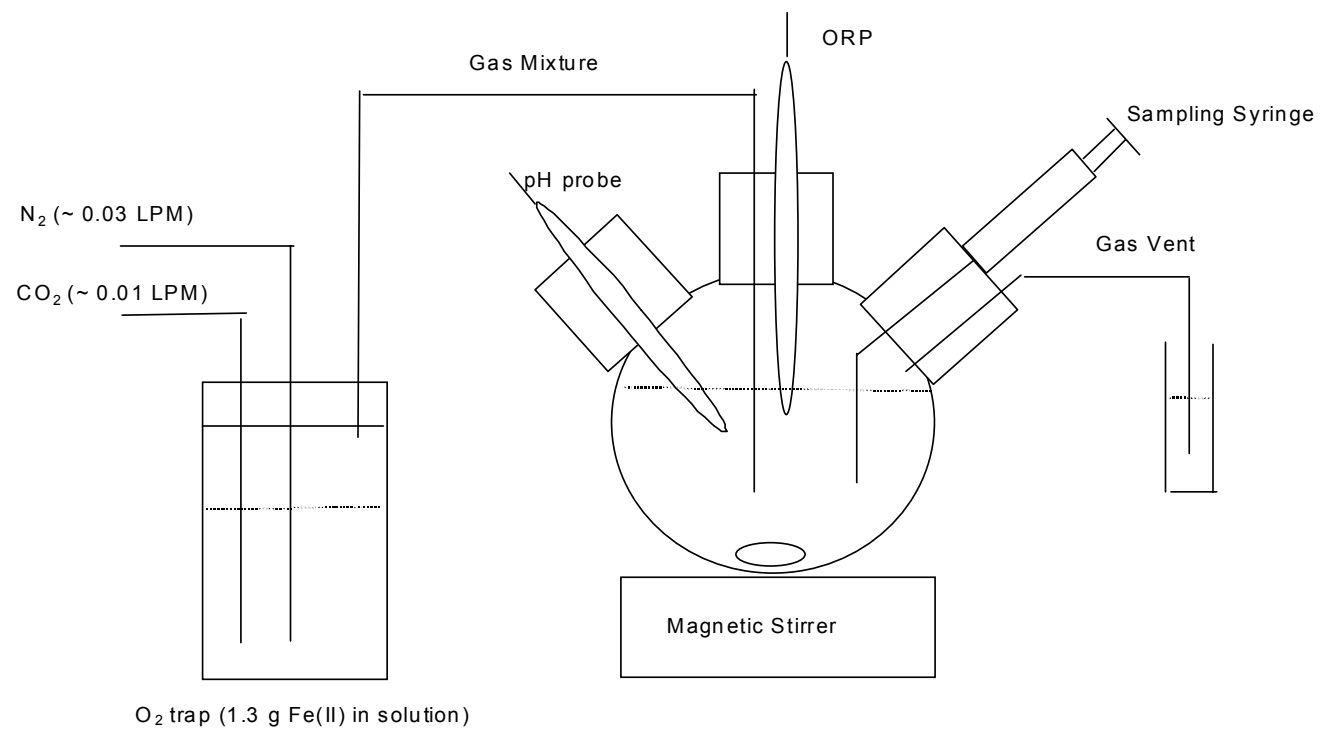

Figure 2. Stirred tank reactor, configured to maintain anoxic conditions.

\section{Investigation of Batch Test Parameters}

In this investigation, we use soluble uranium, a priority contaminant for DOE (Morrison et al., 2001), as a model to assess the effect of material properties and phase contact variables on the uptake of metals by apatite. Much of this scoping work was performed with the use of synthetic water samples traced with ${ }^{233} \mathrm{U}$ isotope (q.v.).

\section{Construction of Soil Columns}

Disposable plastic 50-cc syringes (internal diameter $2.9 \mathrm{~cm}$ ) are used to construct the soil columns. The syringes are mounted vertically, and the syringe drain hole at the bottom is covered with a plug of glass wool ("Series 12" experiments, only) or a disc of paper, punched from a disposable coffee filter, to retain solid phase. By comparison to the retention of alumina particle fractions separated by standard sieves, the coffee filter appears to have good retention for particles $>50-\mu \mathrm{m}$ in dimension. Soil blend $(\sim 40 \mathrm{~g})$ is placed in the barrel of the syringe. Liquid is metered into the top of the soil column with use of a WIZ peristaltic pump (Isco, Lincoln, NE), and perfuses through the soil by gravity flow. Discrete column eluate fractions are collected from the drain into tared and labeled glass beakers for defined time intervals. The net mass of liquid phase collected during the time interval is recorded.

\section{Metal Detection and Analysis}

For synthetic groundwater water samples traced with radionuclides $\left({ }^{233} \mathrm{U}, \mathrm{Th},{ }^{99} \mathrm{Tc}\right)$, a measured mass of filtered solution is counted for activity, using liquid scintillation instrumentation. Other metals (including natural $\mathrm{U}$ ) were quantitated by spectroscopy. In some preliminary testing, we used a Perkin Elmer 5100 PC atomic absorption spectrophotometer. For the majority of metal analyses reported here, we used an 
inductively-coupled plasma with optical emission spectroscopy (ICP-OES), Perkin Elmer Optima 2000 Optical Emission Spectrograph; this is a scanning dual-viewing instrument with a charge-couple solid-state detector. This system allows qualitation (multiwavelength confirmation) and quantitation of all metals with emissions from the lower UV through visible wavelengths and allows simultaneous background correction.

\section{Determination of ${ }^{233} \mathrm{U}$ Traced solutions}

Some of the synthetic water samples were traced with ${ }^{233} \mathrm{U}$ to afford relatively rapid and sensitive analysis. Uranium oxide $\left(\right.$ as $\left.\mathrm{U}_{3} \mathrm{O}_{8}\right)$, enriched in isotope ${ }^{233} \mathrm{U}$, was obtained from the Oak Ridge Y-12 Plant; the oxide was dissolved in a minimal amount of ultrapure nitric acid, and diluted to a known volume to provide a stock tracer solution $(5.78 \mathrm{mg}$ $\mathrm{U} / \mathrm{mL}$, as determined by Davies-Gray titrimetric analysis; Davies and Gray, 1964, and MCL-7737). The decay series for ${ }^{233} U$ and daughters produces $\alpha, \beta$, and $\gamma$ radiation:

$$
{ }^{233} \mathrm{U}->{ }^{229} \mathrm{Th}+\alpha+\gamma->{ }^{225} \mathrm{Ra}+\alpha+\gamma->{ }^{225} \mathrm{Ac}+\beta+\gamma,->\ldots . .->{ }^{209} \mathrm{Bi}
$$

The $\alpha$ and $\beta$ radiation components of the decay series are efficiently measured when an aliquot of dilute solution is placed in a scintillation cocktail (e.g., Ultima Gold, from Packard BioScience), and counted with use of a liquid scintillation counter (LSC; e.g., Packard Instruments 2550 Tri-Carb Liquid Scintillation Analyzer or equivalent). With use of LSC, one microgram $(\mu \mathrm{g})$ of uranium tracer gave a response of $\sim 21,700$ counts per minute $(\mathrm{CPM})$, allowing precise estimates of small residual concentrations (e.g., $<1$ $\mathrm{ng} / \mathrm{L}$ ) of $\mathrm{U}$ and its decay daughters. Thus, the total measured activity of the solution is used to provide a conservative estimate of the total uranium concentration (since the total activity is not strictly specific for $U$, but also includes contributions by the other radionuclides in the decay series).

Testing of Solid Phase Products. A battery of select aqueous extraction procedures was used to examine apatite products and amended soils that had been exposed to heavy metals.

EPA Method 3050B. This method (nitric acid and hydrogen peroxide digestion of solids for metals, as defined in SW-846) is used to prepare samples for analysis of total environmentally available metals.

Toxicity Characteristic Leaching Procedure (TCLP). EPA SW846 Method 1311, is used to determine whether extractable constituents in a solid waste exceed their defined toxicity characteristic ( 40 CFR 261). Phase contact is achieved by tumbling solid phase and extractant solution in sealed plastic containers for 16-h at 30 revolutions per minute (RPM) with use of extraction apparatus (Model 3740-12-BRE, Associated Design \& Mfg. Co., Alexandria, VA 22314). 
Bioaccessibility (BA) testing. The potential bioavailability of metals in soils and other solid matrixes may be assessed by in vitro procedures intended to mimic the dissolution of metal during residence in the human gut. Many such procedures have been proposed, as reviewed by Ruby et al. (1999). One such testing protocol is the draft in vitro bioaccessibility extraction procedure developed by Ruby and co-workers, derived from Ruby et al. (1996). The methodology used is based upon Solubilty/Bioavailability Research Consortium (SBRC) SOP 110499, Rev \#8. The method is briefly described below:

- Sample Preparation: oven drying of substrate at $\sim 50 \mathrm{C}$; dried sample may be sieved to select $<250 \mu \mathrm{m}$ size fraction.

- Buffered extraction medium (60.06 g glycine in 2-L solution, adjusted to $\mathrm{pH} 1.5)$;

- Phase contact: $1.00 \pm 0.005 \mathrm{~g}$ dried test substrate is added to $100 \pm 5 \mathrm{~mL}$ of buffered extraction medium at $37 \pm 2{ }^{\circ} \mathrm{C}$. The phases are contacted by tumbling in a TCLP extractor at $30 \pm 2 \mathrm{rpm}$ for 1 hour, with temperature being maintained at $37 \pm 2{ }^{\circ} \mathrm{C}$.

- At the end of phase contact, an aliquot of liquid phase is filtered through $0.45-\mu \mathrm{m}$ pore cellulose acetate filter medium.

Filtered solution is analyzed for metals according to EPA SW-846 procedure.

Sequential Extractions. In this investigation, we have generally adapted the protocols recommended by Phillips and Chapple (1995). A sample of soil $(\sim 5 \mathrm{~g})$ is contacted sequentially with a series of lixivant solutions of increasing aggressiveness for the extraction of bound metals. After each extraction step, the aqueous phase is separated by centrifugation (with use of IEC Centra MP4 centrifuge operated at 4,000 rpm for at least $8 \mathrm{~min}$.). The decanted aqueous phase is filtered at $0.45-\mu \mathrm{m}$, digested with acid and peroxide (to destroy any interfering organic compounds), and analyzed by ICP-OES. The residual solid phase is then resuspended in the next lixivant solution. The sequence of extractions is briefly described below.

- Fraction \#1, "Exchangeable", is estimated by contacting approximately $5 \mathrm{~g}$ of blended air-dried soil with $40 \mathrm{~mL}$ of $1 \mathrm{~mol} / \mathrm{L}(95 \mathrm{~g} / \mathrm{L}) \mathrm{MgCl}_{2}$ solution $(\mathrm{pH} 7)$, by continuously shaking for $1-\mathrm{h}$ at room temperature.

- Fraction \#2, "Carbonate-bound", is estimated by adding $40 \mathrm{~mL}$ of $1 \mathrm{~mol} / \mathrm{L}$ (82 $\mathrm{g} / \mathrm{L}$ ) sodium acetate solution, adjusted to $\mathrm{pH} 8.2$, to the soil residue. The solids are resuspended in the lixivant, and contact the phases contacted by continuous shaking for $6 \mathrm{~h}$ at room temperature.

- Fraction \#3, "Oxide-Associated" or "Reducible," is estimated by adding $40 \mathrm{~mL}$ hydroxylamine reagent (prepared by adding, per liter final volume of reagent, 0.04 mole $(2.78 \mathrm{~g}) \mathrm{NH}_{2} \mathrm{OH} \cdot \mathrm{HCl}$ and $250 \mathrm{~mL}$ acetic acid (balance demineralized water)). The container is capped. In order to gas pressure developed in the vessel when it is heated, the cap is punctured with a hypodermic sharp, and the cap and top of the vessel is wrapped in parafilm ${ }^{\circledR}$ (American National Can, Greenwich, CT). The film-wrapped vessel and contents are placed in a water bath maintained at $96 \pm 3 \mathrm{C}$ for about $6 \mathrm{~h}$, with occasional agitation of the bottle and contents. 
- Fraction \#4, "Organic-bound" or "Oxidizable," is estimated by extraction with $12 \mathrm{~mL}$ of $0.02 \mathrm{~mol} / \mathrm{L} \mathrm{HNO}_{3}+15 \mathrm{~mL}$ of acid peroxide solution $\left(30 \%(\mathrm{v} / \mathrm{v}) \mathrm{H}_{2} \mathrm{O}_{2}\right.$, with $\mathrm{pH}$ adjusted to 2). The solids are resuspended in this solution, and the slurry heated to $\sim 85 \pm 2 \mathrm{C}$ for $2 \mathrm{~h}$ with occasional shaking. The container and contents are allowed to cool to room temperature. Next, add $\sim 20 \mathrm{~mL}$ of a solution containing $3.2 \mathrm{~mol} / \mathrm{L}(247 \mathrm{~g} / \mathrm{L})$ ammonium acetate in $20 \%(\mathrm{v} / \mathrm{v}) \mathrm{HNO}_{3}$, and the bottle and contents are shaken continuously for $0.5 \mathrm{~h}$ at room temperature.

- Fraction \#5, "Residual." In our protocol, the "Residual" fraction is operationally defined as the mass balance difference between the sums of metal recovered by the sequential extractions (Fractions 1-4, described above) and the "environmentally-assessable" metal inventory of the original material. The latter inventory is determined using a separate aliquot of the original soil sample, after aggressive strong acid and peroxide digestion as described in USEPA Method 3050. This procedure does not digest all components of the soil matrix; for SRM NIST 2711, reported leach recoveries are relatively low $(<30 \%)$ for refractory matrix elements such as $\mathrm{Si}$ and $\mathrm{Al}$, but are relatively high $(>75 \%)$ for most toxic metals in this material

\section{Characterization of Solid Phase Residuals}

\section{Scanning Electron Microscopy (SEM) with Energy-Dispersive X-Ray Spectroscopy (EDS)}

SEM rasters a finely focused electron beam over the area to be imaged. The image (photomicrograph) is formed by either the collection of (inelastically scattered) secondary electrons (SE) or backscattered electrons (BSE). The secondary electron emission is determined to a large extent by the surface topography, whereas backscattered electron emission is determined largely by the compositional differences within the specimen. The image contrast of BSE is proportional to the atomic number of the elements present; deposits containing heavier elements, such as uranium, are readily identified by the relatively bright images produced (in phase-contrast to lighter element substrates). When the electron beam (typically $10-50 \mathrm{keV}$ accelerating voltage) impinges on the sample, X-rays representative of the elements present are also generated. The Xray spectrum for the area rastered is analyzed with an Energy-Dispersive X-Ray Spectrometer (EDS). This analysis can also be used to obtain elemental analysis of a small, discrete portion of the sample.

The instrumentation used in this investigation is an Hitachi S-5000 SEM, with associated Noran X-ray microanalysis systems. With regard to EDS data collection, "bulk" indicates that a general low magnification area or the entire area of a photomicrograph was included in the data analysis; "area" indicates that a reduced area of the photomicrograph was rastered for analysis; and "spot" indicates that a crosshair is placed on a specific area or feature and analysis is conducted at that point. 
X-Ray Diffraction (XRD). X-ray Diffraction data were obtained on a Phillips 3100 high-angle diffractometer using $\mathrm{Cu} \mathrm{K \alpha}(\lambda=1.5418 \AA)$ radiation, operated at $40 \mathrm{kV}$ and $40 \mathrm{~mA}$. Data were collected at a step rate of 0.6 degrees 2 theta per minute, over the peak angle range of 5-85 degrees. The diffraction pattern is analyzed and interpreted to identify the various crystalline phases present in the specimen. The International Center for Diffraction Data (ICDD) has published summaries of the powder diffraction patterns for over 60,000 compounds, which aids in the identification of crystalline phases.

X-Ray Fluorescence (XRF). XRF is a simple, nondestructive method for qualitative and quantitative analysis of the elemental composition in a material. Our instrumentation is a Phillips PW-1480 X-ray spectrophotometer with sequential wavelength dispersive spectral analysis.

X-Ray Photoelectron Spectroscopy (XPS). X-ray Photoelectron Spectroscopy (XPS), or electron spectroscopy for chemical analysis (ESCA), is a surface-sensitive spectroscopic tool that provides information about the chemical state of elements located at the near-surface of a solid (sampling depth generally $10-100 \mathrm{~nm}$ ). XPS data reflects the average surface composition over a relatively large area. XPS uses a soft X-ray source to excite and eject electrons from their orbits (valence and core). The energy spectrum of the emitted photoelectrons for a given element depends upon the elements oxidation state(s) and local chemical environment; these effects are reflected in the measured binding energy shifts. The XPS data were obtained using a Perkin Elmer Physical Electronics XPS system. 


\subsection{RESULTS AND DISCUSSION}

\subsection{Raw Material Characterization}

Apatite II is a processed biogenic material. For consistency, benchmark testing is performed with a single lot of vendor-supplied crushed material, which is blended and characterized by MCLinc before use. Material characteristics that may affect performance for contaminant removal include:

- Particle size. The particle size distribution of crushed bone will affect the specific surface area available for sorption or apatite dissolution phenomena. The sizeweight distribution of blended dry solids is determined by standard sieve analysis (Herdon, 1953), and a lognormal theoretical distribution function for particle size by weight will is to the experimental data. The mass-median particle size will be computed.

- Organic matter. Since the Apatite II product is of biogenic origin, it will be useful to determine the amount of residual organic matter, which may affect the biological activity induced by the media after emplacement. Nitrogenous organic residue may contribute to nuisance odor when material is stored or used aboveground. Organic matter will be estimated by the mass loss on ignition at $400{ }^{\circ} \mathrm{C}$ (Nelson \& Sommers, 1996).

- Crystallinity. An amorphous apatite material will be less stable than a highly crystalline material, and thus it will dissolve more rapidly to provide reactive phosphate to the solution phase. On the other hand, some crystallinity within the apatite solid phase is desirable to initiate sorption of contaminants and nucleation of precipitate phases at the reactive surface. Relative crystallinity in apatite phases will be assessed by the technique of X-ray diffraction (MCL-7712).

\subsubsection{Apatite II ${ }^{\mathrm{TM}}$ : Whole Bone}

PIMS NW, Inc., holds U.S. Patent (and Application for Letter of Patent Application) for the use of processed fish bone material (Apatite II) for the treatment of metalcontaminated soil and leachate solution. MCL, Inc., is a licensee to PIMS NW, Inc. for the use of fish bone for such licensed applications. MCL, Inc., received evaluation samples of biogenic Apatite II product from the supplier, PIMS NW, Inc (Carlsbad, NM 88220). Cleaned whole bone and fishery solid waste product was given the internal sample identification code MCL 01-0262. Visual examination of portions of this material indicates that fish bone and hard parts are preponderant, although there are also small amounts of shellfish exoskeleton (chitin) and some small pieces of dark material that appeared to be residual dried fish flesh. Chitin $\left(\mathrm{C}_{30} \mathrm{H}_{50} \mathrm{~N}_{4} \mathrm{O}_{19}\right)$ is a polymer of acetylated glucosamine, and has some favorable metal-binding properties (Guibal et al., 1999; Dambies et al., 2000). However, chitin in the apatite medium contributes to the organic content (as estimated by loss-on-ignition) and also to the nitrogen burden. 
We also received a sample of dried and coarse-ground biogenic Apatite II material (referred to as "one crush" material, or "APA"), which was given the internal sample identification code MCL 01-0263. This lot of material $(\sim 2.7 \mathrm{~kg})$ was transferred to a large sealed plastic bottle and the contents blended by placing the bottle on a roll mill overnight. This blended sample was examined further.

\subsubsection{Sieve Analysis}

Blended Apatite II (01-0263) was dry-sieved, and the mass distribution was determined as a function of the screen opening size. The solids were noted to be irregular in shape (including elongate bone splinters). Figure 3 illustrates the results of the sieve analysis, with the data fit to a theoretical lognormal distribution function (mass-median particle size, $\mathrm{Cg}, \sim 500 \mu \mathrm{m}$, and spread factor, $S, \sim 2.06$ ); see Table 3.

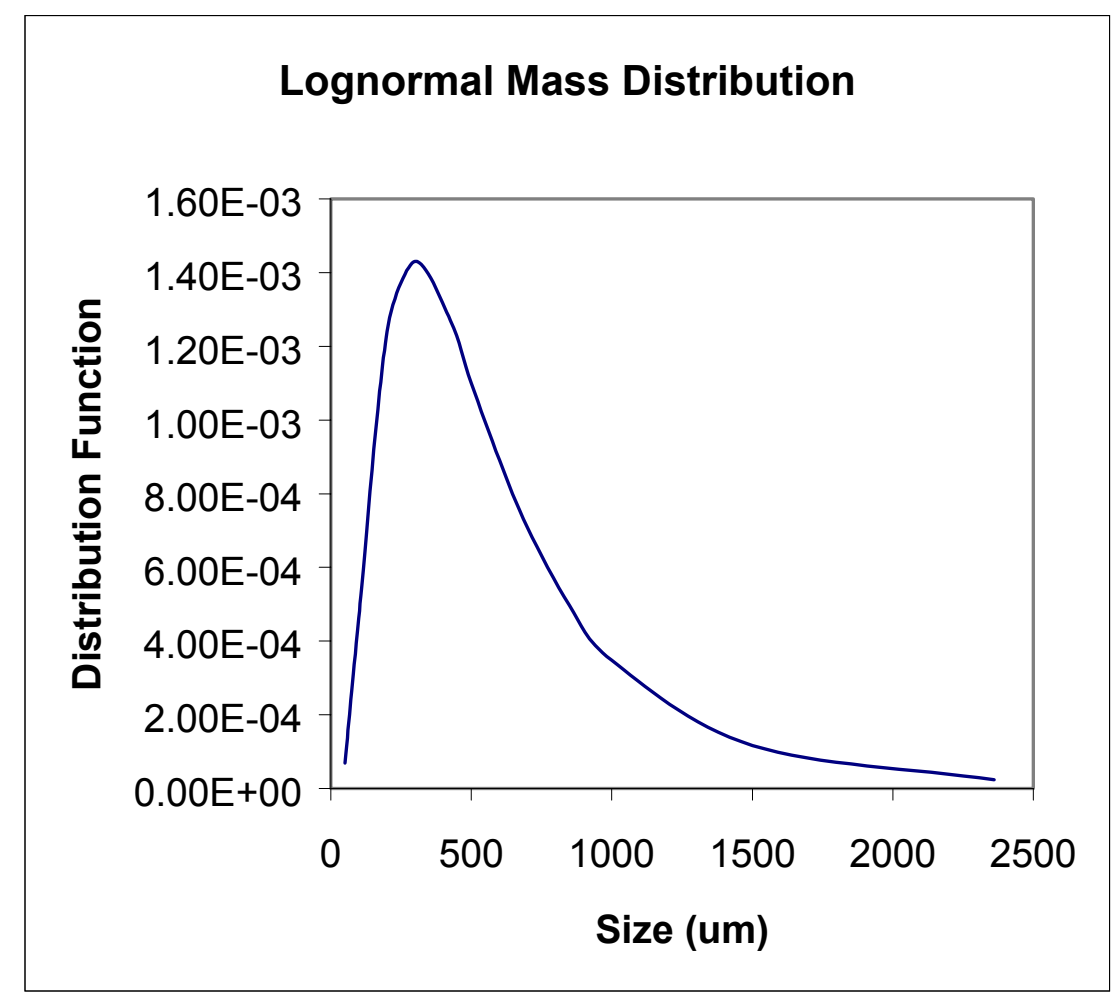

Figure 3. Theoretical lognormal mass distribution function for dry-sieved Apatite II (sample MCL 01-0263). Median (Cg) is $~ 500 \mu \mathrm{m}$, spread factor $(S)$ is 2.06, and the mode is $\sim 300 \mu \mathrm{m}$. 
Table 3. Lognormal Mass Distribution for Dry Sieved Apatite II (MCL 01-0263)

\begin{tabular}{|c|c|c|}
\hline \multirow{2}{*}{ Screen Opening $(\mu \mathrm{m})$} & \multicolumn{2}{|c|}{ Cumulative $\mathrm{Wt} \% \leq$ Stated Size } \\
\cline { 2 - 3 } & Experimental Data & Theoretical Value * \\
\hline 2360 & 98.3 & 98.4 \\
\hline 850 & 75.2 & 76.9 \\
\hline 425 & 42.2 & 41.1 \\
\hline
\end{tabular}

* Computed theoretical lognormal distribution, using $\mathrm{Cg}=500 \mu \mathrm{m}$ and $S=2.06$.

(See, e.g., Mackay and Paterson, 1984).

\subsubsection{Bulk Density (Wet and Dry)}

The estimated average density of bulk packaged whole bone apatite is $0.384 \mathrm{~g} / \mathrm{cm}^{3}$.

The bulk density of the as-received dry "one crush" raw bone material (01-0263) was determined by tap-packing a sample into a tared graduated cylinder. The mean computed result for the dry solids is given in Table 4. A known mass of the as-received dry "one crush" material (01-0263) was then slurried with de-ionized water (DI-water), and the slurry was quantitatively transferred into a tared graduated cylinder. The supernate solution, containing fines and soluble material, is initially turbid; the slurry is allowed to sediment overnight under ambient gravity, then the excess water was then removed to the solid interface, and then the net mass and volume of the wet material column were estimated. The unconstrained (free expansion) volume of the wetted material was as much as $70 \%$ greater than that calculated for an equivalent mass of dry-packed material (i.e., the dry raw ground biogenic apatite material swells when wetted, similar to the behavior of, e.g., certain layered silicates). Estimates for the dry bulk density and the void fraction of wetted apatite are given in Table 4. For hydrated one-crush raw Apatite II, the ratio $\left(\rho_{\mathrm{b}} / \theta\right)$ in Eqn. (2) is $\sim 1$, and thus the Retardation Factor (Eq. 2) is approximately equal in magnitude to the Distribution Coefficient.

Apatite II that has been thermally treated to remove organic matter (Section 4.1.5, below) does not expand when wetted. The dry bulk density is $\sim 0.58 \mathrm{~g} / \mathrm{cm}^{3}$, and the void fraction $(\mathrm{v} / \mathrm{v})$ is $\sim 0.75$. Thus, for hydrated charred one-crush Apatite II, the ratio $\left(\rho_{\mathrm{b}} / \theta\right)$ in Eqn.

(2) is $\sim 0.77$.

Table 4. Select Physical Properties of Apatite

\begin{tabular}{|c|c|c|c|}
\hline Medium & $\begin{array}{c}\text { Bulk Density (dry) } \\
\rho\left(\mathrm{g} / \mathrm{cm}^{3}\right)\end{array}$ & $\begin{array}{c}\text { Void Fraction (wet) } \\
\Theta\end{array}$ & $\begin{array}{c}\rho / \theta \\
\left(\mathrm{g} / \mathrm{cm}^{3}\right)\end{array}$ \\
\hline $\begin{array}{c}\text { Raw Apatite } \\
\text { (01-0263) }\end{array}$ & 0.75 & 0.76 & 0.95 \\
\hline $\begin{array}{c}\text { Apatite Char } \\
\text { (C400) }\end{array}$ & 0.58 & 0.75 & 0.77 \\
\hline
\end{tabular}




\subsubsection{Estimate of Residual Organic Matter}

Apatite $\mathrm{II}^{\mathrm{TM}}$ is a biogenic material, made from fish bones and hard parts processed to remove as much organic matter as practical. A very small amount of chitin, from shellfish, may also be present (as noted from examination of a sample of whole bone product). The resultant processed material is dry and sterile at the time of generation, but it does contain some residual organic material.

Total organic matter in a sample of blended crushed material (01-0263) was estimated by a loss-on-ignition (LOI) method (Nelson \& Sommers, 1996). The free moisture content (estimated by weight loss upon drying at $\sim 105^{\circ} \mathrm{C}$ ) was $\sim 2.6 \mathrm{wt} \%$. The incremental weight loss upon calcination at $400{ }^{\circ} \mathrm{C}$ was $\sim 42.8 \mathrm{wt} \%$, attributed to oxidative destruction of residual organic matter. The overall yield of calcined solids (after loss of moisture and organic matter) was $\sim 57 \mathrm{wt} \%$ (weight loss $\sim 43 \mathrm{wt} \%$ ). The solids remaining after treatment at $400{ }^{\circ} \mathrm{C}$ was designated as " $\mathrm{C} 400$ " material.

\subsubsection{Preparation of A Bone Char Product}

Traditionally, bone char is prepared by the destructive distillation of animal bone at temperatures of $\geq 600^{\circ} \mathrm{C}$; see Mantrell (1951). The bone source is usually cattle, and commercial bone char is relatively costly and in short supply, since most meat in the U.S. and elsewhere is sold bone-in, and subsequent recovery of clean waste bone is not economically feasible. As a consequence, cow bone char is not currently manufactured in the U.S. Typical yield of char product from raw cattle bone is $60-65 \mathrm{wt} \%$. Volatile matter removed by thermal treatment includes tar, oils, and ammonia gas from the decomposition of residual flesh and other organic matter (e.g., cartilage). Anoxic destructive distillation (coking) of animal bone during the commercial manufacture of animal charcoal (or bone black) yields black fetid "bone oil," containing objectionable nitrogenous compounds such as pyrole, pyridine, aniline, nitriles, etc. (Merck, 1976). It is possible that short-term thermal treatment of bone under oxygen-deficient conditions may also leave a small residual of these types of materials condensed on the surface of the product. Coked bone has a residue (typically $\sim 8-10 \mathrm{wt} \%$ ) of activated carbon distributed on the surface and pores of the substrate (hydroxyapatite, tricalcium phosphate, and other trace mineral phases); this (largely elemental) carbon residue imparts some additional sorptive properties.

Commercial bone char has been demonstrated to be an effective treatment medium for aqueous solutions of uranium (Moody et al., 1996; Bostick et al., 2000) and other heavy metals, such as lead, cadmium, copper, and zinc (Cheung et al., 2000). The hydroxyapatite $\left(\mathrm{Ca}_{5}\left(\mathrm{PO}_{4}\right)_{3} \mathrm{OH}\right)$ component of typical commercial cow bone char product is 70-76 wt\% (Cheung et al., 2000). Waterlink ${ }^{\circledR}$ BC 830 (Barnebey \& Sutcliffe, Columbus, $\mathrm{OH}$ ) is an example of a commercial animal bone char product used for treatment of contaminated water.

A fish bone char product ("Apatite IIC") was prepared by heating a sample of blended material $01-0263$ at temperatures $\geq 400{ }^{\circ} \mathrm{C}$ for several hours. 
Note that thermal removal of residual organic matter, especially nitrogenous material (e.g., collagen and other proteins, chitin, etc) would be beneficial for the use of bone apatite in above-surface applications, where adventitious biological activity may otherwise decompose the residual organic matter to potentially cause an objectionable septic odor. (Dried "raw" bone product may be suitable for subsurface applications, where the soil overburden minimizes perceptible odor, and where stimulation of biological activity may facilitate metabolic destruction of nutrients such as organic contaminants, nitrate ion, etc.).

\subsubsection{Synthetic Hydroxyapatite}

Synthetic hydroxyapatite, nominal composition $\mathrm{Ca}_{5}\left(\mathrm{PO}_{4}\right)_{3-\mathrm{x}}\left(\mathrm{CO}_{3}\right)_{\mathrm{x}}(\mathrm{OH})_{1+\mathrm{x}}$, has been used as a sorbent for uranium and many other heavy metals (Jeanjean, 1995; Ko et al., 2001; Leyva et al., 2001; Manecki et al., 2000; Murray et al., 1983; Suzuki et al., 1984). Although it has been demonstrated in many laboratory studies to be effective for removal of soluble metals, a disadvantage to the use of synthetic hydroxyapatite for environmental applications is its relatively high cost. Also, typical synthetic products are comprised of loose agglomerates of very small (sub-micron) particles, which sediment slowly in water suspension, and which may be transported through porous media (e.g., soil).

We prepared our synthetic hydroxyapatite material (MCLinc Sample 01-0297) after the procedure described by Leyva et al., 2001. Dried aggregate material morphology was examined with use of Scanning Electron Microscopy (SEM). The loosely associated aggregates are composed of sub-micron crystals, and thus this synthetic hydroxyapatite product would offer a large surface area for sorption phenomena. Because the agglomerates dissociate in water to form ultrafine particles, this synthetic hydroxyapatite preparation would be unsuitable for use in a flow-through reactor configuration. 


\subsubsection{X-Ray Diffraction (XRD)}

Synthetic hydroxyapatite (syn-HAP, MCLinc ID 01-0297) is selected as the reference material for comparison purposes. The XRD diffractogram pattern for this material matched the International Centre for Diffraction Data (ICDD) standard reference spectrum no. 09-0432 (calcium hydroxide orthophosphate (hydroxyapatite)). Our preparation also matched the diffractogram published by Leyva et at. (2001) for similarly prepared synthetic material.

In contrast, as-received Apatite II (01-0263) is noted to be a poorly crystalline hydroxyapatite material. Figure 4 superimposes the diffractograms for synthetic hydroxyapatite (01-0297) and crushed bone (01-0263). Heating of the biogenic apatite at different temperatures demonstrated that the crystallinity of the product is affected by the thermal treatment history. (At a given set of data acquisition conditions, a higher degree of crystallinity is evidenced in the diffractograms by more intense diffraction signals; also note that the formation of larger crystallites produces sharper (narrow) diffraction lines). Treatment at $400{ }^{\circ} \mathrm{C}$ renders a product that is only slightly more crystalline than the original raw bone (data not shown), whereas higher temperatures render a more highly crystalline material.
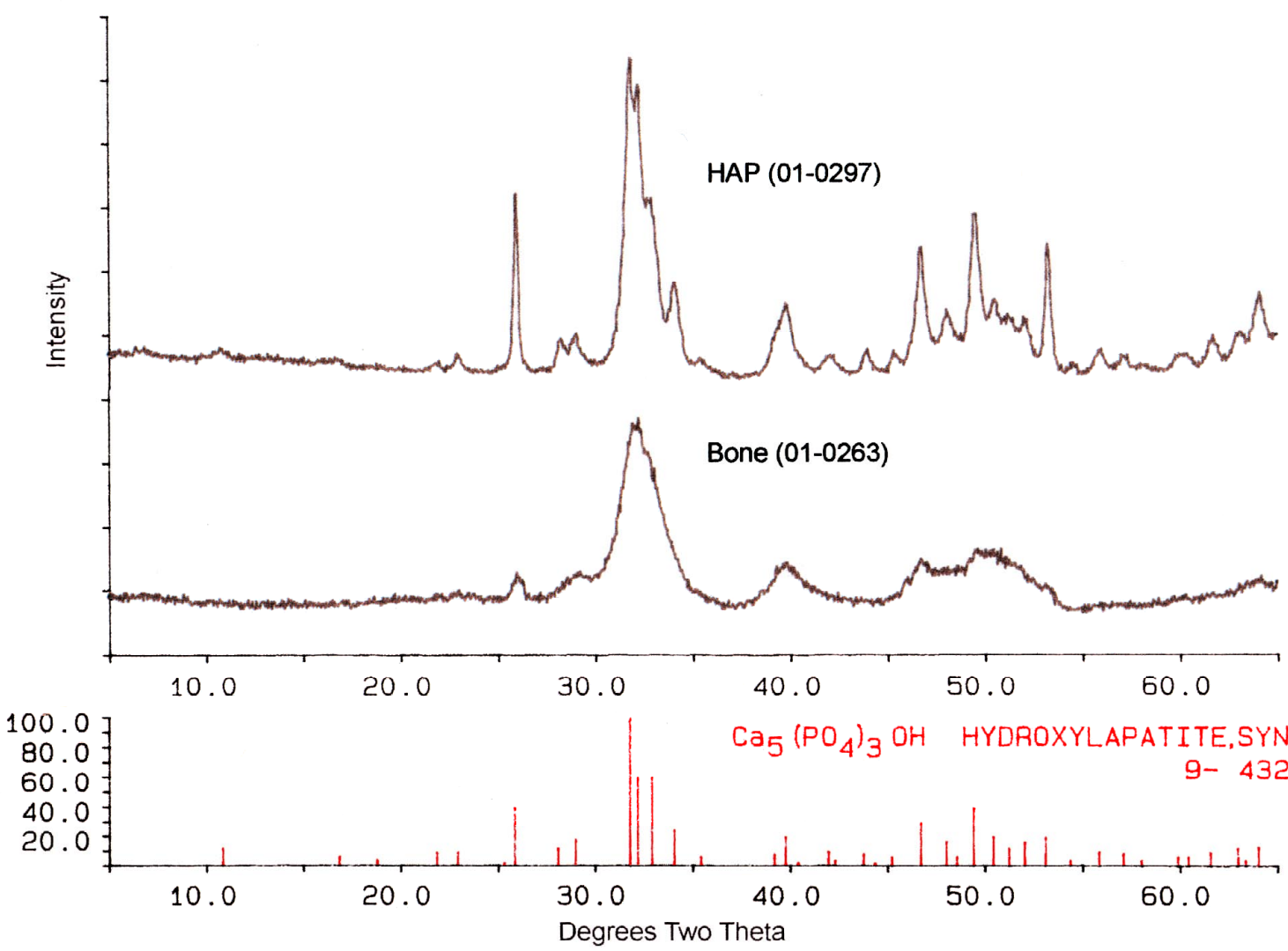

Figure 4. XRD diffractograms for synthetic hydroxyapatite (HAP, MCLinc sample \# 01 0297) and fish bone apatite (MCLinc sample \# 01-0263). Superimposed is the ICDD reference diffractogram 9-432 for synthetic hydroxyapatite. 
These investigations show that the residual organic matter associated with the bone meal, and the extent of crystallization of hydroxyapatite phase, may be manipulated by thermal processing. The X-ray diffractogram for a commercial bone char product, Waterlink BC 830 , indicated a relatively high degree of crystallinity (data not shown), suggesting that it had been processed at an elevated temperature.

Processing at extreme temperature alters the apatite phase mineralogy. Fuller (2002B) reports testing of bone meal product sintered with binder at $\mathrm{T}>1000{ }^{\circ} \mathrm{C}$. Under these conditions, hydroxyapatite phase was reportedly converted to whitlockite, $(\mathrm{Ca}, \mathrm{Mg})_{3}\left(\mathrm{PO}_{4}\right)_{2}$, perhaps altering the metal binding properties of the product. 


\subsubsection{Solubility Estimates for Biogenic Apatite}

The crystallinity of the apatite phase is expected to affect the manner by which metal ions are removed from solution phase. Highly crystalline phases (such as synthetic hydroxyapatite) have relatively low solubility compared to corresponding amorphous phases; see Table 5, which lists the theoretical solubility constants $\left(\mathrm{K}_{\mathrm{sp}}\right)$ for several crystalline phosphate phases (as cited by Conca et al., 2000).

Table 5. Solubility Products for Select Mineral Phases, Derived from the MINTEQ Database.

(Note: highly insoluble phases are associated with a large negative value for $\log _{10} K_{\mathrm{sp}}$ )

\begin{tabular}{|l|c|}
\hline Mineral Phase & $\begin{array}{c}\text { Logarithm of } \\
\text { Solubility Product } \\
\left(\log _{10} \mathrm{~K}_{\mathrm{sp}}\right)\end{array}$ \\
\hline $\mathrm{Pb}_{5}\left(\mathrm{PO}_{4}\right)_{3}(\mathrm{OH}, \mathrm{Cl})$ & -76.5 \\
\hline $\mathrm{Sr}_{5}\left(\mathrm{PO}_{4}\right)_{3}(\mathrm{OH})$ & -51.3 \\
\hline $\mathrm{Ca}\left(\mathrm{UO}_{2}\right)_{2}\left(\mathrm{PO}_{4}\right)_{2} \bullet 10 \mathrm{H}_{2} \mathrm{O}$ & -48 \\
\hline $\mathrm{Zn}{ }_{3}\left(\mathrm{PO}_{4}\right)_{2}$ & -35.3 \\
\hline $\mathrm{Cd}{ }_{3}\left(\mathrm{PO}_{4}\right)_{2}$ & -32.6 \\
\hline $\mathrm{Am}\left(\mathrm{PO}_{4}\right)$ & -24.8 \\
\hline $\mathrm{Pu}\left(\mathrm{PO}_{4}\right)$ & -24.4 \\
\hline $\mathrm{Quartz}\left(\mathrm{SiO}_{2}\right)$ & -4.0 \\
\hline
\end{tabular}

The solubility product values reported in Table 4 may be compared to values reported for hydroxyapatite. Valsami-Jones et al. (1998) report the solubility constant for crystalline synthetic hydroxyapatite as given in Equation (8).

$$
\mathrm{Ca}_{5}\left(\mathrm{PO}_{4}\right)_{3} \mathrm{OH}=5 \mathrm{Ca}^{2+}+3 \mathrm{PO}_{4}{ }^{3-}+\mathrm{OH}^{-} \text {; }
$$

By the formalism of $\mathrm{Eq}(8)$ :

$\log _{10} \mathrm{~K}_{\mathrm{sp}}=5 \log _{10}\left(\mathrm{Ca}^{2+}\right)+3 \log _{10}\left(\mathrm{PO}_{4}^{3-}\right)+\log _{10}\left(\mathrm{OH}^{-}\right)=-58 \pm 1$

Note: Zhang et al. (1998) alternately express the solubility of synthetic hydroxyapatite in terms of a dissolution reaction, consuming protons, as given in equation (10).

$$
\mathrm{Ca}_{5}\left(\mathrm{PO}_{4}\right)_{3} \mathrm{OH}+7 \mathrm{H}^{+}=5 \mathrm{Ca}^{2+}+3 \mathrm{H}_{2} \mathrm{PO}_{4}^{-}+\mathrm{H}_{2} \mathrm{O}
$$


By the formalism of Eq (10):

$\log _{10} \mathrm{~K}_{\text {sp }}^{\prime}=5 \log _{10}\left(\mathrm{Ca}^{2+}\right)+3 \log _{10}\left(\mathrm{HPO}_{4}^{-}\right)-7 \log _{10}\left(\mathrm{H}^{+}\right)=15.8+1.7$

A low solubility apatite phase may favor surface-mediated metals removal mechanisms, e.g., sorption or ion-exchange (Suzuki et al., 1984; Ma et al., 1994; Leyva et al., 2001), or perhaps heterogeneous nucleation and precipitation at the crystal surface (Manecki et al., 2000). On the other hand, an amorphous apatite (such as bone meal) should dissolve more readily, releasing more phosphate ion to the solution phase where homogeneous precipitation of insoluble metal phosphate may occur (Manecki et al., 2000; Hodson et al., 2000). Advantages cited for use of Apatite II in phosphate-induced metal stabilization (PIMS) include the poor crystallinity (for more rapid dissolution to release soluble phosphate ion) coupled with random nanocrystallites (to promote nucleation of precipitates at the solid surface); see Conca et al., 2000.

\subsubsection{Dissolution of Biogenic Apatite: Stirred Tank Reactor}

Dissolution of apatite phase, and the rate of approach to chemical equilibrium, will be determined by the physical and chemical conditions of the system.

Physical conditions include (Bodek et al., 1988, Chapt. 3.4):

- Temperature;

- Solution volume (in a system without flow);

- Solution volume flow rate (in a system with flow); and

- Surface area of the dissolving solid.

Chemical conditions include (Bodek et al., 1988, Chapt. 3-4):

- Chemical composition of the solid, or concentrations of the components of interest in the dissolving solid;

- Chemical composition of the solution, both initially and as a function of time during dissolution; and

- Concentrations and chemical states of other components of the system that may affect the rate of dissolution (such as dissolved gases, complexing agents or common ions).

In order to better understand the reaction-controlled dissolution of biogenic apatite (added as elutriated Apatite II $^{\mathrm{TM}}$ fines, with mass-median particle size $\sim 235-\mu \mathrm{m}$ ), we monitored the reaction under anaerobic conditions with use of the closed-system (no flow) apparatus illustrated in Figure 2. Approximately 5-g of apatite product was added to 1,000 -g of synthetic BYBY water at an ambient laboratory temperature of $\sim 23 \pm 1{ }^{\circ} \mathrm{C}$. The reaction vessel contents were purged with a mixture of nitrogen and carbon dioxide gases to minimize dissolved oxygen and to maintain a target $\mathrm{pH}$ range of 6.0 to 6.5. Mechanical stirring provided additional slurry turbulence for effective phase contact. The use of small particles (relatively high surface area), and slurry turbulence without diluting flow, should permit a relatively rapid approach to equilibrium (chemical saturation) conditions. 
In-situ solution $\mathrm{pH}$ and Eh values were recorded, and at select time intervals aqueous phase samples were withdrawn via syringe and filtered with $0.8-\mu \mathrm{m}$ pore Acrodisc membrane filters. Total calcium and phosphorous concentrations were determined by ICP spectroscopy, and the $\mathrm{pH}$-dependent equilibrium distribution of phosphate ion was computed as illustrated in Figure 5. The ion activity coefficient (IAC) (which is equivalent to $\mathrm{K}_{\mathrm{sp}}$ at saturation) was computed by the formalism of Eq. (9'), where the quantities in \{braces\} are estimates of activity:

$$
\log _{10}(\mathrm{IAP})=5 \log _{10}\left\{\mathrm{Ca}^{2+}\right\}+3 \log _{10}\left\{\mathrm{PO}_{4}{ }^{3-}\right\}+\log _{10}\left\{\mathrm{OH}^{-}\right\}
$$

Activity and concentration are related by the activity coefficient, which is computed as described in Butler (1966), assuming an ionic strength of $\sim 1.42 \mathrm{E}-3 \mathrm{~g}-\mathrm{mol} / \mathrm{L}$. Literature estimates for the solubility product of hydroxyapatite are given in Table 6. 


\section{Fraction of phosphate species as $\mathrm{F}(\mathrm{pH})$}
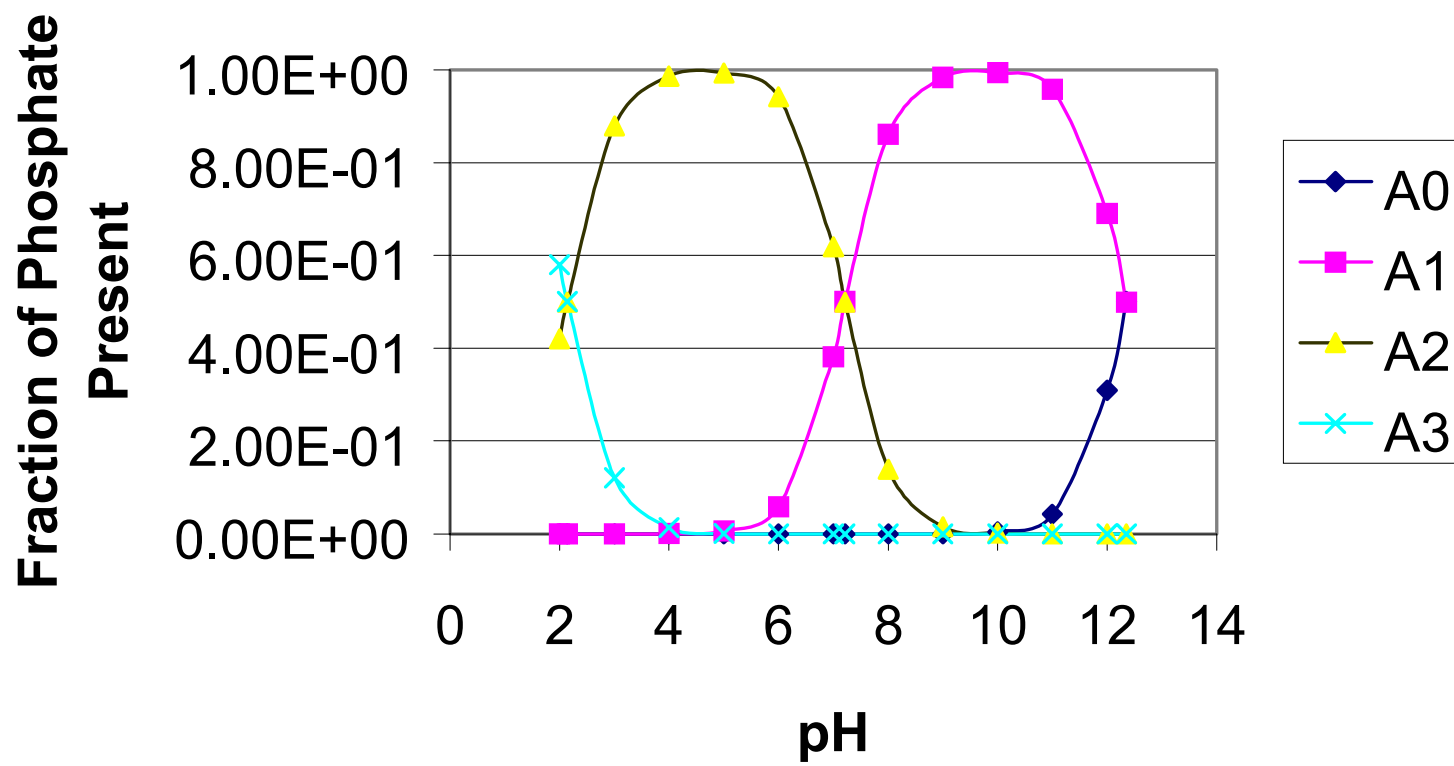

Figure 5. Computed Phosphate Species Distribution Diagram as a Function of Solution $\mathrm{pH}$ Value. $\mathrm{C}_{\mathrm{T}}=$ total phosphate species concentration (sum of all forms, $\mathrm{mol} / \mathrm{L}$ ); $\mathrm{A} 0=\left[\mathrm{PO}_{4}{ }^{3-}\right.$ ]$/ \mathrm{C}_{\mathrm{T}} ; \mathrm{A} 1=\left[\mathrm{HPO}_{4}{ }^{2-}\right] / \mathrm{C}_{\mathrm{T}} ; \mathrm{A} 2=\left[\mathrm{H}_{2} \mathrm{PO}_{4}{ }^{-}\right] / \mathrm{C}_{\mathrm{T}} ;$ and $\mathrm{A} 3=\left[\mathrm{H}_{3} \mathrm{PO}_{4}\right] / \mathrm{C}_{\mathrm{T}}$.

Table 6. Solubility of Synthetic Hydroxyapatite (Reported Literature Values)

\begin{tabular}{|l|l|l|}
\hline Equation & $\log _{10} \mathrm{~K}_{s p}$ & Reference \\
\hline $\mathrm{Ca}_{5}\left(\mathrm{PO}_{4}\right)_{3} \mathrm{OH}(\mathrm{s})=5 \mathrm{Ca}^{2+}+3 \mathrm{PO}_{4}{ }^{3-}+\mathrm{OH}^{-}$ & -59 & $\begin{array}{l}\text { Somasundaran et al. } \\
(1985)\end{array}$ \\
\cline { 2 - 3 } & -58.3 & McDowell et al. (1977) \\
\cline { 2 - 3 } & $-58 \pm 1$ & $\begin{array}{l}\text { Valsami-Jones et al. } \\
(1998)\end{array}$ \\
\cline { 2 - 3 } & -57 & $\begin{array}{l}\text { Zhang et al. (1998) } \\
\text { (recomputed) }\end{array}$ \\
\cline { 2 - 3 } & -55.9 & $\begin{array}{l}\text { Snoeyink and Jenkins } \\
(1980)\end{array}$ \\
\hline $\mathrm{Ca}_{5}\left(\mathrm{PO}_{4}\right)_{3} \mathrm{OH}(\mathrm{s})+7 \mathrm{H}^{+}=5 \mathrm{Ca}^{2+}+3 \mathrm{H}_{2} \mathrm{PO}_{4}{ }^{-}+\mathrm{H}_{2} \mathrm{O}$ & $15.8 \pm 1.7$ & Zhang et al. (1998) \\
\hline
\end{tabular}


Experimental data are summarized in Table 7.

Table 7. Dissolution of Elutriated Apatite II in Synthetic Groundwater ( $\left.\mathrm{T} \sim 23{ }^{\circ} \mathrm{C}\right)$.

\begin{tabular}{ccccccc}
\hline Time $(\mathrm{h})$ & $\mathrm{pH}$ & $\begin{array}{c}\text { Eh } \\
(\mathrm{mV})\end{array}$ & $\begin{array}{c}\text { Filter } \\
(\mu \mathrm{m})\end{array}$ & $\begin{array}{c}\text { Total Ca } \\
(\mathrm{mol} / \mathrm{L})\end{array}$ & $\begin{array}{c}\text { Total P } \\
(\mathrm{mol} / \mathrm{L})\end{array}$ & $\begin{array}{c}\text { Log10 } \\
\text { IAP }\end{array}$ \\
\hline 0 & 6.03 & 379 & 0.8 & $1.36 \mathrm{E}-03$ & -- & -- \\
0.5 & 6.08 & 323 & 0.8 & $1.43 \mathrm{E}-03$ & $2.94 \mathrm{E}-04$ & -55.94 \\
2 & 6.13 & 303 & 0.8 & $1.47 \mathrm{E}-03$ & $4.71 \mathrm{E}-04$ & -54.72 \\
4 & 6.11 & 291 & 0.8 & $1.33 \mathrm{E}-03$ & $4.94 \mathrm{E}-04$ & -55.01 \\
8 & 6.17 & 267 & 0.8 & $1.34 \mathrm{E}-03$ & $5.81 \mathrm{E}-04$ & -54.19 \\
22.5 & 6.24 & 220 & 0.8 & $1.18 \mathrm{E}-03$ & $4.71 \mathrm{E}-04$ & -54.46 \\
30 & 6.10 & 111 & 0.8 & $1.39 \mathrm{E}-03$ & $6.23 \mathrm{E}-04$ & -54.67 \\
47.25 & 6.51 & -93 & 0.8 & $1.05 \mathrm{E}-03$ & $4.26 \mathrm{E}-04$ & -53.06 \\
47.25 & 6.51 & -93 & 0.45 & $1.18 \mathrm{E}-03$ & $4.29 \mathrm{E}-04$ & -52.61 \\
47.25 & 6.51 & -93 & $\sim 50$ & $2.07 \mathrm{E}-03$ & $9.90 \mathrm{E}-04$ & -50.48 \\
\hline
\end{tabular}

Several features of the data may be mentioned. First, the slurry becomes strongly reductive after $>24-\mathrm{h}$ of contact with the biogenic apatite (see Figure 6). This may correspond to the induction of significant anaerobic bacterial activity associated with the biogenic apatite material. After $>8$-h contact, backpressure was noted upon filtration at $0.8-\mu \mathrm{m}$, suggesting that fines were developing. At $\sim 32-\mathrm{h}$, the flow rate of $\mathrm{CO}_{2}$ gas purge was decreased, allowing the solution $\mathrm{pH}$ value to increase.

The slurry became progressively turbid during the experiment. In time, the smaller diameter grains of the original apatite material will partially dissolve in a preferential manner to yield even smaller residual grains. Thus, at the end of the experiment (47.25-h contact), appreciable fine-grained apatite from the aqueous slurry passes through a coffee filter (which has nominal retention of particles $>50-\mu \mathrm{m}$ ), yielding a visibly turbid suspension in the filtrate. [Compare filtration data at 50, 0.8, and 0.45-um in Table 7]. 


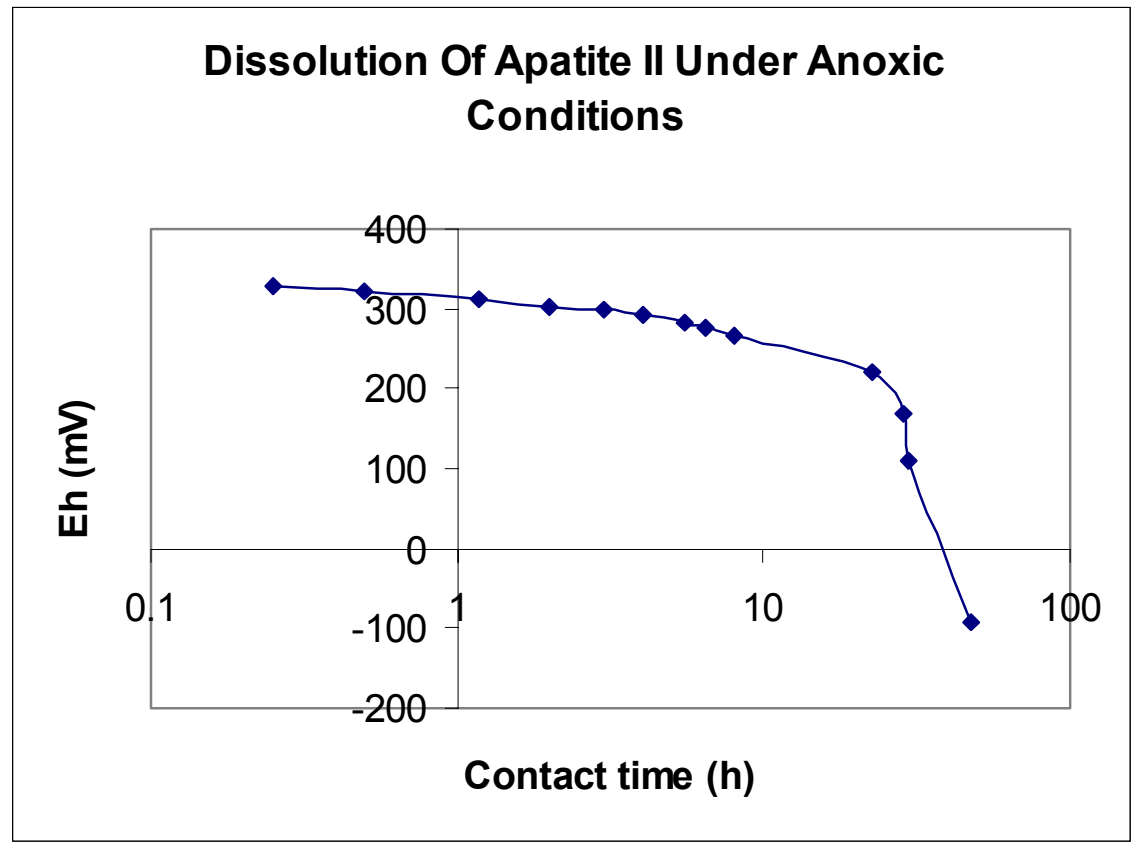

Figure 6. Redox status of anoxic slurry of Apatite II in synthetic groundwater.

The dissolution of biogenic apatite appears to approach equilibrium relatively rapidly under the experimental conditions. For time intervals $>2-\mathrm{h}$, solution filtered at $0.8-\mu \mathrm{m}$ yielded an estimated Ion Activity Product (IAP) of $10^{-(54.7 \pm 0.7)}$ (see Eqn (9'): $\log _{10}($ IAP) $=$ $-54.7 \pm 0.7)$. This value for IAP may be compared to the estimates of Ksp given in Table 6; these data suggest that equilibrium is approached in as little as a few hours in the present experimental set-up.

\subsubsection{Dissolution of Biogenic Apatite: Short-Term Batch-Testing}

We assessed the short-term release of soluble phosphate ion by overnight contact of known masses of apatite materials with de-ionized (DI) water. All materials tested were initially dried at $\sim 105{ }^{\circ} \mathrm{C}$ for 1.3 -h, in an attempt to terminate any associated biological activity that might otherwise metabolize phosphate. Small amounts of dried solids $(\sim 0.1$ to $0.2 \mathrm{~g}$ ) were contacted with $20 \mathrm{~mL}$ of DI-water by tumbling the slurry in sealed containers for 16-h at 30 RPM with use of a TCLP extraction apparatus. Samples of supernate solution were taken via a disposable syringe fitted with $0.2-\mu \mathrm{m}$ filtration media (Nalge Company PN 191-2020), and this filtrate was analyzed for total phosphate ion with use of a Dionex LC20 Ion Chromatography System. The $\mathrm{pH}$ of the slurry was determined, and then the remainder of the slurry was filtered through a $0.4-\mu \mathrm{m}$ Nalge Type A filter unit (PN 135-4040). This filtrate solution was preserved by the addition of $1 \%(\mathrm{v} / \mathrm{v})$ ultrapure nitric acid, for subsequent calcium analysis with use of a Perkin Elmer 5100 PC atomic absorption spectrophotometer. Results are summarized in Table 8. 
Table 8. Short-Term (16-h) Release of Soluble Phosphate and Calcium Ions from Apatite by Leach with Deionized Water *

\begin{tabular}{|c|c|c|c|c|}
\hline $\begin{array}{c}\text { MCLinc } \\
\text { Sample ID }\end{array}$ & Solution $\mathrm{pH}$ & $\begin{array}{c}\text { Total }\left[\mathrm{Ca}^{2+}\right] \\
\mathrm{Mol} / \mathrm{L}\end{array}$ & $\begin{array}{c}\text { Total }\left[\mathrm{PO}_{4}{ }^{3-}\right] \\
\mathrm{Mol} / \mathrm{L}\end{array}$ & $\begin{array}{c}\log _{10}\left(\mathrm{~K}_{\mathrm{sp}}\right) \\
* *\end{array}$ \\
\hline $01-0263$ (APA) & 7.37 & $2.2 \mathrm{E}-4$ & $6.53 \mathrm{E}-4$ & -50.6 \\
\hline Apatite IIC & 8.97 & $1.36 \mathrm{E}-4$ & $4.24 \mathrm{E}-4$ & -45.1 \\
\hline $01-0297$ (HAP) & 8.33 & $4.2 \mathrm{E}-5$ & $4.69 \mathrm{E}-5$ & -52.9 \\
\hline
\end{tabular}

${ }^{*}$ See text for experimental detail.

** Computed using the formalism of text Eq. (9). The reported estimate for the solubility constant includes estimates for the activity coefficients. Not all of the systems tested may have approached equilibrium in these short-term tests.

The computed values for the solubility constants given in Table 8 are based upon the formalism of Equation (9), and include estimates for the activity coefficients (Butler, 1966).

The values of the computed solubility constants reported in Table $\mathbf{8}$ may be compared to values reported in the literature for crystalline synthetic hydroxyapatite (Table 6).

These literature values suggest an appreciably lower solubility for crystalline hydroxyapatite than we observed for our synthetic product (MCLinc sample 01-0297 in Table 8). Our higher solubility estimate may reflect a slow approach to equilibrium, or possibly the destabilizing effect of a partial substitution of carbonate ion into the biogenic apatite structure. Alternately, it is possible that some small amount of colloidal solid passed through the filter medium, and was subsequently dissolved by acid preservation before analysis.

The data in Table 8 are intended for comparative purposes, and may not necessarily represent an approach to equilibrium; Valsami-Jones et al. suggest that hydroxyapatite dissolution equilibrium is approached within 10-50 h of phase contact (for small crystals of synthetic material). As expected, phosphate ion release (attributed to substrate dissolution) is much greater for bone meal products than for crystalline synthetic hydroxyapatite. Also, phosphate and calcium appear to dissolve incongruently (i.e., a non-stoichiometric dissolution) within this $\mathrm{pH}$ range, as has been observed by Narasaraju and Phebe (1996) and by Levya et al. (2001).

The solubility constant is an index to the theoretical solubility of a compound, but the actual release of solution phase phosphate ion in a given situation is strongly affected by complex environmental factors such as the solution $\mathrm{pH}$ value, the presence of common ions and competing reactions, etc. In practice, many factors may affect the fate of phosphate released by dissolution of apatite. First, the solution phase phosphate ion concentration represents an approach to equilibrium (i.e., solubility saturation); continual influx of water may prevent the attainment of equilibrium, and thus the apatite phase will continue to dissolve. In a geochemical environment, released phosphate ion may be subsequently removed by precipitation, sorption or by biological activity. The formation of highly insoluble phosphate phases (see Table 4 for some candidates) may represent an relatively "permanent" phosphate sink, whereas the potentially reversible sorption of 
phosphate ion onto iron oxide (Rietra et al., 2001; Hongshao and Stanforth, 2001) or aluminosilicate soil phases (Parfitt \& Atkinson, 1976) may retard the loss of phosphate ion by forming an exchangeable (thus relatively temporary) sink. For example, hydrolysis products (oxyhydroxides) of $\mathrm{Fe}^{3+}$ and $\mathrm{Al}^{3+}$ have been proposed for use as soil amendments to reduce the flux of low-levels of phosphate ion (Sherwood \& Qualls, 2001 ) by sorption and co-precipitation, whereas, at low $\mathrm{pH}$ values, sulfate ion can competitively displace phosphate ion sorbed to goethite (FeOOH) (Geelhoed et al., 1997). Other water quality factors will affect the dissolution rate of apatite, including the $\mathrm{pH}$ and temperature of the influent water, the calcium ion concentration and relatively high concentrations of anions (e.g., sulfate, carbonate) that can competitively bind calcium ion to shift the equilibrium, etc.

Soil microbial activity also may significantly affect the longevity of biogenic apatite in the subsurface. Recently (2002), a Virtual International Meeting on Microbial Phosphate Solubilization was held under the auspices of the University of Salamanca (presentation abstracts are archived at URL: http://webcd.usal.es/web/psm/index.html). Several soil microorganisms, including pseudomonads, bacilli and rhizoba bacterial groups, as well as certain fungi (e.g., Aspergillus and Penicillium), have been described as phosphate solubilizers (Peix and Martinez-Molina, 2002; Richardson, 2002). Some of these microorganisms exude organic acids and phosphatase enzymes to improve orthophosphate bioavailability from organic and mineral sources. 


\subsection{Establishing Conditions for Batch Testing with use of ${ }^{233} \mathrm{U}$ Isotope}

\subsubsection{Temporal Effects of Batch Contact}

We examined the relative rate of removal of soluble uranium by apatite products, with use of a solution of ${ }^{233} \mathrm{U}$-traced uranyl nitrate in synthetic groundwater (see Fiedor et al., 1998; Bostick et al., 2000). Approximately $0.2 \mathrm{~g}$ of apatite medium (dried at $110{ }^{\circ} \mathrm{C}$ for $1.2-\mathrm{h}$, to terminate or inhibit any biological activity) was contacted with $20-\mathrm{mL}$ of uranium solution (initial $\mathrm{pH} \sim 6.9$ ) by placing the phases in a sealed plastic container and tumbling them at 30 RPM on a TCLP extraction apparatus. At intervals of $\sim 2.5$-h and $24-\mathrm{h}, \sim 2-\mathrm{mL}$ aliquots of the slurry were taken via syringe fitted with a $0.2-\mu \mathrm{m}$ Nalge filter assembly. The filtered solution was mixed with scintillation cocktail and counted to allow estimation of the residual soluble uranium activity (by comparison to the untreated traced solution of known total uranium concentration). Results are summarized in Table 9.

Table 9. Removal of Soluble Uranium $\left(\mathrm{C}_{\mathrm{o}}=464 \mu \mathrm{g}-\mathrm{U} / \mathrm{L}\right)$ from Synthetic Groundwater ${ }^{1}$

\begin{tabular}{|c|c|c|c|c|}
\hline Sample ID & Description & Contact $=2.5 \mathrm{~h}$ & \multicolumn{2}{|c|}{ Contact $=24 \mathrm{~h}$} \\
\cline { 3 - 5 } & & $\mathrm{U}(\mu \mathrm{g} / \mathrm{L})$ & $\mathrm{U}(\mu \mathrm{g} / \mathrm{L})$ & Solution $\mathrm{pH}$ \\
\hline $01-0263$ & Apatite II & 3.3 & 2.8 & 7.26 \\
\hline Apatite C400 & $\begin{array}{c}\text { Apatite charred } \\
\text { at 400 }{ }^{\circ} \mathrm{C}\end{array}$ & 3.0 & 0.43 & 7.83 \\
\hline $01-0297$ & $\begin{array}{c}\text { Synthetic } \\
\text { hydroxyapatite }\end{array}$ & 0.19 & 0.11 & 7.60 \\
\hline
\end{tabular}

${ }^{1}$ See Table 1 for the synthetic groundwater composition. Testing was performed at a nominal Solid-to-Liquid Ratio $\sim$ 1:100 (w/w). Soluble $U$ is estimated from the activity measured on an aliquot of ${ }^{233} \mathrm{U}$ traced liquid phase filtered through $0.2-\mu \mathrm{m}$ pore medium.

The temporal U-removal data presented in Table 9 are for comparative purposes, since actual mass-transfer kinetics are likely limited by the phase contact procedure (low solidto-liquid ratio). However, as noted from the data in Table 9, the biogenic apatite products perform relatively similar to one another, whereas the very fined-grained synthetic apatite (sample 01-0297) reacts more rapidly. The relative effectiveness of the thermally treated apatite product may be compared to the results of early studies reported by Neuman (1953). In Neuman's investigations, the adsorption of uranium by bone product increased in the series: (bone ashed at $\sim 700{ }^{\circ} \mathrm{C}$ ) $<$ (cleaned raw bone) $<$ (bone ashed at $400{ }^{\circ} \mathrm{C}$ ). These data suggest that oxidative thermal treatment of bone at temperatures $>$ $600{ }^{\circ} \mathrm{C}$ may decrease its affinity for soluble uranium. The data also suggest that residual organic matter in nominally cleaned raw bone may be detrimental, since the low temperature $\left(400{ }^{\circ} \mathrm{C}\right)$ ashed material was judged more effective. 


\subsubsection{Effect of Apatite Particle Size}

The effect of apatite grain size on the apparent kinetics for the removal of soluble uranium is further illustrated in Figure 7. A sample of "one crush" biogenic apatite was sieved on a \#40 mesh screen to yield two size fractions, viz, $<425 \mu \mathrm{m}$ (pass screen) and $>$ $425 \mu \mathrm{m}$ (retained on screen). Nominal 0.2-g samples of each size fraction were contacted with $\sim 20$-g solution phase of ${ }^{233} \mathrm{U}$-traced uranyl nitrate in synthetic groundwater $\left(\mathrm{C}_{\mathrm{o}}\right.$, as total $\mathrm{U}, \sim 58 \mu \mathrm{g}-\mathrm{U} / \mathrm{L})$. As before, phase contact was achieved by tumbling the phases in a sealed container placed on a TCLP extraction apparatus. At select time intervals, $\sim 2-$ $\mathrm{mL}$ aliquots of the slurry were taken via syringe fitted with a $0.45-\mu \mathrm{m}$ Nalge filter assembly. As noted in Figure 7, the finer particle size fraction (with greater total surface area for dissolution of apatite phase, sorption of metal ion, and/or nucleation of precipitate phase) removes soluble $U$ more rapidly under the testing conditions. Under the experimental conditions, the solution contacted with the "fine" size fraction of apatite appears to attain an apparent "equilibrium concentration" of $\sim 0.43 \mu \mathrm{g}-\mathrm{U} / \mathrm{L}$ within about 1.3-h or less. Soluble $U$ in the control (no apatite added) remained unchanged during the testing (no nonspecific losses by hydrolysis of $U$ or by sorption to the plastic container used for phase contact). 


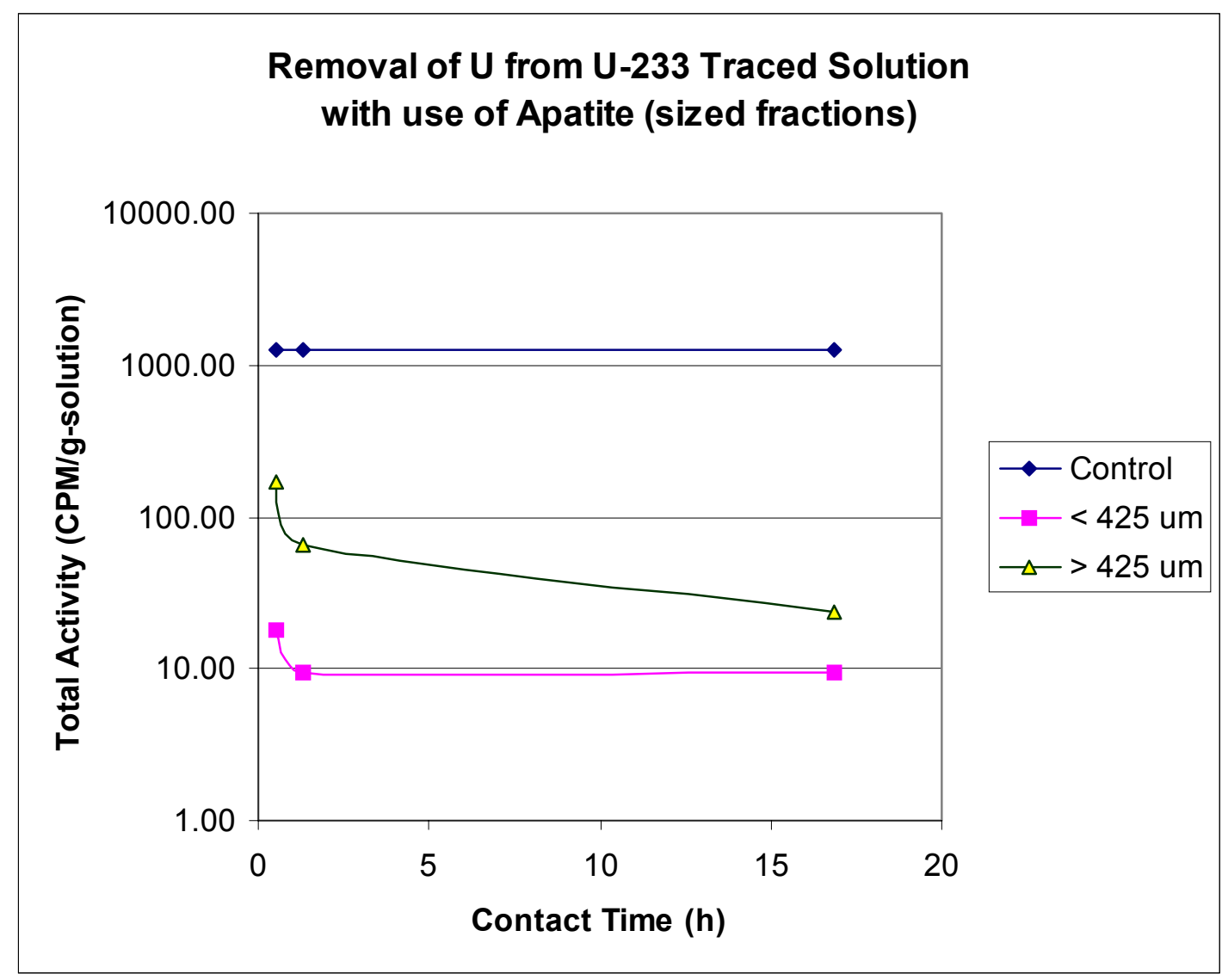

Figure 7. Removal of Uranium from ${ }^{233} \mathrm{U}$-traced Synthetic Groundwater as a function of Partlicle Size. Control is a solution containing total soluble $\mathrm{U}$ at $58 \mu \mathrm{g}-\mathrm{U} / \mathrm{L}$ ( $58 \mathrm{ppb}$ ). This solution is contacted at a solid-to-liquid ratio of 1:100, using one-crush raw apatite size fractions of either less than or greater than $425 \mu \mathrm{m}(+/-40$-mesh sieve). At select time intervals, an aliquot of the slurry is sampled and the phases are separated with use of $0.45-\mu \mathrm{m}$ pore filter medium. Liquid scintillation counting quantitates soluble $\mathrm{U}$ in the filtrate solution. Note that the Y-axis is logarithmic scale. The apparent "equilibrium" activity for soluble ${ }^{233} \mathrm{U}$ in contact with apatite "fines" $(<425 \mu \mathrm{m})$ corresponds to $\sim 0.43$ $\mu \mathrm{g}-\mathrm{U} / \mathrm{L}$.

\subsubsection{Effect of Soluble P, Organic Matter, and Active Microbes on the Long-Term Uptake of Soluble U.}

The intended purpose of this series of experiments was to determine whether trace amounts of soluble $U$ could be precipitated homogeneously from solution phase by phosphate ion in the absence of apatite solid phase. Pre-equilibrating APA with synthetic groundwater, and then removing the solid phase by filtration before adding soluble $U$ tested this premise. In addition, relatively long-term testing (up to 146-h) was performed under anaerobic conditions that encouraged solution phase to go septic, to determine whether leached organic matter and/or anaerobic biological activity may have a detrimental effect on the binding of $U$ to APA. 
A biologically active ("inoculated") liquid phase was prepared for use in this testing. Fresh, moist near-surface forest soil (MCLinc sample 02-0175) (95 wt\%) was mixed with ground raw APA (5-wt $\%)$ and stored for $\sim$ two weeks at ambient temperature in a loosely sealed plastic container before use to encourage proliferation of indigenous soil bacteria. A portion of this biologically active soil was then extracted by tumbling it overnight with synthetic BYBY water (syn-BYBY, at $\mathrm{L} / \mathrm{S}=5 \mathrm{w} / \mathrm{w})$. A small portion $(\sim 2 \mathrm{~mL})$ of soil extract supernate solution was added to $200 \mathrm{~mL}$ of syn-BYBY and nonsterile raw APA (2 g material 01-0263), and the mixture was tumbled in a container overnight. The solution phase, filtered through Whatman 41 paper (nominally retentive to 20-25 $\mu \mathrm{m}$ particulate), had perceptible turbidity and a slight septic odor. The filtrate had a $\mathrm{pH}$ value of 6.4 and a total $\mathrm{P}$ content of $38.8 \mathrm{mg} / \mathrm{L}$. In addition to this relatively high level of soluble $\mathrm{P}$, the "inoculated" liquid phase is expected to contain active bacteria, some soluble organic matter (leached from the extraneous matter in raw APA) and perhaps some colloidal material from the soil extract.

A trace amount of soluble ${ }^{233} \mathrm{U}$ (as uranyl nitrate) was added to aliquots of both original ("clean") and "inoculated" syn-BYBY. The solution phases were tested as-prepared (with and without filtration) and after contact with nominally "sterile" APA phase (i.e., material that had been held overnight at $110 \mathrm{C}$ to terminate most indigenous microbial activity). The liquid to solid mass ratio (L/S) with use of "sterile" APA was $\sim 110$. Specific activities of solution phase (counts per minute (CPM) per gram solution) were measured in solution aliquots collected at select time intervals, with and without prior filtration. The initial solution phase activity corresponds to $\sim 2.7 \times 10^{-6}(2.7 \mathrm{E}-6) \mathrm{mol} / \mathrm{L}$ uranyl ion.

In the absence of APA phase, and with minimal biological activity in the solution phase, uranium remains soluble (i.e., there is little change in liquid phase specific activity over 146-h, indicating little or no loss due to hydrolysis or sorption to container). There was minimal difference in the measured specific activity of solutions filtered at $0.2-\mu \mathrm{m}$ (Nalge 191-2020, surfactant-free cellulose acetate) and at 0.8- $\mu \mathrm{m}$ (Gelman Acrodisc acrylic copolymer), although the latter gave consistently lower specific activities (suggesting a slight sorption of $U$ on the medium); see Figure 8 (Series $1 \& 2$ ). In the presence of APA (L/S 112), there is a rapid removal of soluble $\mathrm{U}$, but a notable "rebound" of $\mathrm{U}$ in the filtrate as the solution equilibrates a long time (with some indication of biological activity).

Figure 9 illustrates the analogous data for "inoculated" solution phase. In the short-term $(\leq 30-\mathrm{h})$, there is little effect of inoculum solution on soluble $\mathrm{U}$ without added APA. This suggests that the initial $\mathrm{P}(\sim 35 \mathrm{ppm}$, or $\sim 1.1 \mathrm{E}-3 \mathrm{~mol} / \mathrm{L})$ in the "inoculated" solution is not sufficient to homogeneously precipitate added $\mathrm{U}(\sim 2.7 \mathrm{E}-6 \mathrm{~mol} / \mathrm{L})$ from solution phase, despite an initial mole ratio for soluble $\mathrm{P} / \mathrm{U}>400$. Short-term removal of soluble $\mathrm{U}$ in the presence of APA thus must be attributed to initial sorption to the solid phase. At longer time $(\sim 146-\mathrm{h})$, there does appear to be some loss of soluble $\mathrm{U}$ from the non-sterile solution without added APA. Perhaps in the longer term (>30-h) some uranyl ion complexes with macromolecules (leached organic matter) and/or microbes, which in turn 
"sorb" (or plate out) on the plastic container. At 146-h, the "inoculated" solution with added APA is very turbid, with appreciable septic odor.

Collectively, the data suggest that, in the long-term, organic matter leached from raw apatite may competitively bind to the apatite surface or sorb uranyl ion, perhaps even displacing a portion of the $U$ that had been initially bound to apatite phase. (See also section 4.2.3 for a comparison of raw APA and APA that has been thermally processed to destroy excess organic matter). 


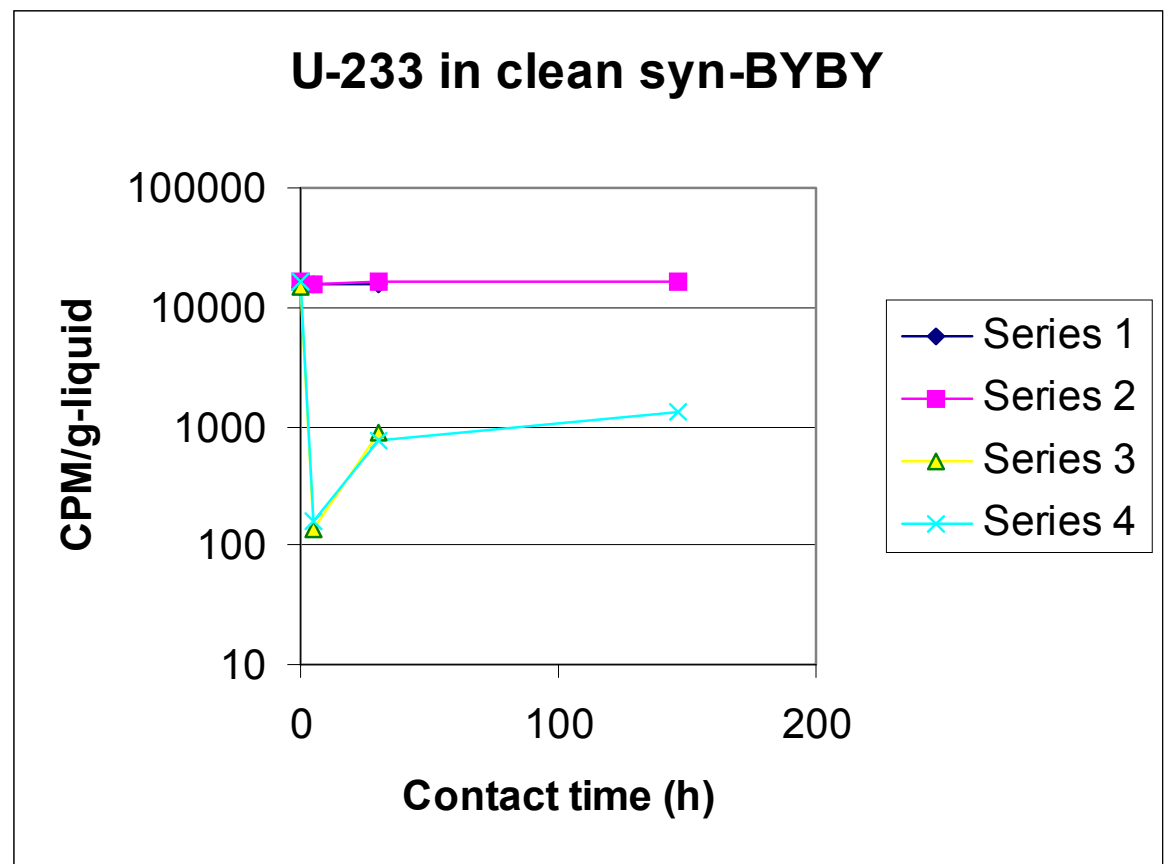

Figure 8. Removal of soluble U-233 from clean syn-BYBY (no initial P or biological activity). Series 1: no APA (filter at $0.8-\mu \mathrm{m}$ ); Series 2: no APA (filter at $0.2-\mu \mathrm{m}$ ); Series 3: APA present $(1: 112(\mathrm{w} / \mathrm{w})$; filter at $0.8-\mu \mathrm{m})$; Series 4: APA present $(1: 112(\mathrm{w} / \mathrm{w})$; filter at $0.2-\mu \mathrm{m})$.

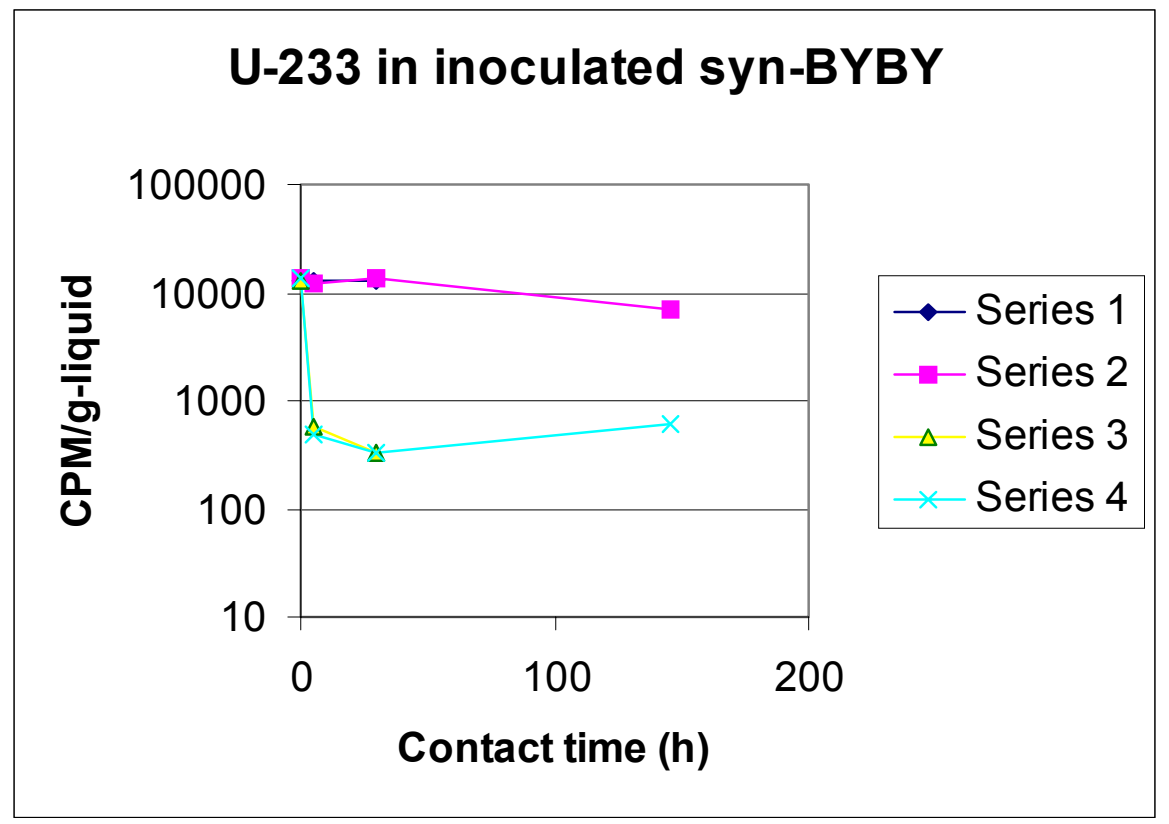

Figure 9. Removal of soluble U-233 from "inoculated" syn-BYBY (pre-equilibrated with non-sterile APA to provide initial $\mathrm{P}$ and biological activity). Series 1: no added APA (filter at $0.8-\mu \mathrm{m}$ ); Series 2: no added APA (filter at 0.2- $\mu \mathrm{m}$ ); Series 3: APA present $(1: 112(\mathrm{w} / \mathrm{w})$; filter at $0.8-\mu \mathrm{m})$; Series 4 : APA present $(1: 112(\mathrm{w} / \mathrm{w})$; filter at $0.2-\mu \mathrm{m})$. 


\subsection{Batch Tests: Survey of Amenable Metals (Single Metal Experiments)}

Cost-effective means are needed by the DOE and industry to minimize the subsurface migration of toxic heavy metals into previously clean areas or the leaching of these metals into groundwater; see Table 1, which lists the reported frequency for metal contaminants to exceed regulatory limits at EPA Superfund sites and at sites controlled at the DOE and DOD.

Based upon the priorities for metals identified in Table 1, the following metals were selected to survey for their amenability to remediation by apatite medium: lead, chromium, arsenic, zinc, cadmium, copper, mercury, strontium, manganese, molybdenum, antimony, selenium, nickel, vanadium, barium and the radionuclides (uranium, thorium and technetium). Initial survey is performed by batch testing under the conditions defined in the Operational Instructions presented in Appendix A-1.

In Section 4.2, we present some of the variables that may affect the results of short-term batch tests for uptake of priority metals by raw apatite. In this series of evaluations, we minimize potential sources of variability with use of a blended ground raw apatite product (01-0263) at a liquid-to-solid ratio of $\sim 50(\mathrm{w} / \mathrm{w})$, and a fixed phase contact time of $\sim 50$-h.

Individual metal salts are supplemented into syn-BYBY water composition. It is anticipated that not all metal salts used for testing purposes will be completely soluble in the groundwater matrix at the initial target value of $\sim 250 \mathrm{mg}-\mathrm{metal} / \mathrm{L}(2.5 \mathrm{E}-04 \mathrm{~g} / \mathrm{mL})$. For example, the solubility of $\mathrm{Pb}$ will be limited by the solution $\mathrm{pH}$ value and by sulfate and carbonate ions present in the synthetic groundwater matrix; the concentration of $\mathrm{Hg}$ (II) in the synthetic groundwater surrogate is shown to be limited by the formation of an hydrolysis product, $\mathrm{HgSO}_{4}(\mathrm{HgO})_{2}$. Therefore, the concentrated metal stock solution is prepared, with mixing, then it is allowed to set quiescently overnight (to allow formation and precipitation of any solid phases that may have been initially oversaturated in solution phase), and finally the stock solution is filtered through $0.45-\mu \mathrm{m}$ media before preparing serial dilutions for use in media testing. Phase contact is made by tumbling the mixtures of liquid and solid in a closed vessel at a rate of 30 revolutions per minute, with use of a TCLP extraction apparatus. Each set of experiments includes solutions that are carried through the process, but without Apatite phase. These companion samples are used to estimate the initial (" $\mathrm{C}_{\mathrm{o}}$ ") conditions, and are intended to compensate for any nonspecific losses (e.g., by hydrolysis or sorption to the container) that are not mediated by the apatite phase. After contact, phases are separated by filtration with $0.2-\mu \mathrm{m}$ media. Filtered solutions are preserved by the addition of metals-grade nitric acid, and are analyzed by inductively coupled plasma (ICP). Results of this screening are summarized below. 


\subsubsection{Antimony, as $\mathrm{Sb}(\mathrm{III})$}

\section{Literature Expectations}

Antimony $(\mathrm{Sb})$ is a priority pollutant, and the USEPA MCL for Sb in drinking water is set at $0.006 \mathrm{mg} / \mathrm{L}(6 \mathrm{E}-09 \mathrm{~g} / \mathrm{mL})$. The toxicity of antimony depends on its valence state, and $\mathrm{Sb}(\mathrm{III})$ is much more toxic than is $\mathrm{Sb}(\mathrm{V})$. Levya et al. (2001) report on the sorption of $\mathrm{Sb}$ (III) on synthetic hydroxyapatite. Removal of soluble $\mathrm{Sb}$ (III) was highly efficient at $\mathrm{pH}$ values $>5$. No new $\mathrm{Sb}$ (III) phase was identified, and the removal mechanism was attributed to chemisorption of the hydrolyzed cation $\left(\mathrm{SbO}^{+}\right)$onto apatite phase.

\section{Experimental Results}

Table 10. Raw Apatite (APA) Contacted 56-h with M Sb(III) (from antimony potassium tartrate, $\left.\mathrm{C}_{8} \mathrm{H}_{4} \mathrm{~K}_{2} \mathrm{O}_{12} \mathrm{Sb}_{2} \cdot 3 \mathrm{H}_{2} \mathrm{O}\right)$ in Synthetic Groundwater Matrix

\begin{tabular}{|c|c|c|c|c|}
\hline Test Series & 1 & 2 & 3 & 4 \\
\hline W (g-APA) & 0.8393 & 0.8044 & 0.8085 & 0.8041 \\
\hline V (Volume Solution, mL) & 40 & 40 & 40 & 40 \\
\hline Co (g-M/mL) & $1.33 \mathrm{E}-04$ & $4.43 \mathrm{E}-05$ & $1.61 \mathrm{E}-05$ & $6.30 \mathrm{E}-06$ \\
\hline $\mathrm{pHo}$ & 6.7 & 7.1 & 7.6 & 8.1 \\
\hline $\mathrm{Ce}(\mathrm{g}-\mathrm{M} / \mathrm{mL})$ & $1.66 \mathrm{E}-05$ & $3.32 \mathrm{E}-06$ & $9.17 \mathrm{E}-7$ & $2.40 \mathrm{E}-07$ \\
\hline $\mathrm{Ce} / \mathrm{Co}$ & $1.25 \mathrm{E}-01$ & $7.48 \mathrm{E}-02$ & $5.71 \mathrm{E}-02$ & $3.81 \mathrm{E}-2$ \\
\hline $\mathrm{pHe}$ & 7.0 & 6.7 & 6.6 & 6.5 \\
\hline $\mathrm{S}(\mathrm{exp}), \mathrm{g}-\mathrm{M} / \mathrm{g}-\mathrm{APA}(1)$ & $4.64 \mathrm{E}-03$ & $1.64 \mathrm{E}-03$ & $6.05 \mathrm{E}-04$ & $2.42 \mathrm{E}-04$ \\
\hline $\mathrm{Kd}=\mathrm{S}(\mathrm{exp}) / \mathrm{Ce}, \mathrm{mL} / \mathrm{g}$ & 280 & 495 & 660 & 1,010 \\
\hline $\mathrm{S}(\mathrm{calc}), \mathrm{g}-\mathrm{M} / \mathrm{g}-\mathrm{APA}(2)$ & $4.77 \mathrm{E}-03$ & $1.54 \mathrm{E}-03$ & $6.24 \mathrm{E}-04$ & $2.43 \mathrm{E}-04$ \\
\hline $\mathrm{Kd}=\mathrm{S}(\mathrm{calc}) / \mathrm{Ce}, \mathrm{mL} / \mathrm{g}$ & 288 & 465 & 681 & 1,010 \\
\hline
\end{tabular}

(1) Estimated from mass-balance considerations as: $\mathrm{S}=\mathrm{Co}(\mathrm{V} / \mathrm{W})(1-\mathrm{C} / \mathrm{Co})$

(2) Estimated from fitted parameters for a Freundlich isotherm; see Figure 10. 




Figure 10. Sorption of $\mathrm{Sb}(\mathrm{III})$ on Raw Apatite. Experimental results are fitted to a linearized Freundlich isotherm (Eq. 4). The units for $\mathrm{S}$ and $\mathrm{C}$ are given in Table 10.



Figure 11. Sorption of $\mathrm{Sb}$ (III) to Raw Apatite II, presented as a linear isotherm. $\mathrm{S}(\exp )$ and $\mathrm{S}(\mathrm{calc})$ are defined in the footnotes to Table $\mathbf{1 0 .}$

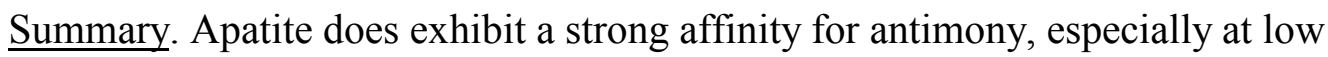
concentration of sorbate. 


\subsubsection{Arsenic, as As(V)}

\section{Literature Expectations}

Arsenic (As) is known for the high toxicity of a number of its compounds. Although As has many chemical similarities to phosphorous, the soil chemistry of arsenic is more complicated because As exists in more than one oxidation state under normal subsurface conditions and more readily forms bonds with sulfur and carbon. Arsenic is considered a Class A carcinogen by the U.S. EPA, and is found as a contaminant of concern at many sites, often the result of the former use of arsenic containing pesticides. Sorption and redox reactions strongly influence the toxicity, bioavailability, and potential mobility of arsenic (As) in soils (McGeehan, 1996). Under the redox conditions of natural water systems, arsenic is commonly found in both oxidized and reduced valence states. Arsenate, $\mathrm{As}(\mathrm{V})$, is the predominant species in oxic environments, with $\mathrm{H}_{3} \mathrm{AsO}_{4}$ predominating in solution phase at near-neutral $\mathrm{pH}$. Arsenite, $\mathrm{As}(\mathrm{III})$, may form under mildly reducing conditions, and is more toxic and more mobile than arsenate in soil systems.

Select oxyanions, including $\mathrm{AsO}_{4}{ }^{3-}, \mathrm{VO}_{4}{ }^{3-}, \mathrm{CO}_{3}{ }^{2-}, \mathrm{SO}_{4}{ }^{2-}$ can potentially replace structural $\mathrm{PO}_{4}{ }^{3-}$ in the apatite host (Narasaraju \& Phebe, 1996). Arsenic (V) chemistry resembles that of phosphorous (V). Arsenate is isostructural and isoelectronic with phosphate, which may facilitate its ion exchange on apatite. It is not known whether the rate of host matrix substitution (or formation of a solid solution) with these select oxyanions (e.g., for removal of toxic arsenate ion) would be sufficiently rapid to permit a practical and efficient removal mechanism for these contaminants. Anderson et al. (1998) evaluated a number of media (natural and synthetic apatites, tricalcium phosphate, bone char, zeolite, magnetite, etc.) for the removal of select metals from solution phase. These media demonstrated only a limited affinity for $\mathrm{As}(\mathrm{V})$ in batch contact tests (i.e., $\mathrm{Kd}$ values $\leq$ $100 \mathrm{~mL} / \mathrm{g}$ ); however (in marked contrast to the batch test results) bone char and synthetic hydroxyapatite media did demonstrate excellent retention of $\mathrm{As}(\mathrm{V})$ in column tests with feed solution containing multi-metals. It is possible that removal of $\mathrm{As}(\mathrm{V})$ is enhanced by synergistic co-precipitation with other cationic metals in the formation of a mixed phosphate-arsenate mineral phase or phases. Investigations by MSE-TA (1998) have shown that arsenic sequestration by compound formation (i.e., co-precipitation with use of soluble calcium and phosphate precursor chemicals, rather than sorption to a preformed apatite particle surface) produces a low-solubility apatite-like structure of the general form $\mathrm{Ca}_{10}\left(\mathrm{As}_{\mathrm{x}} \mathrm{P}_{\mathrm{y}} \mathrm{O}_{4}\right)_{6}(\mathrm{OH})_{2}$.

\section{Experimental Results}

The phase contact is performed in accordance with the Operational Instructions presented in Exhibit \#1. As(V) is added to synthetic groundwater as the salt dibasic sodium arsenate, $\mathrm{Na}_{2} \mathrm{HAsO}_{4} \cdot 7 \mathrm{H}_{2} \mathrm{O}$. 
Table 11. Raw Apatite (APA) Contacted 52-h with As (V) (from Sodium Arsenate) in Synthetic Groundwater

\begin{tabular}{|c|c|c|c|c|}
\hline Test Series & 1 & 2 & 3 & 4 \\
\hline $\mathrm{W}(\mathrm{g}-\mathrm{APA})$ & 0.5156 & 0.8004 & 0.8196 & 0.8222 \\
\hline $\mathrm{V}($ Volume Solution, mL) & 25 & 40 & 40 & 40 \\
\hline $\mathrm{C}_{\mathrm{o}}(\mathrm{g}-\mathrm{As} / \mathrm{mL})$ & $2.47 \mathrm{E}-04$ & $8.49 \mathrm{E}-05$ & $2.93 \mathrm{E}-05$ & $1.01 \mathrm{E}-05$ \\
\hline $\mathrm{pHo}$ & 7.60 & 7.7 & 7.9 & 8.0 \\
\hline $\mathrm{C}_{\mathrm{e}}(\mathrm{g}-\mathrm{As} / \mathrm{mL})$ & $1.88 \mathrm{E}-04$ & $6.21 \mathrm{E}-05$ & $2.02 \mathrm{E}-5$ & $6.45 \mathrm{E}-06$ \\
\hline $\mathrm{C}_{\mathrm{e}} / \mathrm{C}_{\mathrm{o}}$ & $6.19 \mathrm{E}-01$ & $5.94 \mathrm{E}-01$ & $6.64 \mathrm{E}-01$ & $6.33 \mathrm{E}-01$ \\
\hline $\mathrm{pHe}$ & 7.15 & 6.9 & 6.9 & 6.7 \\
\hline $\mathrm{S}(\mathrm{g}-\mathrm{As} / \mathrm{g}-\mathrm{APA})-$ experiment $(1)$ & $1.48 \mathrm{E}-03$ & $9.12 \mathrm{E}-04$ & $3.64 \mathrm{E}-04$ & $1.46 \mathrm{E}-04$ \\
\hline $\mathrm{Kd}(\mathrm{mL} / \mathrm{g})=\mathrm{S}(\exp ) / \mathrm{Ce}$ & 15.4 & 27.3 & 20.3 & 23.2 \\
\hline $\mathrm{S}(\mathrm{g}-\mathrm{As} / \mathrm{g}-\mathrm{APA})-$ Freundlich $(2)$ & $1.66 \mathrm{E}-03$ & $7.66 \mathrm{E}-04$ & $3.49 \mathrm{E}-04$ & $1.57 \mathrm{E}-04$ \\
\hline $\mathrm{Kd}(\mathrm{mL} / \mathrm{g})=\mathrm{S}($ calc$) / \mathrm{Ce}$ & 18.4 & 20.1 & 22.1 & 43.5 \\
\hline
\end{tabular}

(1) Estimated from mass-balance considerations as: $\mathrm{S}=\mathrm{C}_{\mathrm{o}}(\mathrm{V} / \mathrm{W})\left(1-\mathrm{C}_{\mathrm{e}} / \mathrm{C}_{\mathrm{o}}\right)$.

(2) Estimated from fitted parameters for a Freundlich isotherm; see Figure 12.

In Figure As-1, the short-term (52-h) sorption data are presented as a linearized Freundlich isotherm (see Equation 3). The slope of the curve is near unity, suggesting that the data may also be adequately represented as a simple linear sorption isotherm; see Figure 13. For total As at the current Maximum Contaminant Level (MCL) in drinking water $(0.005 \mathrm{mg} / \mathrm{L}), \mathrm{Kd}$ estimated from the data in Figure As- 1 is $\sim 44 \mathrm{~mL} / \mathrm{g}$. This indicates that some As is removed by short-term exposure to raw apatite, but the medium does not achieve the defined test protocol success criterion $(\mathrm{Kd} \geq 1,000 \mathrm{~mL} / \mathrm{g})$. Although removal of arsenate by "sorption" is modest (as evidenced in this single contaminant study), it is possible that efficiency may be improved in the presence of co-contaminants that form insoluble mixed phosphate/arsenate precipitate phases. 


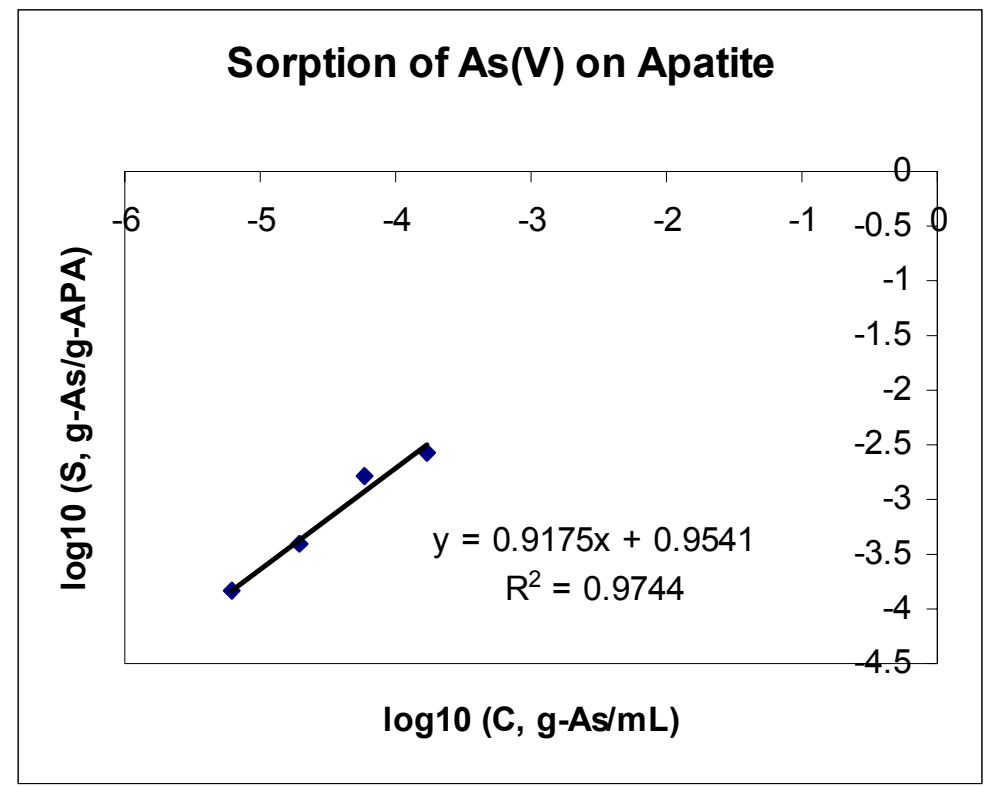

Figure 12. Sorption of $A s(V)$ on Raw Apatite, fitted to a linearized Freundlich isotherm. The liquid-to-solid ratio as-tested is $\sim 50(\mathrm{w} / \mathrm{w})$. The isotherm is described by the empirical expression: $\mathrm{S}($ calc., g-As/g-APA $)=9.00 x(\mathrm{Ce}, \mathrm{g}-\mathrm{As} / \mathrm{mL})^{0.918}$.

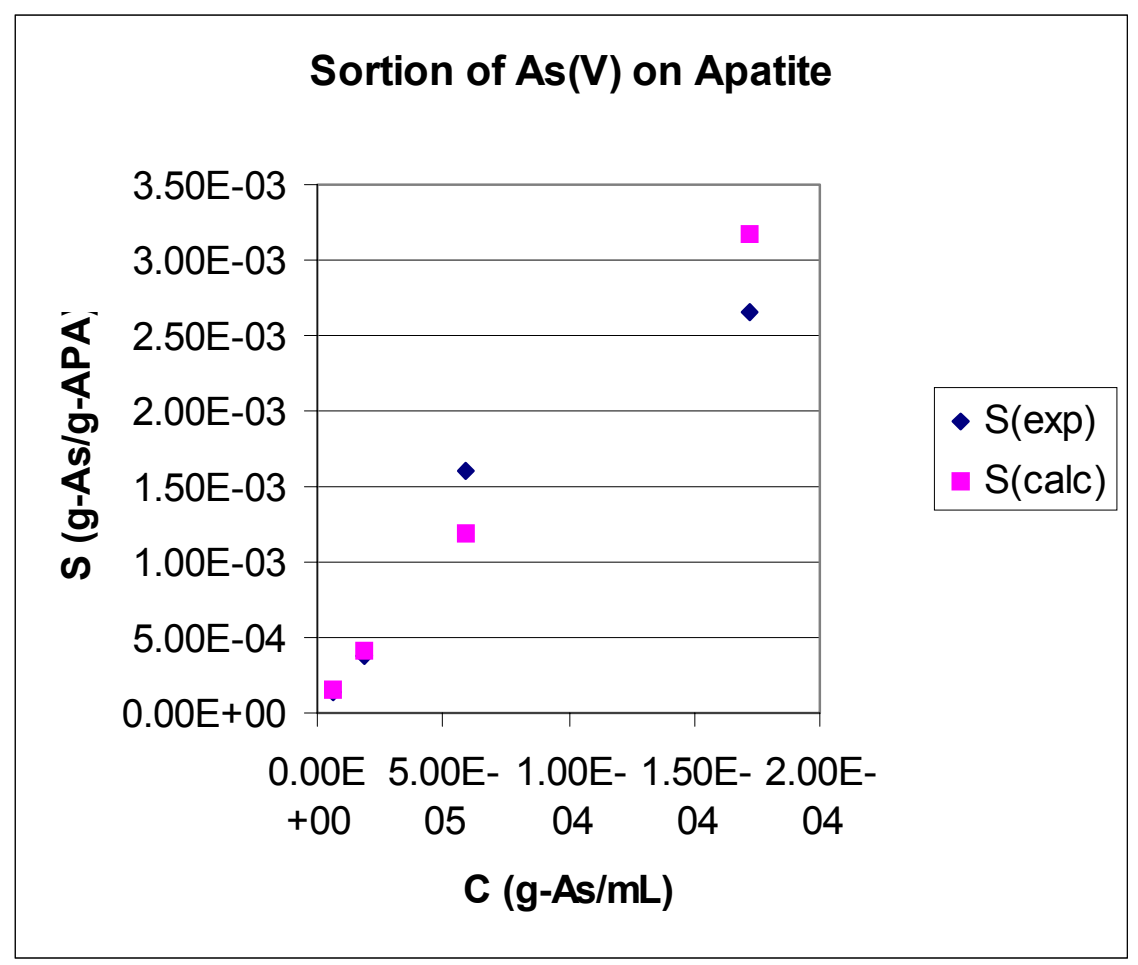

Figure 13. Sorption isotherm for $\mathrm{As}(\mathrm{V})$ partitioning between solution and solid phases. $(\mathrm{APA}=$ ground raw biogenic apatite). S(exp) and S(calc) are defined in the footnotes to Table 11.

Summary: Apatite demonstrates only a modest ability to "sorb" arsenate ion. 


\subsubsection{Barium, as $\mathrm{Ba}(\mathrm{II})$}

\section{Literature Expectations}

Barium ion is similar in size to calcium ion, and can substitute for calcium in the hydroxyapatite structure to form a solid solution. Uptake of $\mathrm{Ba}$ (II) by apatite is enhanced when $\mathrm{Zn}$ (II) is also present, presumably because the $\mathrm{Zn}$ (II) distorts the surface of hydroxyapatite, thereby facilitating a replacement of $\mathrm{Ca}$ (II) by larger alkaline earth elements (Narasaraju and Phebe, 1996). In addition, the existence of mixed bariumcontaining phosphate minerals suggests that synergistic co-precipitation may occur; known phases include (e.g.): gorceixite (hydrated barium aluminum phosphate hyroxide), kulanite (barium iron manganese aluminum phosphate), and uranocircite (hydrated barium uranyl phosphate).

Suzuki et al. (1981) studied the removal of select metals from solutions passed through columns packed with synthetic hydroxyapatite; very limited data suggests that at least some $\mathrm{Ba}$ (II) could be removed. The authors assume a cation exchange mechanism, and the ranking in terms of the amount exchanged was: $\mathrm{Cd}(\mathrm{II}), \mathrm{Zn}(\mathrm{II})>\mathrm{Ni}$ (II) $>\mathrm{Ba}$ (II), $\operatorname{Mg}(\mathrm{II})$.

Barium forms sparingly soluble salts with sulfate and carbonate ions, and its solubility in the proxy groundwater (Table 1) will be limited. Other salts, such as barium arsenate, also have poor solubility.

\section{Experimental Results}

Table 12. Raw Apatite (APA) Contacted 52-h with $\mathrm{M}=\mathrm{Ba}$ (II) (from barium chloride, $\mathrm{BaCl}_{2} \cdot 2 \mathrm{H}_{2} \mathrm{O}$ ) in Synthetic Groundwater Matrix

\begin{tabular}{|c|c|c|c|c|}
\hline Test Series & 1 & 2 & 3 & 4 \\
\hline $\mathrm{W}(\mathrm{g}-\mathrm{APA})$ & 0.8103 & 0.8144 & 0.8230 & 0.8650 \\
\hline $\mathrm{V}$ (Volume Solution, $\mathrm{mL})$ & 40 & 40 & 40 & 40 \\
\hline $\mathrm{Co}(\mathrm{g}-\mathrm{M} / \mathrm{mL})$ & $2.03 \mathrm{E}-04$ & $4.47 \mathrm{E}-05$ & $5.04 \mathrm{E}-06$ & $5.10 \mathrm{E}-06$ \\
\hline $\mathrm{pHo}$ & 6.8 & 8.1 & 8.0 & 8.1 \\
\hline $\mathrm{Ce}(\mathrm{g}-\mathrm{M} / \mathrm{mL})$ & $3.96-05$ & $7.67 \mathrm{E}-06$ & $2.44 \mathrm{E}-06$ & $6.48 \mathrm{E}-07$ \\
\hline $\mathrm{Ce} / \mathrm{Co}$ & $1.95 \mathrm{E}-01$ & $1.72 \mathrm{E}-01$ & $4.85 \mathrm{E}-01$ & $1.27 \mathrm{E}-01$ \\
\hline $\mathrm{pHe}$ & 6.5 & 6.5 & 6.3 & 6.4 \\
\hline $\mathrm{S}(\mathrm{exp}), \mathrm{g}-\mathrm{M} / \mathrm{g}-\mathrm{APA}(\underline{1})$ & $6.52 \mathrm{E}-03$ & $1.48 \mathrm{E}-03$ & $1.04 \mathrm{E}-04$ & $1.78 \mathrm{E}-04$ \\
\hline $\mathrm{Kd}=\mathrm{S}(\mathrm{exp}) / \mathrm{Ce}, \mathrm{mL} / \mathrm{g}$ & 165 & 193 & 42.5 & 275 \\
\hline $\mathrm{S}(\mathrm{calc}), \mathrm{g}-\mathrm{M} / \mathrm{g}-\mathrm{APA}(2)$ & $5.13 \mathrm{E}-03$ & $1.04 \mathrm{E}-03$ & $3.39 \mathrm{E}-04$ & $9.32 \mathrm{E}-05$ \\
\hline $\mathrm{Kd}=\mathrm{S}(\mathrm{calc}) / \mathrm{Ce}, \mathrm{mL} / \mathrm{g}$ & 130 & 136 & 139 & 144 \\
\hline
\end{tabular}

(1) Estimated from mass-balance considerations as: $\mathrm{S}=\mathrm{Co}(\mathrm{V} / \mathrm{W})(1-\mathrm{C} / \mathrm{Co})$.

(2) Estimated from fitted parameters for a Freundlich isotherm; see Figure 14. 


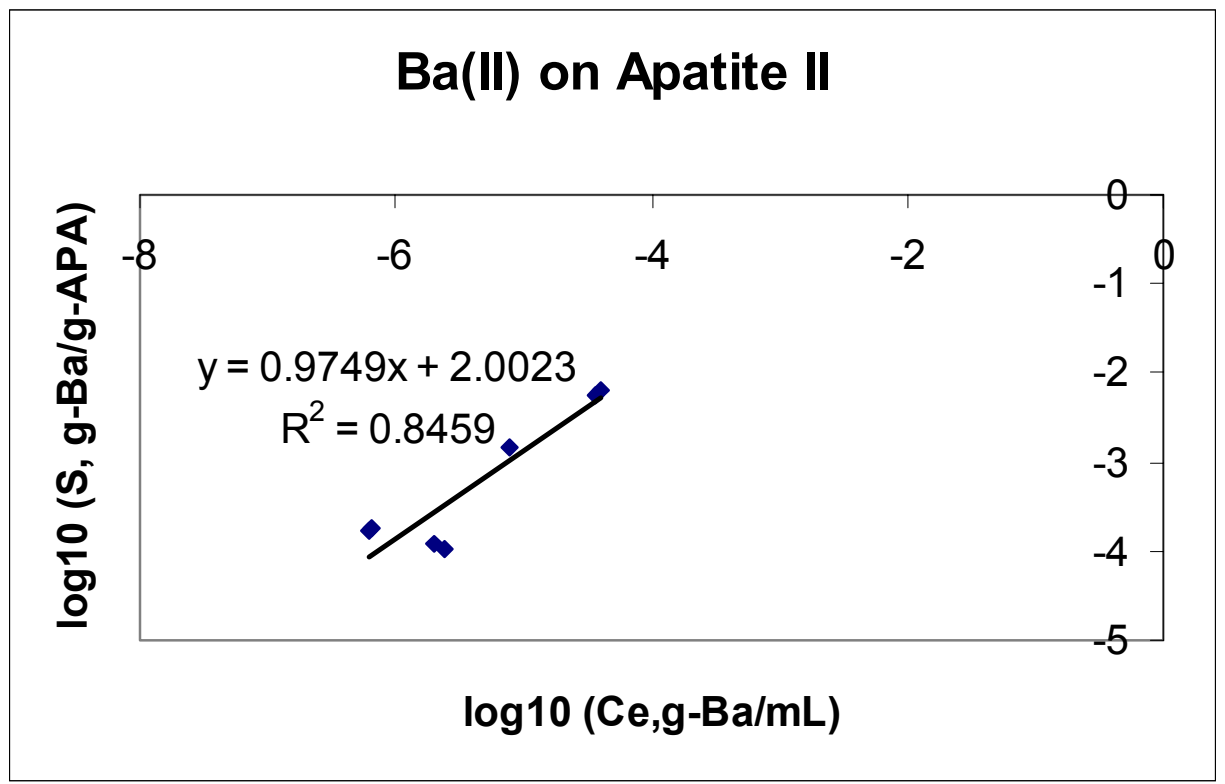

Figure 14. Sorption of $\mathrm{Ba}(\mathrm{II})$ on Raw Apatite, fitted to a linearized Freundlich isotherm.



Figure 15. Sorption of Barium to Raw Apatite II, presented as a linear isotherm. S(exp) and $\mathrm{S}$ (calc) are defined in the footnotes to Table 12.

Summary: Apatite demonstrates only a modest affinity to "sorb" (or exchange for) barium ion. 


\subsubsection{Cadmium, as $\mathrm{Cd}(\mathrm{II})$}

\section{Literature Expectations}

Environmental concern over cadmium stems from its widespread occurrence as a result of industrial use and disposal practices, its high toxicity, and its bioavailability (Bodek et al., 1988, Chapt. 7.5-1). At $\mathrm{pH}$ values $>8$, cadmium tends to hydrolyze, forming relatively insoluble hydroxide and carbonate complexes. Phosphate ion further decreases the solubility of cadmium. Bodek et al. (1988) present thermodynamic predictions for the solubility of $\mathrm{Cd}_{3}\left(\mathrm{PO}_{4}\right)_{2}$ as a function of solution $\mathrm{pH}, \mathrm{pCO}_{2}$, and select mineral phases (e.g., calcite $\left(\mathrm{CaCO}_{3}\right)$, strengite $\left(\mathrm{FePO}_{4} \cdot 2 \mathrm{H}_{2} \mathrm{O}\right)$, etc.); at $\mathrm{pH} \sim 8, \mathrm{CO}_{2}=0.003 \mathrm{~atm}$, and in the presence of calcium phosphate/calcium carbonate mineral phases, the limiting solubility for $\mathrm{Cd}(\mathrm{II})$ is predicted to approach $\sim 1.1 \mathrm{E}-07 M(\sim 1.2 \mathrm{E}-08 \mathrm{~g}-\mathrm{Cd} / \mathrm{mL}$, or $\sim$ $0.012 \mathrm{mg} / \mathrm{L})$. At $\mathrm{pH}=7$, the predicted solubility increases to $\sim 4.3 \mathrm{E}-07 M(\sim 4.8 \mathrm{E}-08 \mathrm{~g}$ $\mathrm{Cd} / \mathrm{mL}$, or $\sim 0.048 \mathrm{mg} / \mathrm{L}$ ). The EPA MCL for Cd in drinking water is $0.005 \mathrm{mg} / \mathrm{L}$.

Although $\mathrm{Cd}$ and $\mathrm{Zn}$ have similar chemical properties, $\mathrm{Cd}$ minerals are scarce in natures. $\mathrm{Cd}$ occurs by isomorphous substitution in almost all $\mathrm{Zn}$ minerals. Cadmium may be adsorbed by clay minerals, carbonates or hydrous oxides of iron and manganese or may be precipitated as cadmium carbonate, hydroxide, and phosphate. Evidence suggests that adsorption mechanisms may be the primary source of Cd removal from soil, sediments and groundwater (Dudley et al., 1988, 1991). In soils and sediments contaminated with metal wastes, the greatest percentage of the total $\mathrm{Cd}$ is associated with the exchangeable fraction (Hickey and Kittrick, 1984). Aqueous concentrations of Cd are limited by $\mathrm{CdCO}_{3}$ solubility in neutral and alkaline soils (Santillan-Medrano and Jurinak, 1975). Under acidic conditions $\mathrm{Cd}$ solubility increases and very little adsorption of $\mathrm{Cd}$ by colloids, hydrous oxides, and organic matter takes place. At $\mathrm{pH}>7$, cadmium is strongly adsorbed by solid phases or is precipitated, and solution concentrations are low.

Apatite is known to effectively remove soluble cadmium; see (e.g.): Jeanjean (1995); Wright (1995); Ma et al. (1997); Mandjiny (1998). From results for short-term contact studies with use of fossil apatite mineral, Ma et al. (1997) concluded that minor octavite $\left(\mathrm{CdCO}_{3}\right)$ precipitation occurs, but that sorption mechanisms (such as surface complexation, ion exchange, or the formation of amorphous solids) are primarily responsible for the removal of soluble $\mathrm{Zn}$ and Cd. Jeanjean et al. (1995) and later Mandjiny (1998) concluded, from batch-contact experiments, that Cd reacts with the apatite media by initial sorption, followed by slower intercrystalline diffusion and cation exchange for $\mathrm{Ca}$ ion. Thus, $\mathrm{Cd}$ is ultimately incorporated into the bulk of the host apatite phase, reportedly as $\left(\mathrm{H}_{3} \mathrm{O}\right)_{2} \mathrm{Cd}_{5}\left(\mathrm{PO}_{4}\right)_{4}$ (Jeanjean, 1996). Jeanjean reports that the relative reactivity with apatite phase, judged by the total amount of metal ion removed at various contact time, was $\mathrm{Pb}>\mathrm{U}>\mathrm{Cd}$. Valsami-Jones et al. (1998) report that removal of soluble $\mathrm{Cd}$ by synthetic hydroxyapatite is $\mathrm{pH}$-dependent, being more effective at nearneutral $\mathrm{pH}$ values; the authors postulate that cadmium forms a mixed cadmium-calcium phosphate with solubility lower than that of the hydroxyapatite. Wright et al. (1995) report that the leachability of $\mathrm{Cd}$ from apatite-amended contaminated soil is below their analytical reporting limit of $0.005 \mathrm{mg} / \mathrm{L}(<5 \mathrm{E}-9 \mathrm{~g}-\mathrm{Cd} / \mathrm{mL})$. 


\section{Experimental Results}

Table 13. Raw Apatite (APA) Contacted 52-h with $\mathrm{M}=\mathrm{Cd}$ (II) (from cadmium nitrate) in Synthetic Groundwater Matrix

\begin{tabular}{|c|c|c|c|c|}
\hline Test Series & 1 & 2 & 3 & 4 \\
\hline W (g-APA) & 0.8072 & 0.8039 & 0.8047 & 0.8067 \\
\hline V (Volume Solution, mL) & 40 & 40 & 40 & 40 \\
\hline Co (g-M/mL) & $9.54 \mathrm{E}-05$ & $2.90 \mathrm{E}-05$ & $8.26 \mathrm{E}-06$ & $2.47 \mathrm{E}-06$ \\
\hline $\mathrm{pHo}$ & & & & \\
\hline $\mathrm{Ce}(\mathrm{g}-\mathrm{M} / \mathrm{mL})$ & $6.26 \mathrm{E}-07$ & $5.80 \mathrm{E}-08$ & $3.10 \mathrm{E}-08$ & $6.00 \mathrm{E}-09$ \\
\hline $\mathrm{pHe}$ & & & & \\
\hline $\mathrm{S}(\mathrm{exp}), \mathrm{g}-\mathrm{M} / \mathrm{g}-\mathrm{APA}(1)$ & $3.79 \mathrm{E}-03$ & $1.16 \mathrm{E}-03$ & $3.29 \mathrm{E}-04$ & $9.86 \mathrm{E}-05$ \\
\hline $\mathrm{Kd}(\mathrm{mL} / \mathrm{g})=\mathrm{S}(\mathrm{exp}) / \mathrm{Ce}$ & 6,060 & 19,900 & 10,600 & 16,400 \\
\hline $\mathrm{S}(\mathrm{calc}), \mathrm{g}-\mathrm{M} / \mathrm{g}-\mathrm{APA}(2)$ & $4.53 \mathrm{E}-03$ & $6.81 \mathrm{E}-04$ & $4.13 \mathrm{E}-04$ & $1.12 \mathrm{E}-04$ \\
\hline $\mathrm{Kd}(\mathrm{mL} / \mathrm{g})=\mathrm{S}(\mathrm{calc}) / \mathrm{Ce}$ & 7,240 & 11,700 & 13,300 & 19,300 \\
\hline
\end{tabular}

(1) Estimated from mass-balance considerations as: $\mathrm{S}=\mathrm{Co}(\mathrm{V} / \mathrm{W})(1-\mathrm{C} / \mathrm{Co})$

(2) Estimated from fitted parameters for a Freundlich isotherm; see Figure 16.

In Figure 16, the "sorption" data are presented as a linearized Freundlich isotherm. Regression analysis gives an empirical expression: $\mathrm{S}(\mathrm{g}-\mathrm{Cd} / \mathrm{g}-\mathrm{APA})=400 *(\mathrm{C}$, g$\mathrm{Cd} / \mathrm{mL})^{0.8}$. For Cd at the USEPA MCL standard of $0.005 \mathrm{mg} / \mathrm{L}$, the $\mathrm{Kd}$ value is projected to be $>19,000 \mathrm{~mL} / \mathrm{g}$, or considerably in excess of the success criterion of $\mathrm{Kd}>1,000$ $\mathrm{mL} / \mathrm{g}$. In Figure 17, the data are plotted as a linear isotherm.

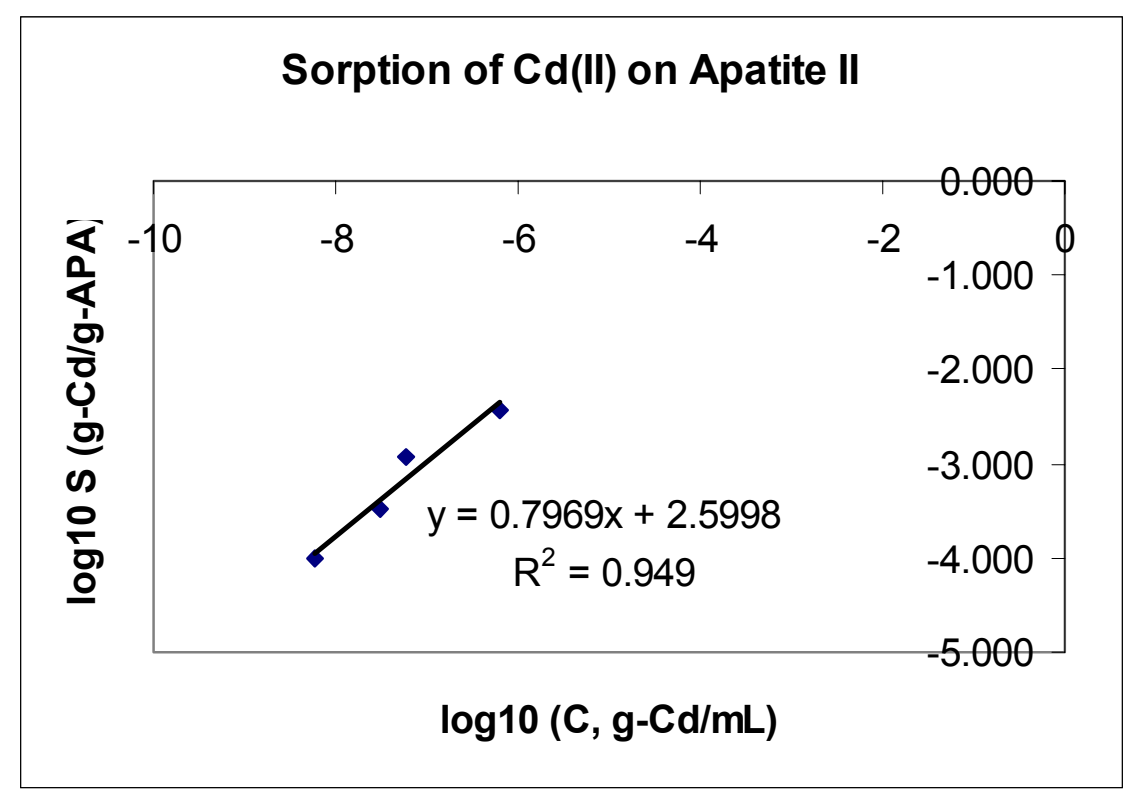

Figure 16. Sorption of $\mathrm{Cd}(\mathrm{II})$ on Raw Apatite. Experimental results are fitted to a linearized Freundlich isotherm (Eq. 4). 


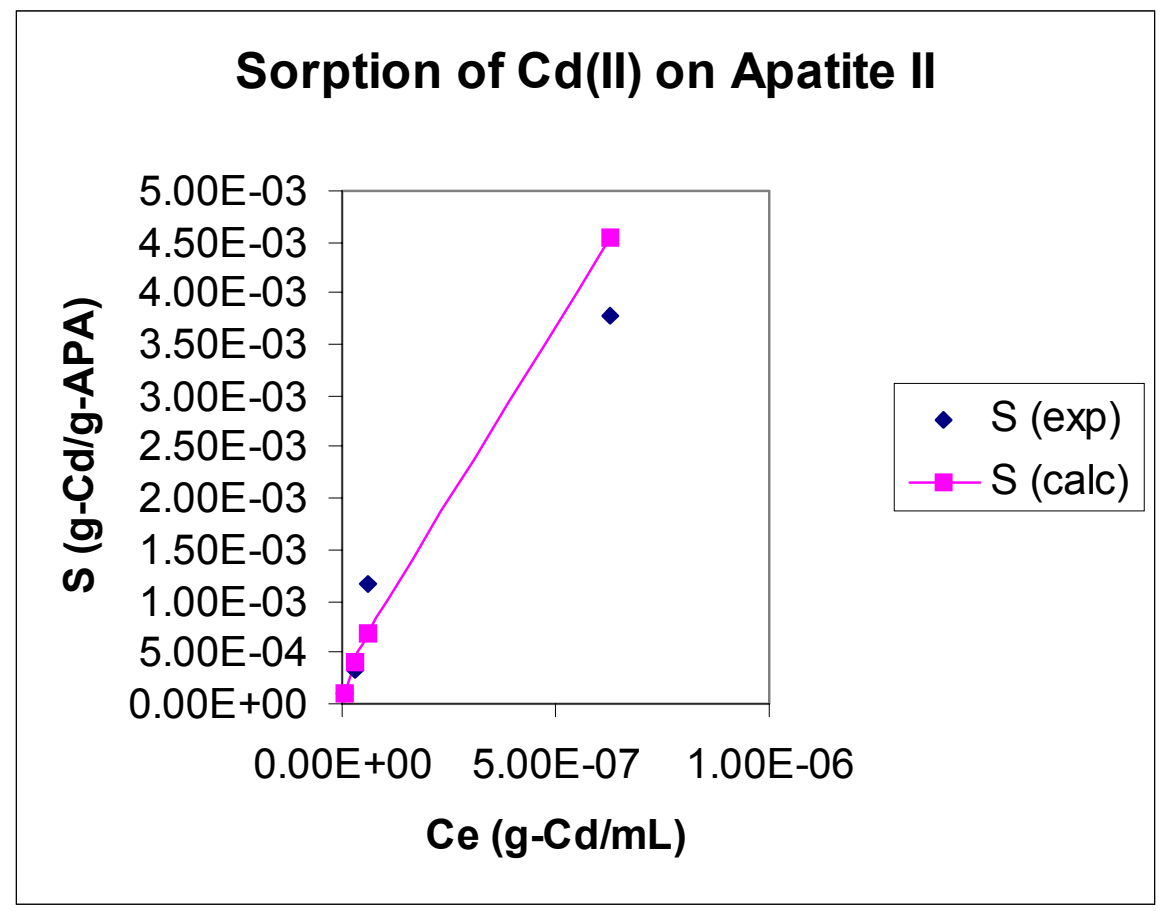

Figure 17. Sorption of Cadmium to Raw Apatite II, presented as a linear isotherm. $\mathrm{S}(\exp )$ and $\mathrm{S}($ calc) are defined in the footnotes to Table 13.

Summary: Apatite demonstrates a very strong affinity to "sorb" cadmium ion, typically yielding residual aqueous concentrations below that predicted for the solubility of carbonate or phosphate salts of cadmium ion. 


\subsubsection{Chromium, as $\mathrm{Cr}(\mathrm{VI})$}

\section{Literature Expectations}

Chromate-contaminated soils present a unique set of problems because the chemistry of chromium is complex (James, 1996). Of the two common valence states that exist under usual environmental conditions, $\mathrm{Cr}^{+6}$ is the more toxic and mobile, whereas the reduced form $\mathrm{Cr}^{+3}$ is relatively nontoxic and immobile. Hexavalent $\mathrm{Cr}\left(\mathrm{Cr}^{+6}\right)$ exists in neutral to alkaline soils as the soluble chromate oxyanion $\left(\mathrm{CrO}_{4}^{-2}\right)$ or occasionally as moderate to sparingly soluble salts with heavy metals such as $\mathrm{Ba}^{2+}, \mathrm{Pb}^{2+}$ or $\mathrm{Ag}^{+}$. Chromate ion sorbs to many soil mineral phases, such as clays and oxides of iron and manganese, but this sorption is pH-dependent and is competitive with common groundwater anions such as sulfate and bicarbonate (Zachara et al., 1987). Thus, chromate generally remains relatively mobile. Reduced $\mathrm{Cr}^{+3}$ is readily hydrolyzed to form $\mathrm{Cr}(\mathrm{OH})_{3}$ hydrates, which also may form solid solutions intermixed with iron oxyhydroxides; the solubility and mobility of reduced $\mathrm{Cr}$ is typically very low. The existence of minerals such as embreyite (hydrated lead chromate phosphate) suggests that it is possible for $\mathrm{Cr}^{+6}$ (as chromate) to be co-precipitated into crystalline structures along with phosphate phases.

\section{Experimental Results}

Hexavalent chromium is added to synthetic groundwater as the salt, potassium dichromate $\left(\mathrm{K}_{2} \mathrm{Cr}_{2} \mathrm{O}_{7}\right)$. For aqueous $\mathrm{Cr}^{+6}$, chromate ion, $\mathrm{CrO}_{4}{ }^{-2}$, predominates in basic solution and dichromate ion, $\mathrm{Cr}_{2} \mathrm{O}_{7}^{-2}$, predominates in acidic solution. Dichromate in acidic solution is a powerful oxidizing agent, whereas chromate ion in basic solution is less powerful.

Data, summarized in Table 14 and Figure 18 indicate that there little or no interaction between Apatite II and $\mathrm{Cr}^{+6}$.

Table 14. Raw Apatite (APA) Contacted 52-h with $\mathrm{M}=\mathrm{Cr}(\mathrm{VI})$ (from potassium dichromate) in Synthetic Groundwater Matrix

\begin{tabular}{|c|c|c|c|c|}
\hline Test Series & 1 & 2 & 3 & 4 \\
\hline W (g-APA) & 0.8278 & 0.8129 & 0.8212 & 0.8055 \\
\hline V (Volume Solution, mL) & 40 & 40 & 40 & 40 \\
\hline Co $(\mathrm{g}-\mathrm{M} / \mathrm{mL})$ & $2.24 \mathrm{E}-04$ & $7.37 \mathrm{E}-05$ & $2.61 \mathrm{E}-05$ & $9.97 \mathrm{E}-06$ \\
\hline $\mathrm{pHo}$ & 6.9 & 7.2 & 7.8 & 7.7 \\
\hline $\mathrm{Ce}(\mathrm{g}-\mathrm{M} / \mathrm{mL})$ & $2.06 \mathrm{E}-04$ & $6.97 \mathrm{E}-05$ & $2.29 \mathrm{E}-05$ & $6.52 \mathrm{E}-06$ \\
\hline $\mathrm{pHe}$ & 6.5 & 7 & 7 & 7.2 \\
\hline $\mathrm{S}(\exp ), \mathrm{g}-\mathrm{M} / \mathrm{g}-\mathrm{APA}(\underline{1})$ & $7.20 \mathrm{E}-04$ & $1.60 \mathrm{E}-04$ & $1.28 \mathrm{E}-04$ & $1.38 \mathrm{E}-04$ \\
\hline $\mathrm{Kd}(\mathrm{mL} / \mathrm{g})=\mathrm{S}(\exp ) / \mathrm{Ce}$ & 3.0 & 2.3 & 5.6 & 21 \\
\hline
\end{tabular}

(1) Estimated from mass-balance considerations as: $\mathrm{S}=\mathrm{Co}(\mathrm{V} / \mathrm{W})(1-\mathrm{C} / \mathrm{Co})$ 




Figure 18. Initial concentration data (Co) are for series $\mathrm{A}$ in Table $\mathrm{Cr}-1$; final concentration data $(\mathrm{Cf})$ are for series B in Table 14.

Summary: Apatite demonstrates minimal affinity for $\mathrm{Cr}$ as the chromate ion $\left(\mathrm{CrO}_{4}{ }^{2-}\right)$. 


\subsubsection{Copper, as $\mathrm{Cu}(\mathrm{II})$}

\section{Literature Expectations}

At trace levels, copper is an essential nutrient, involved in a number of enzyme functions. Excessive intake of $\mathrm{Cu}$ results in accumulation in the liver, and eventual hemolysis. Copper forms complexes with both inorganic and organic ligands in aqueous systems. It is normally strongly sorbed by soil minerals, clays, and organic matter. The USEPA MCL guideline level for copper in drinking water is $0.7 \mathrm{mg} / \mathrm{L}$, and the DOE Fernald site groundwater Final Remediation Level (FRL) is $0.012 \mathrm{mg} / \mathrm{L}$.

Apatite (as bone char) is demonstrated to have an affinity to sorb $\mathrm{Cu}$ (Cheung et al., 2001; Ko et al., 2001). Ryan and Zhang (1995) suggest that the removal of soluble $\mathrm{Cu}$ by synthetic hydroxyapatite is competitive with the removal of soluble lead. Eighmy et al. (1997) have successfully used treatment with use of soluble phosphate reagent to stabilize $\mathrm{Cu}$ in municipal solid waste combustion dry scrubber residue. The existence of a number of mixed $\mathrm{Cu}$ phosphate phases suggests that coprecipitation may occur. Some $\mathrm{Cu}-$ containing phosphate mineral phases include: andrewsite (copper iron phosphate hydroxide), calcosiderite (hydrated copper iron phosphate hydroxide), cornetite (copper phosphate hydroxide), faustite (hydrated zinc copper aluminum phosphate hydroxide), hentschelite (copper iron phosphate hydroxide), libethenite (copper phosphate hydroxide), nissonite (hydrated copper magnesium phosphate hydroxide), pseudomalachite (copper phosphate hydroxide), torbernite (hydrated copper uranyl phosphate hydroxide), turquoise (hydrated copper aluminum phosphate hydroxide), and veszelyite (hydrated copper zinc phosphate hydroxide).

\section{Experimental Results}

Copper (II) was sparingly soluble in the synthetic BYBY water composition, forming a finely divided turquoise-colored precipitate. Solids filtered from the stock solution were examined with use of XRD; the major phase was identified as atacamite, $\mathrm{Cu}_{2}(\mathrm{OH})_{3} \mathrm{Cl}$, with a minor contribution by a similar hydrolysis product, $\mathrm{Cu}(\mathrm{OH}) \mathrm{Cl}$. Table 15 summarizes data for serial dilutions of filtered stock solution, with and without apatite phase. 
Table 15. Raw Apatite (APA) Contacted 52-h with $\mathrm{M}=\mathrm{Cu}$ (II) (from cupric chloride) in Synthetic Groundwater Matrix

\begin{tabular}{|c|c|c|c|c|}
\hline Test Series & 1 & 2 & 3 & 4 \\
\hline W (g-APA) & 0.8026 & 0.8030 & 0.8118 & 0.8124 \\
\hline V (Volume Solution, mL) & 40 & 40 & 40 & 40 \\
\hline $\mathrm{Co}(\mathrm{g}-\mathrm{M} / \mathrm{mL})$ & $1.72-04$ & $1.69 \mathrm{E}-05$ & $1.01 \mathrm{E}-05$ & $4.10 \mathrm{E}-06$ \\
\hline $\mathrm{pHo}$ & 5.9 & 5.9 & 6.1 & 6.3 \\
\hline $\mathrm{Ce}(\mathrm{g}-\mathrm{M} / \mathrm{mL})$ & $2.66 \mathrm{E}-06$ & $7.75 \mathrm{E}-07$ & $3.10 \mathrm{E}-7$ & $1.45 \mathrm{E}-07$ \\
\hline $\mathrm{Ce} / \mathrm{Co}$ & $1.55 \mathrm{E}-02$ & $4.60 \mathrm{E}-02$ & $3.07 \mathrm{E}-02$ & $3.54 \mathrm{E}-2$ \\
\hline $\mathrm{pHe}$ & 6.6 & 6.4 & 6.4 & 6.5 \\
\hline $\mathrm{S}(\exp ), \mathrm{g}-\mathrm{M} / \mathrm{g}-\mathrm{APA}(1)$ & $6.76 \mathrm{E}-03$ & $6.43 \mathrm{E}-04$ & $3.91 \mathrm{E}-04$ & $1.58 \mathrm{E}-04$ \\
\hline $\mathrm{Kd}=\mathrm{S}(\mathrm{exp}) / \mathrm{Ce}, \mathrm{mL} / \mathrm{g}$ & 280 & 495 & 660 & 1,010 \\
\hline $\mathrm{S}(\mathrm{calc}), \mathrm{g}-\mathrm{M} / \mathrm{g}-\mathrm{APA}(2)$ & $4.77 \mathrm{E}-03$ & $1.54 \mathrm{E}-03$ & $6.24 \mathrm{E}-04$ & $2.43 \mathrm{E}-04$ \\
\hline $\mathrm{Kd}=\mathrm{S}(\mathrm{calc}) / \mathrm{Ce}, \mathrm{mL} / \mathrm{g}$ & 2,540 & 830 & 1,260 & 1,090 \\
\hline
\end{tabular}

(1) Estimated from mass-balance considerations as: $\mathrm{S}=\mathrm{Co}(\mathrm{V} / \mathrm{W})(1-\mathrm{C} / \mathrm{Co})$

(2) Estimated from fitted parameters for a Freundlich isotherm; see Figure 19.

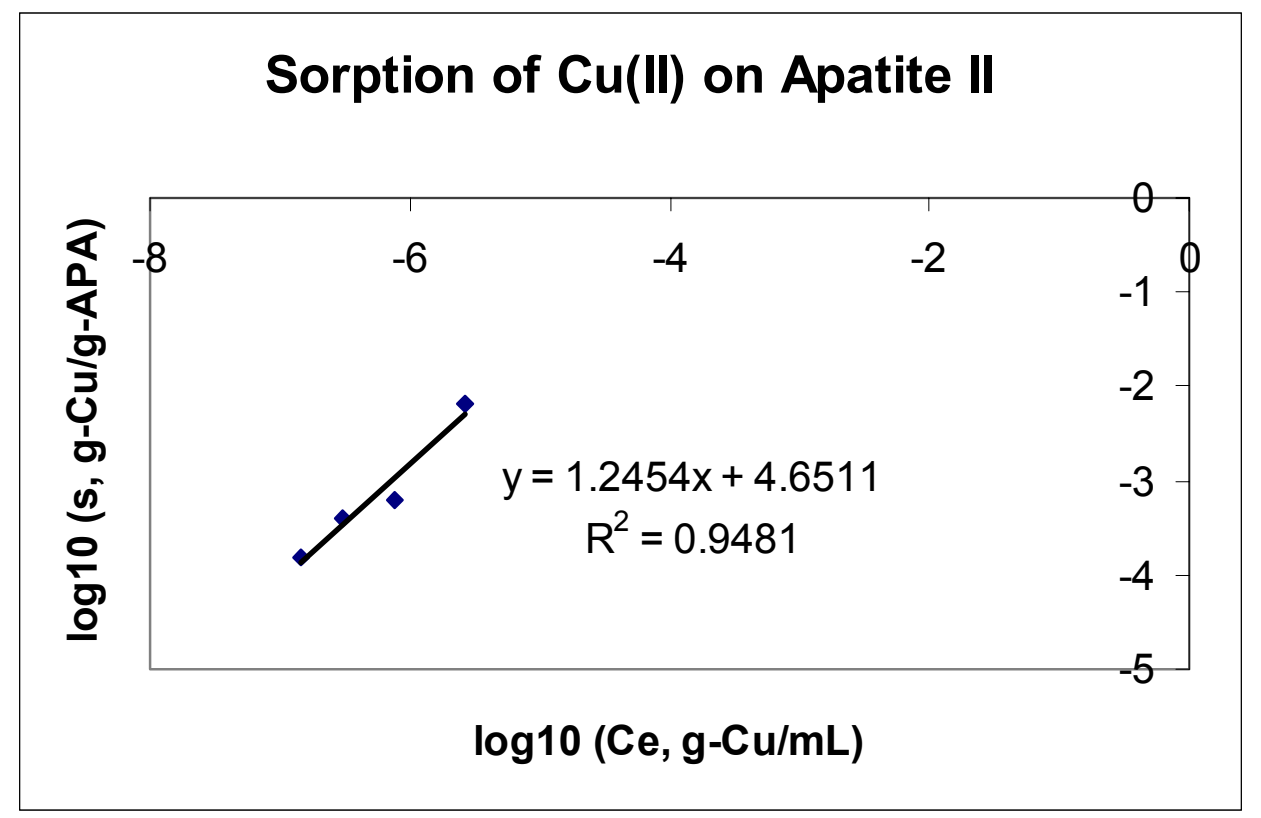

Figure 19. Sorption of $\mathrm{Cu}(\mathrm{II})$ on Raw Apatite. Experimental results are fitted to a linearized Freundlich isotherm (Eq. 4). The units for $\mathrm{S}$ and $\mathrm{C}$ are given in Table 15. 


\section{Sorption of $\mathrm{Cu}$ (II) on Apatite II}

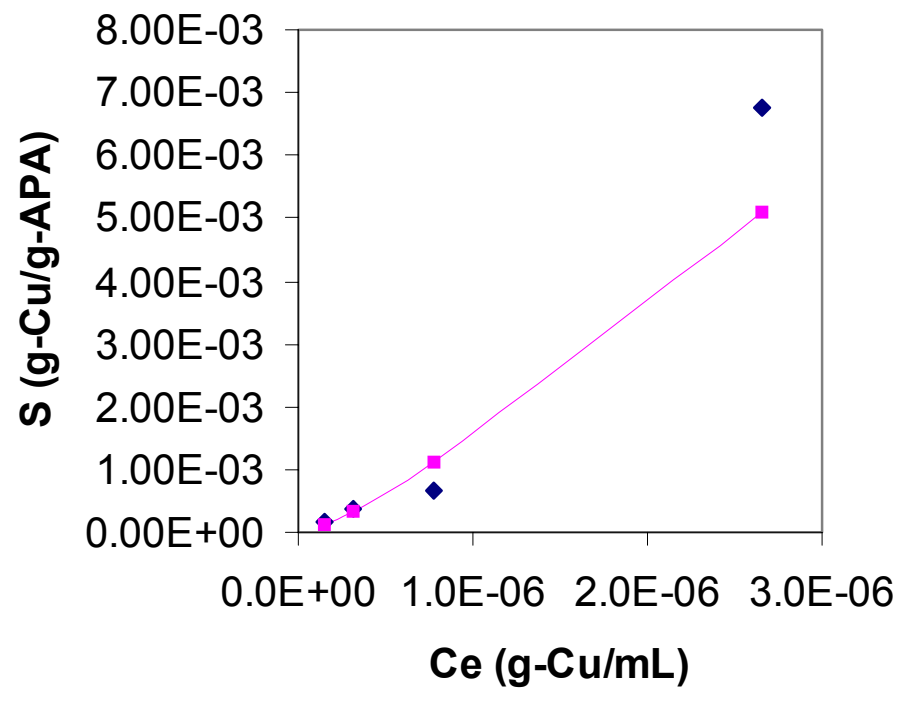

- $S(\exp )$

$-S$ (calc)

Figure 20. Sorption of $\mathrm{Cu}(\mathrm{II})$ to Raw Apatite II, presented as a linear isotherm. S(exp) and $\mathrm{S}($ calc) are defined in the footnotes to Table $\mathbf{1 5 .}$

Summary: Apatite demonstrates a strong affinity to "sorb" $\mathrm{Cu}$ (II) ion from solution phase. 


\subsubsection{Iron, as $\mathrm{Fe}(\mathrm{II})$}

\section{Literature Expectations}

Iron is a major constituent of most soils, occurring mainly as small discrete grains of ferric oxide mineral (e.g., goethite, $\mathrm{FeOOH}$ ) or as amorphous hydrous oxide coatings on other minerals (Bodek et al., 1988). In the soil mantle, insoluble Fe(III) oxides in mineral phases may be mobilized under anaerobic (anoxic) conditions by microbial reduction (Schwertmann and Cornell, 1991), as depicted in Eq. (12):

$$
4 \mathrm{FeOOH}+\mathrm{CH}_{2} \mathrm{O}+8 \mathrm{H}^{+}=4 \mathrm{Fe}^{2+}+\mathrm{CO}_{2}+7 \mathrm{H}_{2} \mathrm{O}
$$

This process involves microbial enzyme-mediated electron transfer from organic biomass (written here as $\mathrm{CH}_{2} \mathrm{O}$ ) to $\mathrm{Fe}(\mathrm{III})$, with formation of soluble $\mathrm{Fe}(\mathrm{II})$.

The main variables affecting the aqueous solubility of iron include $\mathrm{pH}$, redox potential (Eh), and concentrations of the dissolved carbon dioxide and sulfur species (Bodek et al., 1988). Ferric iron (Fe(III)) is very sparingly soluble in water, except under acidic conditions. In oxic surface streams, iron typically occurs as colloidal particulate ferric hydroxide $\left(\mathrm{Fe}(\mathrm{OH})_{3}\right)$ or as some form of organic complex. In anoxic groundwater, ferrous iron ( $\mathrm{Fe}(\mathrm{II}))$ is the most common form of dissolved iron, frequently occurring in the concentration range of $\sim 1$ to $10 \mathrm{mg} / \mathrm{L}$ (Bodek et al., 1988).

Ferrous iron may be oxidized by exposure to oxygen from air, forming ferric ion (Fe(III)), which can subsequently hydrolyze and precipitate from solution at near-neutral and alkaline $\mathrm{pH}$ values; see the simplified Eq. (13).

$$
\mathrm{Fe}^{2+}+1 / 4 \mathrm{O} 2+5 / 2 \mathrm{H}_{2} \mathrm{O}=\mathrm{Fe}(\mathrm{OH})_{3}(s)+2 \mathrm{H}^{+}
$$

Hydrolyzed ferric ion $\left[\mathrm{Fe}(\mathrm{OH})_{3}(s)\right.$ and its amorphous polymer ferrihydrite] is an effective agent for the removal of many heavy metals, by the combined $\mathrm{pH}$-dependent mechanisms of sorption and co-precipitation. (see, e.g., Davis and Leckie, 1978; Merrill et al., 1994).

Both ferrous $\left(\mathrm{Fe}^{2+}\right)$ and ferric $\left(\mathrm{Fe}^{3+}\right)$ iron form insoluble phosphate salts. Iron been used for phosphorous removal by chemical precipitation (EPA 625/1-76-001a). For ferric iron, the optimum range for phosphate precipitation is $\mathrm{pH} 4.5$ to 5.0 , whereas the homogeneous precipitation of phosphate ion by ferrous ion is optimum at $\mathrm{pH} 8$, and good removal is achieved for the range $\mathrm{pH} 7-8$ (EPA 625/1-76-001a). Synthetic iron phosphates (prepared in-house by homogeneous precipitation from mixing soluble precursor solutions, i.e., $\mathrm{Na}_{2} \mathrm{HPO}_{4}$ plus ferrous- or ferric sulfate) tended to form suspensions of colloidal-sized particles that, without the addition of a flocculating polymer, sediment very slowly from the aqueous phase. 
Gschwend et al. (1987) have reported on the in-situ subsurface formation of colloidal $(\sim 100 \mathrm{~nm})$ iron phosphate solids, attributed to sewage-derived phosphate combining with ferrous iron released from aquifer solids. From chemical and thermodynamic inferences, Gschwend et al. (1987) suggest that the solids are consistent with a vivianite (ferrous phosphate hydrate) colloidal phase. Buesseler et al. (2003) remark on the observed loss of soluble phosphorous from groundwater that had been anoxic in situ upon the subsequent exposure of the solution to the ambient atmosphere. This phenomenon is attributed to the oxidation of ferrous iron with subsequent scavenging of $\mathrm{P}$, and possibly traces of metals, by association with the newly formed oxidized metal colloidal solids.

\section{Experimental Results}

In order to differentiate between loss of soluble $\mathrm{Fe}(\mathrm{II})$ by air-oxidation to form insoluble ferrihydrate (or hydrous ferric hydroxide, $\mathrm{Fe}(\mathrm{OH})_{3} * \mathrm{nH}_{2} \mathrm{O}$ ) and loss by sorption to Apatite $\mathrm{II}^{\mathrm{TM}}$ (and/or heterogeneous precipitation as iron phosphate), it is necessary to maintain anoxic conditions. An experimental arrangement to maintain anoxic conditions and to monitor system Eh and $\mathrm{pH}$ values is depicted in Figure 2.

In the first experiment, synthetic groundwater is purged with gas blend for $\sim 1$-h before the addition of $\sim 0.05-\mathrm{g} \mathrm{Fe}$ (II) (added as ferrous sulfate). As illustrated in Figure 21, the redox potential rapidly drops to $<0.1 \mathrm{~V}$ (corrected to $\mathrm{SHE}$ ). For the rapid $\mathrm{Fe}(\mathrm{III}) / \mathrm{Fe}$ (II) redox couple at $\mathrm{T} \sim 25{ }^{\circ} \mathrm{C}$ (Manahan, 1994):

$$
\left.\mathrm{Eh} / 0.0591 \sim 13.2+\log \left[\mathrm{Fe}^{3+}\right] / \mathrm{Fe}^{+2}\right]
$$

At $\mathrm{pH}$ values near 6 (as in our experiments), $\mathrm{Fe}(\mathrm{II})$ predominates over $\mathrm{Fe}(\mathrm{III})$ for $\mathrm{Eh}$ values $<0.4 \mathrm{~V}$ (vs SHE); see Pourbaix, 1974. In the present case, with Eh $\sim+0.1 \mathrm{~V}$ vs. SHE, $\left.\left[\mathrm{Fe}^{3+}\right] / \mathrm{Fe}^{+2}\right] \sim 10^{-11.5}$, i.e., the proportion of ferric ion is negligible. At about $2-\mathrm{h}$ elapsed time, 1-g of elutriated Apatite II $^{\mathrm{TM}}$ was added, with a minor transient disturbance in the system $\mathrm{pH}$ and Eh values, as noted in Figure 21. 




Figure 21. Interaction between Fe(II) and Apatite under Anoxic Conditions: Part I. (See also Table 16).

Little solution phase color or turbidity developed during this test. The data of Table 16 suggests only a modest uptake of Fe by apatite in this experiment $(\mathrm{Kd} \sim 100 \mathrm{~mL} / \mathrm{g})$, perhaps reflecting an incomplete approach to equilibrium (relatively short contact time at a low solid-to-liquid ratio). An aliquot of filtered solution was removed after $\sim 5-h$, and the (initially clear, colorless) aliquot was made oxic by bubbling laboratory air into the liquid. The oxic solution developed orange colored colloid and precipitate phases, and the $\mathrm{pH}$ value increased to $\sim 7.9$ (the latter due in part to equilibration with a lower partial pressure of carbon dioxide). Other data from this experiment is summarized in Table 16, below.

Table 16. Interaction of Fe(II) and Apatite (APA) in 1-L Synthetic Groundwater Under Anoxic Conditions: Part I (See also Fig. )

\begin{tabular}{|c|c|c|c|c|}
\hline \multirow{2}{*}{$\begin{array}{c}\text { Elapsed Time } \\
(\mathrm{h})\end{array}$} & Event & \multicolumn{3}{|c|}{ Concentration in Solution (mg/L) } \\
\cline { 3 - 5 } & & $\mathrm{Fe}$ & $\mathrm{P}$ & $\mathrm{Ca}$ \\
\hline 1.0 & Add Fe(II) & $\mathrm{ND}$ & $\mathrm{ND}$ & $\mathrm{ND}$ \\
\hline 1.5 & $\begin{array}{c}\text { Sample } \\
(0.8-\mu \mathrm{m} \text { filter })\end{array}$ & 42.7 & $\leq 0.06$ & 53.0 \\
\hline 2.0 & Add $\sim$-g APA & $\mathrm{ND}$ & $\mathrm{ND}$ & $\mathrm{ND}$ \\
\hline 3.25 & $\begin{array}{c}\text { Sample } \\
(0.8-\mu \mathrm{m} \text { filter })\end{array}$ & 41.1 & 1.68 & 53.0 \\
\hline 4.7 & $\begin{array}{c}\text { Sample } \\
(0.8-\mu m \text { filter })\end{array}$ & 38.7 & 2.40 & 54.6 \\
\hline
\end{tabular}

ND: Not Determined 
In the second experiment ("Part II"), the synthetic groundwater was first contacted with excess apatite phase for $\sim 4$-h before use. The intent was to determine whether phosphate ion, from the dissolution of apatite, could cause homogeneous precipitation of ferrous ion in the absence of apatite mineral phase. The slurry of apatite and water was first filtered through a coffee filter (nominal retention of particles $>50-\mu \mathrm{m}$ ) and placed in the flask. As shown in Figure 22, addition of $\sim 0.05$-g of Fe(II) at $\sim 1.5$-h elapsed time produced strongly reductive conditions (Eh $\leq 0.1 \mathrm{~V}$ vs. SHE). At $\sim 3.25$-h elapsed, $\sim 9$-g of elutriated Apatite $\mathrm{II}^{\mathrm{TM}}$ was added, with a minor transient disturbance in the system $\mathrm{pH}$ and Eh values; see Figure 22 for a representation of the data. Other data from this experiment is summarized in Table 17, below.

Table 17. Interaction of Fe(II) and Apatite (APA) in 1-L Synthetic Groundwater Under Anoxic Conditions: Part II (See also Fig. )

\begin{tabular}{|c|c|c|c|c|}
\hline \multirow{2}{*}{$\begin{array}{c}\text { Elapsed Time } \\
(\mathrm{h})\end{array}$} & \multirow{2}{*}{ Event } & \multicolumn{3}{|c|}{ Concentration in Solution $(\mathrm{mg} / \mathrm{L})$} \\
\cline { 3 - 5 } & & $\mathrm{Fe}$ & $\mathrm{P}$ & $\mathrm{Ca}$ \\
\hline 1.13 & $\begin{array}{c}\text { Sample } \\
(0.8-\mu \mathrm{m} \text { filter })\end{array}$ & $\leq 0.03$ & 3.25 & 48.9 \\
\hline 1.50 & Add Fe(II) & $\mathrm{ND}$ & $\mathrm{ND}$ & $\mathrm{ND}$ \\
\hline 1.67 & $\begin{array}{c}\text { Sample } \\
(0.8-\mu \mathrm{m} \text { filter })\end{array}$ & 48.8 & 3.30 & 46.5 \\
\hline 3.25 & Add $\sim 9$-g APA & $\mathrm{ND}$ & $\mathrm{ND}$ & $\mathrm{ND}$ \\
\hline$\sim 20$ & $\begin{array}{c}\text { Sample } \\
(\sim 50-\mu \mathrm{m} \text { filter })\end{array}$ & 4.05 & 39.4 & 96.5 \\
\hline$\sim 20$ & $\begin{array}{c}\text { Sample } \\
(\sim 0.8-\mu \mathrm{m} \text { filter })\end{array}$ & 2.18 & 13.2 & 50.2 \\
\hline$\sim 20$ & $\begin{array}{c}\text { Sample (oxic) } \\
(\sim 0.45-\mu \mathrm{m} \text { filter })\end{array}$ & 0.12 & 12.7 & 50.0 \\
\hline
\end{tabular}


Interaction of $\mathrm{Fe}$ (II) \& Apatite II



Figure 22. Interaction between Fe(II) and Apatite under Anoxic Conditions: Part II. (See also Table 17). Soluble Fe refers to the concentration in solution after filtration at 0.8$\mu \mathrm{m}$. 
After 20-h elapsed time, the content of the vessel was removed, and the components of the slurry were separated with use of a coffee filter. This filter paper has nominal retention of particles $\geq 50-\mu \mathrm{m}$. The filtrate was somewhat turbid, but with very little odor. Comparison of the $\mathrm{Ca}$ and $\mathrm{P}$ data for samples filtered at a nominal $\sim 50-\mu \mathrm{m}$ (coffee filter) and at 0.8 - $\mu \mathrm{m}$ suggests that $\sim 2 \%$ (by weight) of the apatite solid phase originally added passed through the coarse filter medium. Assuming that the coarse filter retains particles $>50-\mu \mathrm{m}$, this is a much higher mass fraction loss than predicted from the dry-sieve analysis of the starting material (see sample 119-2S in Fig. 49), suggesting that apatite fines may undergo particle size attrition by the action of dissolution under mildly-acidic conditions. (See also Section 4.1.8.1).

Data from Table 17 suggests that (after 20-h phase contact residual soluble Fe, followed by filtration at $0.8-\mu \mathrm{m}$ ), the isolated apatite solid phase would have an average Fe loading on solids of $\sim 5 \mathrm{mg} / \mathrm{g}$ (as estimated from mass-balance), for an estimated $\mathrm{Kd} \sim 2,000$ $\mathrm{mg} / \mathrm{L}$. Chemical analysis of the actual iron loading on the larger apatite particles (i.e., those retained on the coarse filter) indicates an average Fe loading of only $\sim 0.6 \mathrm{mg} / \mathrm{g}$ (for an estimated $\mathrm{Kd} \sim 200 \mathrm{~mL} / \mathrm{g}$ ). Examination of the isolated fine solids with use of SEMEDS showed apatite fines (predominant elements $\mathrm{O}, \mathrm{C}, \mathrm{Ca}$ and $\mathrm{P}$, with only minor traces of $\mathrm{Fe}, \mathrm{S}$, and $\mathrm{K}$ ). This is consistent with particle size attrition caused by dissolution of apatite in mildly acidic solution (see Section 4.1.8.1).

An aliquot of coarse-filtered solution was made oxic by bubbling laboratory air into the liquid. Subsequent centrifugation (at 3000 RPM for $5 \mathrm{~min}$.) of an aliquot of the oxic solution yielded a small amount of solids. The oxic supernate contained minimal soluble $\mathrm{Fe}(\sim 0.12 \mathrm{mg} / \mathrm{L})$. This suggests that, under the original anoxic conditions, some excess soluble ferrous ion remains in solution, but that most of the residual iron is subsequently precipitated under oxic conditions.

Some computed data from the Part II experiment for solution phase ( $\sim 20$-h contact, then filtered at $0.45-\mu \mathrm{m})$ is summarized in Table 18. The filtered solution phase is undersaturated with respect to vivianite (ferrous phosphate) and calcite (calcium carbonate), as evidenced by ICP $<$ Ksp (Bodek et al., 1988). Also, the solubility of biogenic apatite is greater than the values reported for synthetic hydroxyapatite (cf. Table 6). The estimate for IAP for biogenic apatite in Table $18\left(\log _{10}(\mathrm{IAP})=-54.1\right)$ is comparable in magnitude to the estimates presented in Table $7\left(\log _{10}(\mathrm{IAP})=-54.7 \pm 0.7\right)$. 
Table 18. Computed Data for Experiment 1042-25-7B (Apatite II ${ }^{\mathrm{TM}}$ plus $\mathrm{Fe}^{2+} ; 20-\mathrm{h}$ Contact; $\mathrm{pH}=6.3$; Solution Filtered at $0.45-\mu \mathrm{m})$

\begin{tabular}{|c|c|c|c|c|}
\hline \multirow[t]{2}{*}{ Formula } & \multicolumn{2}{|c|}{ This Study } & Literature & Reference for Cited \\
\hline & $\begin{array}{l}\log _{10} \\
\text { ICP }\end{array}$ & $\begin{array}{l}\log _{10} \\
\text { IAP }\end{array}$ & $\begin{array}{c}\log _{10} \\
\mathrm{~K}_{\mathrm{sp}}\end{array}$ & $\begin{array}{l}\text { Literature Value for } \\
\qquad \mathrm{K}_{\mathrm{sp}}\end{array}$ \\
\hline $\begin{array}{c}\mathrm{Fe}_{3}\left(\mathrm{PO}_{4}\right) * 8 \mathrm{H}_{2} \mathrm{O} \\
\text { (vivianite) }\end{array}$ & -31.9 & -32.4 & -26.4 & Bodek et al. (1988) \\
\hline $\begin{array}{c}\mathrm{FeCO}_{3} \\
\text { (siderite) }\end{array}$ & -13.0 & -13.0 & -16.3 & $\begin{array}{l}\text { CRC Handbook, } 68^{\text {th }} \\
\text { Ed, p. B-207 }\end{array}$ \\
\hline $\begin{array}{l}\mathrm{CaCO}_{3} \\
\text { (calcite) }\end{array}$ & -10.1 & -10.2 & -8.3 & $\begin{array}{c}\text { CRC Handbook, } 68^{\text {th }} \\
\text { Ed, p. B-207 }\end{array}$ \\
\hline $\begin{array}{l}\mathrm{Ca}_{5}\left(\mathrm{PO}_{4}\right)_{3}(\mathrm{OH}) \\
\text { (hydroxyapatite) }\end{array}$ & -53.4 & -54.1 & -55.6 & $\begin{array}{c}\text { CRC Handbook, } 68^{\text {th }} \\
\text { Ed, p. B-207 }\end{array}$ \\
\hline & & & -55.9 & $\begin{array}{l}\text { Snoeyink and Jenkins } \\
\qquad(1980)\end{array}$ \\
\hline & & & $-(58 \pm 1)$ & $\begin{array}{c}\text { Valsami-Jones et al. } \\
\text { (1998) }\end{array}$ \\
\hline & & & -58.3 & McDowell et al. (1977) \\
\hline & & & -59 & $\begin{array}{c}\text { Somasundarin et al. } \\
(1985)\end{array}$ \\
\hline
\end{tabular}

ICP $=$ ion concentration product; IAP $=$ ion activity product (see Bodek et al., 1988, p. 2$11-4)$.

Summary: Under strictly anoxic conditions, apatite appears to have a somewhat modest affinity for $\mathrm{Fe}(\mathrm{II})$. Data from experiment Part I indicated a very modest uptake of Fe(II) $(\mathrm{Kd} \sim 100 \mathrm{~mL} / \mathrm{g})$, but this data may reflect the kinetic mass-transfer effect of relatively short phase contact at a very high liquid-to-solid ratio $(\sim 1,000: 1)$. From experiment Part II (Table 17), there did not appear to be any homogeneous precipitation of Fe(II) by $\mathrm{P}$ when the species were mixed at a total concentrations of $\sim 8.75 \mathrm{E}-4 \mathrm{~mol} / \mathrm{L}(\mathrm{Fe})$ and $\sim$ $1.06 \mathrm{E}-4 \mathrm{~mol} / \mathrm{L}(\mathrm{P})$, at solution $\mathrm{pH}$ value $\sim 6.2$. There was no visually-observed colloid formation. In contrast, there was a significant decrease in soluble Fe(II) when the solution was subsequently contacted with Apatite $\mathrm{II}^{\mathrm{TM}}$ solid phase (at longer contact time with a lower liquid-to-solid ratio), corresponding to an estimated $\mathrm{Kd} \sim 2,300 \mathrm{~mL}$, with a higher Fe loading on the smaller sized particulates formed during dissolution of apatite. Thus, under the observed conditions, sorption of Fe(II) appears favored over heterogeneous precipitation by dissolved phosphate ion. 


\subsubsection{Lead, as $\mathrm{Pb}(\mathrm{II})$}

\section{Literature Expectations}

In the typical near-neutral $\mathrm{pH}$ range found in the freshwater environment, soluble lead occurs predominantly as $\mathrm{PbOH}^{+}$species (Bodek, 1988). Soluble $\mathrm{Pb}$ forms relatively weak complexes with common inorganic ligands. Most $\mathrm{Pb}$ salts (e.g., phosphates, sulfates, sulfides, carbonates, hydroxides) are either sparingly soluble or almost completely insoluble. $\mathrm{Pb}$ also interacts strongly with clay minerals, oxides of iron and manganese, and with organic matter such as humic acids (Bodek, 1988; McLean and Bledsoe, 1992). As a result, $\mathrm{Pb}$ solubility and mobility is low in most subsurface systems. In natural waters at $\mathrm{pH}>7, \mathrm{~Pb}$ is either adsorbed on clay surfaces or forms $\mathrm{Pb}$-carbonate precipitate. Puls et al. (1991) have demonstrated decreased sorption of $\mathrm{Pb}$ in the presence of complexing ligands and competing cations. $\mathrm{Pb}$ has a strong affinity for organic ligands and the formation of such complexes may greatly increase the mobility of $\mathrm{Pb}$ in groundwater and soil water as is evidenced with leaded fuels. The long-term stability of $\mathrm{Pb}$-compounds in the subsurface depends upon differences in the nearly insoluble phases, e.g., pyromorphite-type phosphate minerals versus carbonate or hydroxide phases. Although lead in soil is not generally mobile, the toxicity of lead makes the bioassessibility of its various chemical and physical forms a paramount concern. Lead phosphates, especially pyromorphite minerals $\left[\mathrm{Pb}_{5}\left(\mathrm{PO}_{4}\right)_{3}(\mathrm{Cl}, \mathrm{OH})\right]$, demonstrate minimal solubility and bioassessibility; see (e.g.) Rabinowitz (1993); Ruby (1994); Chen (1997A,B); Zhang (1998); Manecki (2000).

The USEPA action level for lead in drinking water is $0.015 \mathrm{mg} / \mathrm{L}$, and the DOE Fernald site groundwater Final Remediation Level (FRL) is also set at $0.015 \mathrm{mg} / \mathrm{L}$.

\section{Experimental Results}

Results are summarized in Table 19, for $\mathrm{Pb}$ (II) prepared in synthetic groundwater, and Table 20, for $\mathrm{Pb}$ (II) prepared in carbonate-free (nitrogen purged) de-ionized water (DIwater).

\section{$\mathrm{Pb}(\mathrm{II})$ in Synthetic Groundwater}

Lead is poorly soluble in the synthetic groundwater test solution (see Figure 23), so that only the Series 1 data in Table 19 affords the opportunity to assess the distribution coefficient $(\mathrm{Kd}>65,000 \mathrm{~mL} / \mathrm{g})$. The solid phase from test series 1 (Table 19) was examined by XRD, but there was no indication of the formation of a new crystalline phase. This may reflect the low absolute loading of $\mathrm{Pb}(\sim 0.6 \mathrm{wt} \%)$ in the experiment. Ryan \& Zhang (1995) indicate that hydroxypyromorphite $\left(\mathrm{Pb}_{5}\left(\mathrm{PO}_{4}\right)_{3} \mathrm{OH}\right)$ was the primary reaction product for $\mathrm{Pb}$ immobilized by mineral apatite (phosphate rock). 
Table 19. Raw Apatite (APA) Contacted 52-h with $\mathrm{M}=\mathrm{Pb}$ (II) (from lead nitrate) in Synthetic Groundwater Matrix

\begin{tabular}{|c|c|c|c|c|}
\hline Test Series & 1 & 2 & 3 & 4 \\
\hline $\mathrm{W}(\mathrm{g}-\mathrm{APA})$ & 0.8405 & 0.8129 & 0.8114 & 0.8639 \\
\hline V (Volume Solution, $\mathrm{mL})$ & 40 & 40 & 40 & 40 \\
\hline Co $(\mathrm{g}-\mathrm{M} / \mathrm{mL})$ & $1.57 \mathrm{E}-04$ & $1.04 \mathrm{E}-07$ & $1.31 \mathrm{E}-07$ & $1.07 \mathrm{E}-07$ \\
\hline $\mathrm{pHo}$ & 5.5 & 7.9 & 8.4 & 8.3 \\
\hline $\mathrm{Ce}(\mathrm{g}-\mathrm{M} / \mathrm{mL})$ & $9.61 \mathrm{E}-08$ & $9.13 \mathrm{E}-08$ & $1.22 \mathrm{E}-07$ & $7.64 \mathrm{E}-08$ \\
\hline $\mathrm{Ce} / \mathrm{Co}$ & $6.12 \mathrm{E}-04$ & $8.78 \mathrm{E}-01$ & $9.31 \mathrm{E}-01$ & $7.14 \mathrm{E}-01$ \\
\hline $\mathrm{pHe}$ & 6.9 & 7.0 & 7.0 & 7.0 \\
\hline $\mathrm{S}(\exp ), \mathrm{g}-\mathrm{M} / \mathrm{g}-\mathrm{APA}(\underline{1})$ & $6.28 \mathrm{E}-03$ & $5.08 \mathrm{E}-07$ & $3.60 \mathrm{E}-07$ & $1.22 \mathrm{E}-06$ \\
\hline $\mathrm{Kd}=\mathrm{S}(\exp ) / \mathrm{Ce}, \mathrm{mL} / \mathrm{g}$ & 65,300 & 5.6 & 3.0 & 16 \\
\hline
\end{tabular}

(1) Estimated from mass-balance considerations as: $\mathrm{S}=\mathrm{Co}(\mathrm{V} / \mathrm{W})(1-\mathrm{C} / \mathrm{Co})$

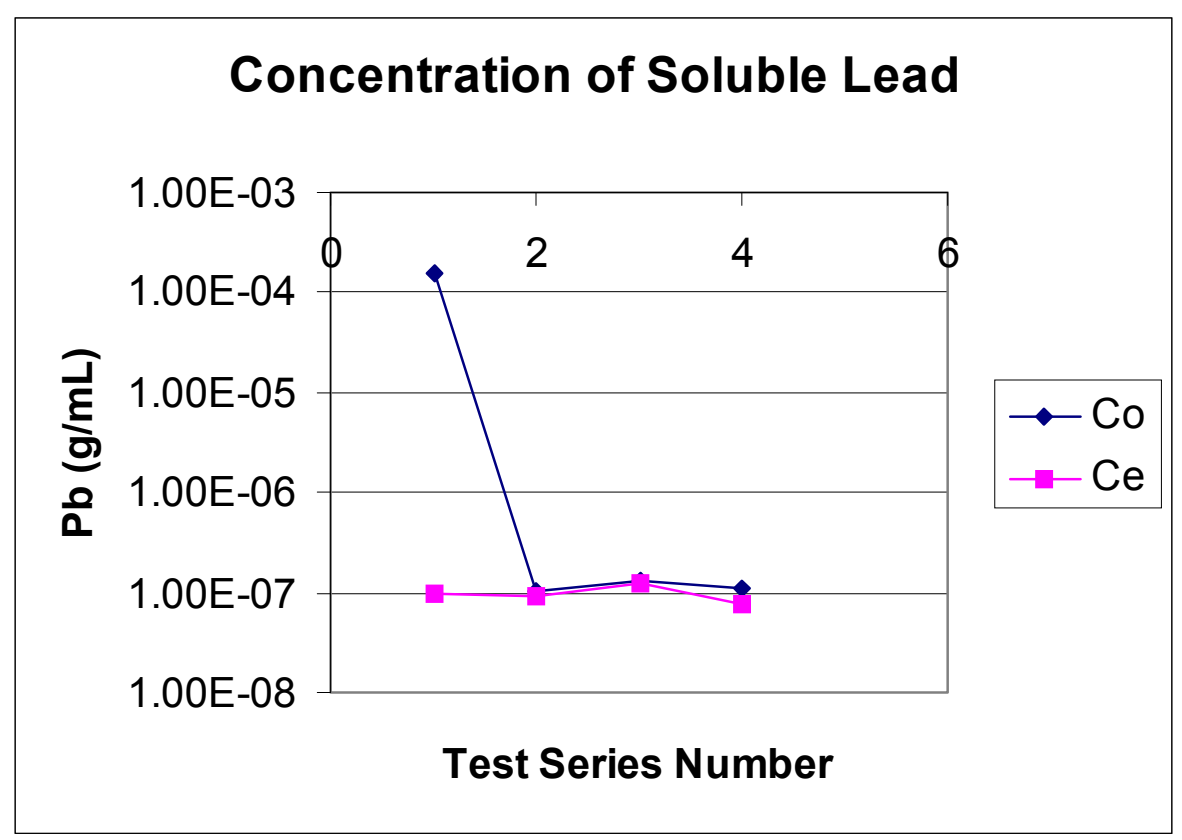

Figure 23. Concentrations of Soluble $\mathrm{Pb}$ (Co: no exposure to Apatite; $\mathrm{Ce}$ : after exposure to Apatite), Sorted by Test Series (See Table 19). This data is for $\mathrm{Pb}$ (II) prepared in synthetic groundwater solution.

\section{$\mathrm{Pb}(\mathrm{II})$ in De-Ionized Water}

In order to assess the sorption of $\mathrm{Pb}(\mathrm{II})$ on apatite, without the confounding effect of solubility-limiting groundwater anions, we prepared serial dilutions in carbonate free (nitrogen purged) de-ionized water (DI-water). Figure 24 illustrates the solubility of $\mathrm{Pb}$ (II) in serial dilutions of stock solutions using (a) DI-water and (b) synthetic groundwater (syn-BYBY) as diluent. Clearly, sulfate and/or carbonate ions in the synBYBY solution limit the solubility of $\mathrm{Pb}(\mathrm{II})$. 


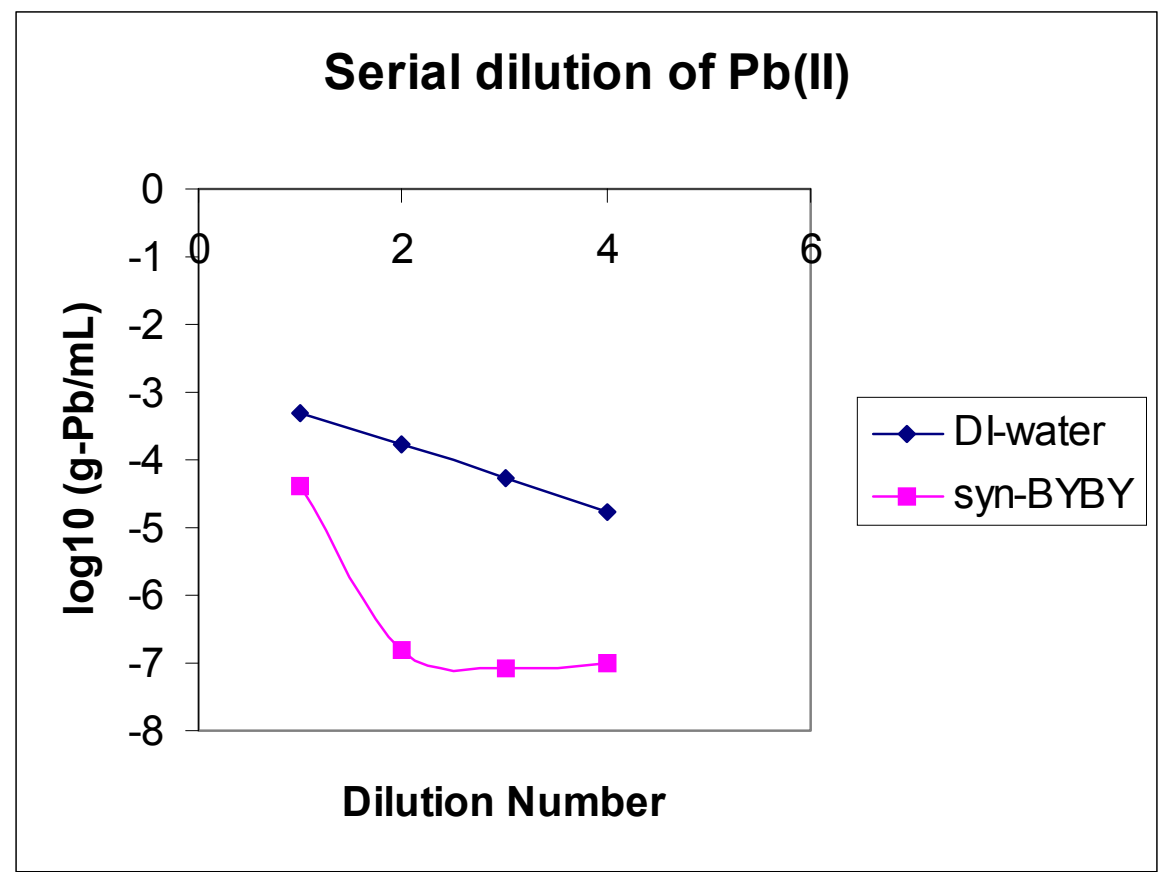

Figure 24. Concentration of $\mathrm{Pb}(\mathrm{II})$ in Serial Dilutions of Stock Solutions using ( $\diamond)$ DIwater and (匹) Synthetic Groundwater (syn-BYBY).

Table 20 summarizes analytical data for $\mathrm{Pb}(\mathrm{II})$ in DI water matrix. The ICP analysis for $\mathrm{Pb}$ was optimized to yield a reporting limit of $2 \mathrm{E}-08 \mathrm{~g} / \mathrm{mL}(20 \mathrm{ppb})$.

Table 20. Raw Apatite (APA) Contacted 52-h with $\mathrm{M}=\mathrm{Pb}$ (II) (from lead nitrate) in DI-Water Matrix

\begin{tabular}{|c|c|c|c|c|}
\hline Test Series & 1 & 2 & 3 & 4 \\
\hline W (g-APA) & 0.8145 & 0.8127 & 0.8041 & 0.8284 \\
\hline V (Volume Solution, mL) & 40 & 40 & 40 & 40 \\
\hline $\mathrm{Co}(\mathrm{g}-\mathrm{Pb} / \mathrm{mL})$ & $5.07 \mathrm{E}-04$ & $1.74 \mathrm{E}-04$ & $5.56 \mathrm{E}-05$ & $1.74 \mathrm{E}-05$ \\
\hline $\mathrm{pHo}$ & 5.4 & 5.7 & 5.9 & 6.0 \\
\hline $\mathrm{Ce}(\mathrm{g}-\mathrm{Pb} / \mathrm{mL})$ & $1.75 \mathrm{E}-06$ & $4.24 \mathrm{E}-07$ & $9.50 \mathrm{E}-08$ & $<2.00 \mathrm{E}-08$ \\
\hline $\mathrm{Ce} / \mathrm{Co}$ & $2.02 \mathrm{E}-02$ & $6.93 \mathrm{E}-03$ & $2.22 \mathrm{E}-03$ & $6.97 \mathrm{E}-04$ \\
\hline $\mathrm{pHe}$ & 7.0 & 7.2 & 7.5 & 7.4 \\
\hline $\mathrm{S}(\exp ), \mathrm{g}-\mathrm{M} / \mathrm{g}-\mathrm{APA}(1)$ & $2.02 \mathrm{E}-02$ & $6.93 \mathrm{E}-03$ & $2.22 \mathrm{E}-03$ & $6.97 \mathrm{E}-04$ \\
\hline $\mathrm{Kd}=\mathrm{S}(\exp ) / \mathrm{Ce}, \mathrm{mL} / \mathrm{g}$ & 11,600 & 16,300 & 23,400 & $>34,800$ \\
\hline $\mathrm{Ce}(\mathrm{g}-\mathrm{Ca} / \mathrm{mL})$ & $14.5 \mathrm{E}-06$ & $19.8 \mathrm{E}-06$ & $26.0 \mathrm{E}-6$ & $41.6 \mathrm{E}-06$ \\
\hline $\mathrm{Ce}(\mathrm{g}-\mathrm{P} / \mathrm{mL})$ & $23.4 \mathrm{E}-06$ & $18.5 \mathrm{E}-06$ & $23.2 \mathrm{E}-06$ & $10.4 \mathrm{E}-06$ \\
\hline
\end{tabular}

(1) Estimated from mass-balance considerations as: $\mathrm{S}=\mathrm{Co}(\mathrm{V} / \mathrm{W})(1-\mathrm{C} / \mathrm{Co})$

For reference, we also include in Table 20 data for total $\mathrm{Ca}$ and $\mathrm{P}$ concentrations in the treated solutions $(\mathrm{Ce})$. Using the formalism described in Eq. 8, in conjunction with estimates for the phosphate ion distribution and ionic activity estimates (Butler, 1966) for ionic strength $\sim 1.4 \mathrm{E}-03 \mathrm{M} / \mathrm{L}$, the solubility constant for Apatite II is estimated as $\log _{10}\left(\mathrm{~K}_{\text {so }}\right)=-(49.5 \pm 1.8)$. This estimate is in agreement with the results obtained by contacting Apatite II and DI-water for a 16-h interval $\left(\log _{10}\left(\mathrm{~K}_{\mathrm{so}}\right)=-50.6\right.$; see Table 8 . 
The data in Table 20 may also be used to estimate the solubility of lead, assuming formation of hydroxypyromorphite (Eq. 15).

$$
\mathrm{Pb}_{5}\left(\mathrm{PO}_{4}\right)_{3} \mathrm{OH}=5 \mathrm{~Pb}^{2+}+3 \mathrm{PO}_{4}^{3-}+\mathrm{OH}^{-}
$$

The data for short-term (50-h) interaction between $\mathrm{Pb}$ and Apatite II (assuming the reaction depicted in Eq. 15) yields an estimate of $\log _{10}\left(\mathrm{~K}_{\mathrm{so}}\right)=-(63.5 \pm 3.6)$, a result significantly greater than the value $\left(\log _{10}\left(\mathrm{~K}_{\mathrm{so}}\right)=-76.8\right)$ tabulated in the MINTEQ-A2 database for crystalline hydroxypyromorphite (see Table 5). This suggests that the system may not be at equilibrium in the short-term testing, with perhaps the formation of relatively more soluble intermediate phase(s), such as $\mathrm{Pb}(\mathrm{OH})_{2}$. Suzuki et al. (1984) and later Valsami-Jones et al. (1998) report that although the initial interaction between lead and syn-HAP is relatively rapid, full equilibrium (ion exchange by apatite dissolution followed by new phase precipitation to replace $\mathrm{Ca}$ in the original apatite structure) may require several weeks. Valsami-Jones et al. (1998) show that the loss of $\mathrm{Pb}^{2+}$ from solution is matched by an equal molar quantity of $\mathrm{Ca}^{2+}$ released into solution, and that (in time) $\mathrm{Pb}$-hydroxyapatite (hydroxypyromorphite) forms throughout the structure and not just on the apatite surface.

Figures 25 and 26 illustrate the sorption isotherm for $\mathrm{Pb}$ (II) sorbed by Apatite II from DI-water.



Figure 25. Sorption of $\mathrm{Pb}(\mathrm{II})$ on Raw Apatite. Experimental results are fitted to a linearized Freundlich isotherm (Eq. 4). The illustrated data are for $\mathrm{Pb}$ (II) in distilled water matrix. 


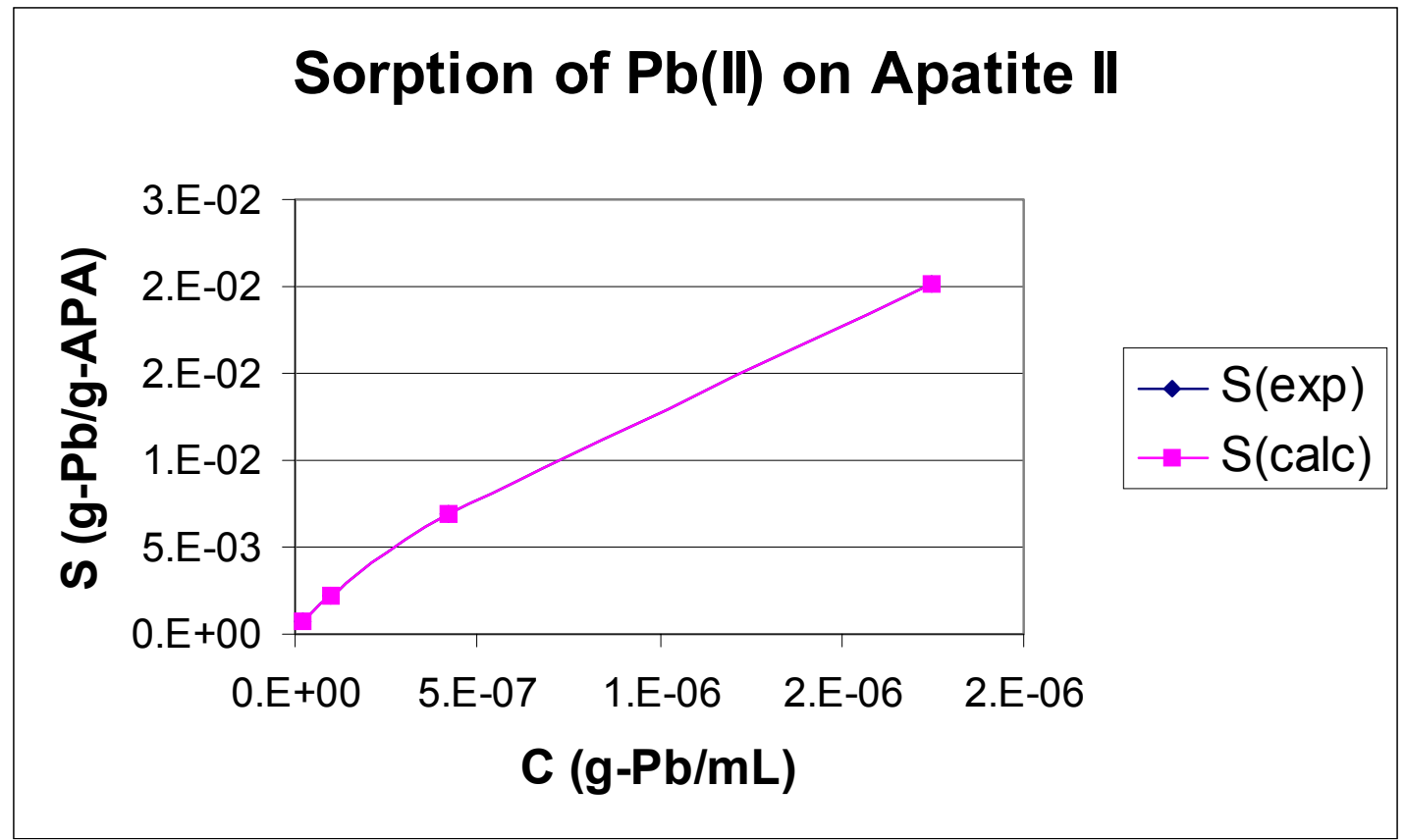

Figure 26. Sorption of $\mathrm{Pb}(\mathrm{II})$ to Raw Apatite II, presented as a linear isotherm. The illustrated data are for $\mathrm{Pb}(\mathrm{II})$ in distilled water matrix.

Summary: Lead demonstrated minimal solubility in the synthetic groundwater composition, confounding estimates for apatite-mediated removal of metal ion. The strong affinity between apatite and lead ion was demonstrated for soluble lead in deionized water solution. 


\subsubsection{Manganese, as $\mathrm{Mn}(\mathrm{II})$}

\section{Literature Expectations}

Many different manganese phosphate compounds exist in nature (Dana and Dana, 1997), and these salts have a wide range of solubilities. In addition, the existence of a multitude of mixed manganese-containing phosphate minerals suggests that synergistic coprecipitation may occur.

The USEPA Secondary Drinking Water Regulation level for manganese in drinking water is $0.05 \mathrm{mg} / \mathrm{L}$, and the Fernald site groundwater Final Remediation Level (FRL) is $0.9 \mathrm{mg} / \mathrm{L}$.

\section{Experimental Results}

Table 21. Raw Apatite (APA) Contacted 52-h with $\mathrm{M}=\mathrm{Mn}$ (II) (from manganese sulfate) in Synthetic Groundwater Matrix

\begin{tabular}{|c|c|c|c|c|}
\hline Test Series & 1 & 2 & 3 & 4 \\
\hline $\mathrm{W}(\mathrm{g}-\mathrm{APA})$ & 0.8288 & 0.7979 & 0.8139 & 0.8173 \\
\hline $\mathrm{V}$ (Volume Solution, mL) & 40 & 40 & 40 & 40 \\
\hline $\mathrm{Co}(\mathrm{g}-\mathrm{M} / \mathrm{mL})$ & $2.05 \mathrm{E}-04$ & $6.83 \mathrm{E}-05$ & $2.29 \mathrm{E}-05$ & $7.81 \mathrm{E}-06$ \\
\hline $\mathrm{pHo}$ & 7.1 & 7.7 & 7.9 & 8.2 \\
\hline $\mathrm{Ce}(\mathrm{g}-\mathrm{M} / \mathrm{mL})$ & $1.93 \mathrm{E}-05$ & $2.58 \mathrm{E}-06$ & $3.68 \mathrm{E}-07$ & $8.24 \mathrm{E}-08$ \\
\hline $\mathrm{Ce} / \mathrm{Co}$ & $9.44 \mathrm{E}-02$ & $3.78 \mathrm{E}-02$ & $1.61 \mathrm{E}-02$ & $1.06 \mathrm{E}-02$ \\
\hline $\mathrm{pHe}$ & 6.5 & 6.7 & 6.7 & 6.8 \\
\hline $\mathrm{S}(\exp ), \mathrm{g}-\mathrm{M} / \mathrm{g}-\mathrm{APA}(1)$ & $7.41 \mathrm{E}-03$ & $2.63 \mathrm{E}-03$ & $9.01 \mathrm{E}-04$ & $3.09 \mathrm{E}-04$ \\
\hline $\mathrm{Kd}=\mathrm{S}(\exp ) / \mathrm{Ce}, \mathrm{mL} / \mathrm{g}$ & 384 & 1,020 & 2,450 & 3,750 \\
\hline $\mathrm{S}(\mathrm{calc}), \mathrm{g}-\mathrm{M} / \mathrm{g}-\mathrm{APA}(2)$ & $7.91 \mathrm{E}-03$ & $2.48 \mathrm{E}-03$ & $8.08 \mathrm{E}-04$ & $3.41 \mathrm{E}-04$ \\
\hline $\mathrm{Kd}=\mathrm{S}(\mathrm{calc}) / \mathrm{Ce}, \mathrm{mL} / \mathrm{g}$ & 410 & 962 & 2,200 & 4,140 \\
\hline
\end{tabular}

(1) Estimated from mass-balance considerations as: $\mathrm{S}=\mathrm{Co}(\mathrm{V} / \mathrm{W})(1-\mathrm{C} / \mathrm{Co})$

(2) Estimated from fitted parameters for a Freundlich isotherm; see Figure 27.

In Figure 27, the "sorption" data are presented as a linearized Freundlich isotherm. For $\mathrm{Mn}$ at the Secondary Drinking Water Regulation level of $0.05 \mathrm{mg} / \mathrm{L}$, the Freundlich isotherm data projects a conditional distribution coefficient $(\mathrm{Kd})$ of $\sim 5,100 \mathrm{~mL} / \mathrm{g}$. However, the data suggest a significantly nonlinear isotherm, with poorer removal efficiency at higher contaminant concentrations (see Figure $\mathbf{2 8}$ for data representation as a linear sorption isotherm). 


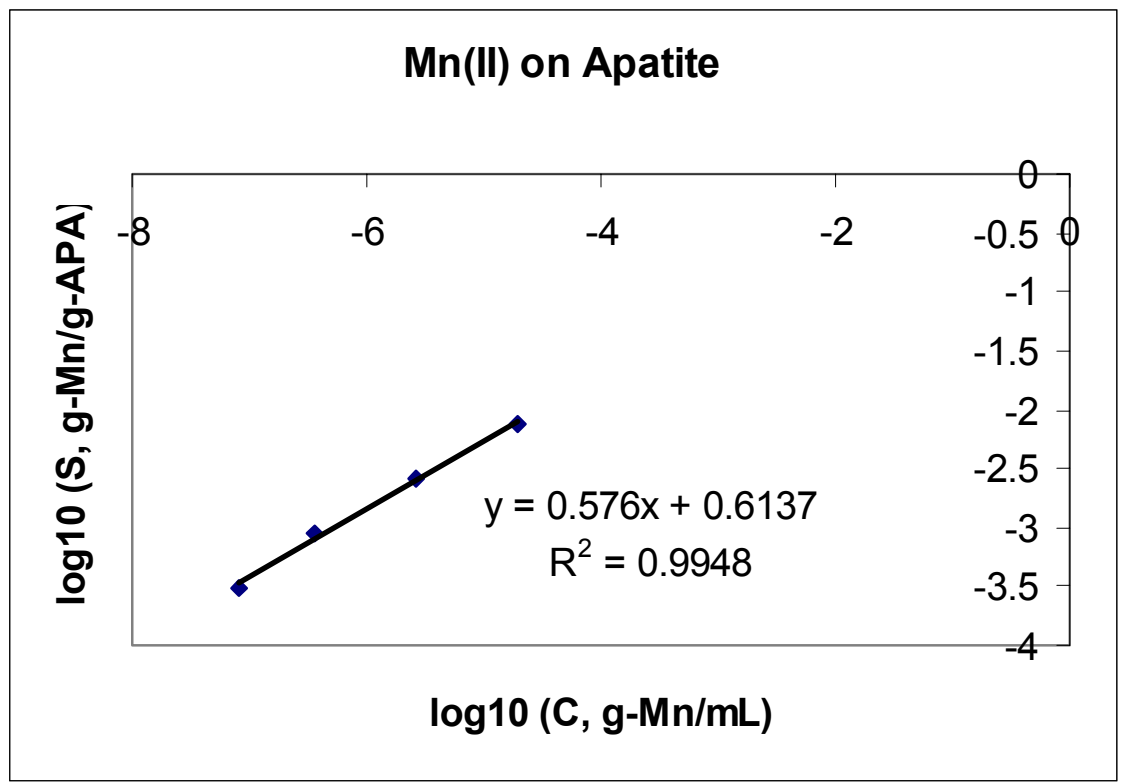

Figure 27. Sorption of Mn(II) on Raw Apatite. Experimental results are fitted to a linearized Freundlich isotherm (Eq. 4).



Figure 28. Sorption of $\mathrm{Mn}$ (II) to Raw Apatite II, presented as a linear isotherm. $\mathrm{S}(\exp )$ and $\mathrm{S}($ calc) are defined in the footnotes to Table Mn-1. A linear regression fit to the $\mathrm{S}($ calc) data (with $\mathrm{Y}$-intercept $=0$ ) yields a slope $(\mathrm{Kd})$ of $420 \mathrm{~mL} / \mathrm{g}$ and squared correlation coefficient $\left(\mathrm{R}^{2}\right)=0.93$.

Summary: Apatite is demonstrated to have a strong affinity to "sorb" (or precipitate) manganous $\left(\mathrm{Mn}^{2+}\right)$ ion. 


\subsubsection{Mercury, as mercuric ion, $\mathrm{Hg}(\mathrm{II})$}

\section{Literature Expectations}

In the absence of elevated levels of chelating agents such as chloride ion, $\mathrm{Hg}$ (II) is strongly sorbed onto hydrous $\mathrm{Fe}$ and Mn oxides, clays and organics in soils and sediments. Inorganic phosphate ion sorbed to soil minerals enhances the retention of $\mathrm{Hg}(\mathrm{II})$; this effect is attributed by investigators as being due to a change in the surface charge of the soil particles, rather than the formation of complexed mercury (Melamed and Bôas, 1998, 2000). However, at elevated levels of chloride ion, stable anionic complexes form with $\mathrm{Hg}(\mathrm{II})$, increasing the mobility of mercury in soil (Melamed and Bôas, 1998, 2000).

Considering the strong $\mathrm{Hg}(\mathrm{II})$ complexation with chloride ion and also the strong hydrolysis of $\mathrm{Hg}$ (II) in aquatic systems, $\mathrm{Cl}^{-}$complexes and hydrolyzed species of $\mathrm{Hg}$ (II) (e.g., $\mathrm{Hg}(\mathrm{OH})_{2}$ and $\mathrm{HgOHCl}$ ) are likely to be the predominant species in fresh water under aerobic environmental conditions [Bodek et al. (1988), Chapter 7.10 ]. Mercury, as $\mathrm{Hg}(\mathrm{II})$, also forms strong complexes with certain organics, especially with humic compounds and the sulfhydryl and amino groups in proteins.

The authors have found no data in the literature for the sorption of mercuric ion on hydroxyapatite media. However, several divalent cations are known to be able to substitute for $\mathrm{Ca}(\mathrm{II})$ in the apatite structure (Narasaraju \& Phebe, 1996), and handbook data for mercuric phosphate, $\mathrm{Hg}_{3}\left(\mathrm{PO}_{4}\right)_{2}$ indicates that this compound is insoluble in cold water. (Our ambient laboratory temperature is typically maintained at $23 \pm 3{ }^{\circ} \mathrm{C}$ ).

Biological methylation of mercury produces relatively volatile chemical species, which can result in remobilization of precipitated or sorbed mercury. Because of extraneous protein and the possible influence of biological activity in raw apatite preparations, mercury removal is evaluated with use of both raw and thermally oxidized apatite (the latter with minimal residual organic matter).

The USEPA MCL for inorganic mercury in drinking water is $0.002 \mathrm{mg} / \mathrm{L}$, and the Fernald site groundwater Final Remediation Level (FRL) is also set at $0.0002 \mathrm{mg} / \mathrm{L}$.

\section{Experimental Results}

The phase contact is performed in accordance with the Operational Instructions presented in Exhibit \#1. Mercuric sulfate was not completely soluble in synthetic groundwater composition at the targeted highest nominal stock solution concentration (nominal $\sim 250$ $\mathrm{mg} / \mathrm{L}$ ), as evidenced by the formation of yellow crystals. The solubility-limiting solid phase, filtered from the $\mathrm{Hg}$ (II) stock solution, was examined by x-ray diffraction (XRD). The material was found to be mercury oxide sulfate, $\mathrm{Hg}_{3}\left(\mathrm{SO}_{4}\right) \mathrm{O}_{2}$ (JCPDS-ICCD Reference \# 12-0724), which appears to have formed as a hydrolysis product.

Data in Table 22 represent the actual solution phase metal concentrations as measured by ICP-OES in a series of filtered solutions. Each filtered solution was carried through the 
contact process, with (Series B) and without (Series A) the addition of apatite phase, to compensate for any metal removal processes not mediated by the apatite.

Table 22. Raw Apatite (APA) Contacted 52-h with $\mathrm{M}=\mathrm{Hg}$ (II) (from mercuric sulfate) in Synthetic Groundwater Matrix

\begin{tabular}{|c|c|c|c|c|}
\hline Test Series & 1 & 2 & 3 & 4 \\
\hline W (g-APA) & 0.8033 & 0.8057 & 0.8486 & 0.8046 \\
\hline V (Volume Solution, mL) & 40 & 40 & 40 & 40 \\
\hline Co (g-M/mL) & $1.68 \mathrm{E}-05$ & $7.02 \mathrm{E}-06$ & $2.35 \mathrm{E}-06$ & $1.08 \mathrm{E}-06$ \\
\hline $\mathrm{pHo}$ & 3.1 & 6.9 & 7.4 & 7.8 \\
\hline $\mathrm{Ce}(\mathrm{g}-\mathrm{M} / \mathrm{mL})$ & $8.51 \mathrm{E}-07$ & $5.02 \mathrm{E}-07$ & $1.14 \mathrm{E}-07$ & $5.33 \mathrm{E}-08$ \\
\hline $\mathrm{Co} / \mathrm{Ce}$ & $5.08 \mathrm{E}-02$ & $7.16 \mathrm{E}-02$ & $4.86 \mathrm{E}-02$ & $4.96 \mathrm{E}-02$ \\
\hline $\mathrm{pHe}$ & 6.8 & 6.8 & 6.9 & 6.9 \\
\hline $\mathrm{S}(\mathrm{exp}), \mathrm{g}-\mathrm{M} / \mathrm{g}-\mathrm{APA}(1)$ & $7.93 \mathrm{E}-04$ & $3.23 \mathrm{E}-04$ & $1.05 \mathrm{E}-04$ & $5.08 \mathrm{E}-05$ \\
\hline $\mathrm{Kd}(\mathrm{mL} / \mathrm{g})=\mathrm{S}(\mathrm{exp}) / \mathrm{Ce}$ & 931 & 644 & 923 & 953 \\
\hline $\mathrm{S}(\mathrm{calc}), \mathrm{g}-\mathrm{M} / \mathrm{g}-\mathrm{APA}(2)$ & $6.66 \mathrm{E}-04$ & $4.07 \mathrm{E}-04$ & $1.02 \mathrm{E}-04$ & $4.99 \mathrm{E}-05$ \\
\hline $\mathrm{Kd}(\mathrm{mL} / \mathrm{g})=\mathrm{S}(\mathrm{calc}) / \mathrm{Ce}$ & 782 & 810 & 892 & 937 \\
\hline
\end{tabular}

(1) Estimated from mass-balance considerations as: $\mathrm{S}=\mathrm{Co}(\mathrm{V} / \mathrm{W})(1-\mathrm{C} / \mathrm{Co})$

(2) Estimated from fitted parameters for a Freundlich isotherm; see Figure 29.

In Figure 29, the sorption data are presented as a linearized Freundlich isotherm. The slope of the plot $\log _{10}(\mathrm{Sexp})$ vs $\log _{10}(\mathrm{Ce})$ is nearly unity, supporting the premise that the data may be approximated by a linear sorption isotherm (see Figure 30). For inorganic $\mathrm{Hg}$ at the MCL $(0.002 \mathrm{mg} / \mathrm{L})$, the extrapolated value of $\mathrm{Kd}(\mathrm{mL} / \mathrm{g})$ calculated from the curve-fitted Freundlich isotherm is $\sim 1,160 \mathrm{~mL} / \mathrm{g}$, or slightly greater than the success criterion of $1,000 \mathrm{~mL} / \mathrm{g}$, as defined in the Test Plan.

In Figure 30, short-term (52-h) sorption data are presented in the form of a simple linear isotherm $(\mathrm{Kd}=\mathrm{S} / \mathrm{C})$, where $\mathrm{S}(\exp )$ and $\mathrm{S}($ calc) have the meanings defined in the footnotes to Table 22. In the concentration range investigated, the data are adequately described by a linear isotherm. The value for the conditional distribution coefficient, $\mathrm{Kd}$ $(\mathrm{mL} / \mathrm{g})$, may be estimated from the slope of the data shown in Figure 30; for data set $\mathrm{S}(\exp )$, linear regression analysis yields $\mathrm{Kd}=858 \mathrm{~mL} / \mathrm{g}\left(\mathrm{R}^{2}=0.9547\right)$, and for data set $\mathrm{S}\left(\right.$ calc), linear regression analysis yields $\mathrm{Kd}=791 \mathrm{~mL} / \mathrm{g}\left(\mathrm{R}^{2}=0.9988\right)$.

The residual organic matter in raw Apatite II (APA-II) would leach and/or biodegrade fairly rapidly in the subsurface. However, due to the possibility of $\mathrm{Hg}$ (II) binding to the organic matter in raw Apatite II, we also tested the sorption of $\mathrm{Hg}$ (II) to the mineral phase remaining after organic matter had been destroyed by the loss on ignition procedure (oxidative heating at $400{ }^{\circ} \mathrm{C}$ for $16-\mathrm{h}$ ); this calcined material is referred to as "Apatite C" (or APA-C). Data for sorption by APA-C are summarized in Table 23, and they are compared to those for raw apatite in Figure 31. Soluble mercury is effectively removed by the Apatite-C mineral phase to a residual level of $\sim 0.1 \mathrm{mg} / \mathrm{L}$ (see Figure 32). Thus, relatively high initial levels of soluble $\mathrm{Hg}$ are readily removed by apatite, but the residual levels are above regulatory limits. The residual soluble $\mathrm{Hg}$ may be affected by the salinity of the aqueous system. 




Figure 29. Sorption of $\mathrm{Hg}(\mathrm{II})$ on Raw Apatite. Experimental results are fitted to a linearized Freundlich isotherm (Eq. 4). The units for $\mathrm{S}$ and $\mathrm{C}$ are given in the Figure legend. The isotherm is described by the empirical expression: $\mathrm{S}$ (calc., g-Hg/g-APA) = $315 \mathrm{x}(\mathrm{Ce}, \mathrm{g}-\mathrm{Hg} / \mathrm{mL})^{0.935}$. 


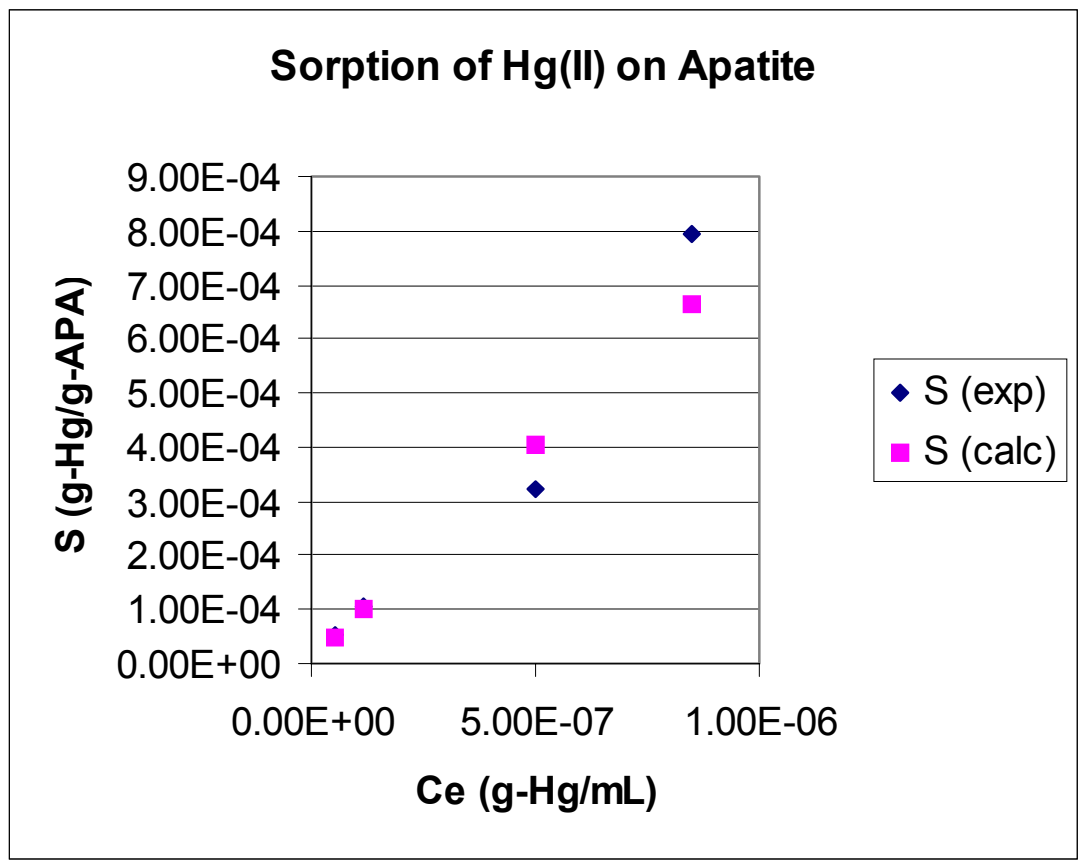

Figure 30. Sorption of $\mathrm{Hg}(\mathrm{II})$ to Raw Apatite II, presented as a linear isotherm. Regression analysis (for data as a linear isotherm, using $\mathrm{S}($ calc)) yields $\mathrm{Kd}=800 \mathrm{~mL} / \mathrm{g}$.

Table 23. Calcined Apatite (APA-C) Contacted 52-h with $\mathrm{M}=\mathrm{Hg}$ (II) (from mercuric sulfate) in Synthetic Groundwater Matrix

\begin{tabular}{|c|c|c|c|c|}
\hline Test Series & 1 & 2 & 3 & 4 \\
\hline W (g-APA) & 0.8062 & 0.8028 & 0.8039 & 0.8165 \\
\hline V (Volume Solution, mL) & 40 & 40 & 40 & 40 \\
\hline Co $(\mathrm{g}-\mathrm{M} / \mathrm{mL})$ & $1.02 \mathrm{E}-05$ & $3.43 \mathrm{E}-06$ & $1.12 \mathrm{E}-06$ & $3.82 \mathrm{E}-07$ \\
\hline $\mathrm{pHo}$ & 6.2 & 6.2 & 6.0 & 6.2 \\
\hline $\mathrm{Ce}(\mathrm{g}-\mathrm{M} / \mathrm{mL})$ & $3.34 \mathrm{E}-07$ & $1.09 \mathrm{E}-07$ & $1.02 \mathrm{E}-07$ & $1.03 \mathrm{E}-07$ \\
\hline $\mathrm{Co} / \mathrm{Ce}$ & $3.27 \mathrm{E}-02$ & $3.18 \mathrm{E}-02$ & $9.13 \mathrm{E}-02$ & $2.7 \mathrm{E}-01$ \\
\hline $\mathrm{pHe}$ & 6.7 & 6.6 & 6.4 & 6.5 \\
\hline $\mathrm{S}(\exp ), \mathrm{g}-\mathrm{M} / \mathrm{g}-\mathrm{APA}(1)$ & $4.89 \mathrm{E}-04$ & $1.65 \mathrm{E}-04$ & $5.06 \mathrm{E}-05$ & $1.36 \mathrm{E}-05$ \\
\hline $\mathrm{Kd}(\mathrm{mL} / \mathrm{g})=\mathrm{S}(\exp ) / \mathrm{Ce}$ & 1,470 & 1,520 & 495 & 132 \\
\hline
\end{tabular}

(1) Estimated from mass-balance considerations as: $\mathrm{S}=\mathrm{Co}(\mathrm{V} / \mathrm{W})(1-\mathrm{C} / \mathrm{Co})$ 


\section{Sorption of $\mathrm{Hg}$ (II) by Apatite}

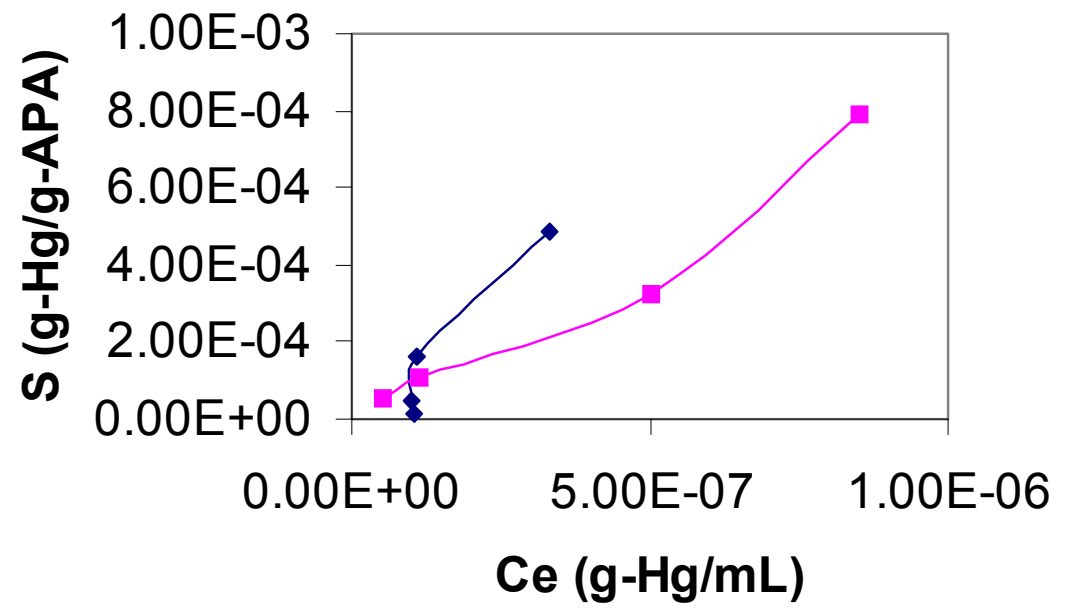

Figure 31. Sorption of $\mathrm{Hg}(\mathrm{II})$ to Raw Apatite II (APA-II) and Calcined Apatite (APA-C).



Figure 32. Concentrations of Soluble $\mathrm{Hg}$ (Co: Series A, no exposure to Apatite C; Ce: Series B, after exposure to Apatite), Sorted by Test Series (See Table 23).

Summary: Apatite, with or without extraneous organic matter, demonstrates a strong affinity to "sorb" (or precipitate) mercuric ion, but the limiting residual level of soluble $\mathrm{Hg}$ may be in the range of $\sim 0.1 \mathrm{mg} / \mathrm{L}$. 


\subsubsection{Molybdenum, as Mo(VI)}

\section{Literature Expectations}

At trace levels, molybdenum is an essential nutrient. The usual soluble form is the oxyanion, molybdate $\left(\mathrm{MoO}_{4}{ }^{2-}\right)$, which is considerably less toxic than chromate, and like chromate, it tends to be sorbed to iron minerals in soil. Most molybdate salts are sparingly soluble, other than those of the alkali metals. Molybdenum may be toxic to grazing animals (especially sheep and cattle) at levels that are not toxic to plants (Bodek et al., 1988).

The USEPA DWEL (health advisory) level for molybdenum is $0.2 \mathrm{mg} / \mathrm{L}$, and the DOE Fernald site groundwater Final Remediation Level (FRL) is $0.1 \mathrm{mg} / \mathrm{L}$.

\section{Experimental Results}

Molybdenum is added to synthetic groundwater in the form of sodium molybdate $\left(\mathrm{Na}_{2} \mathrm{MoO}_{4} \cdot 2 \mathrm{H}_{2} \mathrm{O}\right)$.

Table 24. Raw Apatite (APA) Contacted 52-h with $\mathrm{M}=\mathrm{Mo}$ (VI) (from sodium molybdate, $\mathrm{Na}_{2} \mathrm{MoO}_{4} \cdot 2 \mathrm{H}_{2} \mathrm{O}$ ) in Synthetic Groundwater Matrix

\begin{tabular}{|c|c|c|c|c|}
\hline Test Series & 1 & 2 & 3 & 4 \\
\hline $\mathrm{W}(\mathrm{g}-\mathrm{APA})$ & 0.8113 & 0.8303 & 0.8112 & 0.8669 \\
\hline $\mathrm{V}$ (Volume Solution, mL) & 40 & 40 & 40 & 40 \\
\hline $\mathrm{Co}(\mathrm{g}-\mathrm{M} / \mathrm{mL})$ & $2.12 \mathrm{E}-04$ & $7.26 \mathrm{E}-05$ & $2.46 \mathrm{E}-05$ & $9.15 \mathrm{E}-06$ \\
\hline $\mathrm{pHo}$ & 7.0 & 7.6 & 7.9 & 8.1 \\
\hline $\mathrm{Ce}(\mathrm{g}-\mathrm{M} / \mathrm{mL})$ & $1.62 \mathrm{E}-04$ & $4.83 \mathrm{E}-05$ & $1.43 \mathrm{E}-05$ & $3.83 \mathrm{E}-06$ \\
\hline $\mathrm{Ce} / \mathrm{Co}$ & $7.66 \mathrm{E}-01$ & $6.65 \mathrm{E}-01$ & $5.79 \mathrm{E}-01$ & $4.19 \mathrm{E}-01$ \\
\hline $\mathrm{pHe}$ & 6.4 & 6.5 & 6.2 & 6.3 \\
\hline $\mathrm{S}(\mathrm{exp}), \mathrm{g}-\mathrm{M} / \mathrm{g}-\mathrm{APA}(1)$ & $2.44 \mathrm{E}-03$ & $1.17 \mathrm{E}-03$ & $5.10 \mathrm{E}-04$ & $2.45 \mathrm{E}-04$ \\
\hline $\mathrm{Kd}=\mathrm{S}(\mathrm{exp}) / \mathrm{Ce}, \mathrm{mL} / \mathrm{g}$ & 15.1 & 24.3 & 35.8 & 64.1 \\
\hline $\mathrm{S}(\mathrm{calc}), \mathrm{g}-\mathrm{M} / \mathrm{g}-\mathrm{APA}(2)$ & $2.43 \mathrm{E}-03$ & $1.15 \mathrm{E}-03$ & $5.39 \mathrm{E}-04$ & $2.39 \mathrm{E}-04$ \\
\hline $\mathrm{Kd}=\mathrm{S}(\mathrm{calc}) / \mathrm{Ce}, \mathrm{mL} / \mathrm{g}$ & 15.0 & 23.8 & 37.8 & 249 \\
\hline
\end{tabular}

(1) Estimated from mass-balance considerations as: $\mathrm{S}=\mathrm{Co}(\mathrm{V} / \mathrm{W})(1-\mathrm{C} / \mathrm{Co})$

(2) Estimated from fitted parameters for a Freundlich isotherm; see Figure 33. 


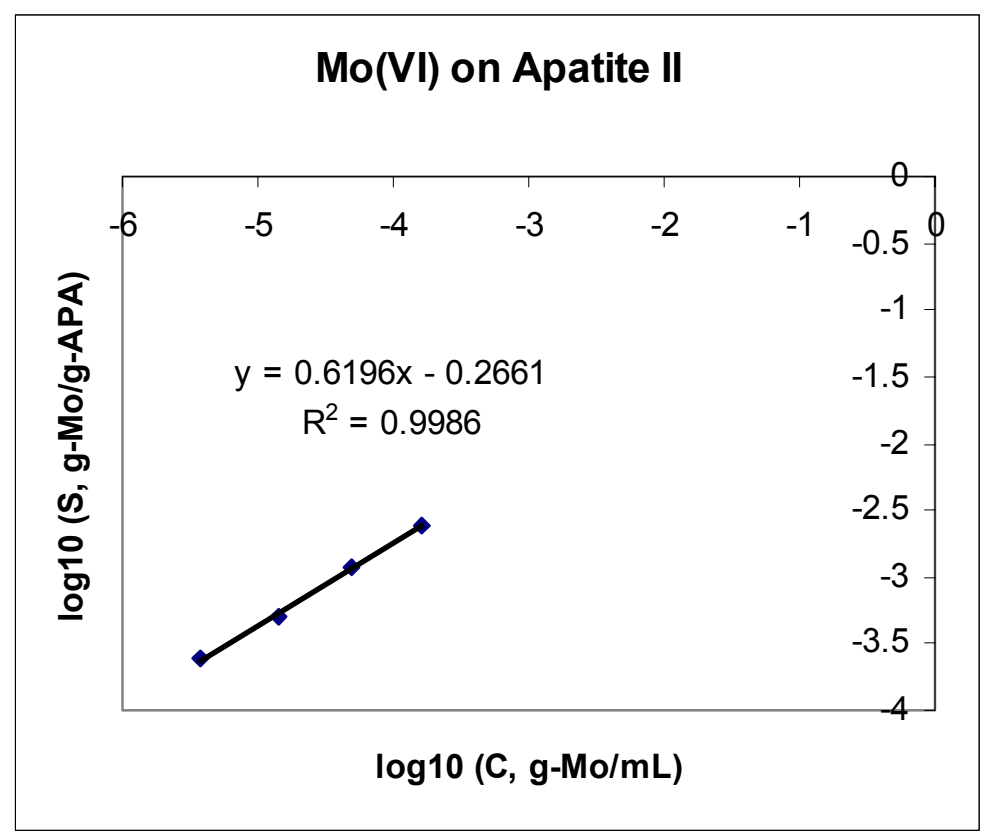

Figure 33. Sorption of Mo(VI), as Molybdate, on Raw Apatite. Experimental results are fitted to a linearized Freundlich isotherm (Eq. 4). The units for $\mathrm{S}$ and $\mathrm{C}$ are given in the Figure legend. The isotherm is described by the empirical expression: $\mathrm{S}=0.54^{*}(\mathrm{Ce})^{0.62}$.

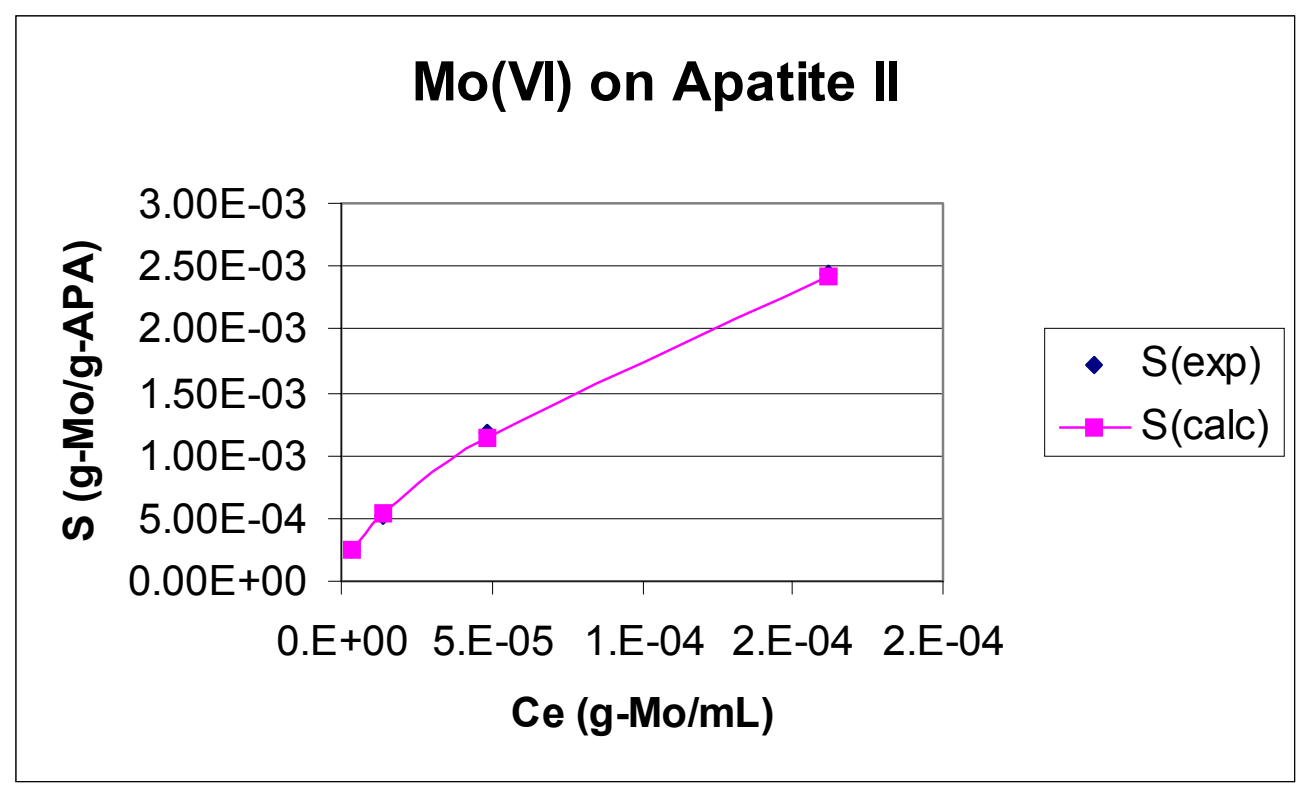

Figure 34. Sorption of Molybdenum (as Molybdate) to Raw Apatite II, presented as a linear isotherm. S(exp) and S(calc) are defined in the footnotes to Table 24.

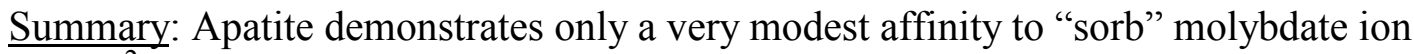
$\left(\mathrm{MoO}_{4}{ }^{2-}\right)$. 


\subsubsection{Nickel, as $\mathrm{Ni}(\mathrm{II})$}

\section{Literature Expectations}

Suzuki et al. (1981) studied the removal of select metals from solutions passed through columns packed with synthetic hydroxyapatite; very limited data suggests that appreciable $\mathrm{Ni}$ (II) could be removed. The authors assume a cation exchange mechanism, and ranking in terms of the amount exchanged was $\mathrm{Cd}(\mathrm{II}), \mathrm{Zn}(\mathrm{II})>\mathrm{Ni}(\mathrm{II})>\mathrm{Ba}(\mathrm{II})$, $\mathrm{Mg}(\mathrm{II})$. Sowder et al. (1999) also suggest that hydroxyapatite may be effective for reducing nickel availability in sediment.

Nickel forms an insoluble phosphate salt $\left(\mathrm{Ni}_{3}\left(\mathrm{PO}_{4}\right)_{2} \cdot 7 \mathrm{H}_{2} \mathrm{O}\right)$, and should be amenable to precipitation by the phosphate released by dissolving apatite phase. In addition, the existence of mixed nickel-containing phosphate minerals (e.g., cassidyite, hydrated calcium nickel magnesium phosphate) suggests that synergistic co-precipitation may occur.

The USEPA health advisory level for nickel in drinking water is $0.7 \mathrm{mg} / \mathrm{L}$, and the Fernald site groundwater Final Remediation Level (FRL) is $0.1 \mathrm{mg} / \mathrm{L}$.

\section{Experimental Results}

Table 25. Raw Apatite (APA) Contacted 52-h with $\mathrm{M}=\mathrm{Ni}$ (II) (from nickel acetate) in Synthetic Groundwater Matrix

\begin{tabular}{|c|c|c|c|c|}
\hline Test Series & 1 & 2 & 3 & 4 \\
\hline $\mathrm{W}$ (g-APA) & 0.8523 & 0.8034 & 0.8082 & 0.8068 \\
\hline $\mathrm{V}$ (Volume Solution, mL) & 40 & 40 & 40 & 40 \\
\hline $\mathrm{Co}(\mathrm{g}-\mathrm{M} / \mathrm{mL})$ & $1.80 \mathrm{E}-04$ & $5.90 \mathrm{E}-05$ & $1.77 \mathrm{E}-05$ & $5.63 \mathrm{E}-06$ \\
\hline $\mathrm{pHo}$ & 7.3 & 7.7 & 8.0 & 8.1 \\
\hline $\mathrm{Ce}(\mathrm{g}-\mathrm{M} / \mathrm{mL})$ & $3.57 \mathrm{E}-05$ & $4.69 \mathrm{E}-06$ & $1.20 \mathrm{E}-06$ & $5.27 \mathrm{E}-07$ \\
\hline $\mathrm{Ce} / \mathrm{Co}$ & $1.98 \mathrm{E}-01$ & $7.95 \mathrm{E}-02$ & $6.80 \mathrm{E}-02$ & $9.37 \mathrm{E}-02$ \\
\hline $\mathrm{pHe}$ & 6.7 & 6.8 & 6.8 & 6.8 \\
\hline $\mathrm{S}(\exp ), \mathrm{g}-\mathrm{M} / \mathrm{g}-\mathrm{APA}(\underline{1})$ & $7.41 \mathrm{E}-03$ & $2.63 \mathrm{E}-03$ & $9.01 \mathrm{E}-04$ & $3.09 \mathrm{E}-04$ \\
\hline $\mathrm{Kd}=\mathrm{S}(\exp ) / \mathrm{Ce}, \mathrm{mL} / \mathrm{g}$ & 162 & 463 & 548 & 387 \\
\hline $\mathrm{S}(\mathrm{calc}), \mathrm{g}-\mathrm{M} / \mathrm{g}-\mathrm{APA}(2)$ & $7.91 \mathrm{E}-03$ & $2.48 \mathrm{E}-03$ & $8.08 \mathrm{E}-04$ & $3.41 \mathrm{E}-04$ \\
\hline $\mathrm{Kd}=\mathrm{S}(\mathrm{calc}) / \mathrm{Ce}, \mathrm{mL} / \mathrm{g}$ & 202 & 325 & 447 & 542 \\
\hline
\end{tabular}

(1) Estimated from mass-balance considerations as: $\mathrm{S}=\mathrm{Co}(\mathrm{V} / \mathrm{W})(1-\mathrm{C} / \mathrm{Co})$

(2) Estimated from fitted parameters for a Freundlich isotherm; see Figure 35. 


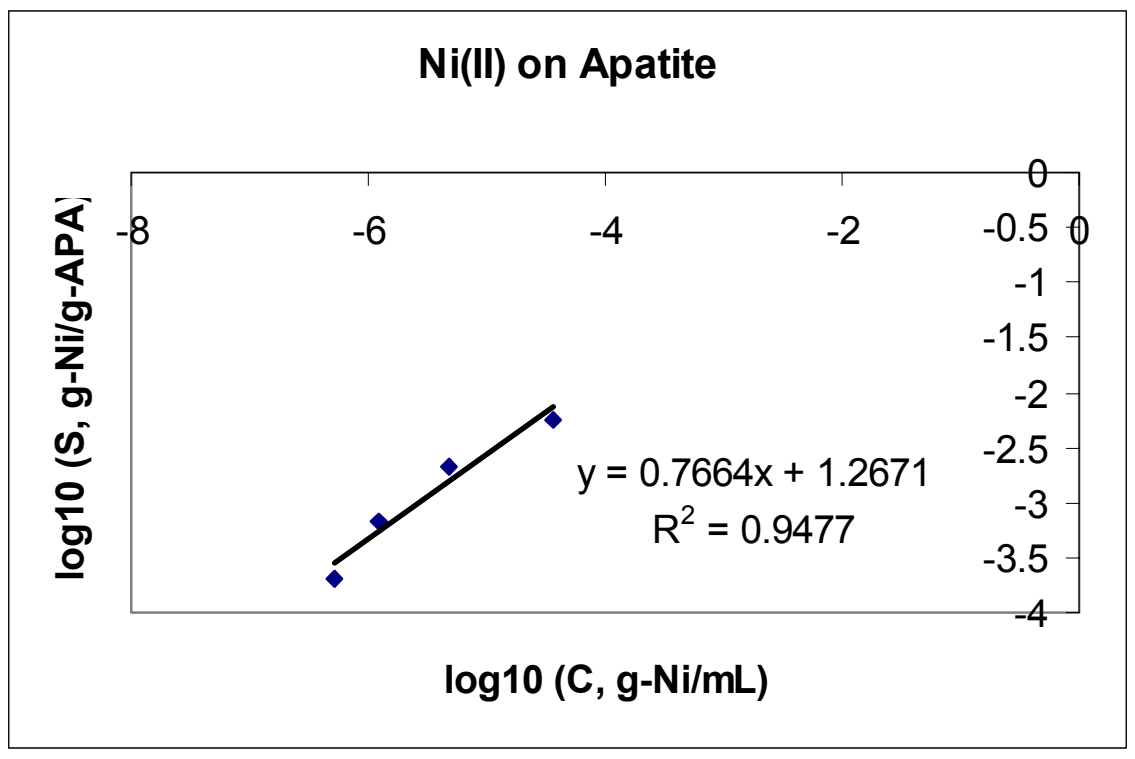

Figure 35. Sorption of $\mathrm{Ni}(\mathrm{II})$ on Raw Apatite. Experimental results are fitted to a linearized Freundlich isotherm (Eq. 4). The units for $\mathrm{S}$ and $\mathrm{C}$ are given in the Figure legend. The isotherm is described by the empirical expression: $\mathrm{S}=18.5^{*}(\mathrm{Ce})^{0.766}$.

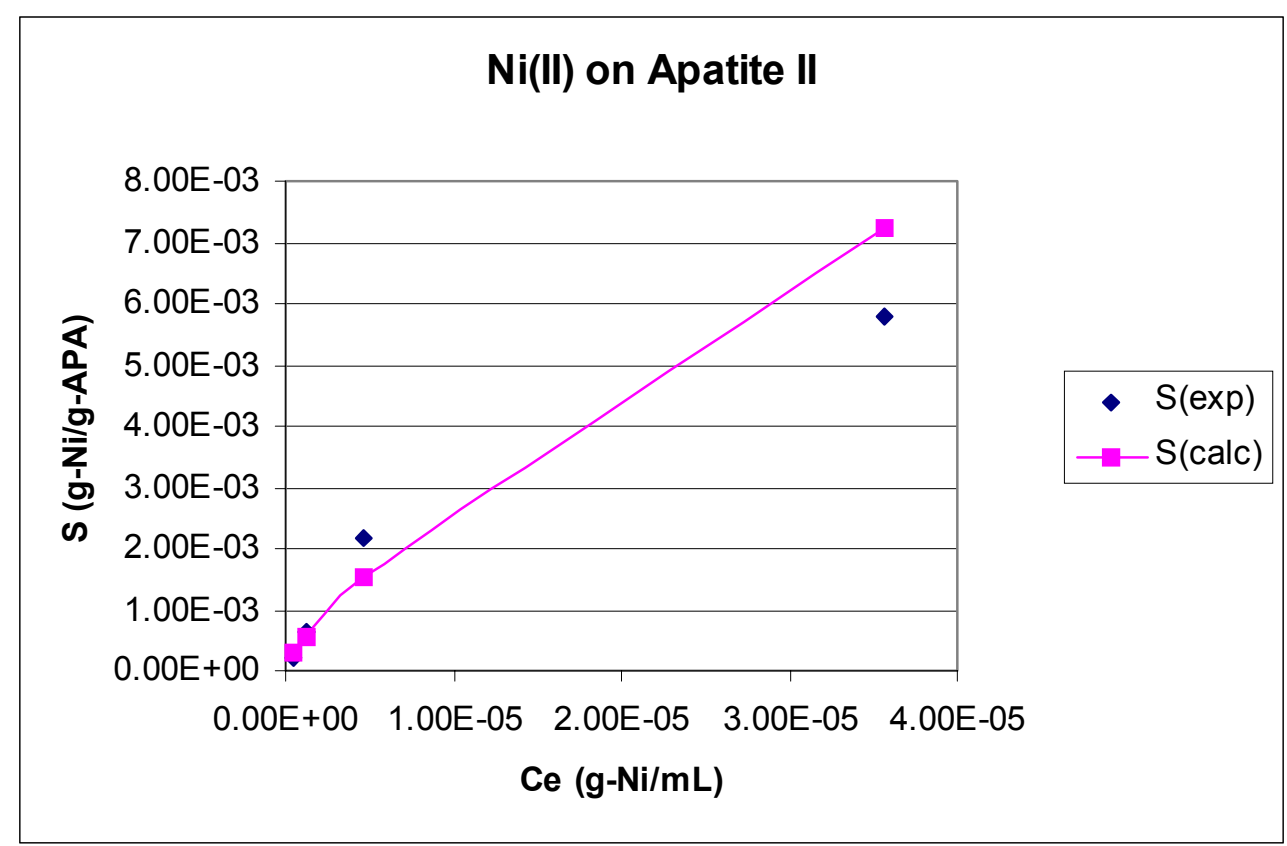

Figure 36. Sorption of Ni(II) to Raw Apatite II, presented as a linear isotherm. S(exp) and $\mathrm{S}$ (calc) are defined in the footnotes to Table 25.

Summary: Apatite demonstrates a modest affinity to "sorb" Ni(II) from solution. 


\subsubsection{Selenium, as $\operatorname{Se}(I V)$}

\section{Literature Expectations}

The chemistry of selenium is somewhat similar to sulfur, and Se is associated with naturally occurring sulfides of many heavy metals. Selenium, like sulfur, forms oxyanions (selenites, $\mathrm{SeO}_{3}{ }^{-2}$, and selenates, $\mathrm{SeO}_{4}{ }^{-2}$ ), and exhibits anionic chemistry in aqueous solution. The speciation of $\mathrm{Se}$ is dependent upon the $\mathrm{pH}$ and redox potential of the solution. Selenous acid $\left(\mathrm{H}_{2} \mathrm{SeO}_{3}\right)$ species occur under the intermediate to slightly oxidizing conditions encountered in aerobic waters (Bodek et al., 1988), with $\mathrm{HSeO}_{3}{ }^{-}$ predominating at near-neutral $\mathrm{pH}$ values. Selenite salts are generally less soluble than the corresponding selenates. Selenates are stable under alkaline oxidizing conditions, and have high bioavailability. Selenium is an essential animal nutrient, but is toxic at high concentrations. In alkaline soils, selenium can bioaccumulate in plant tissue.

Recent literature suggests that the reduced species selenite ion can exchange for phosphate ion in the apatite structure, with optimum retention around $\mathrm{pH} 8$, with a decrease in retention at lower $\mathrm{pH}$ values (Monteil-Rivera et al., 1999).

Reference regulatory criteria for Se are the USEPA MCL and the DOE Fernald Site FRL, both established as $0.05 \mathrm{mg} / \mathrm{L}$.

\section{Experimental Results}

Data are summarized in Table 26. Selenous acid is strong enough to significantly lower the $\mathrm{pH}$ of the diluent system. Exposed apatite solids from test Series 1 looked like ordinary raw apatite, but others in the series (more dilute Co) had a pink tint, possibly due to reduction of Se(IV) occurring in the sealed test system (biological activity associated with nonsterile raw apatite in an aqueous system within a closed vessel can produce anaerobic conditions; see Fig. 6). The pink tint may be indicative of microbial reduction to form red amorphous selenium (Barton et al., 1992). However, overall removal of soluble Se by apatite is very modest, and the "sorption" isotherm is distinctly nonlinear (see Figure 37). 
Table 26. Raw Apatite (APA) Contacted 52-h with $\mathrm{M}=\mathrm{Se}$ (IV) (from selenous acid, $\mathrm{H}_{2} \mathrm{SeO}_{3}$ ) in Synthetic Groundwater Matrix

\begin{tabular}{|c|c|c|c|c|}
\hline Test Series & 1 & 2 & 3 & 4 \\
\hline W (g-APA) & 0.8117 & 0.8366 & 0.8048 & 0.8580 \\
\hline V (Volume Solution, mL) & 40 & 40 & 40 & 40 \\
\hline Co (g-M/mL) & $7.20 \mathrm{E}-04$ & $2.54 \mathrm{E}-04$ & $8.63 \mathrm{E}-05$ & $2.84 \mathrm{E}-05$ \\
\hline $\mathrm{pHo}$ & 2.7 & 3.7 & 6.8 & 8.1 \\
\hline $\mathrm{Ce}(\mathrm{g}-\mathrm{M} / \mathrm{mL})$ & $5.11 \mathrm{E}-04$ & $1.27 \mathrm{E}-04$ & $2.34 \mathrm{E}-05$ & $7.15 \mathrm{E}-06$ \\
\hline $\mathrm{Ce} / \mathrm{Co}$ & $7.10 \mathrm{E}-01$ & $5.00 \mathrm{E}-01$ & $2.71 \mathrm{E}-01$ & $2.52 \mathrm{E}-01$ \\
\hline $\mathrm{pHe}$ & 5.8 & 6.4 & 6.6 & 6.6 \\
\hline $\mathrm{S}(\mathrm{exp}), \mathrm{g}-\mathrm{M} / \mathrm{g}-\mathrm{APA}(1)$ & $8.36 \mathrm{E}-03$ & $5.08 \mathrm{E}-03$ & $2.52 \mathrm{E}-03$ & $8.50 \mathrm{E}-04$ \\
\hline $\mathrm{Kd}=\mathrm{S}(\mathrm{exp}) / \mathrm{Ce}, \mathrm{mL} / \mathrm{g}$ & 16.4 & 40 & 108 & 119 \\
\hline $\mathrm{S}(\mathrm{calc}), \mathrm{g}-\mathrm{M} / \mathrm{g}-\mathrm{APA}(2)$ & $9.53 \mathrm{E}-03$ & $4.65 \mathrm{E}-03$ & $1.94-03$ & $1.05 \mathrm{E}-03$ \\
\hline $\mathrm{Kd}=\mathrm{S}(\mathrm{calc}) / \mathrm{Ce}, \mathrm{mL} / \mathrm{g}$ & 18.7 & 36.6 & 83 & 147 \\
\hline
\end{tabular}

(1) Estimated from mass-balance considerations as: $\mathrm{S}=\mathrm{Co}(\mathrm{V} / \mathrm{W})(1-\mathrm{C} / \mathrm{Co})$.

(2) Estimated from fitted parameters for a Freundlich isotherm; see Figure 37.

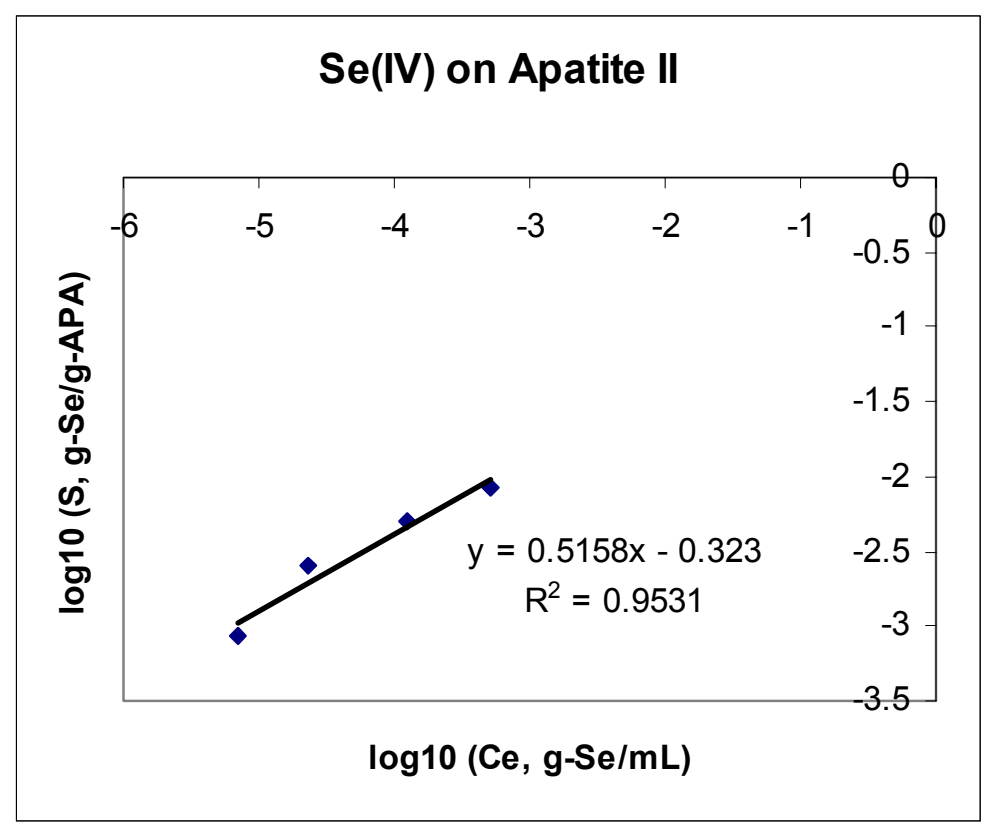

Figure 37. Removal of soluble Se, added as selenous acid, by Raw Apatite.

Experimental results are fitted to a linearized Freundlich isotherm (Eq. 4). The units for $\mathrm{S}$ and $\mathrm{C}$ are given in the Figure legend. The isotherm is described by the empirical expression: $\mathrm{S}=0.475^{*}(\mathrm{Ce})^{0.516}$. 


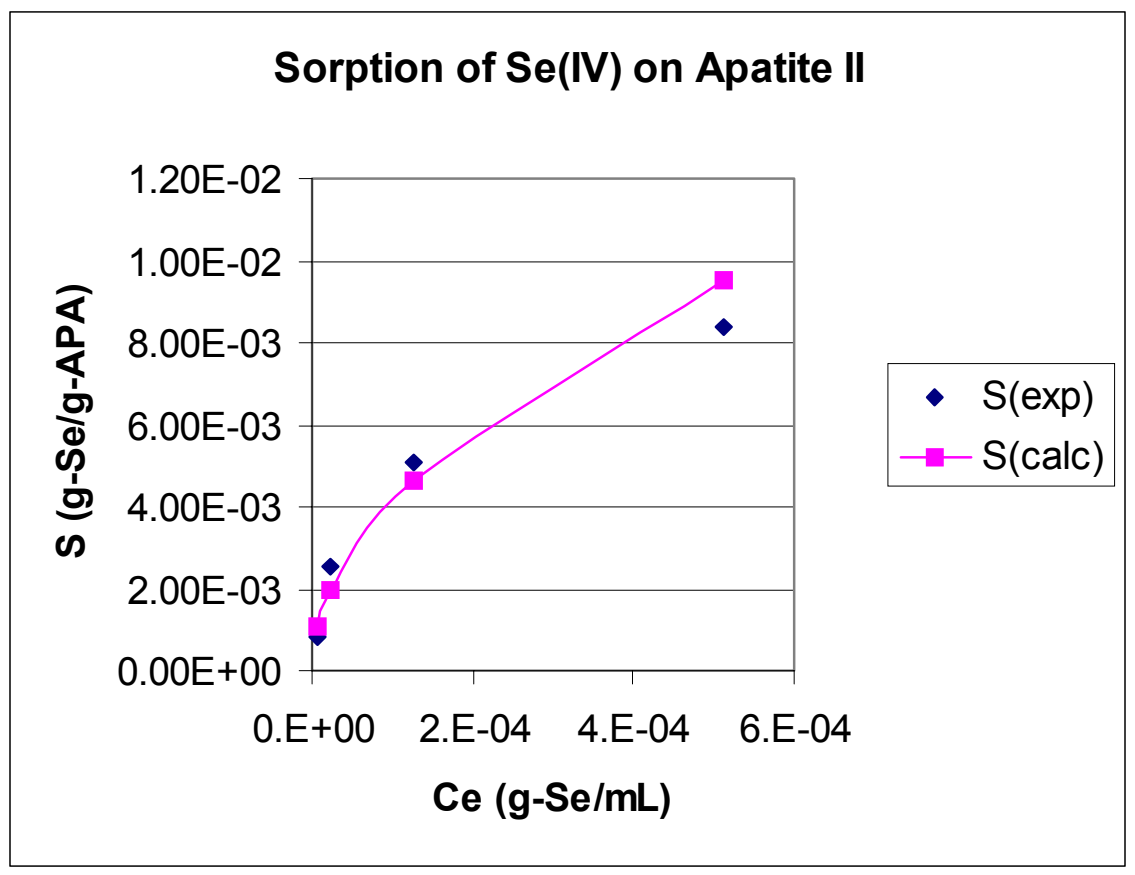

Figure 38. Sorption of Selenium (Added as Selenous Acid) to Raw Apatite II, presented as a linear isotherm. S(exp) and S(calc) are defined in the footnotes to Table 26.

Summary: Apatite demonstrates only a very modest affinity for the removal of selenous acid $\left(\mathrm{H}_{2} \mathrm{SeO}_{3}\right)$ from slightly acidic solution, but has increased removal efficiency for selenate ion at $\mathrm{pH}$ values near 8 . 


\subsubsection{Strontium, as $\operatorname{Sr}(\mathrm{II})$}

\section{Literature Expectations}

Radiostrontium (half-life about 28.5 years) is a "bone-seeker", and may be incorporated into the human skeletal system. Narasaraju and Phebe (1996) indicate that strontium can be incorporated into apatite by isomorphous substitution. Strontium ions may be initially sorbed to hydroxyapatite phase, with subsequent slow diffusion into the crystal interior, accompanied by simultaneous recrystalization of the apatite phase. Coprecipitation of strontium and calcium as phosphate salts yields ideal solid solutions of isomorphous apatite over the entire composition range. Strontium is readily incorporated into growing calcium phosphate crystal lattices, due to the similarity of its ionic radius with that of calcium (Zawacki et al., 1986), although there is a significant discrimination against $\mathrm{Sr}$ incorporation in mixed precipitates (in agreement with the observed discrimination against $\mathrm{Sr}$ in the bones and teeth of a living organism; Driessens, 1986).

Moody et al. (1996) investigated various media for the stabilization of radioactive ${ }^{90} \mathrm{Sr}$, such as found in soil at the Hanford Site. The ability to retain $\mathrm{Sr}$ in media-amended soil decreased in the order: clinoptilolite (zeolite) $>$ bone char $>$ synthetic hydroxyapatite $>$ fossil apatite (phosphate rock). A later study (Moody 1997) tested the efficacy of solid phases hydroxyapatite and bone char, as well as soluble phosphate compounds including ordinary superphosphate, triple superphosphate and trisodium phosphate. The application of soluble superphosphate compounds (as precursors to the formation of amorphous insoluble phosphate phases within the soil matrix) was largely ineffective. Use of trisodium phosphate, mixtures of trisodium phosphate plus calcium carbonate, and bone char (at treatment dosages of 1 to $10 \%$, by weight in the soil matrix) were each relatively effective in reducing the Sr-90 activity (by $>90 \%$ ) in the groundwater leachate from the treated soil. It is noted that the testing protocol used was shaking soil, groundwater, and reagents together in mixture. Thus it is possible that $\mathrm{Sr}$ is coprecipitated from solution phase along with amorphous calcium phosphate that is formed in-situ from soluble phosphate precursors. The use of preformed amorphous phosphate compounds as a treatment medium may be less effective for strontium removal than is the removal from solution phase by coprecipitation with calcium and phosphate salts. Anderson et al. (1998) report that solid phosphate media (including synthetic hydroxyapatite and bone char) were only modestly effective for the removal of soluble $\mathrm{Sr}$ in short-term batch equilibrations, with conditional distribution coefficients typically $<100 \mathrm{~mL} / \mathrm{g}$. Bostick and Bostick (1999, unpublished) tested the sorption of radiostrontium (as ${ }^{90} \mathrm{Sr}$ ) by Apatite II in simulated ORNL Corehole 8 Seep water, having a "typical" background value for natural $\mathrm{Sr}$ of $\sim 0.1 \mathrm{mg} / \mathrm{L}$; cf. Table 1 . Computed $\mathrm{Kd}$ values at this relatively low background $\mathrm{Sr}$ level were in the range of $\sim 500-1,000 \mathrm{~mL} / \mathrm{g}$. Conca et al. (2002) noted that Apatite II solids themselves tend to leach ${ }^{87} \mathrm{Sr}$ (the most abundant natural isotope); this additional background level of Sr leached from the apatite solids may limit the kinetics of isotopic exchange for trace levels of radiostrontium $\left({ }^{85} \mathrm{Sr}\right.$ and $\left.{ }^{90} \mathrm{Sr}\right)$. 


\section{$\underline{\text { Experimental Results }}$}

Table 27. Raw Apatite (APA) Contacted 52-h with $\mathrm{M}=\mathrm{Sr}$ (II) (from strontium nitrate) in Synthetic Groundwater Matrix

\begin{tabular}{|c|c|c|c|c|}
\hline Test Series & 1 & 2 & 3 & 4 \\
\hline W (g-APA) & 0.8356 & 0.8241 & 0.8016 & 0.8298 \\
\hline V (Volume Solution, mL) & 40 & 40 & 40 & 40 \\
\hline Co (g-M/mL) & $2.95 \mathrm{E}-04$ & $9.42 \mathrm{E}-05$ & $3.34 \mathrm{E}-05$ & $1.12 \mathrm{E}-05$ \\
\hline $\mathrm{pHo}$ & 6.8 & 7.7 & 8.0 & 8.2 \\
\hline $\mathrm{Ce}(\mathrm{g}-\mathrm{M} / \mathrm{mL})$ & $1.04 \mathrm{E}-04$ & $1.49 \mathrm{E}-05$ & $4.45 \mathrm{E}-06$ & $2.05 \mathrm{E}-06$ \\
\hline $\mathrm{Ce} / \mathrm{Co}$ & $3.49 \mathrm{E}-01$ & $1.58 \mathrm{E}-01$ & $1.33 \mathrm{E}-01$ & $1.83 \mathrm{E}-01$ \\
\hline $\mathrm{pHe}$ & 6.4 & 6.6 & 6.6 & 6.4 \\
\hline $\mathrm{S}(\mathrm{exp}), \mathrm{g}-\mathrm{M} / \mathrm{g}-\mathrm{APA}(1)$ & $7.68 \mathrm{E}-03$ & $3.17 \mathrm{E}-03$ & $1.16 \mathrm{E}-03$ & $3.64 \mathrm{E}-04$ \\
\hline $\mathrm{Kd}(\mathrm{mL} / \mathrm{g})=\mathrm{S}(\exp ) / \mathrm{Ce}$ & 74.5 & 213 & 260 & 178 \\
\hline $\mathrm{S}(\mathrm{calc}), \mathrm{g}-\mathrm{M} / \mathrm{g}-\mathrm{APA}(2)$ & $9.53 \mathrm{E}-03$ & $2.26 \mathrm{E}-03$ & $9.20 \mathrm{E}-04$ & $5.17 \mathrm{E}-04$ \\
\hline $\mathrm{Kd}(\mathrm{mL} / \mathrm{g})=\mathrm{S}(\mathrm{calc}) / \mathrm{Ce}$ & 92.4 & 152 & 290 & 253 \\
\hline
\end{tabular}

(1) Estimated from mass-balance considerations as: $\mathrm{S}=\mathrm{Co}(\mathrm{V} / \mathrm{W})(1-\mathrm{C} / \mathrm{Co})$

(2) Estimated from fitted parameters for a Freundlich isotherm; see Figure 39.

Data summarized in Figures 39 and 40 suggest a very modest "sorption" of Sr onto raw Apatite II, in short-term batch testing.

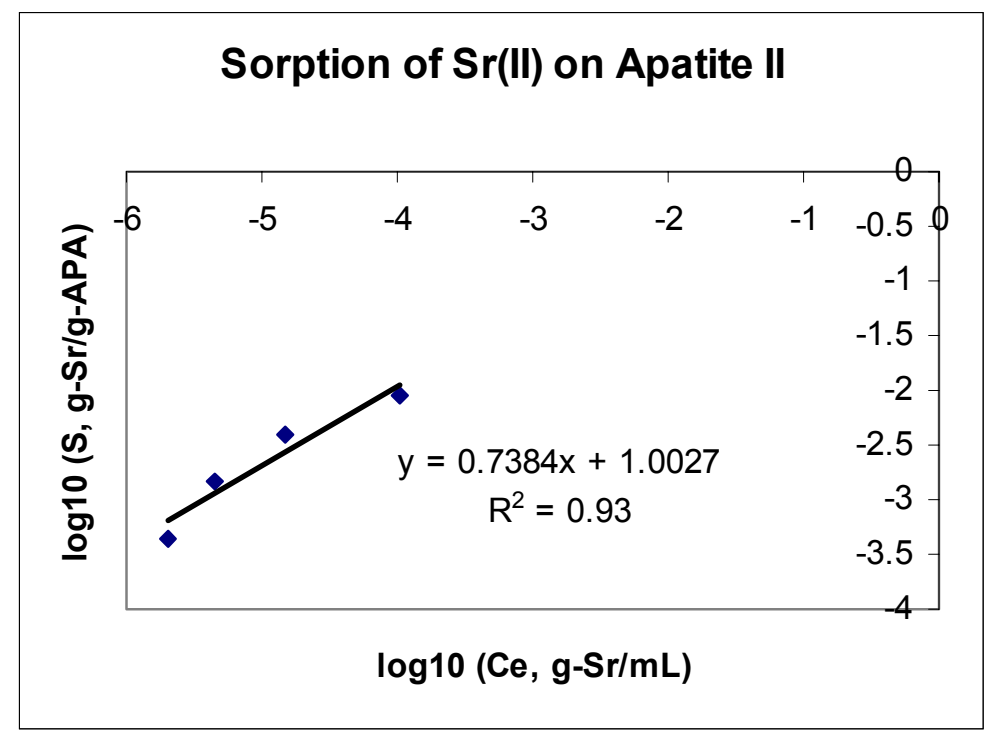

Figure 39. Sorption of $\mathrm{Sr}(\mathrm{II})$ on Raw Apatite. Experimental results are fitted to a linearized Freundlich isotherm (Eq. 4). The units for $\mathrm{S}$ and $\mathrm{C}$ are given in the Figure legend. The isotherm is described by the empirical expression: $\mathrm{S}=10.1 *(\mathrm{Ce})^{0.738}$. 


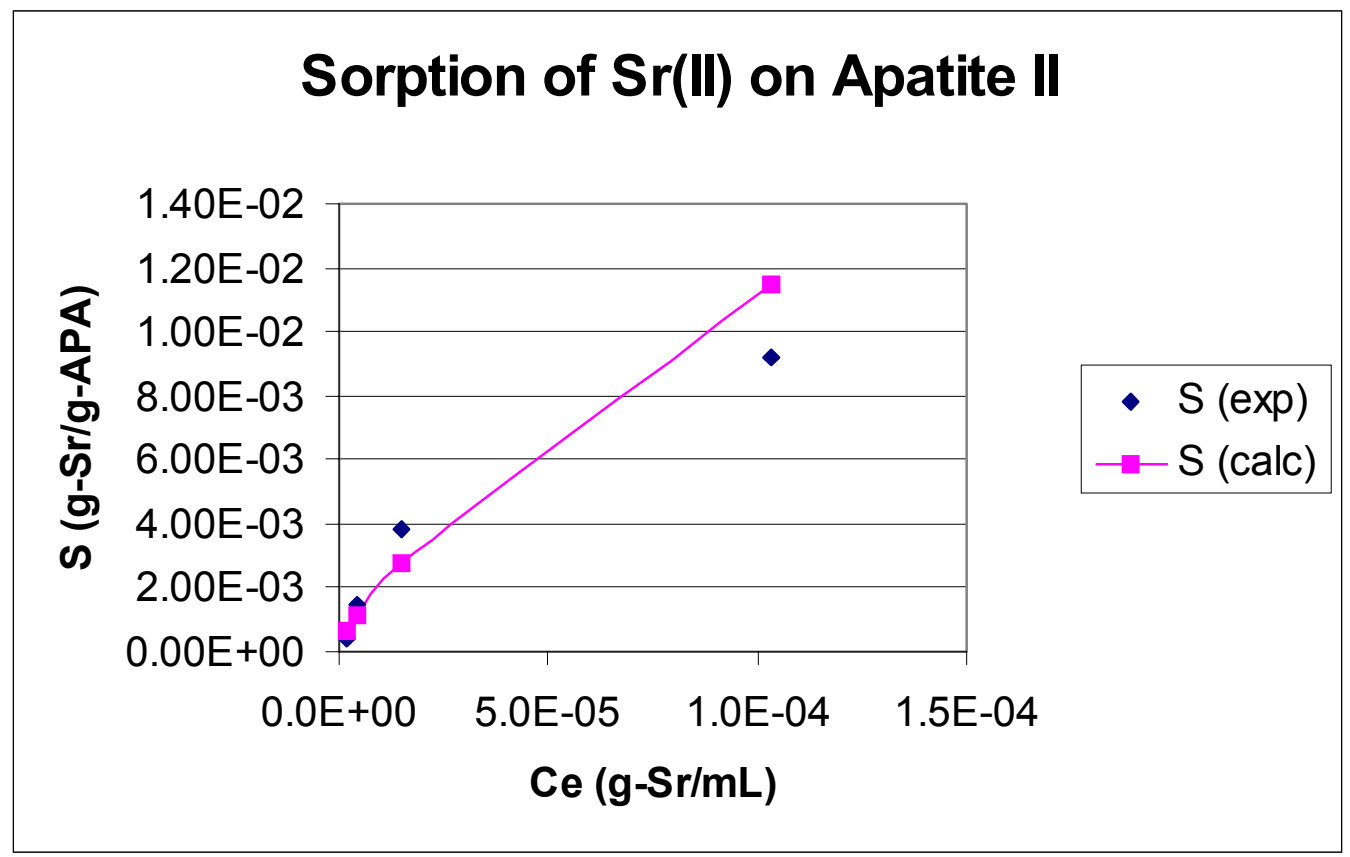

Figure 40. Sorption of Strontium to Raw Apatite II, presented as a linear isotherm. $\mathrm{S}(\exp )$ and $\mathrm{S}($ calc) are defined in the footnotes to Table 27.

Summary: Apatite demonstates only a modest removal of strontium ion from solution phase. 


\subsubsection{Technetium-99, Tc(VII) Literature Expectations}

Pertechnetate ion $\left(\mathrm{TcO}_{4}^{-}\right)$is the most stable Tc chemical species in aqueous systems that do not contain strong reducing agents (Wildung et al., 1979; Lieser and Bauscher, 1987). Pertechnetate ion is highly soluble and is only slightly (if at all) sorbed to mineral substrates. Anderson et al. (1998) evaluated a number of media (natural and synthetic apatites, tricalcium phosphate, bone char, zeolite, activated magnetite, etc.) for the removal of select metals from solution phase. None of these media were particularly effective for the removal of Tc-99 as the pertechnetate ion, although bone char demonstrated a modest affinity ( $\mathrm{Kd}<100 \mathrm{~mL} / \mathrm{g})$, probably due to the associated activated carbon component.

Experimental Results

Due to the relatively high specific activity for Tc-99 $(0.017 \mathrm{Ci} / \mathrm{g})$, we did not follow the standard testing protocol for this radionuclide. Rather, we performed a simple comparison of select media at a single initial concentration of Tc-99 $\left(\right.$ as NH$\left._{4} \mathrm{TcO}_{4}\right)$ in synthetic groundwater. Media evaluated include: raw Apatite II; Apatite IIC; a commercial bone char (Waterlink BC), and acid-washed coal (Cameron Coal G6/AW). The beta particle activity (counts per minute, CPM) of Tc-99 in a filtered sample of solution is determined by liquid scintillation counting. Results, summarized in Table 28, indicate that apatite products have relatively modest affinity for pertechnetate ion, compared to the acid-washed coal. In low-ionic strength solution, the pertechnetate ion readily binds to various forms of activated carbon (Gu and Dowlen, 1996); the Waterlink ${ }^{\circledR}$ animal bone char contains a residual of $\sim 10.8 \mathrm{wt} \%$ activated carbon, which likely imparts some affinity for the pertechnetate ion, relative to raw or oxidized fish bone.

Table 28. Removal of Soluble Tc-99 by Select Media (22-h Phase Contact)

\begin{tabular}{|c|c|c|c|c|}
\hline Test Series & $\begin{array}{c}\text { Apatite II } \\
(8 / 20 \text { mesh })\end{array}$ & $\begin{array}{c}\text { Apatite IIC } \\
(8 / 20 \text { mesh })\end{array}$ & $\begin{array}{c}\text { Waterlink BC } \\
(8 / 20 \text { mesh })\end{array}$ & $\begin{array}{c}\text { Cameron G6/AW } \\
(12 / 40 \text { mesh })\end{array}$ \\
\hline $\mathrm{W}(\mathrm{g}$-solid) & 0.2295 & 0.2194 & 0.2246 & 0.2050 \\
\hline $\mathrm{V}(\mathrm{mL})$ & 10.25 & 10.22 & 10.22 & 10.42 \\
\hline $\mathrm{Ao}(\mathrm{CPM} / \mathrm{mL})$ & 910 & 910 & 910 & 910 \\
\hline $\mathrm{pHo}$ & 6.6 & 6.6 & 6.6 & 6.6 \\
\hline $\mathrm{Ae}(\mathrm{CPM} / \mathrm{mL})$ & 842 & 925 & 184 & 0.29 \\
\hline $\mathrm{Ae} / \mathrm{Ao}$ & 0.925 & 1.02 & 0.202 & $3.18 \mathrm{E}-04$ \\
\hline $\mathrm{pHe}$ & 7.8 & 8.2 & 9.0 & 7.3 \\
\hline $\mathrm{Kd}(\mathrm{mL} / \mathrm{g})$ & 4.3 & -0.2 & 436 & 133,000 \\
\hline
\end{tabular}

Ao is the initial activity of the test solution; Ae is the activity of the solution after contact with the solid phase.

Summary: Apatite demonstrates little or no affinity for the removal of soluble pertechnetate anion. 


\subsubsection{Thorium, as $\mathrm{Th}(\mathrm{IV})$}

\section{$\underline{\text { Literature Expectations }}$}

Natural thorium exists primarily as the isotope ${ }^{232} \mathrm{Th}$, with a radioactive decay half-life of $1.4 \times 10^{10}$ years. Other short-lived thorium isotopes are progeny of the nuclear decay of $U$ isotopes. According to the U.S. EPA (EPA 402-R-99-004B): "Of the contaminated sites considered in EPA/DOE/NRC (1993), radioactive contamination of soil, surface water, and/or groundwater by (thorium isotopes) has been identified at 21 of the 45 Superfund National Priority List (NPL) sites and 23 of the 38 NRC Site Decommissioning Management Plan (SDMP) sites.”

Thorium normally does not exhibit high mobility in soils, due to a strong affinity for clay and other mineral phases (e.g., hydrous iron and manganese oxides). Thorium is soluble in acidic solution (e.g., $\mathrm{pH}<3.5$ ), but in near-neutral aqueous solutions, especially in groundwater, the concentrations of dissolved thorium are typically very low (EPA 402-R99-004B). In groundwater at $\mathrm{pH}>5$, thorium solubility is limited by sparingly soluble hydrous thorium oxides, forming species such as $\mathrm{Th}(\mathrm{OH})_{3}{ }^{+}$and $\mathrm{Th}(\mathrm{OH})_{4}$ (Bodek et al, p. 9.2-19; EPA 402-R-99-004B). Carbonate complexation can significantly increase the solubility of Th (EPA 402-R-99-004B). At near-neutral pH values, Th mobility may also be affected by phosphate complexation, although there is not adequate thermodynamic data to estimate the stability of these complexes (EPA 402-R-99-004B).

Thorium is incorporated as a significant component of monazite minerals (mixed lanthanide group phosphates). Gauglitz et al. (1992) show that Th is rapidly removed by contact with synthetic HAP, but suggest that daughters Ra and Ac may remain in solution. These authors could not identify any definite Th crystalline precipitate phase. [Note that Murray et al. (1983) have demonstrated the use of synthetic apatite for the retention of uranium and its daughter products from uranium mine leachate; radium leach values were reduced to very low levels (typically below $0.1 \mathrm{pCi} / \mathrm{L}$ ).]

Experimental Results

Thorium, as hydrous thorium nitrate, $\mathrm{Th}\left(\mathrm{NO}_{3}\right)_{4} \cdot \mathrm{nH}_{2} \mathrm{O}$, was added to synthetic groundwater. The Th was highly soluble at the resultant $\mathrm{pH}$ value $(\mathrm{pH} \sim 3.3)$, yielding a solution containing a nominal $50 \mu \mathrm{g}$ - Th/mL, and a total activity ( $\alpha$ and $\beta$ ) of $\sim 1200$ $\mathrm{DPM} / \mathrm{mL}$. This solution was contacted overnight with Apatite IIC medium. As indicated in Table 29, aliquots of initial $\left(\mathrm{C}_{\mathrm{o}}\right)$ and final (treated) solutions, with and without filtration (0.2- $\mu \mathrm{m}$ medium), were counted with use of a Packard TR-2550 liquid scintillation counter. The distribution coefficient, $\mathrm{Kd}$, is computed based upon the solution phase activities of ${ }^{232} \mathrm{Th}$ and all of its decay progeny (Eq. 16). Thus, this measurement is not specific for thorium only.

${ }^{232} \mathrm{Th} \rightarrow{ }^{228} \mathrm{Ra}+\alpha \rightarrow{ }^{228} \mathrm{Ac}+\alpha, \beta \rightarrow{ }^{228} \mathrm{Th}+\alpha \rightarrow{ }^{224} \mathrm{Ra}+\alpha \rightarrow{ }^{220} \mathrm{Rn}+\alpha \rightarrow{ }^{216} \mathrm{Po}+\alpha \rightarrow$ ${ }^{212} \mathrm{~Pb}+\beta \rightarrow{ }^{212} \mathrm{Bi}+\alpha, \beta \rightarrow \rightarrow{ }^{208} \mathrm{~Pb}$

Immediately after phase contact (by tumbling phases on a TCLP extraction apparatus), the solution was somewhat turbid. The data in Table 29 indicate that the activities of all 
$\alpha$ and $\beta$ nuclides (Eq. 16) are greatly reduced in the filtered solution, but that appreciable activity is associated in the fine particulate in the unfiltered solution phase (taken before fine particulate sedimentation). After the phases were allowed to sediment from quiescent solution, a layer of fine gray particulate ("silt") formed on top of the apatite phase. A sample of these solids was taken with use of a pipette, concentrated on a filter $(0.2-\mu \mathrm{m}$ medium $)$, and the major elemental constituents in the solids were identified with use of scanning electron microscopy with energy-dispersive x-ray spectroscopy (SEMEDS; see Figure 41). The elemental associations for the Th-rich particles (Th, O, P, with smaller residuals of $\mathrm{Ca}$ ) are consistent with formation of a thorium phosphate phase (as opposed to, e.g., being a simple hydrolysis product). The surface morphology of the particulate phase shows agglomerations (greatest dimension up to several $\mathrm{mm}$ ) comprised of submicron-sized crystals, suggesting an origin by homogeneous precipitation from the aqueous phase.

Table 29. Thorium Solution Activities After Contact with Apatite C-400 (16-h at L/S =

\begin{tabular}{|c|c|c|c|c|}
\hline \multirow{2}{*}{ Property } & \multicolumn{2}{c|}{ Co (Untreated Solution) } & \multicolumn{2}{c|}{ Ce (Treated Solution) } \\
\cline { 2 - 5 } & Unfiltered & Filtered & Unfiltered & Filtered \\
\hline $\mathrm{pH}$ & 3.28 & & 6.02 & \\
\hline Beta $(\mathrm{CPM} / \mathrm{g})$ & 454.61 & 454.43 & 62.44 & 1.29 \\
\hline Alpha $(\mathrm{CPM} / \mathrm{g})$ & 525.14 & 520.43 & 71.58 & 1.19 \\
\hline Total $(\mathrm{CPM} / \mathrm{g})$ & 979.75 & 974.87 & 134.02 & 2.48 \\
\hline Total $(\mathrm{A} / \mathrm{Ao})$ & 1 & 0.995 & 0.137 & 0.0025 \\
\hline $\mathrm{Kd}(\mathrm{mL} / \mathrm{g}){ }^{*}$ & & & 481 & 30,100 \\
\hline
\end{tabular}

- $\mathrm{Kd}$ is estimated from the change in total activity in the aqueous phase, and reflects the activity contributions of Th and all of its decay progeny (Eq. 16). 


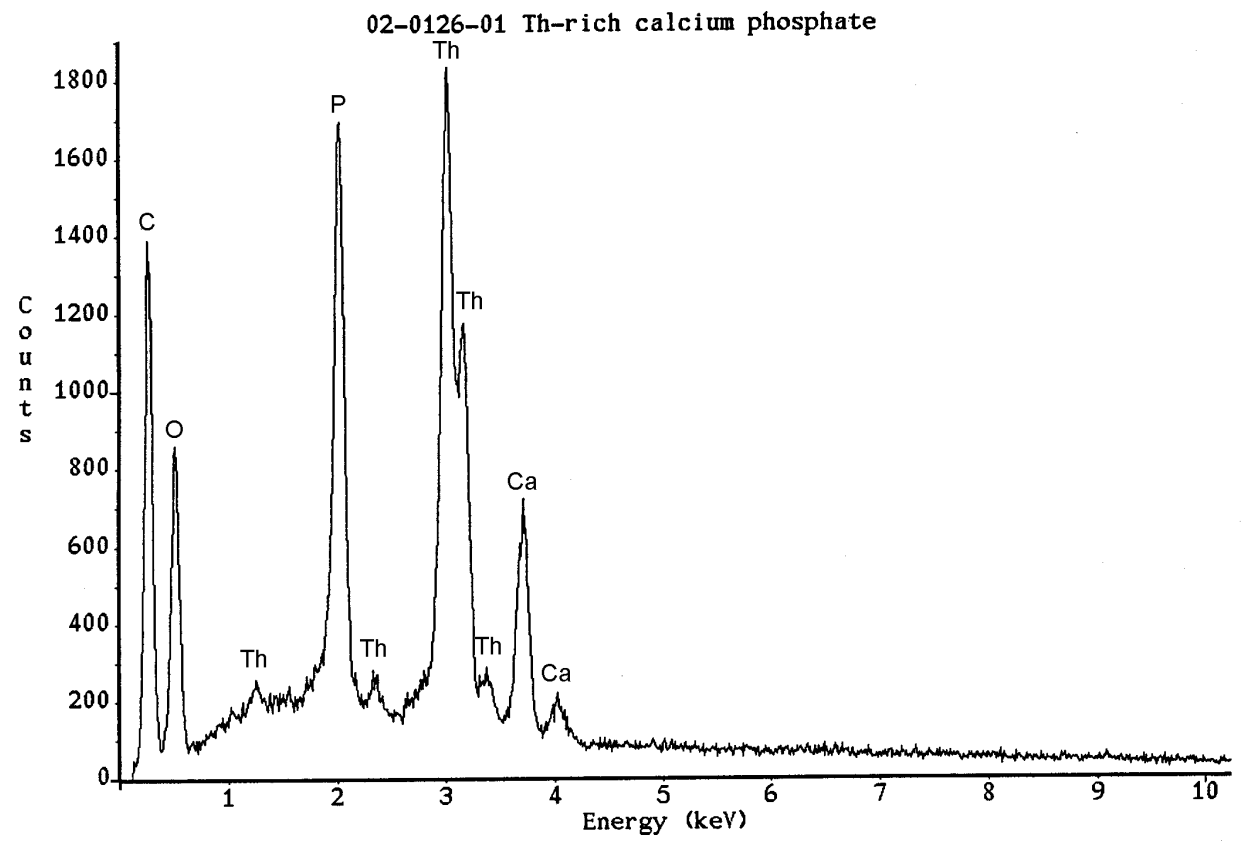

Figure 41. (Scan 02-0126-01: Scanning Electron Microscopy with Energy-Dispersive X-ray Spectroscopy (SEM-EDS) for Th-rich calcium phosphate solid phase formed by contact of thorium nitrate solution and Apatite II).

Summary: Apatite demonstrates a strong ability to remove soluble thorium, in part by the formation of a thorium phosphate particulate phase. 


\subsubsection{Uranium, as U(VI) \\ Literature Expectations}

Uranyl ion forms strong complexes with carbonate ion, which increases its solubility under all conditions (Miyahara, 1993). Uranium sorption to soil and aquifer material usually decreases with increasing concentrations of carbonates in solution, due to formation of negatively charged uranium-carbonate complexes (Flury \& Harsh, 2000; Duff \& Amrhein, 1996). Carbonate complexation renders $\mathrm{UO}_{2}{ }^{2+}$ soluble even under fairly strong reducing conditions $(\mathrm{Eh}=-0.1 \mathrm{~V})$ (Bodek et al., 1988). The groundwater surrogate solution used in this testing contains an alkalinity equivalent to $\sim 3.2 \mathrm{mmol} / \mathrm{L}$ bicarbonate ion, which should enhance the solubility of uranyl ion at near neutral $\mathrm{pH}$ values.

Uranyl ion may react with apatite to form mineral phases of the autunite group, a diverse group of over 40 minerals (Dana), having the general formula: $\mathrm{M}\left(\mathrm{UO}_{2} \mathrm{PO}_{4}\right)_{2} \bullet \mathrm{nH}_{2} \mathrm{O}$.

Murray et al. (1983) have demonstrated the use of synthetic apatite for the retention of uranium and its daughter products from uranium mine leachate. Gauglitz et al. (1992) and later Jeanjean (1996) also demonstrated the removal of soluble $U$ by crystalline apatite phase. Anderson et al. (1998) evaluated a number of media (natural and synthetic apatites, tricalcium phosphate, bone char, zeolite, magnetite, etc.) for the removal of select metals from solution phase. Their results indicated that all apatite phases that were evaluated were effective for removal of soluble U. Arey and coworkers (1999) have recently shown that hydroxyapatite amendments, at dosages as little as $1 \mathrm{wt} \%$ in batch tests, effectively immobilized uranium in contaminated sediments, even in the presence of natural organic matter (NOM) that otherwise rendered an appreciable fraction of the uranium contamination highly leachable. However, Sowder et al. (1999) suggest that the effectiveness of apatite amendment for stabilization of $U$ in contaminated sediment does diminish with increasing concentrations of NOM.

Gauglitz et al. (1992) report that contact of concentrated $\mathrm{U}$ in synthetic brine solutions with synthetic HAP produced crystalline phases such as saléeite $\left(\mathrm{Mg}\left(\mathrm{UO}_{2}\right)_{2}\left(\mathrm{PO}_{4}\right) \cdot 9 \mathrm{H}_{2} \mathrm{O}\right)$ and meta-autunite $\left(\mathrm{Ca}\left(\mathrm{UO}_{2}\right)_{2}\left(\mathrm{PO}_{4}\right) \cdot 6 \mathrm{H}_{2} \mathrm{O}\right)$. Bostick et al. (2000) demonstrated that ground fish bone product (Apatite II) is highly effective for the removal of soluble uranium from synthetic groundwater matrix, and that autunite (calcium uranyl phosphate, $\left.\mathrm{Ca}\left(\mathrm{UO}_{2}\right)_{2}\left(\mathrm{PO}_{4}\right)_{2} \bullet \mathrm{nH}_{2} \mathrm{O}\right)$ crystalline phase is formed at high loadings of uranium. Matheson et al. (2001) have used packed bed, flow-through reactor (column) tests to demonstrate the efficacy of raw biogenic apatite for the removal of soluble uranium from a simulated groundwater; at a nominal loading of up to $\sim 10 \mathrm{wt} \% \mathrm{U}$ in the apatite medium, crystalline chernikovite (or hydrogen autunite, $\mathrm{H}_{2}\left(\mathrm{UO}_{2}\right)_{2}\left(\mathrm{PO}_{4}\right)_{2} \bullet \mathrm{nH}_{2} \mathrm{O}$ ) was formed. (Note: the reported X-ray diffractograms of hydrogen and sodium meta-autunite minerals are virtually identical $)^{\frac{B}{3}}$. These highly insoluble phosphate mineral phases are favorable for the removal of soluble uranium from aqueous systems at $\mathrm{pH}$ values $>3$

\footnotetext{
${ }^{3}$ The most recent ICDD card for the compound identified as chernikovite $\left[\mathrm{H}_{2}\left(\mathrm{UO}_{2}\right)_{2}\left(\mathrm{PO}_{4}\right)_{2} \bullet 8 \mathrm{H}_{2} \mathrm{O}\right]$, index $\# 29-670$, has a diffraction pattern nearly identical to Na-meta-autunite $\left[\mathrm{NaUO}_{2} \mathrm{PO}_{4} \bullet 3 \mathrm{H}_{2} \mathrm{O}\right]$, index $\# 29$ 1284, "except" for the basal reflection, i.e. 8.57 vs $9.02 \AA$.
} 
(Van Haverbeke et al., 1996). Figure 42 illustrates the growth of meta-autunite crystals on the surface of biogenic apatite used in the column studies reported by Matheson et al. (2001, 2002). In this demonstration, Apatite II ${ }^{\mathrm{TM}}$ demonstrated an average uptake of uranium equivalent to $\sim 10 \mathrm{wt} \%$ on the apatite phase, before detectable uranium appeared in the column effluent. Similarly, Flury \& Harsh (2000) used fossil North Carolina apatite mineral in a column configuration to demonstrate the potential for remediation of uranium contaminated mine waste.

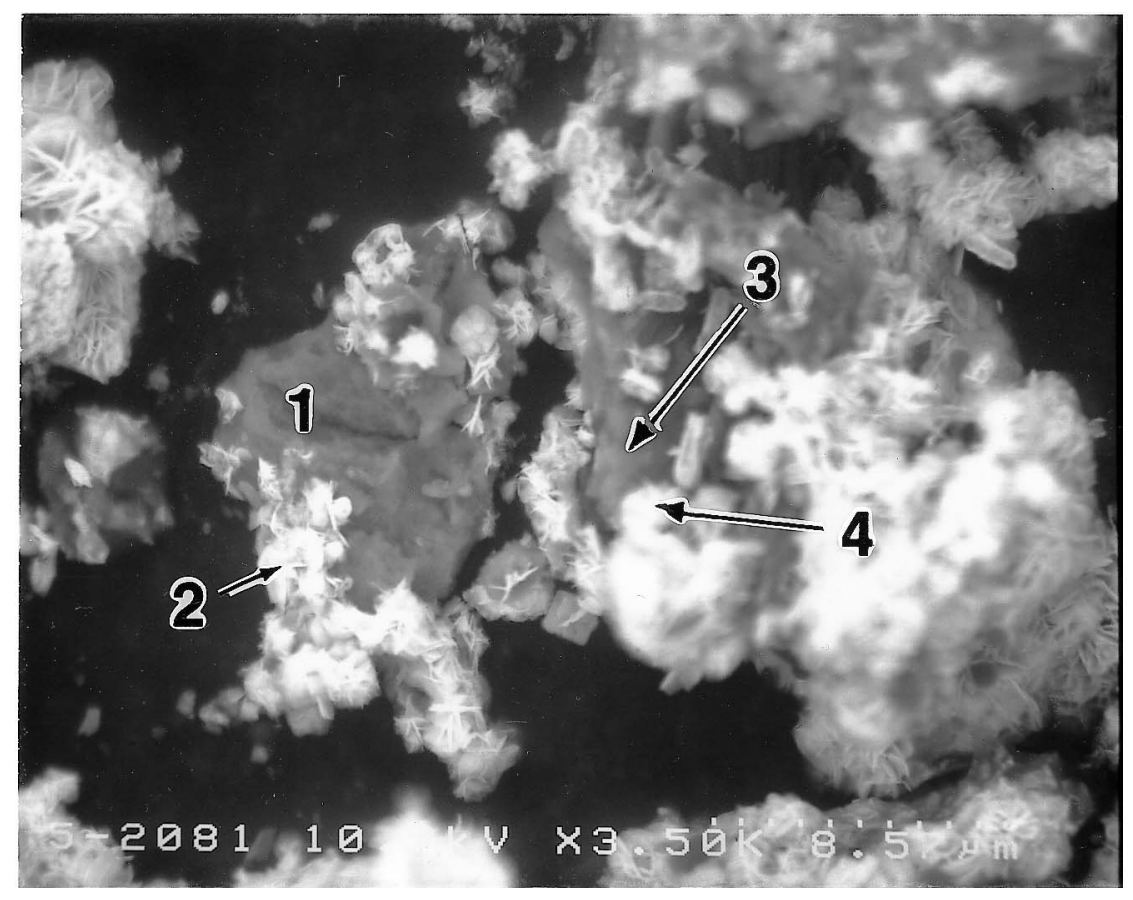

Figure 42. Scanning Electron Micrograph Back-Scattered Electron Image of Apatite from Column Study. Brighter images reflect higher density of heavy atoms (uranium). Numbered "arrows" point to select "spots" at which elemental composition was determined. All areas examined contained C, O, P, U and Ca, but the composition near bright images (areas 2 and 4) contain major amounts of $\mathrm{U}$ and smaller amounts of $\mathrm{Ca}$, in comparison to the composition near dark images (areas 1 and 3), which contain major amounts of $\mathrm{Ca}$ and only minor amounts of U. (Matheson et al., 2001, 2002).

Consistent with these observations, Fuller et al. (2002A, 2002B) recently reported on the mechanisms of U(VI) removal by (reagent grade synthetic) apatite (HA). They report that at relatively low loading (e.g., $<0.5 \mathrm{wt} \%$ loading on HA), U(VI) adsorbs to the HA surfaces as an inner-sphere complex. When loadings exceed $\sim 0.7 \mathrm{wt} \% \mathrm{U}$ on HA, a crystalline $U$ phosphate (identified as chernikovite) precipitates. At still higher loading (e.g. $>0.2$ U:P), a second phase (autunite) appears and may become dominant. 


\section{Experimental Results}

The phase contact is performed in accordance with the Operational Instructions presented in Exhibit \#1. U(VI) at natural isotopic abundance is added to synthetic groundwater as uranyl nitrate, $\mathrm{UO}_{2}\left(\mathrm{NO}_{3}\right)_{2} \cdot 6 \mathrm{H}_{2} \mathrm{O}$. Data in Table 30 represent the actual solution phase metal concentrations as measured by ICP-OES in a series of filtered solutions. Each filtered solution was carried through the contact process, with (Series B) and without (Series A) the addition of apatite phase, to compensate for any metal removal processes not mediated by the apatite.

Table 30. Raw Apatite (APA) Contacted 52-h with $\mathrm{M}=\mathrm{U}(\mathrm{VI})$ (from uranyl nitrate) in Synthetic Groundwater Matrix

\begin{tabular}{|c|c|c|c|c|}
\hline Test Series & 1 & 2 & 3 & 4 \\
\hline W (g-APA) & 0.8316 & 0.8361 & 0.8165 & 0.8325 \\
\hline V (Volume Solution, mL) & 40 & 40 & 40 & 40 \\
\hline $\mathrm{Co}(\mathrm{g}-\mathrm{M} / \mathrm{mL})$ & $1.30 \mathrm{E}-04$ & $6.33 \mathrm{E}-05$ & $3.13 \mathrm{E}-05$ & $1.04 \mathrm{E}-05$ \\
\hline $\mathrm{pHo}$ & 5.5 & 6.6 & 7.2 & 7.7 \\
\hline $\mathrm{Ce}(\mathrm{g}-\mathrm{M} / \mathrm{mL})$ & $<5.00 \mathrm{E}-08$ & $<5.00 \mathrm{E}-08$ & $<5.00 \mathrm{E}-08$ & $<5.00 \mathrm{E}-08$ \\
\hline $\mathrm{Ce} / \mathrm{Co}$ & $<4.84 \mathrm{E}-04$ & & & \\
\hline $\mathrm{pHe}$ & 6.4 & 6.5 & 6.6 & 6.3 \\
\hline $\mathrm{S}(\exp ), \mathrm{g}-\mathrm{M} / \mathrm{g}-\mathrm{APA}(1)$ & $>5.21 \mathrm{E}-03$ & & & \\
\hline $\mathrm{Kd}(\mathrm{mL} / \mathrm{g})=\mathrm{S}(\exp ) / \mathrm{Ce}$ & $>100,000$ & & & \\
\hline
\end{tabular}

(1) Estimated from mass-balance considerations as: $\mathrm{S}=\mathrm{Co}(\mathrm{V} / \mathrm{W})(1-\mathrm{C} / \mathrm{Co})$

All tests with apatite medium removed soluble $\mathrm{U}$ to a value at or below the method detection limit of $0.05 \mathrm{mg} / \mathrm{L}$, a value that is greater than the proposed $\mathrm{MCL}$ for $\mathrm{U}(0.02$ $\mathrm{mg} / \mathrm{L}$ or $2 \mathrm{E}-8 \mathrm{~g} / \mathrm{mL}$ ). However, the more sensitive U-233 tracer studies reported in Section 4.2 indicate that apatite is capable of controlling soluble $U$ to levels well below the proposed MCL criterion. The data for Test Series 1 suggests a Kd value $\geq 100,000$ $\mathrm{mL} / \mathrm{g}$.

The solid residues from the batch tests performed with uranium solution had a maximum loading of $\sim 0.62 \mathrm{wt} \%$ as $\mathrm{U}$ (see Table). Examination of this U-exposed solid phase by XRD did not reveal that any new phases that had formed at this relatively low loading, consistent with the observations of Fuller et al. (2002A, 2002B).

In a separate series of tests, relatively short-term exposure of raw apatite to more concentrated solutions of uranyl ion (containing 250 to $1,000 \mathrm{mg}-\mathrm{U} / \mathrm{L}$ ) did produce dried apatite solid phases having a modified $\mathrm{x}$-ray diffractogram, with weak intensity peaks that match well with principal lines for ICDD Reference 35-0194, uranyl phosphate hydrate, $\left(\mathrm{UO}_{2}\right)_{3}\left(\mathrm{PO}_{4}\right)_{2} \bullet \mathrm{H}_{2} \mathrm{O}$. From mass-balance considerations, the estimated solid-phase loading yielding these observable effects were in the range $\sim 3$ to $9 \mathrm{wt} \% \mathrm{U}$. The weak intensities of the $\mathrm{x}$-ray diffractograms for samples with these relatively high loadings of uranium suggest that the uranyl phosphate phase was poorly crystallized and/or that the crystallites that are formed are very small (possibly formed by homogeneous precipitation). Exposing of the solid samples for several days to a 
controlled environment $\left(\sim 50{ }^{\circ} \mathrm{C}\right.$ and $\left.50 \% \mathrm{RH}\right)$, in an attempt to accelerate the aging of the material, did not significantly affect the $\mathrm{x}$-ray diffractogram. The data of Sandino and Bruno (1992) indicates that uranyl orthophosphate is a highly insoluble phase $\left(\mathrm{pK}_{\mathrm{sp}}=\right.$ 48.5), comparable to autunite (cf. Table 4). As noted previously, yet higher loading of $U$ on apatite appears to induce the formation of autunite phases.

Summary: Apatite demonstrates a very strong affinity for uranyl ion, removing soluble U by sorption and mineral deposition. 


\subsubsection{Vanadium, as $\mathrm{V}(\mathrm{V})$}

\section{Literature Expectations}

Select oxyanions, including $\mathrm{AsO}_{4}{ }^{3-}, \mathrm{VO}_{4}{ }^{3-}, \mathrm{CO}_{3}{ }^{2-}, \mathrm{SO}_{4}{ }^{2-}$ can potentially replace structural $\mathrm{PO}_{4}{ }^{3-}$ in the apatite host (Narasaraju \& Phebe, 1996). Thus vanadate would likely be coprecipitated along with insoluble phosphate mineral phases. Pentavalent vanadium, V(V), is a moderately strong oxidant, comparable to chromate. At elevated $\mathrm{pH}$ values, various solid "polyvanadate" phases may be precipitated from solution.

\section{Experimental Results}

Table 31. Raw Apatite (APA) Contacted 52-h with $\mathrm{M}=\mathrm{V}(\mathrm{V})$ (from sodium vanadate, $\left.\mathrm{Na}_{3} \mathrm{VO}_{4} \cdot 16 \mathrm{H}_{2} \mathrm{O}\right)$ in Synthetic Groundwater Matrix

\begin{tabular}{|c|c|c|c|c|}
\hline Test Series & 1 & 2 & 3 & 4 \\
\hline $\mathrm{W}(\mathrm{g}-\mathrm{APA})$ & 0.8071 & 0.8233 & 0.8011 & 0.8008 \\
\hline $\mathrm{V}$ (Volume Solution, $\mathrm{mL})$ & 40 & 40 & 40 & 40 \\
\hline $\mathrm{Co}(\mathrm{g}-\mathrm{M} / \mathrm{mL})$ & $7.82 \mathrm{E}-04$ & $2.54 \mathrm{E}-04$ & $8.88 \mathrm{E}-05$ & $2.91 \mathrm{E}-05$ \\
\hline $\mathrm{pHo}$ & 7.4 & 7.4 & 7.9 & 7.7 \\
\hline $\mathrm{Ce}(\mathrm{g}-\mathrm{M} / \mathrm{mL})$ & $5.64 \mathrm{E}-04$ & $1.34 \mathrm{E}-04$ & $2.35 \mathrm{E}-05$ & $3.12 \mathrm{E}-06$ \\
\hline $\mathrm{Ce} / \mathrm{Co}$ & $7.21 \mathrm{E}-01$ & $5.28 \mathrm{E}-01$ & $2.65 \mathrm{E}-01$ & $1.07 \mathrm{E}-01$ \\
\hline $\mathrm{pHe}$ & 6.9 & 6.8 & 6.7 & 6.6 \\
\hline $\mathrm{S}(\mathrm{exp}), \mathrm{g}-\mathrm{M} / \mathrm{g}-\mathrm{APA}(1)$ & $8.74 \mathrm{E}-03$ & $4.80 \mathrm{E}-03$ & $2.61 \mathrm{E}-03$ & $1.04 \mathrm{E}-03$ \\
\hline $\mathrm{Kd}=\mathrm{S}(\mathrm{exp}) / \mathrm{Ce}, \mathrm{mL} / \mathrm{g}$ & 15.5 & 35.8 & 111 & 333 \\
\hline $\mathrm{S}(\mathrm{calc}), \mathrm{g}-\mathrm{M} / \mathrm{g}-\mathrm{APA}(2)$ & $8.81 \mathrm{E}-03$ & $4.93 \mathrm{E}-03$ & $2.44 \mathrm{E}-03$ & $1.07 \mathrm{E}-03$ \\
\hline $\mathrm{Kd}=\mathrm{S}(\mathrm{calc}) / \mathrm{Ce}, \mathrm{mL} / \mathrm{g}$ & 15.6 & 36.8 & 104 & 343 \\
\hline
\end{tabular}

(1) Estimated from mass-balance considerations as: $\mathrm{S}=\mathrm{Co}(\mathrm{V} / \mathrm{W})(1-\mathrm{C} / \mathrm{Co})$

(2) Estimated from fitted parameters for a Freundlich isotherm; see Figure 43.

Data summarized in Figures $\mathbf{4 3}$ and $\mathbf{4 4}$ suggest a relatively modest "sorption" of V(V) onto raw Apatite II, in short-term batch testing. As may be noted from Figure 44, "sorption" of vanadium is distinctly nonlinear, with greater removal at lower concentrations. A reference regulatory criterion for V is the DOE Fernald Site FRL goal of $0.038 \mathrm{mg} / \mathrm{L}$; this criterion concentration is too far below the range of experimental data to allow a meaningful projection of performance (given the nonlinearity of the data), but migration of $\mathrm{V}$ should be retarded to some extent.

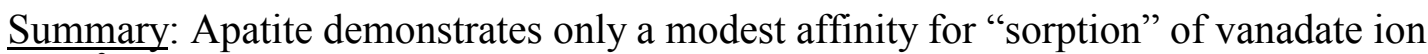
$\left(\mathrm{VO}_{4}{ }^{3-}\right)$. 


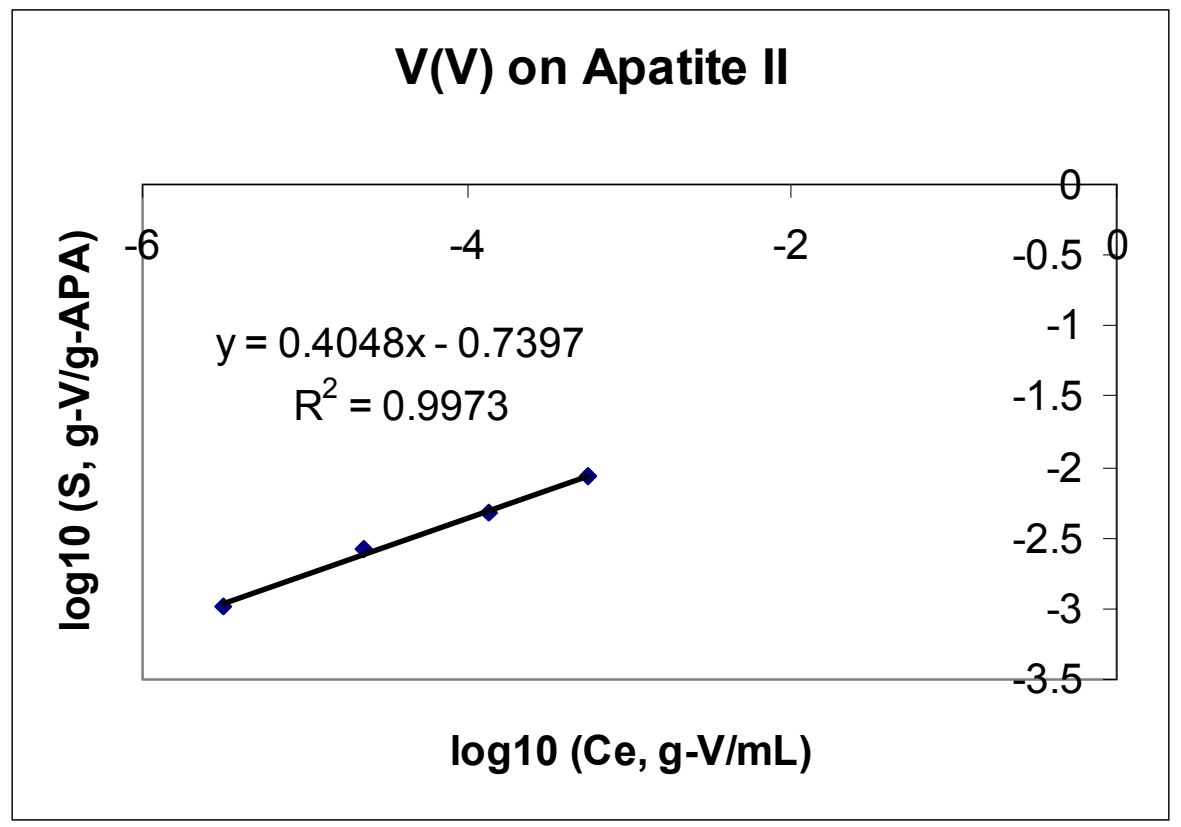

Figure 43. Sorption of V(V) on Raw Apatite. Experimental results are fitted to a linearized Freundlich isotherm (Eq. 4). The units for $\mathrm{S}$ and $\mathrm{C}$ are given in the Figure legend. The isotherm is described by the empirical expression: $\mathrm{S}=0.18^{*}(\mathrm{Ce})^{0.4}$.

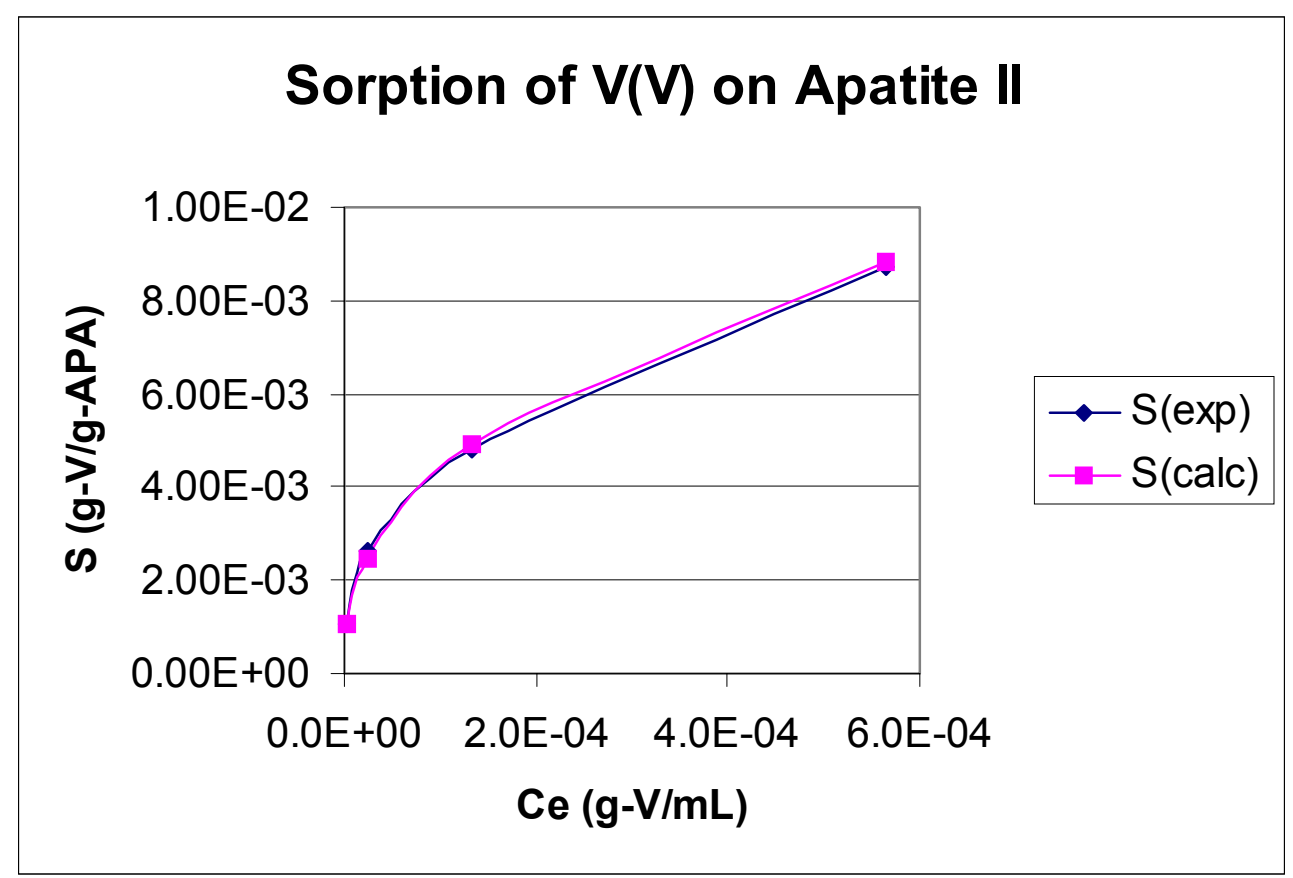

Figure 44. Sorption of Vanadium to Raw Apatite II, presented as a linear isotherm. $\mathrm{S}(\exp )$ and $\mathrm{S}($ calc) are defined in the footnotes to Table 29. 


\subsubsection{Zinc, as $\mathrm{Zn}(\mathrm{II})$}

Literature Expectations

Zinc in dilute solution hydrolyzes negligibly below $\mathrm{pH} 6$, but at $\mathrm{pH}$ values $>7.5$, the neutral species $\mathrm{Zn}(\mathrm{OH})_{2}$ typically becomes the predominant soluble species in aqueous systems (Bodek et al., 1988). As its species formed with the common ligands in surface waters are soluble in neutral and acidic solution, zinc is readily transported in most natural waters and is one of the most mobile heavy metals (Bodek et al., 1988).

Zinc may be sequestered by reaction with apatite, as demonstrated by Wright et al. (1995), Moody \& Wright (1995), and Chen et al. (1997a). Chen et al. (1997a) report that sorptive removal of $\mathrm{Zn}$ (II) by mineral apatite is significantly $\mathrm{pH}$ dependent, with a sharp increase in the removal of soluble $\mathrm{Zn}$ when the final solution $\mathrm{pH}$ value is $\geq 6.5$. Chen et al. (1997a) also report that hopeite $\left[\mathrm{Zn}_{3}\left(\mathrm{PO}_{4}\right)_{2} \bullet 4 \mathrm{H}_{2} \mathrm{O}\right]$ is the principal mineral phase formed by interaction of $\mathrm{Zn}(\mathrm{II})$ and apatite at near-neutral $\mathrm{pH}$ values. Cheung et al. (2001) and Ko et al. (2001) have shown that bone char is effective for the sorptive removal of metals, including $\mathrm{Cd}, \mathrm{Cu}$, and $\mathrm{Zn}$.

The USEPA Secondary Drinking Water Regulation level for zinc is $5 \mathrm{mg} / \mathrm{L}$, and the DOE Fernald site groundwater Final Remediation Level (FRL) is $0.021 \mathrm{mg} / \mathrm{L}$.

Experimental Results

The phase contact is performed in accordance with the Operational Instructions presented in Appendix A1. Divalent zinc is added to synthetic groundwater in the form of the salt zinc sulfate, $\mathrm{ZnSO}_{4} \cdot 7 \mathrm{H}_{2} \mathrm{O}$. Not all of the added $\mathrm{Zn}$ was soluble in the initial stock solution, which was filtered before use in preparing serial dilutions in synthetic groundwater.

Table 32. Raw Apatite (APA) Contacted 52-h with Zn(II) (from zinc sulfate) in Synthetic Groundwater

\begin{tabular}{|c|c|c|c|c|}
\hline Test Series & 1 & 2 & 3 & 4 \\
\hline W (g-APA) & 0.6300 & 0.5371 & 0.5017 & 0.5280 \\
\hline V (Volume Solution, mL) & 25 & 25 & 25 & 25 \\
\hline Co (g-M/mL) & $2.12 \mathrm{E}-04$ & $3.73 \mathrm{E}-05$ & $8.07 \mathrm{E}-6$ & $4.95 \mathrm{E}-06$ \\
\hline $\mathrm{pHo}$ & 6.6 & 7.0 & 7.3 & 7.4 \\
\hline $\mathrm{Ce}(\mathrm{g}-\mathrm{M} / \mathrm{mL})$ & $2.07 \mathrm{E}-06$ & $3.66 \mathrm{E}-07$ & $6.98 \mathrm{E}-08$ & $5.08-08$ \\
\hline $\mathrm{Ce} / \mathrm{Co}$ & $9.74 \mathrm{E}-03$ & $9.93 \mathrm{E}-03$ & $8.53 \mathrm{E}-03$ & $1.03 \mathrm{E}-02$ \\
\hline $\mathrm{pHe}$ & 6.4 & 6.6 & 6.7 & 6.6 \\
\hline $\mathrm{S}(\mathrm{g}-\mathrm{M} / \mathrm{g}-\mathrm{APA})-$ experiment $(1)$ & $8.33 \mathrm{E}-03$ & $1.72 \mathrm{E}-03$ & $3.99-04$ & $2.32 \mathrm{E}-04$ \\
\hline $\mathrm{Kd}(\mathrm{mL} / \mathrm{g})=$ S(exp)/Ce & 4,030 & 4,690 & 5,790 & 4,060 \\
\hline $\mathrm{S}(\mathrm{g}-\mathrm{M} / \mathrm{g}-\mathrm{APA})-$ Freundlich $(2)$ & $8.52 \mathrm{E}-03$ & $1.68 \mathrm{E}-03$ & $3.51 \mathrm{E}-04$ & $2.64 \mathrm{E}-04$ \\
\hline $\mathrm{Kd}(\mathrm{mL} / \mathrm{g})=\mathrm{S}(\mathrm{calc}) / \mathrm{Ce}$ & 4,130 & 4,590 & 5,090 & 3,910 \\
\hline$(1) \mathrm{Es}$ & & & &
\end{tabular}

(1) Estimated from mass-balance considerations as: $\mathrm{S}=\mathrm{Co}(\mathrm{V} / \mathrm{W})(1-\mathrm{C} / \mathrm{Co})$

(2) Estimated from fitted parameters for a Freundlich isotherm; see Figure 45. 
In Figure 45, the sorption data are presented as a linearized Freundlich isotherm (see Equation 4). The Secondary Drinking Water Regulation (SDWR) for $\mathrm{Zn}$ is $5 \mathrm{mg} / \mathrm{L}$. Using the parameters for the Freundlich isotherm presented in Figure $46(n=4)$, the projected $\mathrm{Kd}$ for $\mathrm{Zn}$ at the $\mathrm{SDWR}$ is $\sim 3,910 \mathrm{~mL} / \mathrm{g}$.

In Figure 46, short-term (52-h) sorption data are presented in the form of a simple linear isotherm. Linear regression analysis on the experimental data yields a conditional distribution coefficient $\mathrm{Kd}=4,056 \mathrm{~mL} / \mathrm{g}\left(\mathrm{r}^{2}=0.9984\right)$, a value greater than the defined success criterion of $\mathrm{Kd}>1,000 \mathrm{~mL} / \mathrm{g}$.

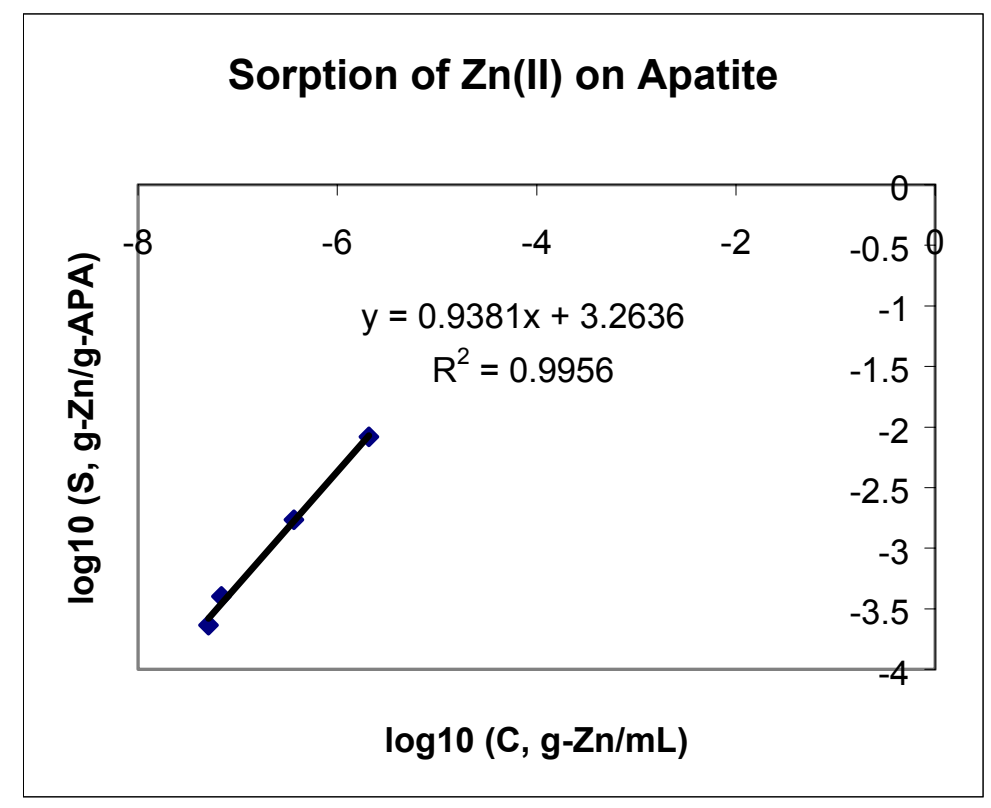

Figure 45. Sorption of $\mathrm{Zn}$ (II) to Raw Apatite II, presented as a Freundlich Sorption Isotherm. The isotherm is described by the empirical expression: $\mathrm{S}($ calc., g-Zn/g-APA) = $1835 \mathrm{x}(\mathrm{Ce}, \mathrm{g}-\mathrm{Zn} / \mathrm{mL})^{0.938}$. 


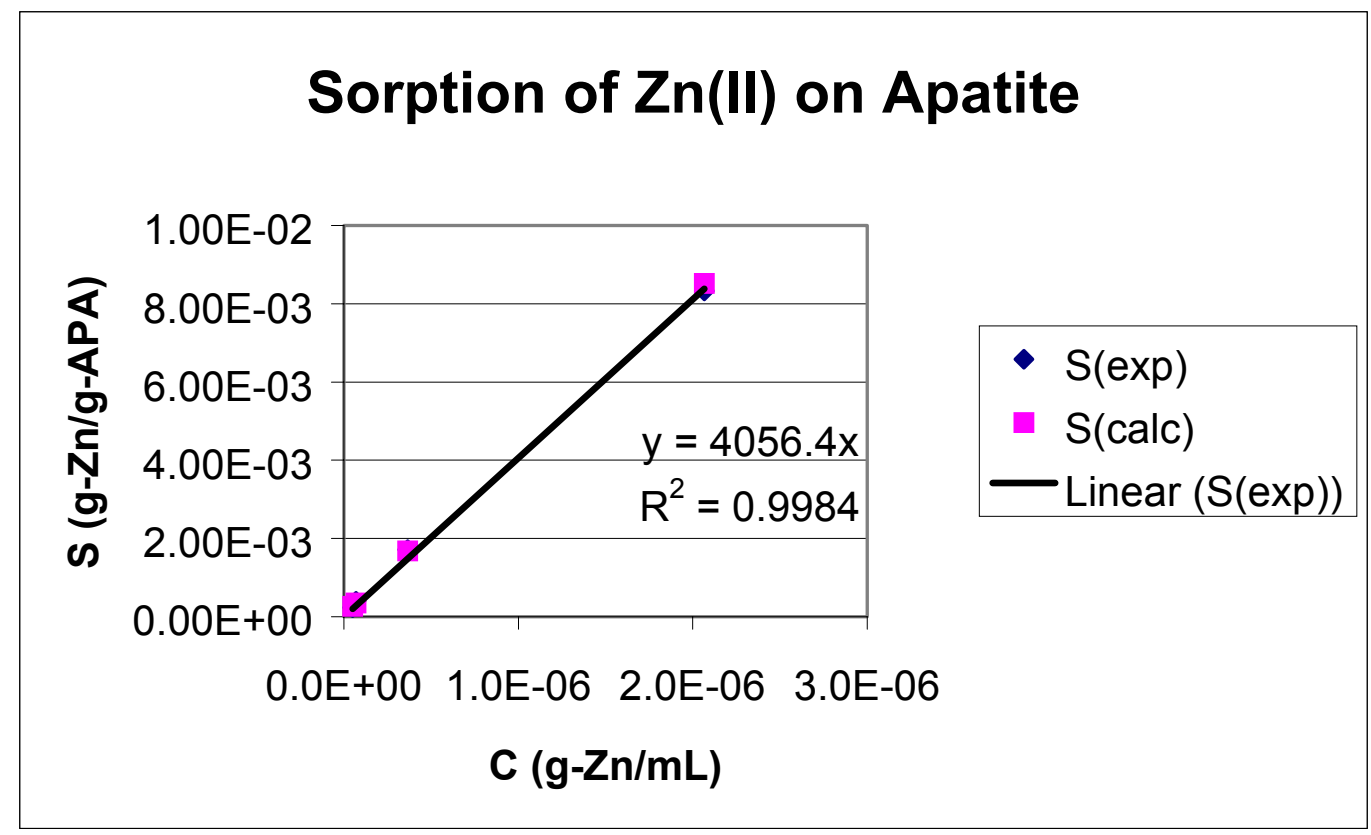

Figure 46. Sorption isotherm for $\mathrm{Zn}$ (II) partitioning between solution and solid phases. $(\mathrm{APA}=$ ground raw biogenic apatite). $\mathrm{S}(\exp )$ and $\mathrm{S}($ calc) are defined in the footnotes to Table 30. Regression analysis (for data as a linear isotherm) yields $\mathrm{Kd}=4060 \mathrm{~mL} / \mathrm{g}$. 


\subsubsection{Summary and Comparison of Single Metal Batch Test Results}

In the present investigation, biogenic apatite (Apatite II) is evaluated as a "sorbent" for the removal of select priority metals in aqueous solution (synthetic DOE Y-12 Plant groundwater). The high reactivity of Apatite II relative to other phosphate reagents comes from the unusual structure of the solid. Most of the material is porous amorphous hydroxyapatite. The amorphous structure is relatively reactive and is sufficiently soluble to provide phosphate ion to solution, locally exceeding the solubility limit of many metalphosphate phases and resulting in precipitation reactions. At the same time, the random nanocrystals within Apatite II provide the structure for nucleating the precipitates to form crystallites on the host material surface. The apatite surface itself is an excellent sorbent or ion exchange medium for many cations; for example, uranium (as the uranyl ion) is first sorbed to the surface, then at higher loading (several weight percent metal), crystalline phases begin to appear as $\mathrm{U}$ replaces $\mathrm{Ca}$ in the host material.

Three types of substitutions that can occur in apatite structures:

- Cations, e.g., $\mathrm{Pb}^{2+}, \mathrm{Sr}^{2+}, \mathrm{Zn}^{2+}, \mathrm{Mn}^{+2}, \mathrm{Ce}^{3+}$, etc., can substitute for $\mathrm{Ca}^{2+}$;

- Oxyanions, e.g., $\mathrm{AsO}_{4}{ }^{3-}, \mathrm{VO}_{4}{ }^{3-}, \mathrm{CO}_{3}{ }^{2-}, \mathrm{SO}_{4}{ }^{2-}$ can replace structural $\mathrm{PO}_{4}{ }^{3-}$;

- Anions $\mathrm{F}^{-}, \mathrm{Cl}^{-}$can exchange with $\mathrm{OH}^{-}$. (fluoroapatite is the least soluble)

In our investigations, the affinity for priority cationic contaminants on Apatite II follows the approximate series (ranked by decreasing magnitude of the contaminant distribution coefficient, $\mathrm{Kd}$, at lowest solution phase residual concentration evaluated):

$$
\mathrm{UO}_{2}^{+2}>\mathrm{Pb}^{+2} \geq \mathrm{Th}^{+4}>\mathrm{Cd}^{+2}>\mathrm{Mn}^{+2} \sim \mathrm{Zn}^{+2}>\mathrm{Cu}^{+2} \sim \mathrm{SbO}^{+} \sim \mathrm{Hg}^{+2}>\mathrm{Ni}^{+2}>\mathrm{Sr}^{+2}>\mathrm{Ba}^{+2}
$$

In the test plan for this project, we established a success criterion of $\mathrm{Kd} \geq 1,000 \mathrm{~mL} / \mathrm{g}$. By this criterion, the migration rate of contaminants in typical groundwaters would be retarded by $\geq 1,000$-fold. Evaluated metals that met this project-defined success criterion were $\mathrm{U}, \mathrm{Pb}, \mathrm{Th}, \mathrm{Cd}, \mathrm{Mn}, \mathrm{Zn}, \mathrm{Cu}, \mathrm{Sb}$ and $\mathrm{Hg}$. Ferrous ion $\left(\mathrm{Fe}^{2+}\right)$ was not especially strongly sorbed to apatite $(\mathrm{Kd}>200 \mathrm{~mL} / \mathrm{g})$, but its binding may be important due to its relatively high concentrations (up to $10 \mathrm{mg} / \mathrm{L}$ ) in strongly anoxic groundwater, and its possible association with apatite fines.

Figure 47 illustrates the isotherms for some of the metals that meet or approach this success criterion. The interaction between Th and apatite is shown to produce a thorium phosphate phase, containing only a small residual of the calcium ion in the original apatite material. It is likely that at least some of the Th is precipitated homogeneously by phosphate ion in the aqueous phase, rather than sorption of the Th to the apatite surface.

Removal of contaminant oxyanions to pre-existing apatite phase in short-term batch tests was less successful; the approximate order of preference for sorption is:

$$
\mathrm{VO}_{4}^{-3}>\mathrm{MoO}_{4}^{-2}>\mathrm{SeO}_{3}^{-2}>\mathrm{AsO}_{4}^{-3}>\mathrm{CrO}_{4}^{-2}>\mathrm{TcO}_{4}^{-}
$$


None of the oxyanions tested met the project-defined success criterion of $\mathrm{Kd} \geq 1,000$ $\mathrm{mL} / \mathrm{g}$ in the range of contaminant concentrations studied, but several (e.g., $\mathrm{VO}_{4}^{-3}$ and $\mathrm{SeO}_{3}^{-2}$ ) evidenced distinctly nonlinear sorption isotherms, with projected strong sorption for low levels of soluble contaminant. The observed sorption of selenium was likely affected by the induced acidity of the solution phase (Monteil-Rivera et al., 1999), and possibly by bioreduction under the testing conditions.

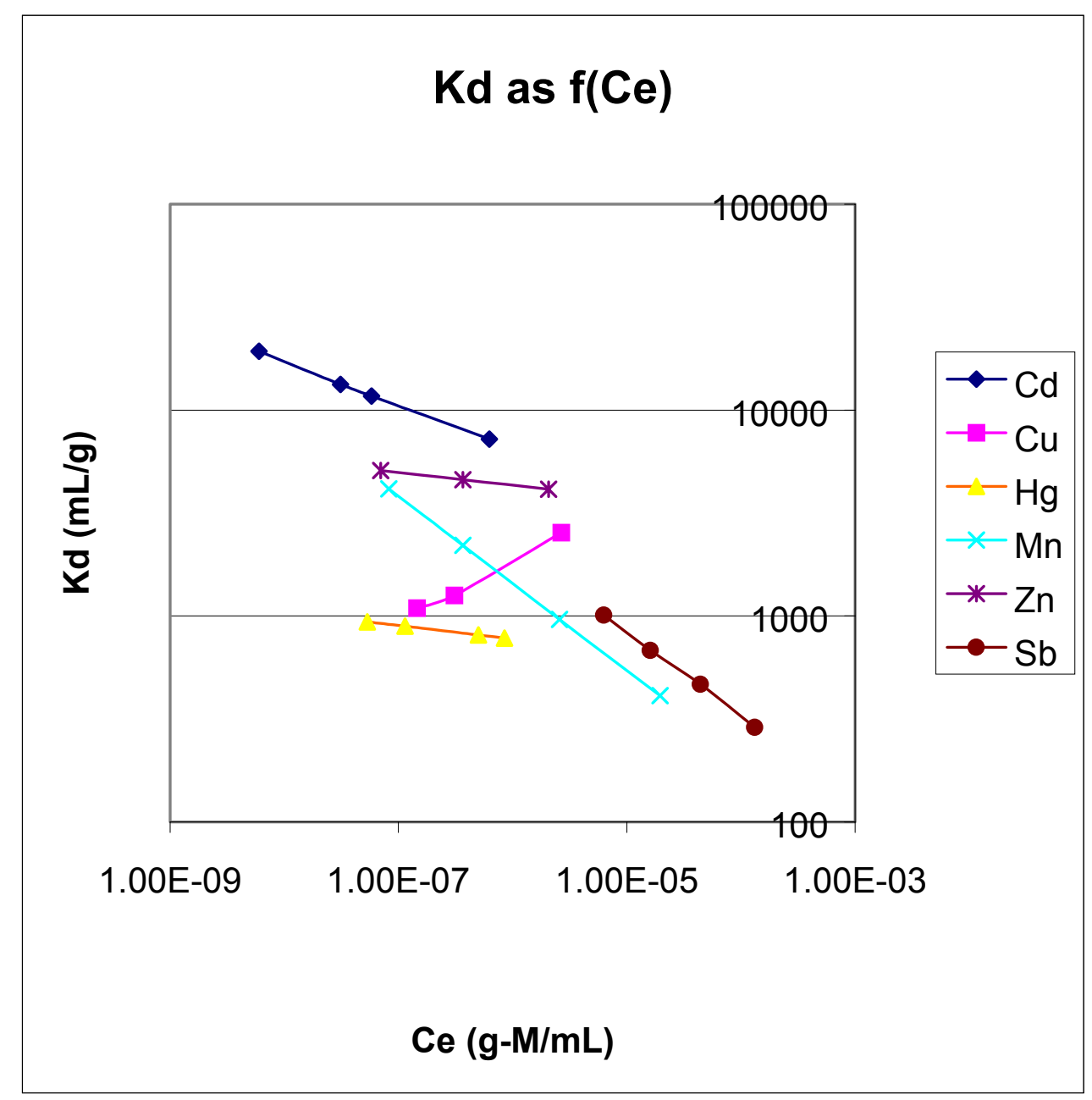

Figure 47. Distribution Coefficient (Kd, $\mathrm{mL} / \mathrm{g}$ ) For Select Metals On Apatite II As A Function Of Equilibrium Concentration in Solution Phase $(\mathrm{Ce}, \mathrm{g} / \mathrm{mL})$. (Note: $1 \mathrm{ppm}=$ $1.00 \mathrm{E}-06 \mathrm{~g} / \mathrm{mL} ; 1 \mathrm{ppb}=1.00 \mathrm{E}-09 \mathrm{~g} / \mathrm{mL}$ ). Not illustrated are data for $\mathrm{U}$, Th, and $\mathrm{Pb}$. 


\subsection{Batch Tests: Experimental Design (Multi-Metal Experiments; Project Task 1.2.5)}

The survey results reported in Section 4.3 are for the removal of individual metals from solution. A very large number of insoluble apatite and other phosphate phases are known to exist in nature, containing multiple metal constituents. Possible synergistic interactions among priority metals were investigated using a central composite statistical experimental design.

The experimental design is called a four-factor central composite design run in three blocks. Each factor will be run at five different levels. There are six center replicates, two in each experimental block. There are thirty total experiments, ten per block. The running order of the experiments was randomized within each block.

The intent of this study is to contact 3 different series of spiked solutions with Apatite to evaluate any possible competition or synergism among the metals for take-up by the Apatite. The four metals of concern ("factors") in this study are uranium, mercury, cadmium and lead. These are added in prescribed combinations, according to a statistical experimental design. The experimental design is called a four-factor central composite design run in three blocks. Each factor will be run at five different levels. There are six center replicates, two in each experimental block. There are thirty total experiments, ten per block. The running order of the experiments was randomized within each block. See Exhibit A-2 for a description of the experimental design.

For this series of experiments, the metals of interest were supplemented into synthetic BYBY groundwater, and then the solution was contacted for an interval of 50-h with ground raw apatite II (01-0263) at a liquid to solid ratio of $50(\mathrm{w} / \mathrm{w})$. Exhibit A-2 presents a summary of regression analysis of Ce ("equilibrium" solution phase concentration of metal after contact with apatite) and the computed Kd values (distribution coefficient for the solid phase) from the Multi-Metal Experimental Design.

All multi-metal experiment (MME) solution phase results for lead $(\mathrm{Pb})$ after contact with apatite were reduced to the analytical detection limit $(0.05 \mathrm{mg} / \mathrm{L})$. Therefore, no statistical conclusion may be drawn for this metal as a factor. Similarly, a high proportion (20 of 30) of the MME results for uranium (U) in solution after contact with apatite were reduced to the analytical detection limit $(0.02 \mathrm{mg} / \mathrm{L})$. For those solutions with detectable $U$ after phase contact, the computed $\mathrm{Kd}$ value averaged $(2.9 \pm 1.1) \times 10^{4}$ $\mathrm{mL} / \mathrm{g}$. In the limited Single Metal Experiment (SME) survey (Section 4.3), all (4 of 4) post-contact solution phase results were at the analytical detection limit. The factors of liquid to solid ratio, contact time, and initial solution $\mathrm{pH}$ values were held at the same values for both the SME and MME phase contacts. All post-contact solutions were promptly filtered through $0.45-\mu \mathrm{m}$ media, to permit analytical determination of soluble metal concentrations. 
For cadmium $(\mathrm{Cd})$ and mercury $(\mathrm{Hg})$, partitioning to the solid (apatite) phase was statistically greater in the MME than had been observed in the limited SME survey; see Exhibit A-3 for data summaries. This is a positive synergistic effect for these metals, possibly caused by co-precipitation with other metals in the mixture. Comparison between SME survey results and all MME results are presented in Figure $48(\mathrm{Hg})$ and Figure $49(\mathrm{Cd})$.

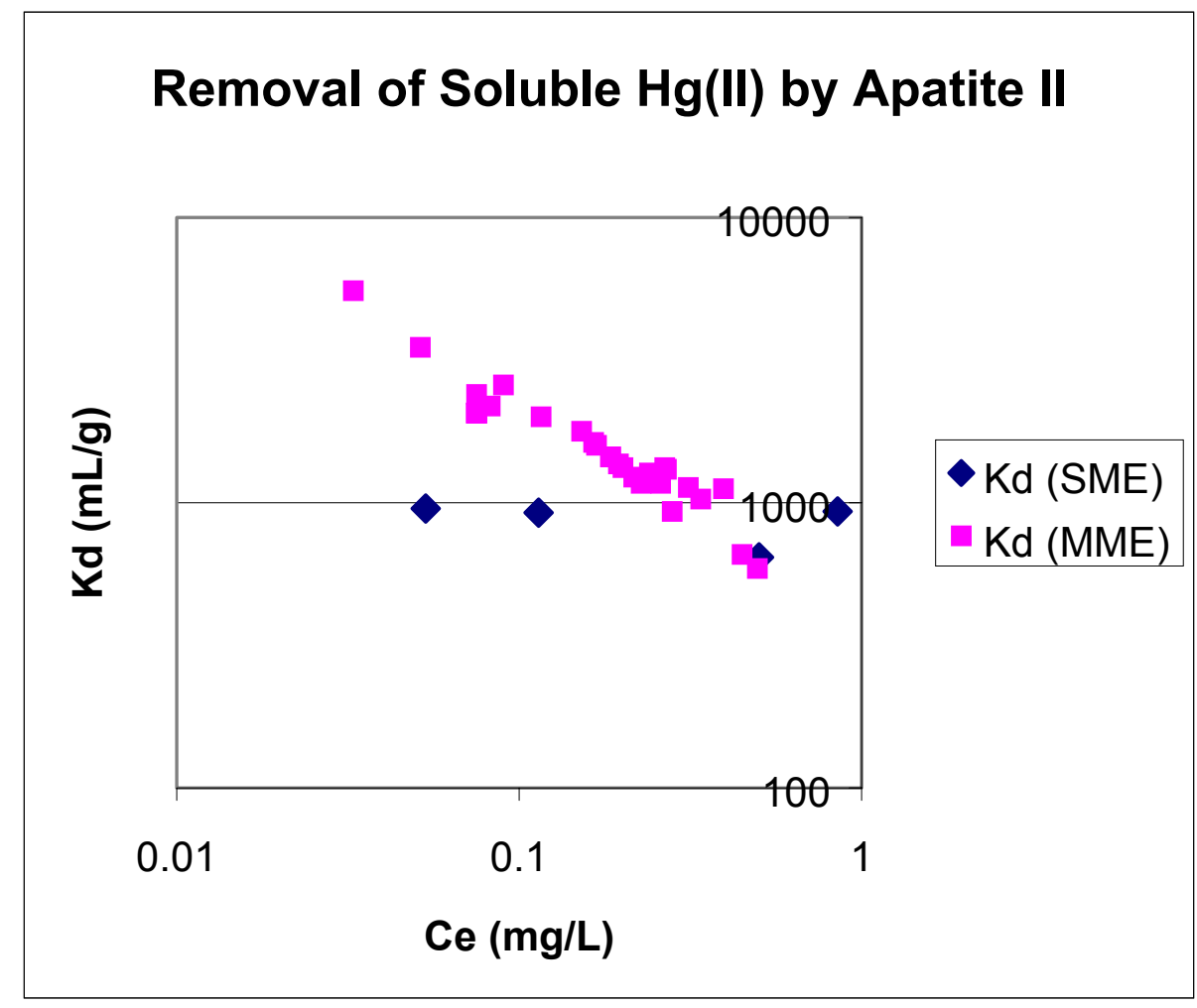

Figure 48. A comparison of computed solid-phase distribution coefficient (Kd) vs. the corresponding equilibrium solution phase metal concentration $(\mathrm{Ce})$ for mercury in the Single-Metal Experiment (SME) and the Multi-Metal Experiment (MME). 


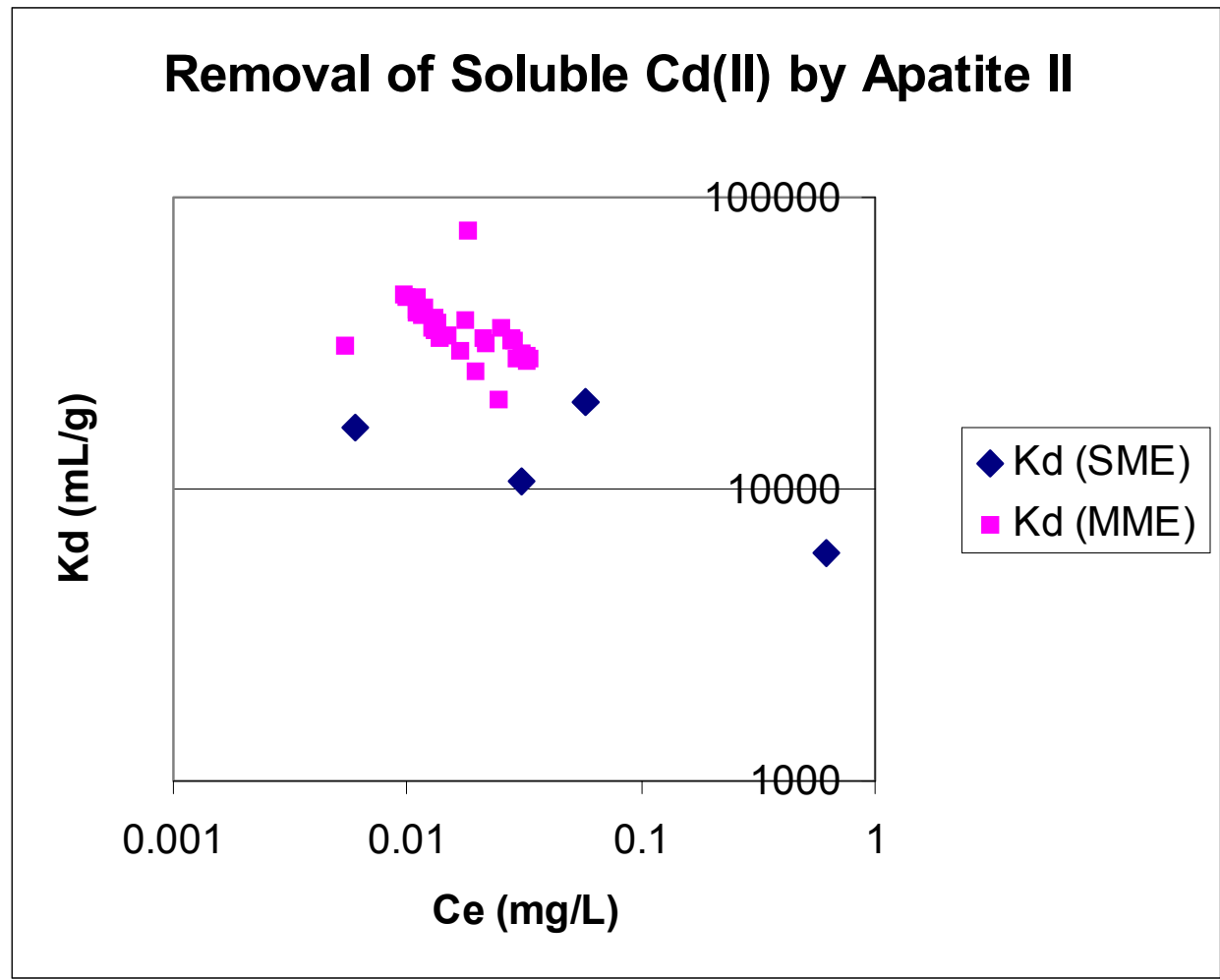

Figure 49. A comparison of computed solid-phase distribution coefficient (Kd) vs. the corresponding equilibrium solution phase metal concentration $(\mathrm{Ce})$ for cadmium in the Single-Metal Experiment (SME) and the Multi-Metal Experiment (MME). See Exhibit A-3 for a statistical summary. 


\subsection{Treatability Demonstration: Use of APA-C to Treat Wastewater}

During the course of this investigation, MCLinc, in conjunction with Florida International University and Weskem, had the opportunity to treat a DOE legacy wastewater at the Paducah Gaseous Diffusion Plant (PGDP). This work was not supported by NETL, but a brief synopsis is included here to illustrate the ability of apatite to treat waste at a moderate scale, in a manner analogous to the use of apatite as a permeable reactive barrier. The water to be treated was an inventory of over 100,000 gal. of "mixed" aqueous waste, containing soluble radionuclides ( $\left.\mathrm{U}, \mathrm{Np}, \mathrm{TcO}_{4}{ }^{-}\right)$and $\mathrm{RCRA}-$ regulated toxic metals $(\mathrm{Cd}, \mathrm{Zn}, \mathrm{Cu})$. The negotiated compliance goals required very high removal efficiencies for several metal species, especially cadmium (see Table 4.5-1). Treatability tests (jar tests) were performed with select solid media and authentic and simulated Site water. Media investigated included activated carbon (several forms with significantly different performance), zero-valent iron (ZVI), iron co-precipitation, synthetic ion exchange media, mineral zeolite, activated alumnina (Rhône-Poulenc, Inc.), and charred biogenic apatite (Apatite IIC and commercial cow bone char, Waterlink BC, Barneby Sutcliffe).

In jar tests with authentic wastewater, both ZVI (in the form of steel wool) and iron coprecipitation (with use of ferric sulfate) produced colloidal contaminant-laden particulate phase that was difficult to flocculate and filter. Mineral zeolite (Cameron Carbon) and synthetic weak cation exchange medium (Amberlite IRG-50) were not especially effective for any of the contaminants of concern in the raw water; anion exchange medium (Dowex $21 \mathrm{~K}$ ) removed pertechnetate and a portion of uranium as anionic carbonate complex, but relatively inexpensive acid-washed coal (AWC; Cameron CarbonCG6/AW 12x40 mesh) was also effective for this purpose (see Section 4.3.15). Of the media evaluated, only apatite derivatives were capable of reducing cadmium to the challenging compliance requirements. Based upon the batch-treatment survey, biogenic apatite was selected for the removal of $\mathrm{Cd}, \mathrm{U}$, and $\mathrm{Zn}$. Acid-washed coal was selected for the removal of Tc-99.

Since the intended application involved above-surface treatment (packed media contained within flow-through drums), we selected the charred form of apatite products to minimize the potential to develop nuisance odor. In Table 33, select apatite products are compared for the treatment of a sample of authentic PGDP wastewater. Media used in the treatability study were screened to $8 / 20$ mesh $(\sim 0.84$ to $2.4 \mathrm{~mm})$, to compensate for any differences in particle size, and phases (liquid/solid $\sim 160 \mathrm{w} / \mathrm{w}$ ) were contacted $\sim 20$-h before separation $\left(0.45-\mu \mathrm{m}\right.$ filter). Commercial bone char (Waterlink ${ }^{\circledR} \mathrm{BC} 830$ ) performed very well for removal of soluble $\mathrm{Cd}$ and $\mathrm{Zn}$, but performance for $\mathrm{U}$ was less effective than that of raw fish bone (01-380) or fish bone char (Apatite IIC). The relatively modest performance of the as-received commercial bone char with respect to soluble uranium was also confirmed by testing with ${ }^{233} \mathrm{U}$-traced synthetic BYBY water (Figure 50). The commercial animal bone char contains a residual of $10.8 \mathrm{wt} \%$ organic char; removing the organic matter (by the LOI procedure, i.e., by heating at $400{ }^{\circ} \mathrm{C}$ for 16-h) improves performance for removal of soluble $\mathrm{U}$, but not to the extent noted for the more porous fish bone char (Apatite IIC). 
For the data in Table 33, the soluble U after contact with Apatite C400 is at or near the reporting limit ( $150 \mathrm{ppb}$ ) by the analytical technique used (ICP-OES). Residual concentration of soluble $\mathrm{P}$ in the wastewater sample after contact with apatite is modest (mean value $\sim 1.6 \mathrm{mg}-\mathrm{P} / \mathrm{L}$, or $\sim 0.5 \mathrm{E}-4 \mathrm{~mol} / \mathrm{L}$ ), compared to the release of $\mathrm{P}$ in deionized water (see Table 8), suggesting that $\mathrm{P}$ is either scavenged from the aqueous phase by reaction with metal ions in the wastewater and/or the wastewater composition (ionic strength, $\left[\mathrm{Ca}^{2+}\right]$, etc.) inhibits apatite solubility (note that contact of the solution with apatite decreases the concentration of soluble $\mathrm{Ca}$ ).

Table 33. Batch-Treatment of a Wastewater Sample from Paducah Gaseous Diffusion Plant*

\begin{tabular}{|c|c|c|c|c|c|}
\hline Attribute & Unit & $\begin{array}{c}\text { Control } \\
(01-0339) \\
\end{array}$ & $\begin{array}{c}\text { Raw Apatite } \\
(01-0380)\end{array}$ & $\begin{array}{l}\text { Apatite Char } \\
\text { (Apatite IIC) }\end{array}$ & $\begin{array}{c}\text { Waterlink } \AA \\
(\mathrm{BC}-830)\end{array}$ \\
\hline $\mathrm{pH}$ & Standard & 7.23 & 7.26 & 7.49 & 8.77 \\
\hline $\mathrm{P}$ & $\mathrm{mg} / \mathrm{L}$ & $<0.05$ & 2.12 & 1.19 & 1.42 \\
\hline $\mathrm{Ca}$ & $\mathrm{mg} / \mathrm{L}$ & 86.7 & 57.6 & 36.8 & 47.9 \\
\hline \multirow[t]{2}{*}{$\mathrm{Cd}$} & $\mathrm{mg} / \mathrm{L}$ & 12.1 & 0.103 & 0.013 & 0.025 \\
\hline & $\mathrm{Kd}(\mathrm{mL} / \mathrm{g})$ & & 1,690 & 14,500 & 8,040 \\
\hline \multirow[t]{2}{*}{$\mathrm{U}$} & $\mathrm{mg} / \mathrm{L}$ & 16.2 & 0.7 & $\leq 0.15$ & 9.08 \\
\hline & $\mathrm{Kd}(\mathrm{mL} / \mathrm{g})$ & & 3,480 & $\geq 16,300$ & 123 \\
\hline \multirow[t]{2}{*}{$\mathrm{Zn}$} & $\mathrm{mg} / \mathrm{L}$ & 3.46 & 0.28 & 0.029 & 0.057 \\
\hline & $\mathrm{Kd}(\mathrm{mL} / \mathrm{g})$ & & 1,780 & 18,500 & 9,360 \\
\hline Hardness & $\begin{array}{c}\mathrm{mg} / \mathrm{L} \\
\left(\text { as } \mathrm{CaCO}_{3} \text { ) }\right.\end{array}$ & 318 & 242 & 195 & 251 \\
\hline
\end{tabular}

* Control is untreated solution. All treatment media are screened to select a size range of $\sim 0.84-2.4 \mathrm{~mm}$, and used at a solid to liquid ratio of $\sim 1: 160(\mathrm{w} / \mathrm{w})$. Phases were contacted by tumbling for $\sim 20$-h before separation with $0.45-\mu \mathrm{m}$ pore membrane filter medium. Inductively Coupled Plasma with Optical Emission Spectroscopy (ICP-OES) is used to estimate metal ion concentrations in the filtrate. The conditional distribution coefficient $(\mathrm{Kd})$ is defined in Eq. 1. 


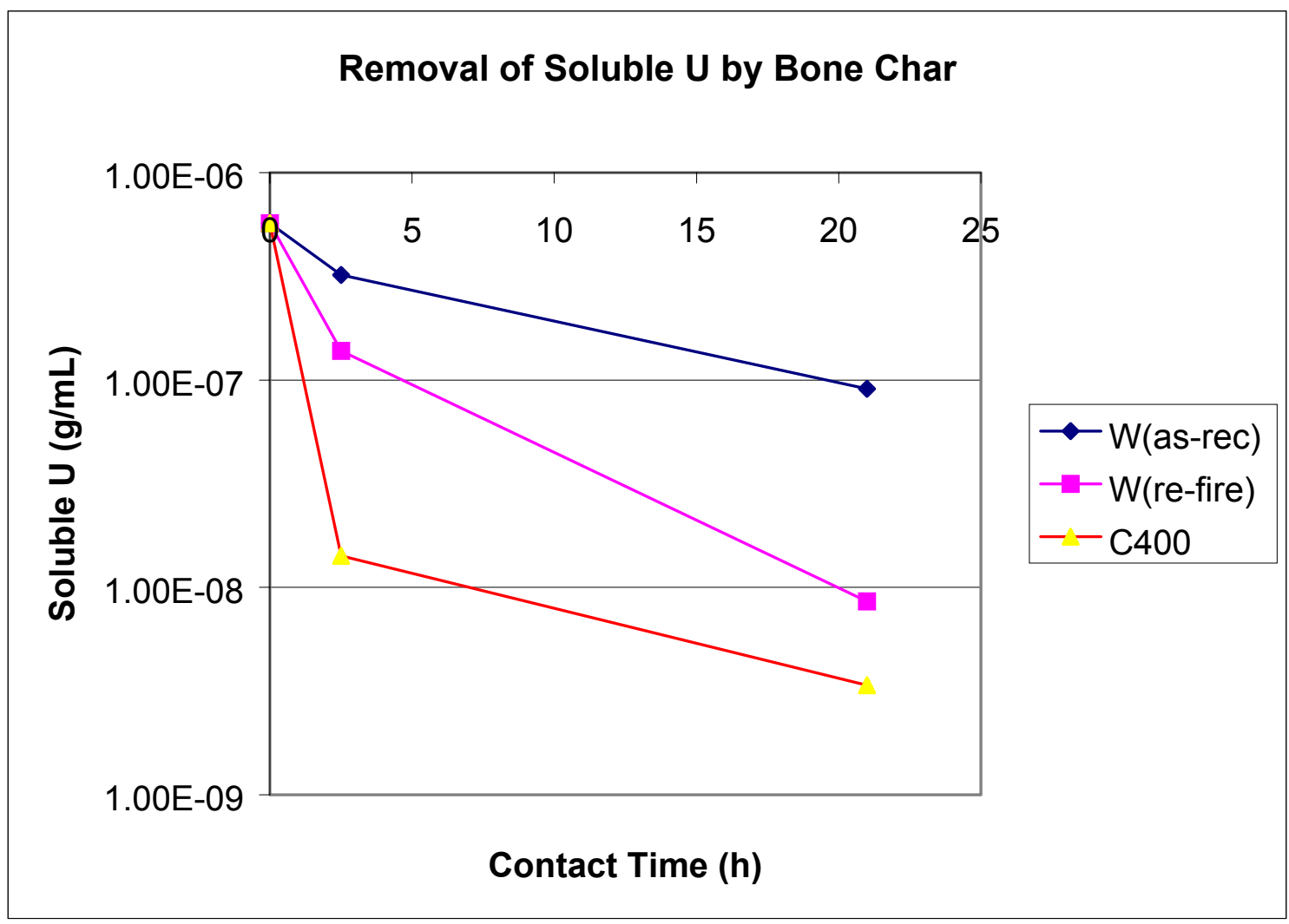

Figure 50. Removal of Soluble Uranium from Synthetic BYBY Water with use of Bone Char Products. Synthetic groundwater is supplemented with ${ }^{233} U$ isotope, and the total soluble $U$ is estimated by the activity in the solution phase filtered through $0.2-\mu \mathrm{m}$ medium. Treatment media are screened to a size range of $\sim 0.84-2.4 \mathrm{~mm}$, and used at a solid to liquid ratio of $\sim 1: 75(\mathrm{w} / \mathrm{w})$. Commercial bone char from Waterlink $($ ("W") is tested "as-received" and after "re-firing" in an oxidative environment (i.e., medium held in a muffle furnace at $400{ }^{\circ} \mathrm{C}$ for 16 -h, for a loss-on-ignition of $10.8 \mathrm{wt} \%$ ). "C400" is fishbone char (i.e., Apatite IIC). The computed conditional distribution coefficients (Kd, $\mathrm{mL} / \mathrm{g}$ ) for $\mathrm{U}$ with use of the media at 20-h contact are: "W (as-rec)" 400; "W (re-fire)" $\sim 5,000$, and "C-400" 12,700.

The authentic as-received wastewater samples were noted to contain some portion of contaminants (especially $U$ ) that were associated with insoluble fine $(\sim 1-5 \mu \mathrm{m})$ ironbearing particulate phase, thus requiring filtration of the aqueous phase to meet the stringent treatment goals. The selected treatment train consisted of pre-filtration, AWC, APAC, and post-filtration. Some lots of wastewater were noted to contain very high alkalinity $\left(>1,000 \mathrm{mg} / \mathrm{L}\right.$ as $\left.\mathrm{CaCO}_{3}\right)$; these lots required $\mathrm{pH}$-adjustment (to $\mathrm{pH}<6$ ) for effective treatment. The overall average field performance of the selected treatment train (media in flow-through 55-gal drum canisters at an aqueous flux $\sim 2.5$ GPM, or $\sim 0.25$ $\mathrm{mL} / \mathrm{min} / \mathrm{cm}^{2}$ ) is given in Table 34 . 
Table 34. Overall Removal of Select Contaminants from PGDP Wastewater with use of Acid-Washed Coal (AWC) and Apatite IIC.

\begin{tabular}{ccccc}
\hline Contaminant & $\begin{array}{c}\text { Ave. Feed } \\
(\mathrm{mg} / \mathrm{L})\end{array}$ & $\begin{array}{c}\text { Ave. Effluent } \\
(\mathrm{mg} / \mathrm{L})\end{array}$ & $\begin{array}{c}\text { Treatment Goal } \\
(\mathrm{mg} / \mathrm{L})\end{array}$ & $\begin{array}{c}\text { Ave. } \\
\text { \% Removed }\end{array}$ \\
\hline $\mathrm{U}$ & 18.1 & 0.045 & 0.378 & $>99.7$ \\
$\mathrm{Cd}$ & 1.67 & 0.0087 & 0.0099 & $>99.5$ \\
$\mathrm{Zn}$ & 4.6 & 0.015 & 0.216 & $>99.7$ \\
\hline
\end{tabular}

\subsection{Leachability Tests for Solid Phase Apatite Residuals}

This series of experiments supports Project Task 1.2.6: Characterization of the exposed high-level Apatite material, as described in the Test Plan (MCL-614-TP)

A bulk material, designated "Exposed Dry Apatite" (EDA) was prepared for use in leach testing. The solid phase is raw apatite (01-0263) that has been exposed to a mixture of $\mathrm{UO}_{2}\left(\mathrm{NO}_{3}\right)_{2} \bullet 6 \mathrm{H}_{2} \mathrm{O}, \mathrm{Cd}\left(\mathrm{NO}_{3}\right)_{2} \bullet 4 \mathrm{H}_{2} \mathrm{O}, \mathrm{HgCl}_{2}$, and $\mathrm{Pb}\left(\mathrm{NO}_{3}\right)_{2}$ stock solutions, as used in the Multi-Metal Experiment (cf. Section 4.4). The filtered solution phase, before contact with APA, contained U $(\sim 104 \mathrm{mg} / \mathrm{L}), \mathrm{Cd}(\sim 104 \mathrm{mg} / \mathrm{L}), \mathrm{Hg}(\sim 13.8 \mathrm{mg} / \mathrm{L})$, and lead $(\sim$ $110 \mathrm{mg} / \mathrm{L})$. Phases were contacted, at a liquid/solid mass ratio of 5.0, by tumbling for 50$\mathrm{h}$, and then the phases were separated by centrifugation. Isolated solids were then oven dried at $115^{\circ} \mathrm{C}$. Aqueous filtrate was analyzed for residual soluble metals, and metal loading (inventory) was calculated by mass balance.

\subsubsection{TCLP of Metal-Exposed Apatite (Project Task 1.2.4)}

We tested replicate samples of EDA product by the TCLP protocol (SW846 Method 1311). Results are summarized in Table 35. All regulated metals that leached from the sample were below their regulatory toxicity criteria. Uranium does not have a defined toxicity criterion, but the EPA action level for $U$ in groundwater is $32 \mathrm{pCi} / \mathrm{L}$, or $\sim 44 \mu \mathrm{g} / \mathrm{L}$ for natural U (Abdelouas et al., 1999; Morrison et al., 2001).

Table 35. TCLP Extraction of Exposed Dry Apatite-II (EDA) from Short-Term Exposure Study

\begin{tabular}{ccccc}
\hline Metal & $\begin{array}{c}\text { Inventory } \\
(\mathrm{mg} / \mathrm{kg})\end{array}$ & TCLP Criterion $(\mu \mathrm{g} / \mathrm{L})$ & $\begin{array}{c}\text { TCLP Result } \\
(\mu \mathrm{g} / \mathrm{L})\end{array}$ & $\begin{array}{c}\text { Wt\% Inventory } \\
\text { Extracted }\end{array}$ \\
\hline $\mathrm{Cd}$ & 488 & 1,000 & 26 & 0.1 \\
$\mathrm{Hg}$ & 67 & 200 & $<75$ & $<2.2$ \\
$\mathrm{~Pb}$ & 492 & 5,000 & 4,300 & 17.6 \\
$\mathrm{U}$ & 236 & $\mathrm{NA}$ & $<30$ & $<0.3$ \\
$\mathrm{Ca}$ & 207,800 & $\mathrm{NA}$ & 287,700 & 2.8 \\
$\mathrm{Mg}$ & 4,000 & $\mathrm{NA}$ & 86,500 & 43.2 \\
$\mathrm{P}$ & 104,900 & $\mathrm{NA}$ & 147,000 & 2.8 \\
\hline
\end{tabular}

Average of three determinations, with use of TCLP Extraction Fluid \#1: pH (initial) = $4.94, \mathrm{pH}($ final $)=(5.29 \pm 0.03)$. 
The TCLP procedure was also performed on the APA-C material (MCL ID 02-0071) used in bench-scale treatability studies with use of simulated and authentic PGDP wastewater (see Section 4.5). All regulated metals that leached from the sample were below their regulatory criteria.

Table 36. TCLP Extraction of Used Apatite-C from Long-Term FIU Treatability Study (MCL ID 02-0071)

\begin{tabular}{ccccc}
\hline Metal & $\begin{array}{c}\text { Inventory } \\
(\mathrm{mg} / \mathrm{kg})\end{array}$ & TCLP Criterion $(\mu \mathrm{g} / \mathrm{L})$ & $\begin{array}{c}\text { TCLP Result } \\
(\mu \mathrm{g} / \mathrm{L})\end{array}$ & $\begin{array}{c}\text { Wt \% Inventory } \\
\text { Extracted }\end{array}$ \\
\hline $\mathrm{Ag}$ & $<8$ & 5,000 & $<10$ & \\
$\mathrm{As}$ & $<8$ & 5,000 & $<8$ & \\
$\mathrm{Ba}$ & 21 & 100,000 & 194 & 18.4 \\
$\mathrm{Cd}$ & 1047 & 1,000 & 203 & 0.4 \\
$\mathrm{Cr}$ & $<5$ & 5,000 & $<5$ & \\
$\mathrm{Hg}$ & $<75$ & 200 & $<75$ & $<22$ \\
$\mathrm{~Pb}$ & 4.6 & 5,000 & $<50$ & \\
$\mathrm{Se}$ & $<25$ & 1,000 & $<5$ & $<0.006$ \\
$\mathrm{U}$ & 6490 & $\mathrm{NA}$ & $<20$ & 2.9 \\
$\mathrm{Ca}$ & 306,422 & $\mathrm{NA}$ & 44,200 & 42.3 \\
$\mathrm{Mg}$ & 3466 & $\mathrm{NA}$ & 73,300 & 1.1 \\
$\mathrm{P}$ & 132,209 & $\mathrm{NA}$ & 7,530 & \\
\hline
\end{tabular}

TCLP Extraction Fluid \#1: $\mathrm{pH}($ initial $)=4.94, \mathrm{pH}($ final $)=5.12$

\subsubsection{Bioaccessibility Testing of Metal-Exposed Apatite}

A desirable attribute for a toxic metal which has been stabilized in situ in soil matrix would be to have the metal complex evidence a reduced bioavailability, that is, to reduce the adsorption/uptake of the metal by plants or animals. Actual animal model bioavailability tests are complex and expensive. The potential bioavailability of metals in soils may be assessed by in vitro procedures intended to mimic the dissolution of metal during residence in the human gut. Many such procedures have been proposed, as reviewed by Ruby et al. (1999). One such testing protocol is the draft in vitro bioaccessibility (BA) extraction procedure developed by Ruby and co-workers' (SOP 110499), derived from Ruby et al. (1996). The SOP uses acid conditions that yield conservative (high) estimates of bioaccessibility (i.e., extraction is performed at $\mathrm{pH} 1.5$, characteristic of gastric $\mathrm{pH}$ under fasting conditions, vs. $\mathrm{pH} \sim 4$, characteristic of gastric $\mathrm{pH}$ under fed condition).

Note also that bioaccessibility refers to the fraction of metal source that is dissolved into simulated gastric juice, whereas bioavailability refers to the fraction of ingested metal source that is actually absorbed into systemic circulation where it may subsequently exert toxic effects. 


\subsubsection{BA Testing for Raw Apatite}

Conca et al. (2000) state that the apatite structure is stable over a wide range of conditions, including $\mathrm{pH}$ values between about 2 to 12. However, Zhang et al. (1998) report that even synthetic crystalline hydroxyapatite dissolves appreciably at $\mathrm{pH}$ values $<$ 4; poorly crystalline biogenic apatite would be expected to be less stable. The harsh conditions of the BA test protocol (Section 3.1: $\mathrm{pH} 1.5$ ) effectively digest the raw (asreceived) fish bone matrix, as noted in Table 37 (i.e., for a given mass of sample, the quantity of metal liberated into the BA extract is essentially equivalent to the quantity of metal extracted by the aggressive EPA Method 3050 acid peroxide digestion procedure).

Table 37. Bioaccessibility Extraction of As-Received Raw Fishbone Apatite (Sample 01-0263)

\begin{tabular}{cccc}
\hline Metal & $\begin{array}{c}\text { Metal }(\mathrm{mg} / \mathrm{kg}) \\
\text { (Based on EPA Method } \\
\text { 3050 Digestion) }\end{array}$ & $\begin{array}{c}\text { Metal }(\mathrm{mg} / \mathrm{kg}) \\
\text { (Based on BA } \\
\text { extraction, SOP } \\
110499)^{*}\end{array}$ & $\begin{array}{c}\text { Fraction of Method 3050 } \\
\text { inventory Extracted by } \\
\text { BA protocol }\end{array}$ \\
\hline $\mathrm{Ca}$ & 183,000 & 175,000 & 0.95 \\
$\mathrm{Cd}$ & $<4$ & $<4$ & \\
$\mathrm{Hg}$ & $<75$ & $<75$ & 1.11 \\
$\mathrm{Mg}$ & 3,270 & 3,630 & 0.94 \\
$\mathrm{P}$ & 95,400 & 89,200 & \\
$\mathrm{~Pb}$ & $<50$ & $<50$ & \\
$\mathrm{U}$ & $<20$ & $<50$ & \\
\hline
\end{tabular}

- Solubilty/Bioavailability Research Consortium, In Vitro Method for Determination of Lead and Arsenic Bioaccessibility, Draft Standard Operating Procedure 110499 (Rev. 8).

Ryan and Zhang (1995) report that phosphate soil amendment converts more soluble forms of lead to the mineral pyromorphite $\left(\mathrm{Pb}_{5}\left(\mathrm{PO}_{4}\right)_{3} \mathrm{OH}\right)$, an apatite analog that is stable even at $\mathrm{pH}$ values as low as 3 . Ruby et al. (1996) report that dissolution of $\mathrm{Pb}$ in the acidic stomach environment was strongly $\mathrm{pH}$ dependent; the extent of dissolution decreased $65 \%$ when stomach $\mathrm{pH}$ was increased from 1.3 to 2.5 (representing a range of $\mathrm{pH}$ values for gastric contents at fasting condition). In contrast, arsenic solubility decreased by only $16 \%$ over this same $\mathrm{pH}$ range. However, at $\mathrm{pH} 1.5$ (the condition imposed in SOP 110499), $97 \mathrm{wt} \%$ of the raw apatite phase is dissolved under the testing conditions, as estimated by the dissolution of $\mathrm{Ca}$ and $\mathrm{P}$ from the substrate (Table 37), and also as verified by gravimetric estimate of the residual solid mass.

\subsubsection{BA Testing on Exposed Dry Apatite (EDA)}

The bioaccessibility test protocol was performed on Exposed Dry Apatite (EDA), prepared by batch-equilibration of raw apatite with select contaminants added to synthetic groundwater; see Table 38. Similar to the as-received material (Table 37), Mg as well as the major apatite phase matrix elements ( $\mathrm{Ca}$ and $\mathrm{P})$ are all essentially dissolved ( $\geq 97 \%$ of inventory liberated into extraction medium). Metals that have been bound 
primarily by surface sorption (vs. mineral formation) will be more susceptible to dissolution when the substrate itself dissolves. Most of the (presumably) surface-sorbed toxic metals (e.g., $\mathrm{Cd}$ and $\mathrm{Pb}$ ) are liberated (Table 38); however $\mathrm{Hg}$ and $\mathrm{U}$ do have appreciably less solubility under the defined testing conditions than do the matrix elements. The relatively high portion of lead $(\sim 88 \%)$ liberated in the test procedure is contrary to the expectations in the literature for lead as pyromorphite (e.g., Rabinowitz, 1993; Zhang et al., 1998; Traina and Laperche, 1999). This may indicate that short-term loading of modest amounts of lead on apatite is primarily a surface sorption phenomenon, with minimal formation of more refractory pyromorphite mineral phase, or else that the extreme $\mathrm{pH}$ condition $(\mathrm{pH} 1.5)$ dissolves nearly all forms of lead produced by the phase contact. The modest loading of $\mathrm{Pb}$ on the EDA did not allow phase identification.

Table 38. BA Extraction of Apatite-II (EDA) "Bulk” from Short-Term Metal Exposure Study

\begin{tabular}{cccc}
\hline Metal & $\begin{array}{c}\text { Inventory } \\
(\mathrm{mg} / \mathrm{kg})\end{array}$ & $\begin{array}{c}\text { BA Extract } \\
\text { Result }(\mu \mathrm{g} / \mathrm{L})\end{array}$ & Wt\% Inventory Extracted \\
\hline $\mathrm{Cd}$ & 488 & 4,580 & 93.8 \\
$\mathrm{Hg}$ & 67 & $<75$ & $<11.2$ \\
$\mathrm{~Pb}$ & 492 & 4,330 & 88.0 \\
$\mathrm{U}$ & 236 & 1,617 & 68.5 \\
$\mathrm{Ca}$ & 207,800 & $2,030,000$ & 97.7 \\
$\mathrm{Mg}$ & 4,000 & 38,700 & 96.8 \\
$\mathrm{P}$ & 104,900 & $1,020,000$ & 97.0 \\
\hline
\end{tabular}

Test run in triplicate; initial $\mathrm{pH}=(1.54 \pm 0.01)$; final $\mathrm{pH}=(1.71 \pm 0.02)$. Final temperature $=(35.6 \pm 0.2){ }^{\circ} \mathrm{C}$.

\subsubsection{BA testing on Treatability Study Sample (02-0071)}

Bioaccessibility testing was performed on the "fines" fraction $(<60$-mesh, or $<250-\mu \mathrm{m})$ of dried apatite char from the long-term FIU treatability study; see Table 39. As for previous examples, the preponderance of sorbed metals (and the apatite matrix itself) is dissolved by the aggressive BA extraction.

Table 39. BA Extraction of Used Apatite-C from Long-Term FIU Treatability Study (Sample 02-0071, "fines" fraction)

\begin{tabular}{cccc}
\hline Metal & $\begin{array}{c}\text { Inventory } \\
(\mathrm{mg} / \mathrm{kg})\end{array}$ & $\begin{array}{c}\text { BA Extract } \\
\text { Result }(\mu \mathrm{g} / \mathrm{L})\end{array}$ & Wt\% Inventory Extracted \\
\hline $\mathrm{Cd}$ & 1360 & 12,500 & 91.9 \\
$\mathrm{Cu}$ & 16.3 & 214 & 131 \\
$\mathrm{Zn}$ & 5800 & 56,400 & 97.2 \\
$\mathrm{U}$ & 11,000 & 97,400 & 88.5 \\
$\mathrm{Ca}$ & 360,000 & $3,500,000$ & 97.2 \\
$\mathrm{P}$ & 176,000 & $1,800,000$ & 102 \\
\hline
\end{tabular}

Inventory is based upon results from EPA Method 3050 digestion 


\subsection{Soil Column Studies (Project Task 1.3)}

Short-term batch testing, as described in Sections 4.3 and 4.4, is a rapid means to screen for the applicability of the apatite technology. However, by its nature, batch testing does not reflect the field conditions of a slow percolation of groundwater through the soil, interactions of solutes with soil minerals and microbes, nor does it assess relatively slow approaches to equilibrium. Soil column testing requires lengthy exposure to a continuous influx of water, but it is the closest approximation to field conditions, encompassing a variety of diffusive and chemical interaction processes, and is the preferred means to determine contaminant loading and total system performance.

Flow-through studies of untreated and apatite-treated contaminated soils can be performed to better replicate actual field conditions that batch studies cannot reproduce, e.g., natural flow rates, low water-to-soil ratios, channelized flow paths, etc. Traditional soil columns consist of a column of soil having solution dripping into the top at a fixed rate and effluent collected as it exits the bottom of the sample column. The degree of saturation in the sample is high, nearly saturated for most soils, if the experiment is to take less than a year. This is especially true for soil having large retardation factors for the metals of interest, see Eq. (2), requiring a large number of pore volumes to achieve even partial breakthrough. A long run time is especially required if the soil column influent water velocity is selected to be comparable to typical groundwater advection in the range of $\sim 0.3$ to $300 \mathrm{~m} / \mathrm{y}\left(\sim 6 \times 10^{-5}\right.$ to $\left.6 \times 10^{-2} \mathrm{~cm} / \mathrm{s}\right)$ (Nyer et al., 1996).

In this Section, we describe relatively short-term ( $\sim 500$ to $\sim 1000 \mathrm{~h})$ soil column experiments conducted at influent water velocity in the range of $\sim(1-3) \times 10^{-4} \mathrm{~cm} / \mathrm{s}$. This corresponded to only $\sim 300-530$ total pore volumes of eluate collected, and many strongly retained solutes did not break through the column within this time interval. At the termination of the experiment designated "Series 57," the approximate concentration gradient of select metals along the soil columns was estimated by analyzing for metal within select sections sampled along the column length. This allowed us to verify the strong retention of select metals within apatite-amended soils.

\subsubsection{Description of Soils Used}

Three different soil samples were used in soil column testing. Each soil composition was air-dried, de-lumped by application of gentle pressure, screened to remove particles and debris greater than 2-mm, and finally blended by tumble mixing. The individual soils are described below.

Soil 02-0175 is first-cut (near-surface) forest subsoil, predominantly comprised of fine quartz, with minor clay components. This soil was used in a series of preliminary tests (designated "Series 12"), with a gravity feed (percolation) of metal-supplemented aqueous feed solution. 
Soil 00-0608 is a deep subsurface soil from the DOE Fernald site (provided courtesy of Chris Lutes of Arcadis G\&M). It was used in "Series 57" soil column experiments, with a gravity feed (percolation) of metal-supplemented aqueous solution. By XRD, the major crystalline components in this soil are quartz, the carbonate minerals calcite $\left(\mathrm{CaCO}_{3}\right)$ and dolomite $\left(\mathrm{CaMg}\left(\mathrm{CO}_{3}\right)_{2}\right)$, plus some small amount of illitic clays.

Soil 00-0656 is a blended composite of authentic contaminated soil, originating from a commercial site supporting the nuclear fuel cycle. It was used in "Series 31 " column testing (gravity feed (percolation) of "clean" artificial groundwater). By XRD, the major crystalline component is quartz, with minor layered aluminosilicate minerals such as vermiculite (phyllosilicate) and illite (hydrated phyllosilicate). By optical petrography, additional near-opaque minerals such as hematite $\left(\mathrm{Fe}_{2} \mathrm{O}_{3}\right)$ and magnetite $\left(\mathrm{Fe}_{3} \mathrm{O}_{4}\right)$ are also observed. Some small spherical opaque framboids were noted, possibly pyrite $\left(\mathrm{FeS}_{2}\right)$. The uranium content of the dried, blended soil composite (MCL sample 00-0656), as estimated by $x$-ray fluorescence (XRF), is $(531 \pm 11.2) \mathrm{mg} / \mathrm{kg}$, and the total uranium activity, as estimated by gamma spectroscopy, is $(420 \pm 24.3) \mathrm{pCi} / \mathrm{g}$. These elevated values may be compared to EPA action level for U in soil at the U.S. Department of Energy (DOE) Uranium Mill Tailings Remedial Action (UMTRA) Project, viz., 35 pCi/g, or (for natural U) $0.055 \mathrm{mg} / \mathrm{kg}$ (Abdelouas et al., 1999; Morrison et al., 2001). Select physical properties of this soil are given in Table 40.

Table 40. Select Physical Properties for Reference Soil 00-0656 (Used in Soil Column Series 31)

\begin{tabular}{|c|c|c|c|}
\hline Property & Unit & Result & Comment \\
\hline Mass-median particle size & $\mu \mathrm{m}$ & 220 & Lognormal fit to sieve data (1) \\
\hline Median grain density & $\mathrm{g} / \mathrm{cc}$ & 2.6 & Pycnometric estimate \\
\hline Dry Bulk density & $\mathrm{g} / \mathrm{cc}$ & 1.76 & \\
\hline Saturation density & $\mathrm{g} / \mathrm{cc}$ & 2.08 & \\
\hline Void fraction & $(\mathrm{v} / \mathrm{v})$ & 0.31 & \\
\hline Loss on ignition & $\mathrm{Wt} \%$ & 0.65 & $16-\mathrm{h}$ at $400^{\circ} \mathrm{C}(2)$ \\
\hline
\end{tabular}

(1) See (e.g.) Mackay and Paterson (1984). See also Figure 52.

(2) Method of Ben-Dor \& Banin (1989).

The major elemental composition of the three soils used in the soil column experiments was estimated by X-ray fluorescence (XRF); see Table 41. 
Table 41. Estimate of Major Constituents in Soil Samples by X-Ray Fluorescence(XRF)

\begin{tabular}{|c|c|c|c|c|c|}
\hline Element & Unit & $00-0656$ & $02-0175$ & $02-0608$ & Median Value Earth's Crust * \\
\hline $\mathrm{Si}$ & Wt. \% & 31.0 & 42.2 & 22.0 & 28.2 \\
\hline $\mathrm{Al}$ & Wt. \% & 8.27 & 3.66 & 4.05 & 8.32 \\
\hline $\mathrm{Fe}$ & Wt. \% & 2.03 & 1.36 & 1.13 & 5.63 \\
\hline $\mathrm{Ca}$ & Wt. $\%$ & 1.11 & 0.12 & 17.6 & 4.15 \\
\hline $\mathrm{Na}$ & Wt. $\%$ & 1.31 & 0.21 & 0.42 & 2.36 \\
\hline $\mathrm{Mg}$ & Wt. \% & 0.68 & 0.00 & 2.33 & 2.33 \\
\hline $\mathrm{K}$ & Wt. \% & 2.20 & 0.38 & 1.12 & 2.09 \\
\hline $\mathrm{Ti}$ & Wt. \% & 0.38 & 0.56 & 0.13 & 0.57 \\
\hline $\mathrm{Mn}$ & Wt. $\%$ & 0.03 & 0.02 & 0.03 & 0.10 \\
\hline
\end{tabular}

* Value Tabulated in CRC Handbook of Chemistry \& Physics ( $68^{\text {th }}$ Ed.), p F-139.

The soil grain size distribution was determined by dry-sieving the solids, and determining the mass of solids retained on a series of standard screens. Data for tested soils, fitted to a lognormal distribution (Mackay and Paterson, 1984), are presented in Figure 51. By mass, soil 00-0656 predominantly contains soil grains within the fine to medium sand range $(0.10-0.25 \mathrm{~mm})$, whereas soils $02-0175$ and $02-0608$ predominantly contain grains within the medium to coarse sand range $(0.25-0.50 \mathrm{~mm})$. Note that the dry sieve grain fractions all have fine surface coatings of (e.g.) amorphous iron oxides and clays, but these surface coatings (although very important for sorption phenomena) do not greatly alter the mass-size distribution (i.e., soil 02-0608 was sieved both dry and wet, with minimal effect on the measured mass-size distribution). The preponderance of small grains of silica (quartz) in the soils tested (and especially soil 02-0175, containing $\sim 90$ $\mathrm{wt} \% \mathrm{SiO}_{2}$; see Table 39) is expected to give the soil matrix a net negative surface charge under most environmental $\mathrm{pH}$ conditions, which attracts colloidal-sized iron oxide particles, the latter generally having a net positive surface charge under the same conditions (Puls \& Powell, 1982). (Note: for soils with high calcite or dolomite content, at low to neutral $\mathrm{pH}$ values, the solid/liquid interface may be positively charged, and anions will be higher absorbing than similar cations; Harwell, 1992). 


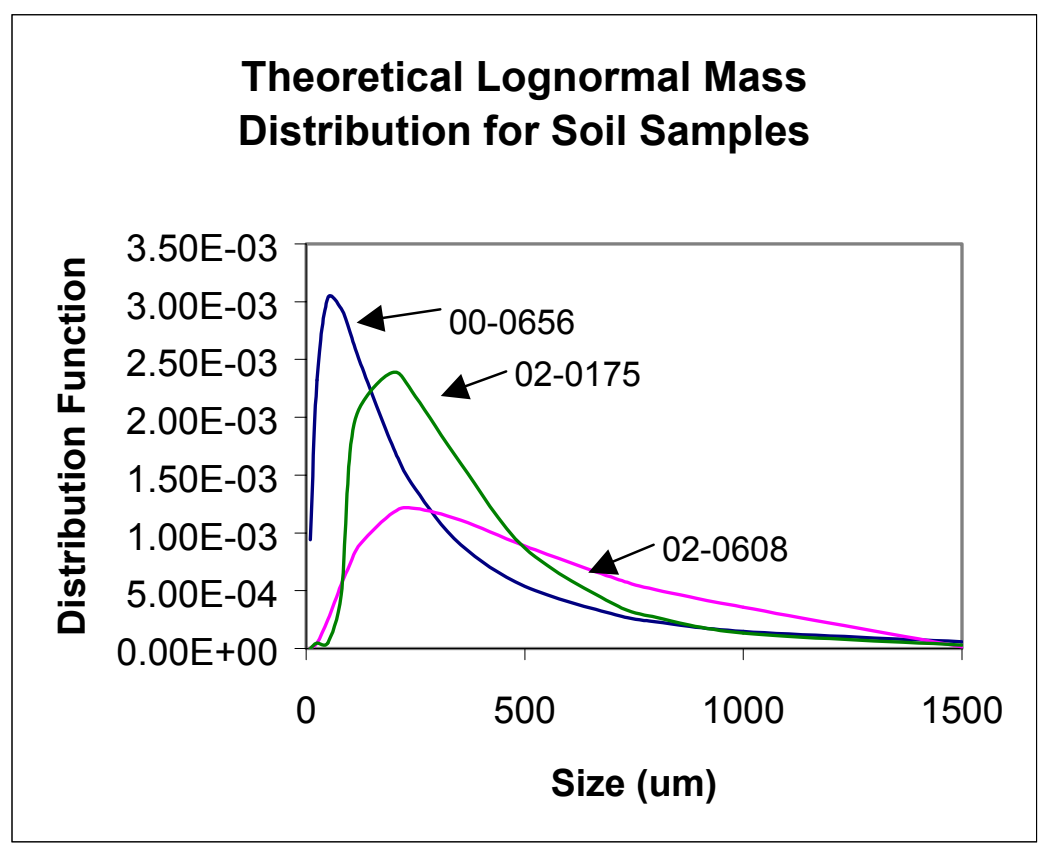

Figure 51. Theoretical Lognormal Mass Distribution for Dried Soil Grains. Fitting parameters: Soil 00-0656 $(\mathrm{Cg}=220 \mu \mathrm{m}, S=3.16)$; Soil 02-0175 $(\mathrm{Cg}=300 \mu \mathrm{m}, S=$ 2.03); and Soil 02-0608 ( $\mathrm{Cg}=550 \mu \mathrm{m}, S=2.45)$. Soil 02-0175 was used in soil column "Series 12," soil 00-0656 was used in soil column "Series 31," and soil 02-0608 was used in soil column "Series 57."

\subsubsection{Apatite Amendment}

Three different samples of apatite product were used for soil amendment, representing a range of particle size (Figure 52) and organic matter (Table 42). The latter is estimated by loss on ignition at $400{ }^{\circ} \mathrm{C}$; see Ben-Dor \& Banin (1989). The material identified as "<40-mesh" is the "fines" fraction from ground raw apatite. 


\section{Theoretical Lognormal Mass Distribution for Apatite Products}

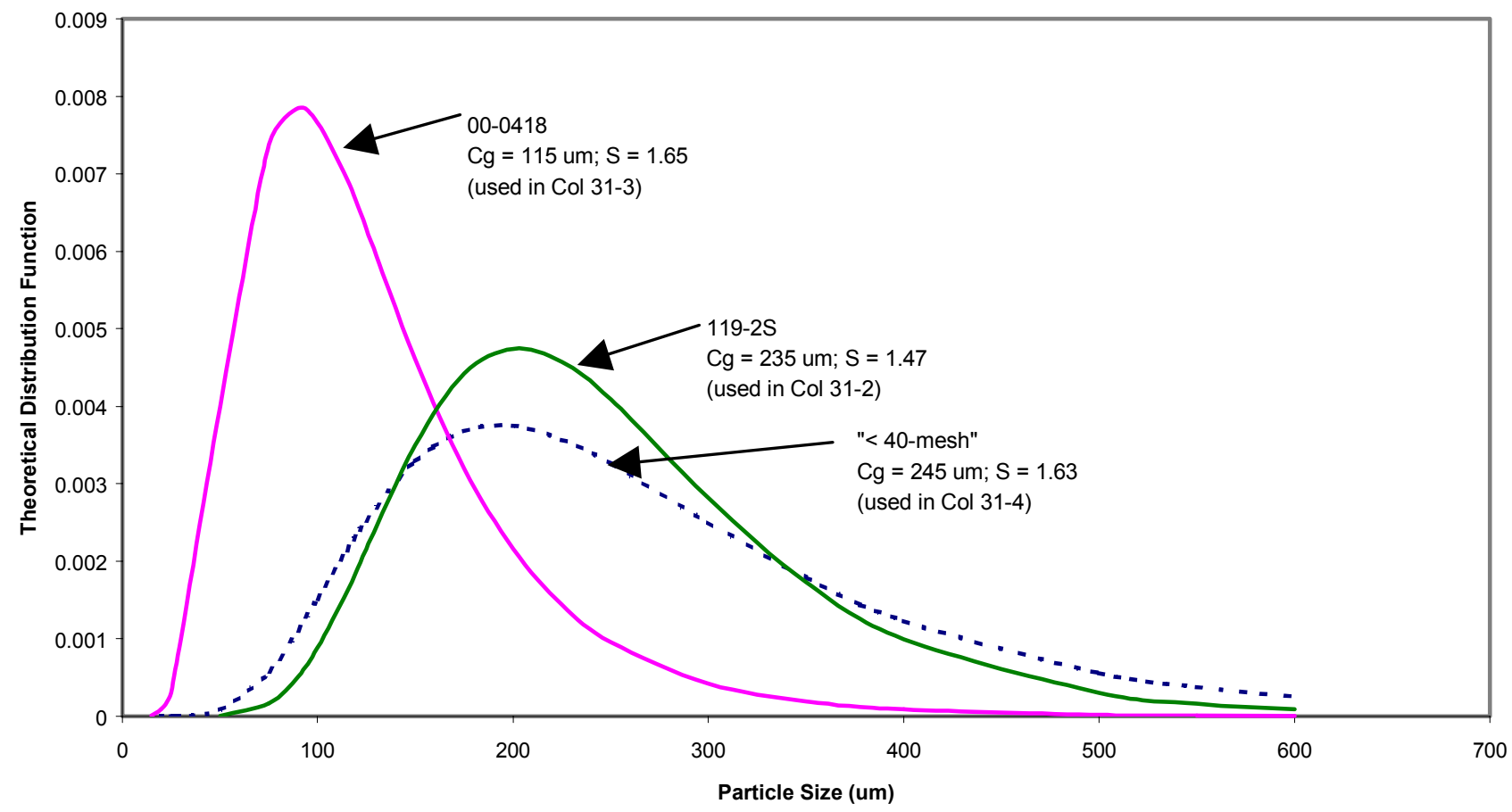

Figure 52. Theoretical Lognormal Particle Mass Distribution for Select Apatite Products. Data represent mass distribution of material retained on standard sieves.

Table 42. Select properties of Apatite Products Used in Soil Columns

\begin{tabular}{cccc} 
Material Designation & $\begin{array}{c}\text { Mass-Median Particle } \\
\text { Size }(\mu \mathrm{m})\end{array}$ & $\begin{array}{c}\text { Organic Matter } \\
\left(\text { LOI at } 400{ }^{\circ} \mathrm{C}\right) *\end{array}$ & Used in Soil Column: \\
\hline $119-2 \mathrm{~S}$ & 235 & $27.2 \mathrm{wt} \%$ & $12-4 ; 31-2 ; 57-2$ \\
$00-0418$ & 115 & $46.6 \mathrm{wt} \%$ & $31-3$ \\
01-0380 fines & 245 & $46.7 \mathrm{wt} \%$ & $12-2 ; 12-3 ; 31-4$ \\
"<40-mesh" & & & \\
\hline
\end{tabular}

* Estimated by loss on ignition; see Ben-Dor \& Banin (1989).

\subsubsection{Soil Column Tests}

Figure 53 illustrates the collection of eluate fractions from soil columns. Soil sample (approximately 40-g), with or without amendment, is placed in the barrel of a 50-cc disposable syringe to form soil columns with dimensions 2.9-cm (internal diameter) by 4.5-cm (length), for $\sim 28$-cc nominal bed volume. Aqueous phase is metered by a peristaltic pump into the top of the column, and percolates down through the column by gravity and capillary action. 


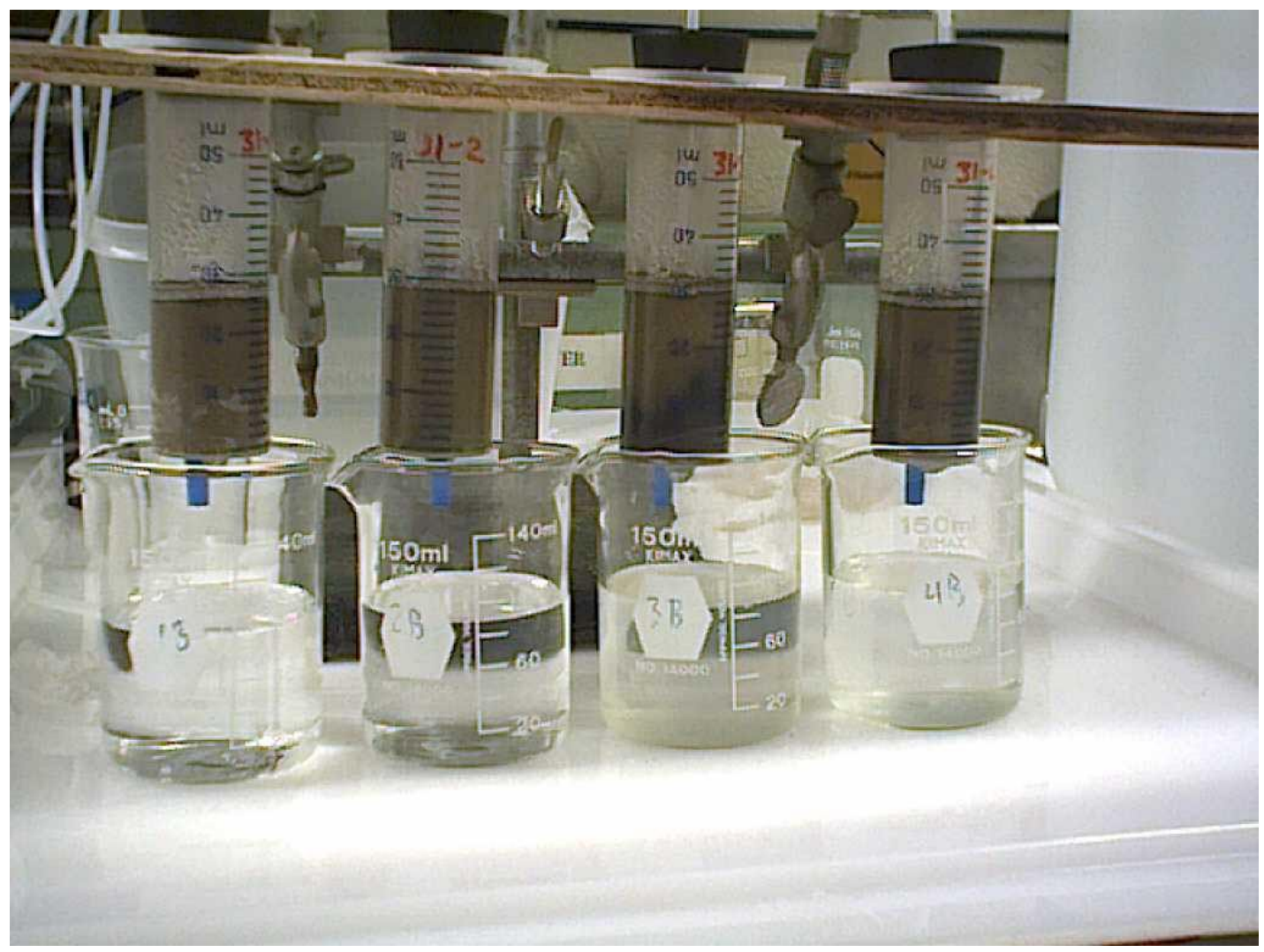

Figure 53. Illustration of Soil Column Elution. This photograph was taken during the collection of Eluate Fraction \#60 from experiment "Series 31". At this time, a total of 125 bed volumes had been eluted from the columns.

\subsubsection{Preliminary Testing: Spiked Synthetic Groundwater Fed to "Clean" Soil ("Series 12")(NETL/Task 1.4.3(A) Clean Soil)}

An initial series of tests ("Series 12") was performed using soil 02-0175. As indicated in Section 4.7.1, this is a first cut (near-surface) forest subsoil, presumably with relatively high indigenous biological activity. Preliminary short-term flow testing suggested that the soil amended with ground raw apatite had a tendency to flood (column drain rate less than feed rate) after several hours when fed clean water at a nominal velocity of $3.5 \times 10^{-4} \mathrm{~cm} / \mathrm{s}(0.14 \mathrm{cc} / \mathrm{min})$. The extraneous matter in the raw apatite fines swelled greatly when wetted (see Section 4.1.3), and also bacteria rapidly proliferated in the vicinity of the raw apatite to possibly further decrease soil permeability. In an attempt to increase soil permeability, the soil (02-0175) was subsequently premixed with $\sim 25 \mathrm{wt} \%$ standard Ottawa sand (EM Scientific PN SX0070-1; mass-median grain size $~ 385 \pm 65$ $\mu \mathrm{m})$. 
The soil/sand blend was used to prepare four soil columns, for performance comparison. Soil sample (approximately 40-g), with or without sand and apatite amendment, was placed in the barrel of a 50-cc disposable syringe to form soil columns with dimensions 2.9 -cm (I.D.) by $\sim 4.5-\mathrm{cm}$ (L), for $\sim 30$-cc nominal bed volume. With the native soil containing $\sim 10 \mathrm{wt} \%$ moisture, the packed columns had initial bulk densities of $\sim 1.33$ $\mathrm{g} / \mathrm{cc}$, and estimated gross porosities $\sim 31 \%(\mathrm{v} / \mathrm{v})$. The preparation of the soil columns is described below:

- Column \#12-1 contained blended soil/sand mixture only.

- Column \#12-2 contained soil/sand mixture further supplemented with raw apatite "fines" ( $<40$-mesh material), added to soil at $\sim 5 \mathrm{wt} \%$, and the mixture blended well before being placed in the column).

- Column \#12-3 was an attempt to investigate the effect of layering the raw apatite "fines" (at $\sim 5 \mathrm{wt} \%$, relative to the total dry mass of soil and amendment used) between two zones of clean soil. Since the raw apatite fines tend to swell when wetted, the APA was first blended with Ottawa sand ( $32 \%$ APA $+68 \%$ sand, by mass) and water to form a paste, which was placed between layers $(\sim 20-\mathrm{g}$ each) of clean soil.

- Column \#12-4 was prepared in a manner similar to column \#2, with the exception that the raw apatite used had first been cleaned in flowing water to elutriate away a large proportion of the less-dense extraneous (organic-rich, non-apatite) matter. The washed apatite fines (119-2S) used in Column \#4 contained much less extraneous organic matter than the original raw apatite fines (as used in columns $\# 2$ and \#3). The measured LOI for elutriated (cleaned) APA $(\leq 30 \mathrm{wt} \%$; see Table 40$)$ is essentially identical to that determined ( $34 \mathrm{wt} \%)$ for a sampling of select large fish bone shard fragments, indicating a high degree of removal of extraneous matter.

The test soil samples were retained in the column with use of a filter plug of glass wool placed between the soil and column drain hole. Eluate fractions for analysis were collected by allowing the liquid from the column to drip from the drain hole into collection vessels for defined intervals of time. The loose glass wool plug at the drain hole allowed some soil "fines" to elute, as evidenced by detection of soil matrix elements, including $\mathrm{Fe}$, in the first several fractions collected from all columns.

The assembled soil columns were initially exposed to a feed of clean synthetic ground water for 13 days, to verify that they could drain properly at the selected feed rate $(\sim 3.2$ $\mathrm{x} 10^{-4} \mathrm{~cm} / \mathrm{s}$ ). For non-sterile soil amended with biogenic apatite, this pre-incubation period would stimulate biological activity forming within the solid phase. Also, phosphate ion (from the limited dissolution of apatite phase) could be distributed within the soil medium. Following this conditioning step, the feed solution was switched to synthetic groundwater spiked with metals of interest. 
Biological activity within the raw APA-amended soil appeared to reductively solubilize some iron as the soil columns approached saturation with aqueous phase (minimal dissolved oxygen), as evidenced by the persistent detection of Fe in the column eluate (especially column12-2, containing APA fines with high organic matter; see Figure 54) and the formation of orange precipitate near the drain hole (where $\mathrm{Fe}^{2+}$ would be exposed to air, forming $\mathrm{Fe}^{3+}$ ). The elution of total Fe from Column 12-4 (amended with cleaned APA) is comparable to that measured for the control (Column12-1) without APA, suggesting that the extraneous organic matter in Columns 12-2 (Table 40) especially stimulates anaerobic biological activity.

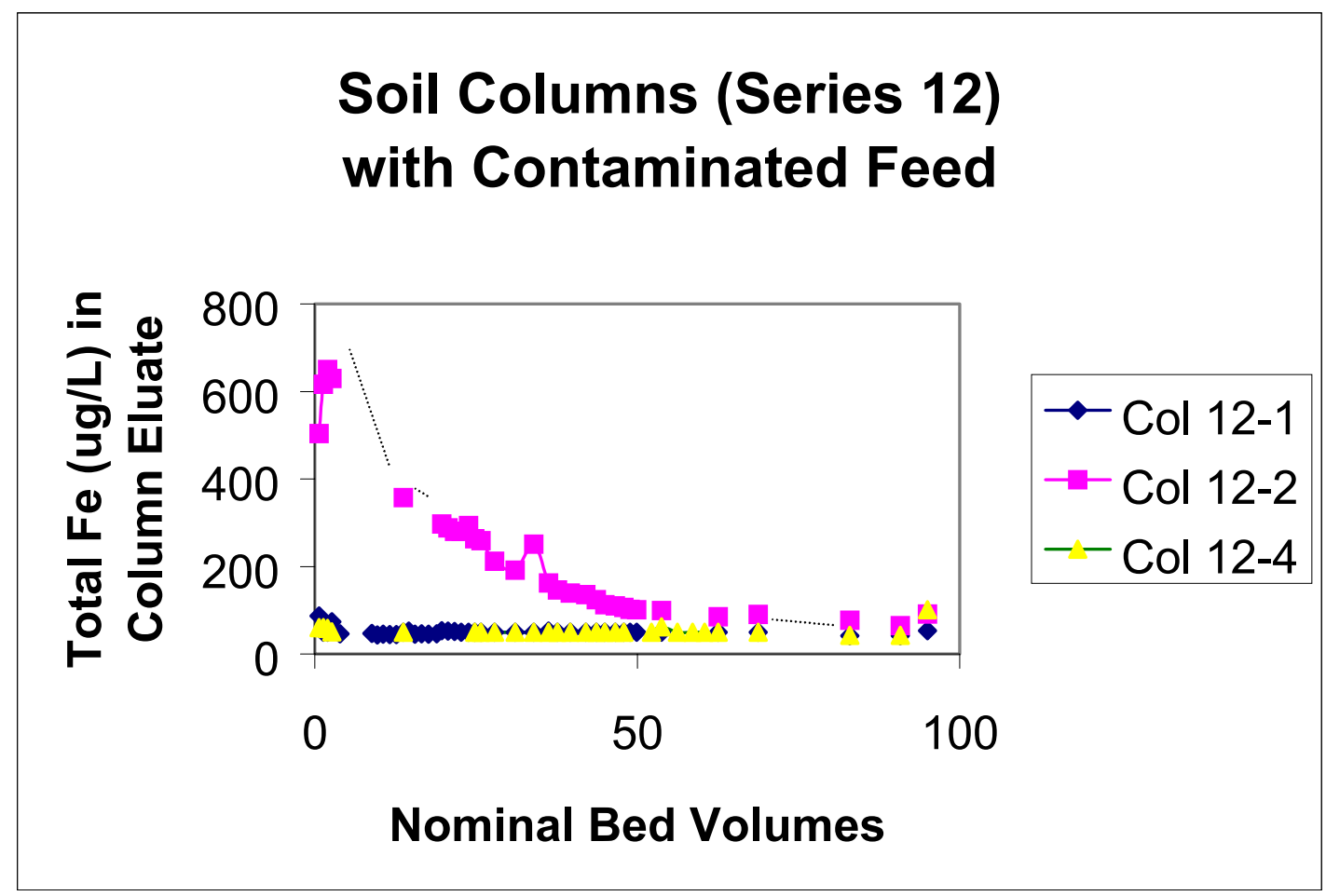

Figure 54. Total Iron (Fe) in Series 12 Soil Column Eluates. Column 12-1 is a control (no apatite). Column 12-2 contains raw biogenic apatite fines $(\sim 5 \mathrm{wt} \%)$, with high organic matter. Column 12-4 contains biogenic apatite fines $(\sim 5 \mathrm{wt} \%)$, which had been cleansed of the majority of extraneous matter by elutrating the solids in flowing water. Abscissa is nominal bed volumes ( $1 \mathrm{BV} \sim 30 \mathrm{cc} \sim 3.8$-h run time) for spiked synthetic groundwater feed.

The spiked feed consisted of synthetic groundwater, adjusted to $\mathrm{pH} \sim 5.6$ with use of blended $\mathrm{CO}_{2}$ and humidified air gas purge, and supplemented with (nominally) 1E-04 mol/L each of the chemicals: $\mathrm{UO}_{2}\left(\mathrm{NO}_{3}\right)_{2} \bullet 6 \mathrm{H}_{2} \mathrm{O} ; \mathrm{Cd}\left(\mathrm{NO}_{3}\right)_{2} \bullet 4 \mathrm{H}_{2} \mathrm{O} ; \mathrm{HgSO}_{4}$; and $\mathrm{Na}_{2} \mathrm{HAsO}_{4} \cdot 7 \mathrm{H}_{2} \mathrm{O}$. In previous testing with use of single metal compound contaminants (Section 4.3), each of these chemicals was readily soluble in the synthetic groundwater composition at this target level. An unanticipated effect of combining these chemicals at the selected level was the interaction to gradually form a very fine particulate phase containing $\mathrm{Ca}, \mathrm{U}$, and As, presumably analogous to the formation of autunite (but with 
$\mathrm{AsO}_{4}{ }^{-3}$ substituting for $\mathrm{PO}_{4}^{-3}$ ). This sparingly soluble crystalline phase appears to have the general composition $\mathrm{M}\left(\mathrm{UO}_{2}\right)_{2}\left(\mathrm{XO}_{4}\right) \cdot \mathrm{nH}_{2} \mathrm{O}$, as suggested by X-ray diffraction similarities to autunite, where $\mathrm{M}$ was preferentially $\mathrm{Ca}$ and $\mathrm{X}$ was As (as determined by $\mathrm{X}$-ray fluorescence analysis). This reaction to form fine particulate phase occurred somewhat slowly in the stock feed solution (generally maintained at $\mathrm{pH} \sim 5.6$ ), but appeared to accelerate as the solution $\mathrm{pH}$ increased. At the low flow rate employed, an increase in $\mathrm{pH}$ occurs within the somewhat gas-permeable (silicone) peristaltic pump tubing connecting the gas-purged feed reservoir to the test columns, as excess dissolved $\mathrm{CO}_{2}$ is gradually lost to the ambient atmosphere, raising the solution $\mathrm{pH}$ value. As a result, it was noted that fluffy crystal deposits formed within the column tubing that fed the columns, and that some of these crystals were transported and subsequently deposited on the top of the soil columns themselves. At 7 days into the spiked metal feed, a sample of the turbid feed was taken from the delivery line; $>90 \%$ each of the total U \& As in the slurry sample were removed by filtration with $0.2-\mu \mathrm{m}$ pore medium (indicating the presence of fine particulate phase), and the molar ratio of $U$ and As removed by this filtration were essentially equal. That the crystals contained uranyl ion was further evidenced by observation of a yellow-green fluorescence when they were illuminated by $\mathrm{UV}$ radiation. Because of this interaction, the levels of soluble $\mathrm{U}$ and As fed to the columns were considerably less than intended; levels of soluble $\mathrm{Cd}$ and $\mathrm{Hg}$ were largely unaffected by this precipitation phenomenon. These observations also suggest that a significant portion of $\mathrm{U}$ and As in the feed slurry may pass through the soil columns as colloidal solids, largely unaffected by the APA amendment (the U-As molecular complex would need to dissociate to form ions in order to effectively sorb to the APA phase). Uranium data for all columns is presented in Figure 55. It is probable that $U$ in column eluates includes both soluble and colloidal (U-As complex) forms. When the influx of particulate phase $\mathrm{U}$ to the columns was minimized, the total $\mathrm{U}$ in the column eluate slowly declined (see Figure caption for details). 


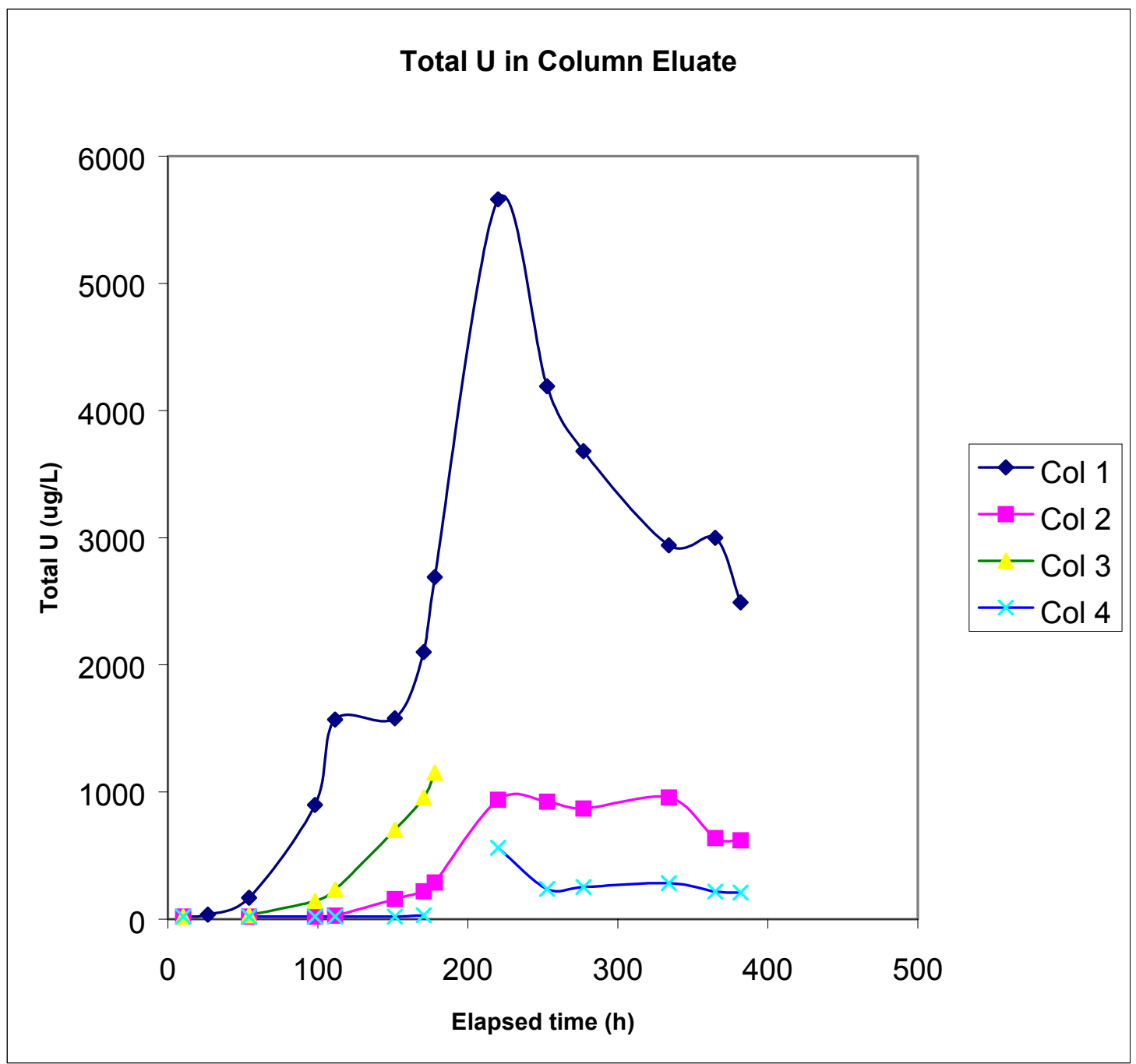

Figure 55. Total Uranium (U) in "Series 12" Soil Column Eluates. Column 12-1 is a control (no apatite). Column 12-2 contains raw biogenic apatite fines ( $\sim 5 \mathrm{wt} \%)$, with high organic matter. Column 12-4 contains biogenic apatite fines ( $\sim \mathrm{wt} \%)$, which had been cleansed of the majority of extraneous matter by elutrating the solids in flowing water. At total elapsed time $\sim 220$-h ( $~ 60$ nominal bed volumes $)$, Column 12-3 was decommissioned. At this time, the feed lines were flushed free of crystals, and the $\mathrm{pH}$ in the feed reservoir was more precisely regulated (to $\mathrm{pH} \sim 5.6$ ), presumably minimizing the feed of additional particulate $U$ to the columns (note the subsequent decline of $U$ in the eluate from control column 12-1). 
For the soil column without apatite amendment (viz., column12-1), the volume of column eluate required for significant breakthrough of metal contaminants increased in the order: $\mathrm{U}<\mathrm{Hg} \sim \mathrm{Cd}>\mathrm{As}$; see Figure 56. The apatite-amended columns showed significantly increased retardation for all contaminants of interest, except for a very minor decrease in the retention of As; see Figure 57 for corresponding data from Column \#12-4. The slightly reduced retention of As in the apatite-amended soil may be a consequence of having phosphate ion initially bound to the sites on soil minerals that would otherwise bind arsenate. Phosphate ion is produced from the dissolution of apatite; phosphate eluting from the apatite-amended soil columns progressively decreased from a maximum initial value of a few $\mathrm{mg} / \mathrm{L}$ total $\mathrm{P}$ to values below $1 \mathrm{mg} / \mathrm{L}$ after several hundred hours of continuous flow (see Figure 58 for data from Column \#12-4). These levels for soluble P are significantly lower than the corresponding value observed for apatite contacted with synthetic groundwater in the absence of soil. It is assumed that a significant portion of phosphate produced by dissolution of apatite within the soil column thus was sorbed to the soil minerals (Parfitt \& Atkinson, 1976), or was consumed by microbial activity and/or metal precipitation reactions. 


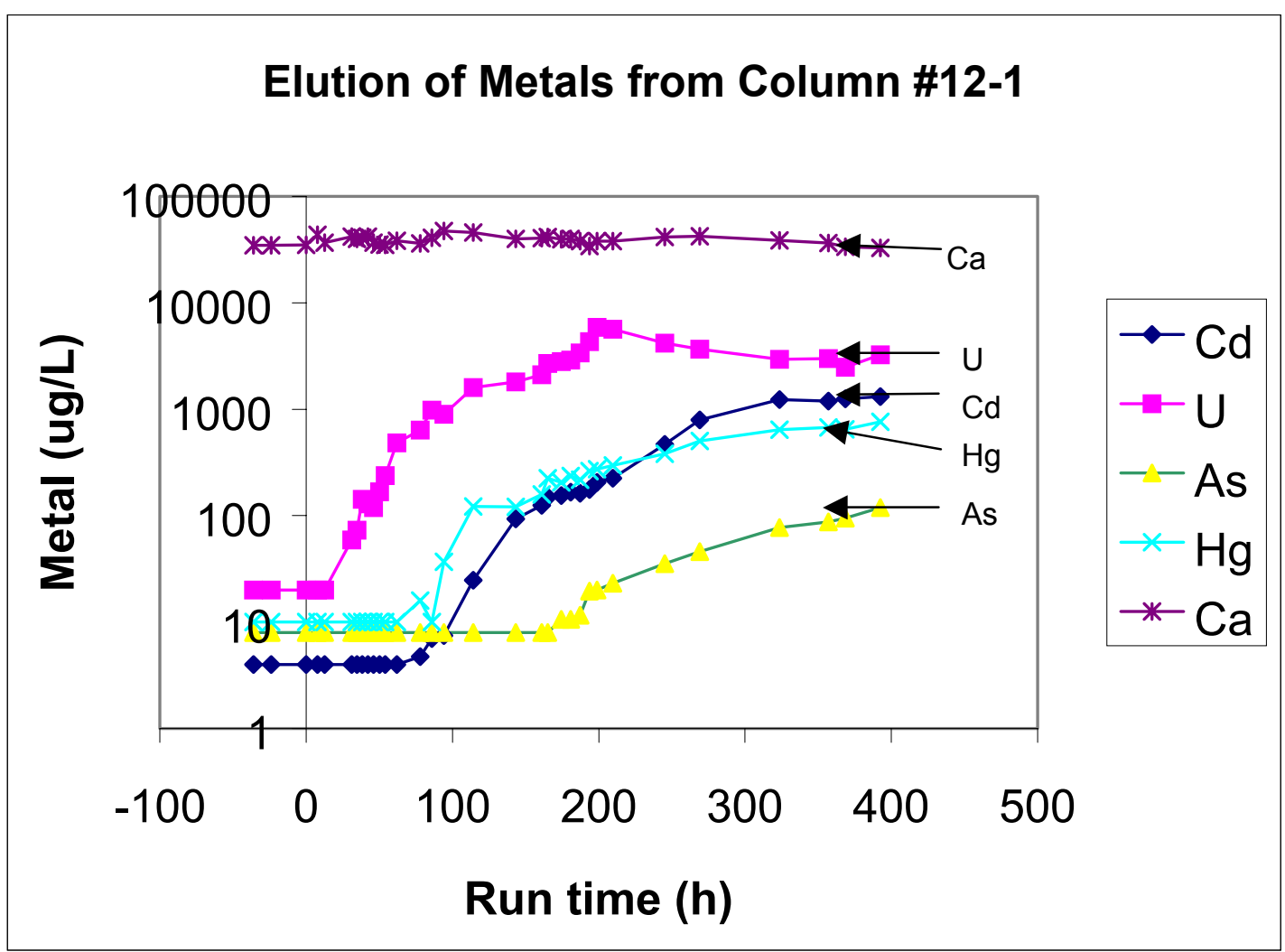

Figure 56. Elution of Select Metals from Soil Column 12-1 (Control, with no Apatite Added). Elution order is $\mathrm{U}>\mathrm{Hg} \sim \mathrm{Cd}>$ As. 


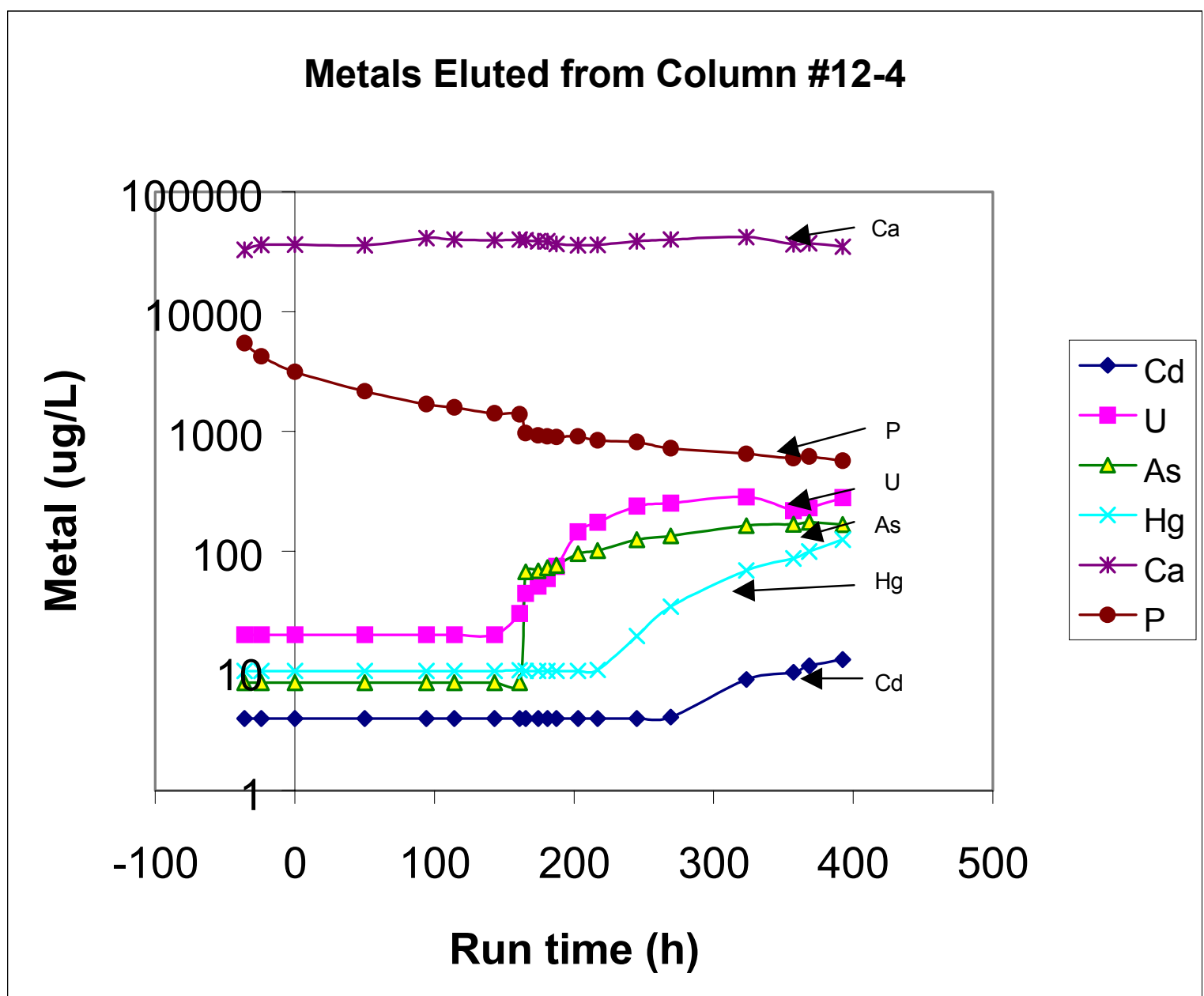

Figure 57. Elution of Select Metals from Soil Column 12-4 (Soil Amended with $\sim 5$ wt $\%$ Elutriated Apatite). Negative values for the run time represent feed of clean synthetic groundwater, whereas positive values represent feed of metal-spiked groundwater. At a run time of $\sim 160$-h ( $\sim 43$ nominal bed volumes), there is a sharp excursion for both $U$ and As, suggesting that U-As colloidal solid may be eluting. Compare to Figure 57 for the control soil (no APA added). 
The laboratory attempt to demonstrate the utility of layered apatite (Column \#12-3) was largely unsuccessful. The liquid residence time within the relatively thin apatite-rich layer was rather minimal $(<10-\mathrm{min})$; retardation of metals of interest for the layered apatite soil was intermediate between the performances for soils in which an equivalent amount of apatite was well dispersed and the control soil (no apatite added). In addition, the expansive nature of the raw apatite used, and possibly the proliferation of biomass within the concentrated apatite zone and the deposition of crystals at the top of the column, likely contributed to early column plugging and flooding, causing this part of the study to be aborted early (at $\sim 210 \mathrm{~h}$ run time).

This initial series of soil column studies ("Series 12") had several flaws (column flooding; poor feed $\mathrm{pH}$ control; formation of colloidal forms of metals of interest in feed; etc.) that were addressed, in large part, in a repeat run ("Series 57"), using a different soil type (02-0608). 


\subsubsection{Spiked Synthetic Groundwater Fed to "Clean"Soil ("Series 57")}

A repeat series of soil column tests ("Series 57") was run vs. spiked metal feed, incorporating several "lessons learned" from the "Series 12" tests, described above (Section 4.7.3.1). "Clean" soil (02-0608, from the DOE Fernald Site) was retained in the column with use of discs punched from coffee filters, supported on polyethylene screens. The multi-metal spiked feed was the same as used in "Series 12", except that the aqueous phase was allowed to set quiescent for several weeks, to allow uranium-arsenic fine particulate to settle out. This precipitate phase was removed with use of a siphon, and the remaining solution phase was filtered at $0.45-\mu \mathrm{m}$ before use. Soluble arsenic in the feed was therefore relatively low $(\leq 1,000 \mu \mathrm{g}-\mathrm{As} / \mathrm{L}$ in the filtrate, vs. $\sim 8,000 \mu \mathrm{g}-\mathrm{As} / \mathrm{L}$ as originally formulated $)$, as was soluble $\mathrm{U}(\leq 3,000 \mu \mathrm{g}-\mathrm{U} / \mathrm{L}$ in the filtrate, vs. $\sim 26,000 \mu \mathrm{g}$ $\mathrm{U} / \mathrm{L}$ as originally formulated). Additionally, careful metering of humidified carbon dioxide and air into the feed solution reservoir more precisely controlled the solution $\mathrm{pH}$ value (to a value $\sim 5.6$ ). As a result, no apparent $U$-As colloid was fed to the soil columns. The average propagation velocity of the aqueous phase within the soil columns was $\sim 1.12 \times 10^{-4} \mathrm{~cm} / \mathrm{s}\left(9.66 \times 10^{-2} \mathrm{~m} / \mathrm{d}\right)$, which was noted to maintain slightly subsaturated conditions within the soil (i.e., no "flooding" of the columns was observed during the experiment).

Column 57-1 (nominal bed volume $\sim 29 \mathrm{cc}$ ) was a control, with no apatite (APA) amendment, whereas column 57-2 (nominal bed volume $\sim 33 \mathrm{cc}$ ) was amended by blending with $\sim 4.6 \mathrm{wt} \%$ APA (as material 119-2S; this is crushed fish bone product that has been elutrified with flowing water to float away much of the extraneous matter (see Table 42). This APA product is equivalent to that used for Column 12-4). The waterfilled volume fraction of the soil columns is estimated at $\sim 0.31$ (based upon mass of the soil dry and at saturation). The columns were pre-equilibrated by flow of $\sim 1.2$ bed volumes of clean synthetic groundwater. Thereafter, the spiked metal solution was fed for a total of $960-\mathrm{h}(40-\mathrm{d})$, corresponding to the elution of $\sim 87$ nominal bed volumes ( 300 pore volumes) of eluate for column $57-1$ and $\sim 77$ nominal bed volumes ( $\sim 250$ pore volumes) for column 57-2.

Detection of traced metals in the column aqueous eluate indicates that the metal of interest may be poorly retained by the soil component, without apatite amendment. Analysis of the column eluate fractions indicates that the sequence of breakthrough of metal from column 57-1 (no APA) progressed in the order: $\mathrm{Hg}(\geq 60 \%$ of the cumulative amount fed appears in the eluate $) \geq \mathrm{U}(\geq 40 \%$ in eluate $)>>\mathrm{Cd}(\sim 1 \%$ in eluate). Fuller (1978) has evaluated the relative mobility of select cation-forming elements in a variety of soils and found that $\mathrm{Hg}$ has high to moderate mobility compared to $\mathrm{Cd}$. The relative mobility of $U$ in the selected soil matrix may be related to the high carbonate content of the soil (and the alkalinity of the pore water phase within the soil), which enhances the formation of soluble uranyl carbonate complexes (Giblin et al., 1981; Miyahara, 1992; Meinrath et al., 1996). In contrast, the alkalinity may actually enhance the retardation of $\mathrm{Cd}$ by precipitation of otavite $\left(\mathrm{CaCO}_{3}\right)$. In addition, metals such as $\mathrm{Cd}$ and $\mathrm{Zn}$ show 
appreciable sorption on calcite (Zachara et al., 1993). No detectable As was found in the column 57-1 eluate fractions. Again, Fuller (1978) indicates that As has relatively low mobility in many soil types. Elution of $U$ and $\mathrm{Cd}$ from column $57-1$ is illustrated in Figure 58.

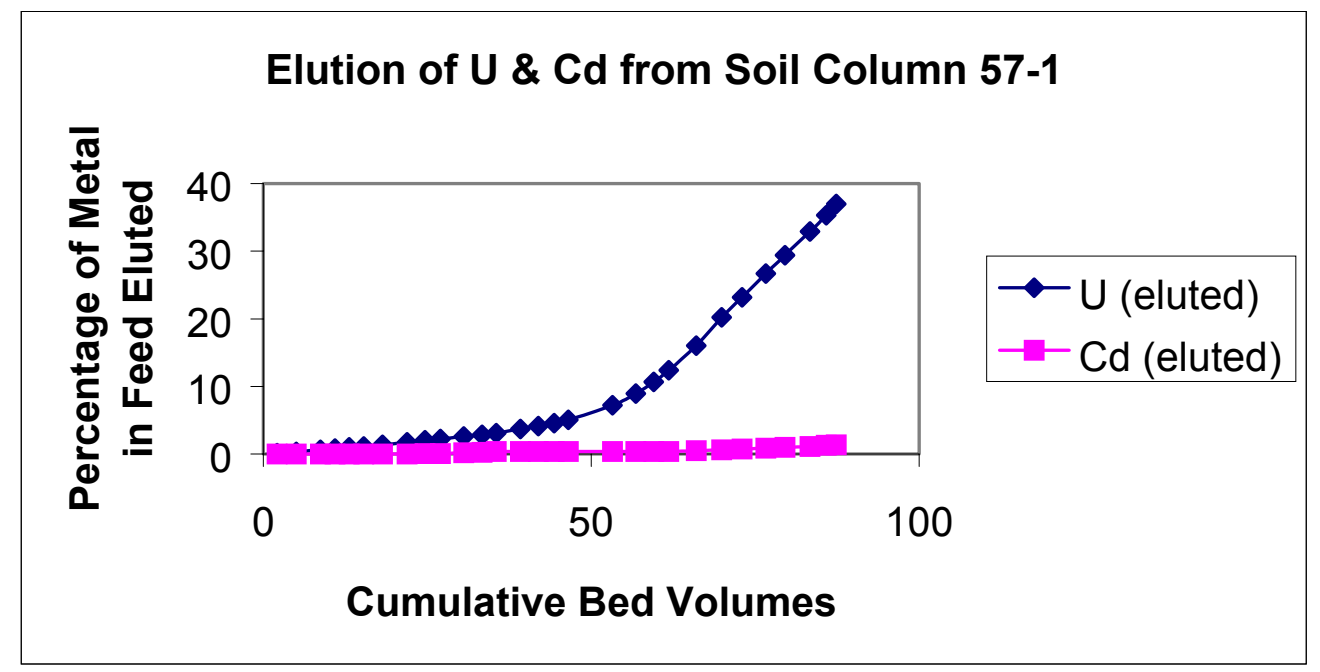

Figure 58. Breakthrough of $U$ and $\mathrm{Cd}$ in the eluate from Soil Column 57-1 (no Apatite amendment). The ordinate of the graph represents the cumulative amount of metal found in the column eluate compared to the cumulative amount of metal fed to the soil column.

Figure 59 illustrates the concentration of soluble $\mathrm{Hg}$ in the feed and column eluate fractions. Mercury was noted to have a tendency to diffuse into the column feed lines and the plastic containers used to collect solutions, causing a greater analytical variability (as noted by the analytical data scatter in the Figure). No detectable $\mathrm{Hg}(\leq 20 \mu \mathrm{g} / \mathrm{L})$ was found in the eluate from Column 57-2 (containing APA). The only "spiked" contaminant found in the eluate from Column 57-2 was a small amount of As (see Figure 60). 


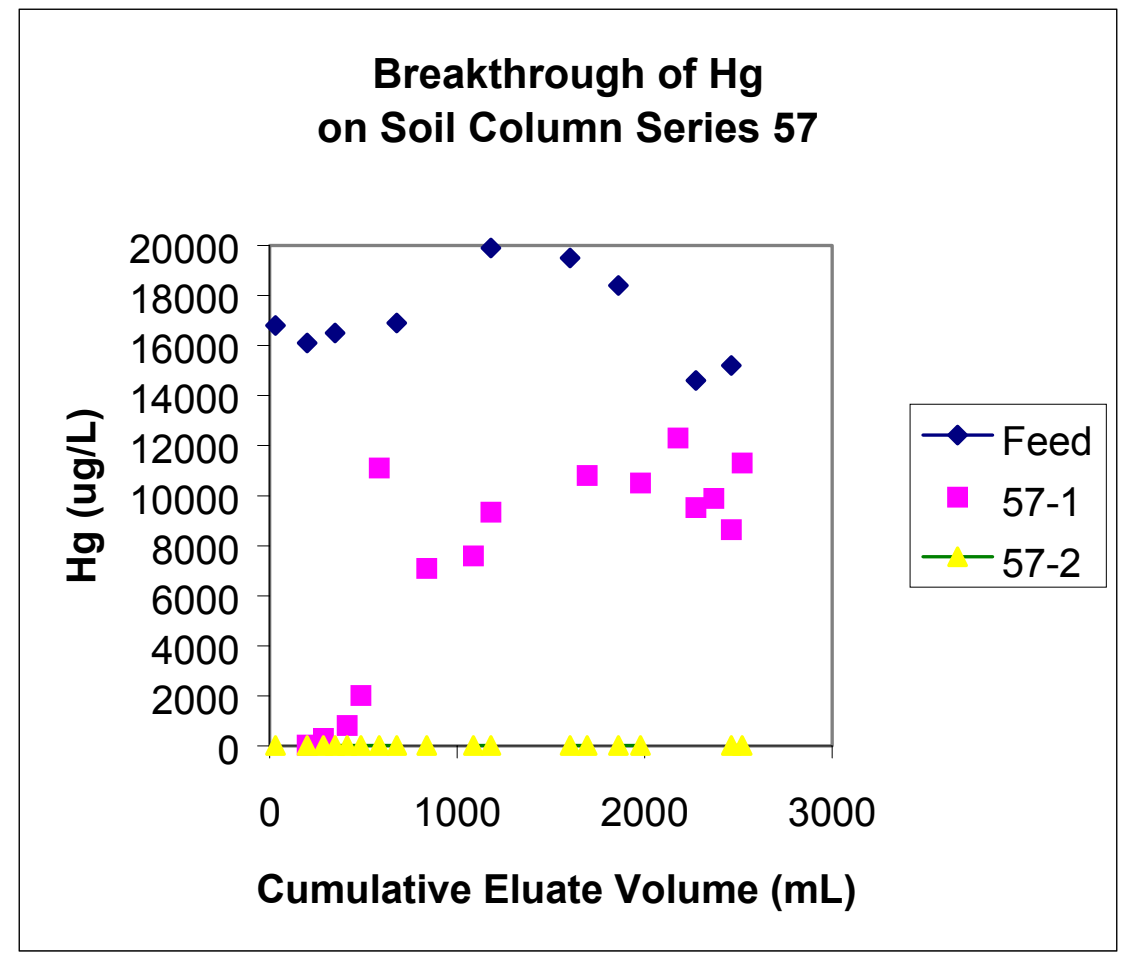

Figure 59. Mercury in Aqueous Solution (Feed and Column Eluate Samples). Mercury in the eluate from column 57-2 (with 5\% APA) was always at or below the analytical reporting limit $(\leq 20 \mu \mathrm{g} / \mathrm{L})$. 


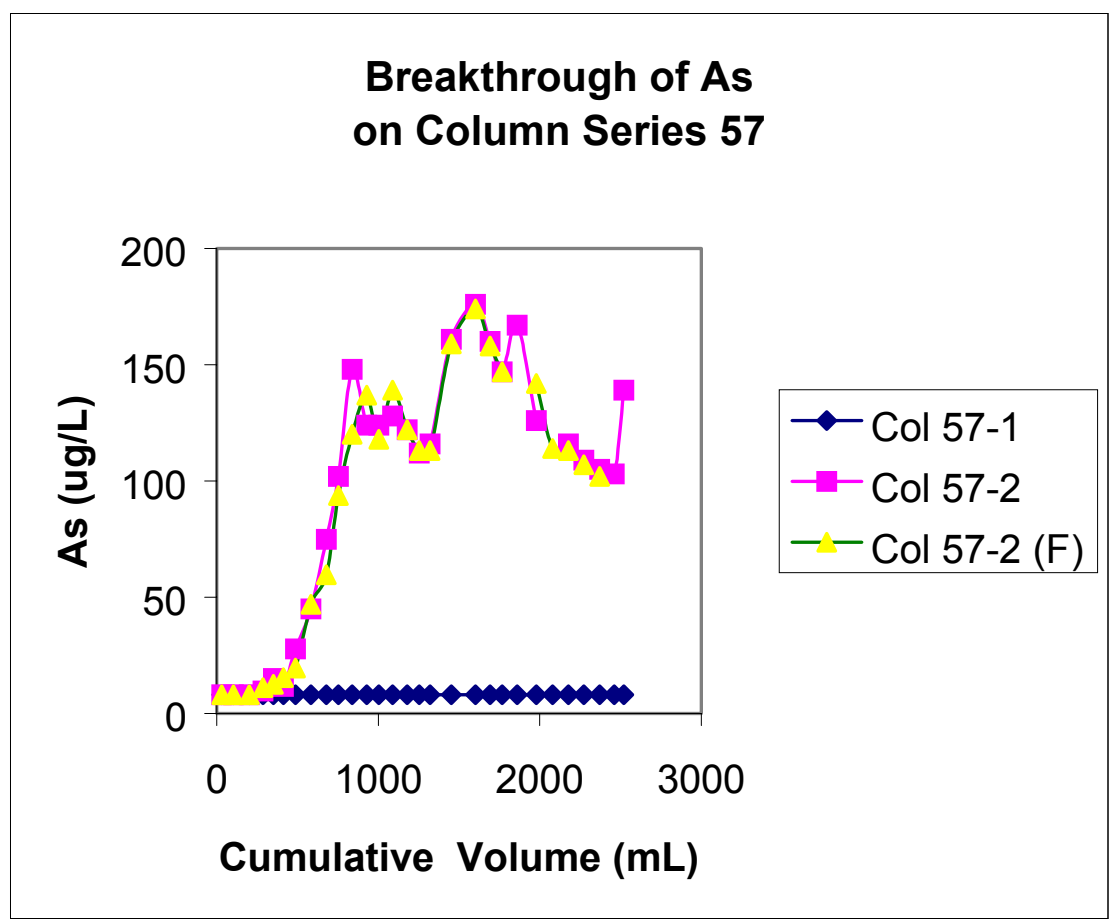

Figure 60. Arsenic Concentration in Soil Column Series 57 Eluate. (Note: Col 57-2 (F) represents data for column 57-2 eluate that has been filtered through $0.45-\mu \mathrm{m}$ media; the As in raw and filtered eluate is comparable, indicating that eluted As is in a nominally "soluble" form). Arsenic in the eluent from column 57-1 (no APA) was always at or below the analytical reporting limit $(\leq 8 \mu \mathrm{g} / \mathrm{L})$. 


\subsubsection{Aqueous Feed to Contaminated Soil ("Series 31")}

In this series of experiments, untraced synthetic BYBY groundwater is percolated into contaminated soil 00-0656. In preliminary testing (Project Task 1.3.3), the potential mobility of select metals in this soil was evaluated by the TCLP procedure (MCL SOP 7743, based upon EPA SW846 Method 1311). In addition, samples of soil 00-0656 were mixed with varying amounts of raw apatite (screened to a size range of $\sim 250-450 \mu \mathrm{m}$ ), to determine the effect of added APA. The results of this series of tests are presented in Table 43.

Table 43. Effect of Added Apatite on the TCLP Leachate for Soil 00-0656

\begin{tabular}{|c|c|c|c|c|c|c|c|}
\hline \multirow{2}{*}{$\begin{array}{c}\text { Wt } \% \\
\text { APA }\end{array}$} & \multicolumn{7}{|c|}{ Metal in TCLP Extract $(\mathrm{mg} / \mathrm{L})$} \\
\cline { 2 - 8 } Added & $\mathrm{Ca}$ & $\mathrm{Cd}$ & $\mathrm{Cu}$ & $\mathrm{Mg}$ & $\mathrm{P}$ & $\mathrm{U}$ & $\mathrm{Zn}$ \\
\hline 0 & 21.9 & 1.07 & 2.05 & 4.68 & 0.159 & 11.2 & 2.93 \\
\hline 0.5 & 59.0 & 0.948 & 1.68 & 5.05 & 15.5 & 2.90 & 2.42 \\
\hline 1.0 & 92.5 & 0.862 & 1.45 & 5.93 & 25.6 & 1.77 & 2.22 \\
\hline 2.0 & 146 & 0.612 & 0.957 & 6.96 & 58.4 & 1.14 & 1.54 \\
\hline 5.1 & 301 & 0.208 & 0.431 & 12.1 & 132 & 0.859 & 0.59 \\
\hline
\end{tabular}

Note that the data in Table 43 are for dried soil and APA blend extracted for 16-h by the TCLP protocol. Final leachate $\mathrm{pH}$ value ranged from 4.96 (no APA) to 5.23 (5 wt\% APA). There was no pre-equilibration period, so that metal is simultaneously leaching from the soil phase and sorbing on the APA phase. The effect of APA, normalized to the concentration of metal with no added APA, is shown in Figure 61. APA appears to affect leached $\mathrm{Cd}, \mathrm{Cu}$, and $\mathrm{Zn}$ in a similar manner, but $\mathrm{U}$ appears to be sorbed more readily under the testing conditions. 


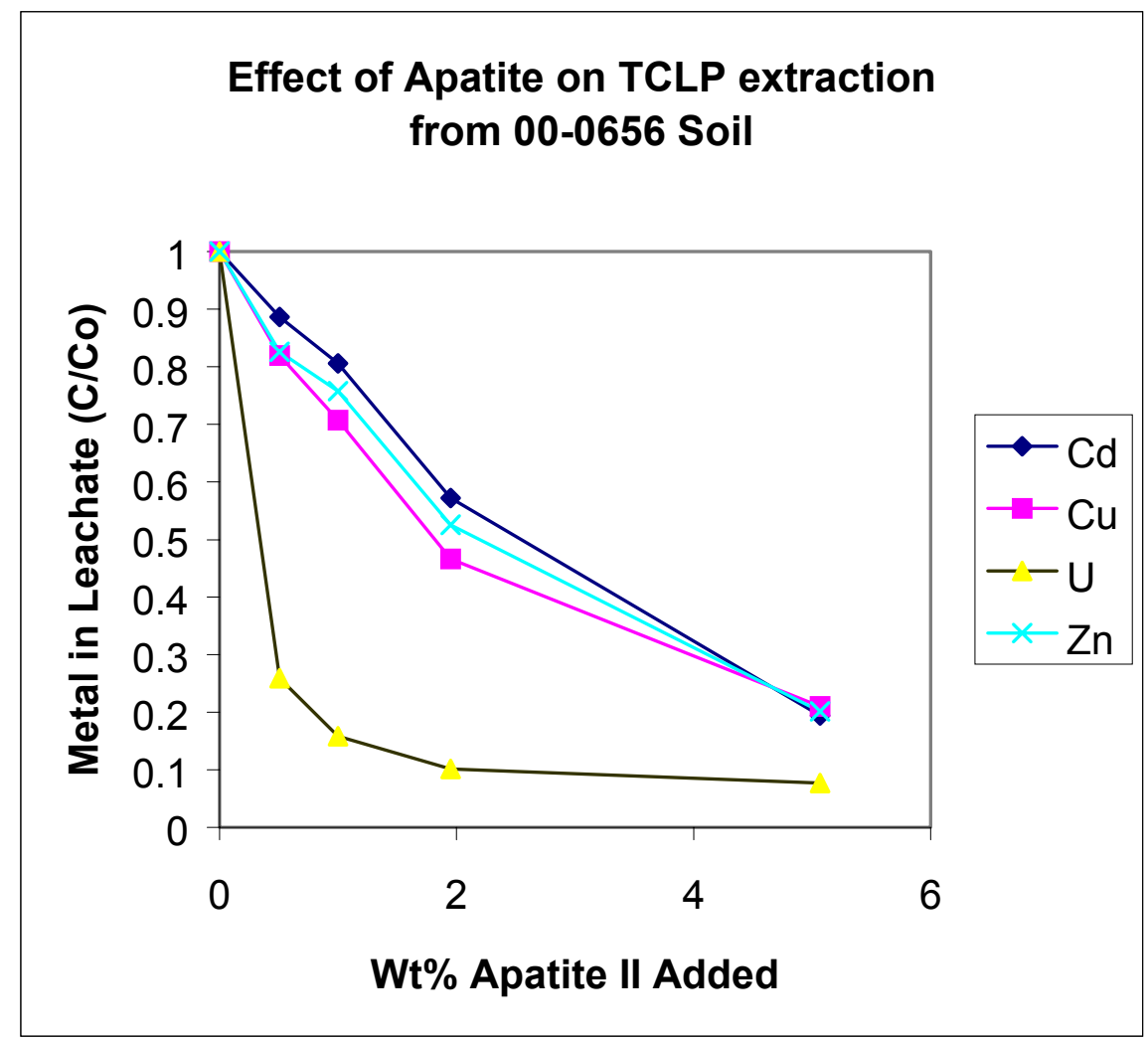

Figure 61. Raw Apatite II is added to dry blended soil 00-0656, and then the blend is subjected to the TCLP protocol. Results are normalized to the concentration of metal in the leachate from soil with no added APA (see Table 41).

For purposes of soil column testing, amended soil was prepared by blending with $\sim 5$ wt $\%$ APA product. Column 31-1 was a control, with no added APA. Column 31-2 was prepared with elutriated APA (material 119-2S; see Section 4.7.2). Apatite product designation "00-0418", used in preparation of column 31-3, is a very fine-grained ground biogenic apatite product, with B.E.T. surface area $\sim 1.9 \mathrm{~m}^{2} / \mathrm{g}$; see Bostick et al. (2000). Apatite product designation "01-0380 fines," used in preparation of column 31-4, is ground biogenic apatite that passed through a \#40 screen.

Initially, the average eluent flow rate was $\sim 5.01 \mathrm{~g} / \mathrm{h}\left(\sim 2.1 \times 10^{-4} \mathrm{~cm} / \mathrm{s}\right)$. At this flow rate, the columns eventually "flooded," i.e., the feed rate exceeded the drain rate and a small amount of free liquid began to accumulate on the tops of the columns. At sampling interval $63(\sim 770 \mathrm{~h})$, the feed flow rate was transitioned to an average value of $2.59 \mathrm{~g} / \mathrm{h}$ $\left(\sim 1.1 \times 10^{-4} \mathrm{~cm} / \mathrm{s}\right)$. 
Figure 62 illustrates the elution of $U$ from control column 31-1. Hexavalent uranium, as the uranyl ion, forms a soluble anionic complex with bicarbonate ion. Initially, a peak of poorly retained uranium elutes from the column (at $\sim 4.8$ nominal bed volumes), followed by a steady-state desorption of uranium. At an alkalinity of $\sim 1.75 \mathrm{meq} / \mathrm{L}$ as bicarbonate $\left(\mathrm{HCO}_{3}{ }^{-}\right)$ion, the steady-state desorption of $\mathrm{U}$ from Column $31-1$ is $\sim 800$ $\mu \mathrm{g} / \mathrm{L}$. Later, when the alkalinity of the feed solution was transitioned to $\sim 3 \mathrm{meq} / \mathrm{L}$ (as $\mathrm{HCO}_{3}{ }^{-}$), the steady-state desorption of $\mathrm{U}$ increased to $\sim 1200 \mu \mathrm{g} / \mathrm{L}$.

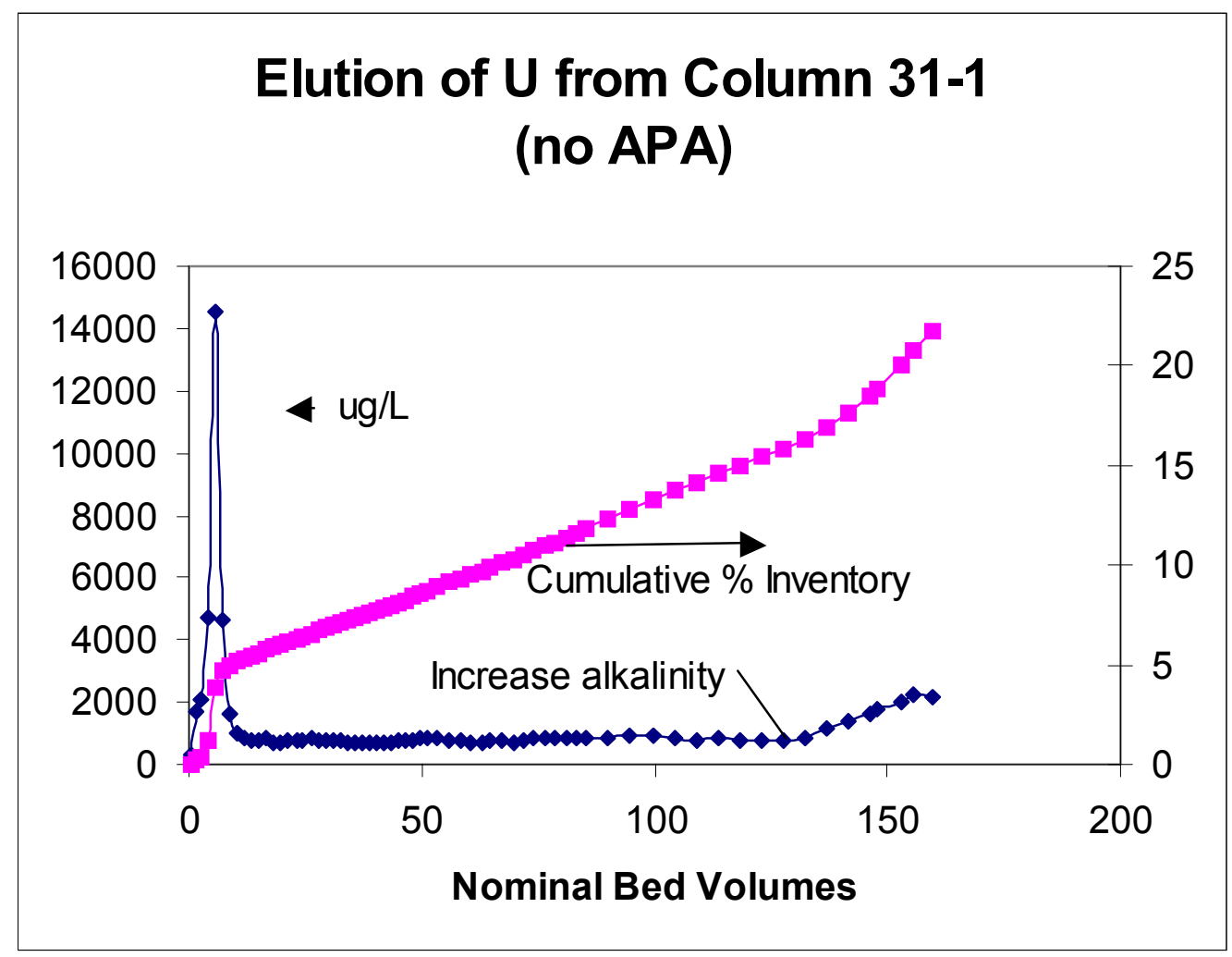

Figure 62. Elution of $U$ from Column 31-1 (No Apatite Amendment). The right hand ordinate represents the cumulative amount of metal found in the column eluate compared to the cumulative amount of metal fed to the soil column.

Figure 63 compares the performance of Column 31-1 (control) with the apatite-amended soil columns for the retention of $U$. Other than a small initial wash-off of soil fines for all columns, the $U$ in the eluate from apatite-amended soil soon is at or near the method detection limit $(20 \mu \mathrm{g} / \mathrm{L})$. 
Elution of U from 00-0656 Soil Columns

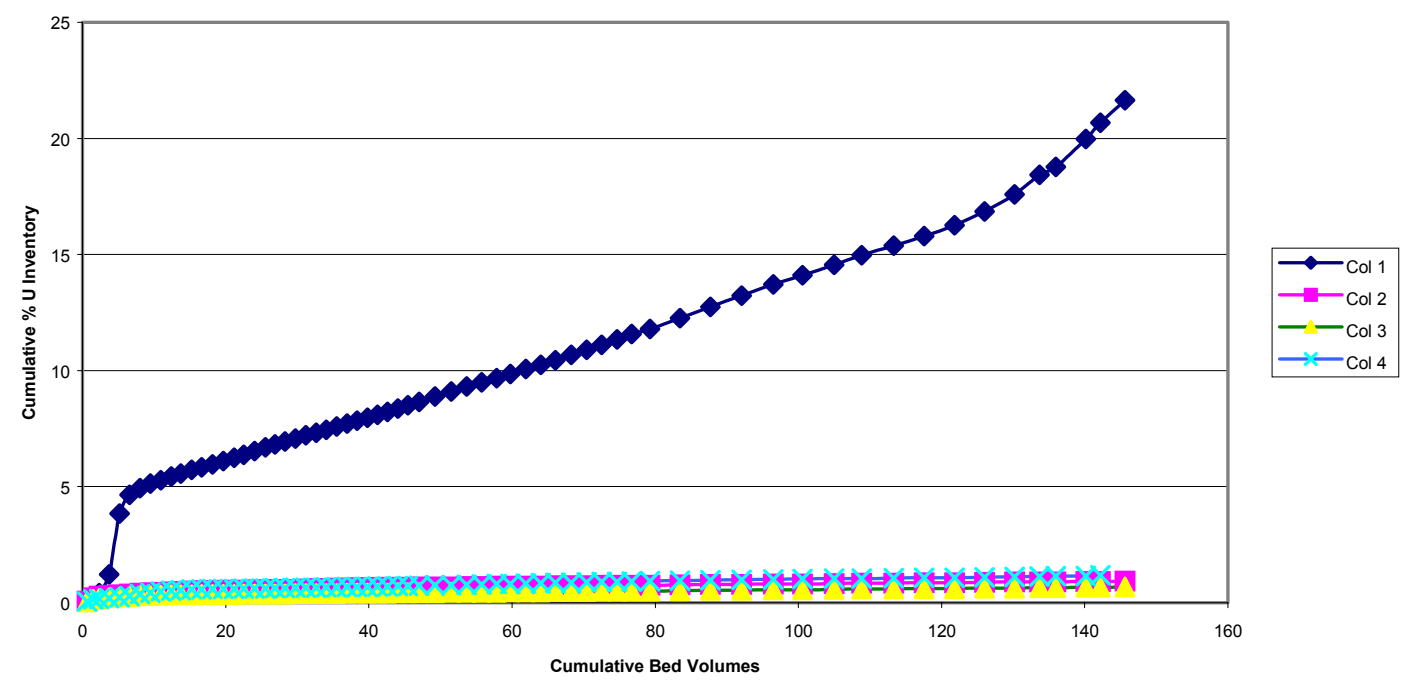

Figure 63. Cumulative elution of $U$ from "Series 31" Soil Columns. The ordinate represents the cumulative amount of metal found in the column eluate compared to the cumulative amount of metal fed to the soil column. Column \#1 (31-1) was a control, with no added APA. Column \#2 (31-2) was prepared with elutriated APA. Apatite product designation "00-0418", used in preparation of Column \#3 (31-3) is prepared with a very fine-grained ground biogenic apatite product. Apatite product designation "01-0380 fines," used in preparation of Column \#4 (31-4) is prepared with ground biogenic apatite that passed through a \#40 screen.

Other monitored metals were generally well retained by the soil columns. No detectable $\mathrm{Cd}$ eluted from any of the columns. A small amount of $\mathrm{Zn}$ appeared in the eluate from the control (31-1), and a small but detectable amount of $\mathrm{Cu}$ appeared in the earlier eluate fractions of all soil columns.

During the course of the experiment, the Series 31 columns began to flood, producing a film of free liquid at the top of the column that limited the diffusion of oxygen into the soil. For the columns amended with raw apatite (a nutrient source), this resulted in the apparent proliferation of anaerobic bacteria. This is suggested in Figure 54: at $\sim 125$ bed volumes eluted, APA-amended columns 31-3 and 31-4 have developed a dark stain near the bottom of the column, and the eluates from these columns have developed noticeable odor and turbidity.

Manganese in the column eluate appeared to track these observations (Figure 64). Much of the potentially available $\mathrm{Mn}$ in soil is in the form of higher Mn oxide minerals or adsorbed or coprecipitated with hydrous oxides of Fe (Gambrell \& Patrick, 1982). A change in soil $\mathrm{pH}$ or oxidation-reduction potential can have a marked influence on forms of Mn. Acid and reducing soil conditions favor divalent Mn forms that result in increased levels of soluble and exchangeable Mn. Flooding of soil, with resultant 
decrease in air permeation into the soil, and biological activity on organic matter may each contribute to the creation of reducing environments, and subsequent enhanced mobilization of Mn. Figure 64 illustrates the elution of Mn from the soil columns. Column 31-1 (no apatite) developed a thin film of excess liquid early, and eluted a broad peak of Mn. Soils with added apatite generally retained Mn until the eluate developed a septic odor and turbidity, suggesting that reductive conditions were developing (see Figure 65. Note, however, that eluate from Column 31-2, amended with APA product having relatively low organic matter, never developed appreciable odor or turbidity. After the eluate became turbid, some small portion of the Mn was associated with the fine particulate (i.e., filtration of eluate removed appreciable Mn). Note, however, that only a relatively small proportion of the total soil inventory of Mn (e.g., $<5 \%$ of the total Mn estimated by EPA Method 3050 extraction) eluted during the testing interval.

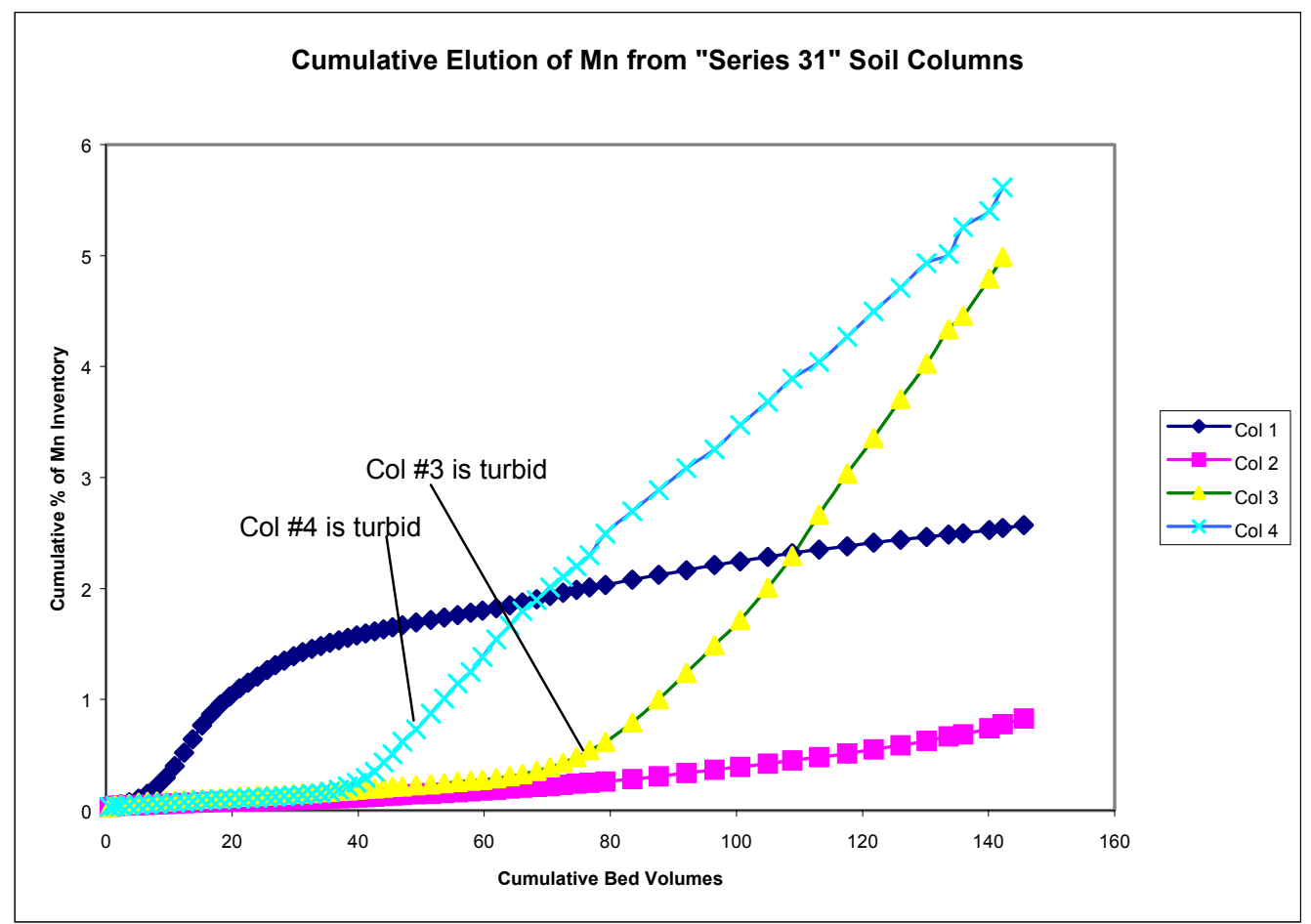

Figure 64. Elution of Mn from Soil Column Series 31. Column \#1 (31-1) was a control, with no added APA. Column \#2 (31-2) was prepared with elutriated APA. Apatite product designation "00-0418", used in preparation of Column \#3 (31-3) is prepared with a very fine-grained ground biogenic apatite product. Apatite product designation "010380 fines," used in preparation of Column \#4 (31-4) is prepared with ground biogenic apatite that passed through a \#40 screen.

Figure 65 illustrates the elution of $\mathrm{P}$ from the soil columns. The inventory of $\mathrm{P}$ in the non-amended soil is modest $(370 \mu \mathrm{g}-\mathrm{P} / \mathrm{g})$. The elution of $\mathrm{P}$ from amended soil columns is greatest for Column 31-3, containing fine-grained apatite. For eluate from columns 313 and 31-4, some $P$ is removed by filtration of the eluate (with use of $0.45-\mu \mathrm{m}$ medium), suggesting that a portion of the $\mathrm{P}$ is associated with the fine particulate phase escaping 
past the coarse filter paper used to retain soil grains in the column. The overall rate of loss of $\mathrm{P}$ decreases somewhat as the concentration of soluble $\mathrm{Ca}$ ion is increased, possibly by common ion effect on the solubility of apatite phase.

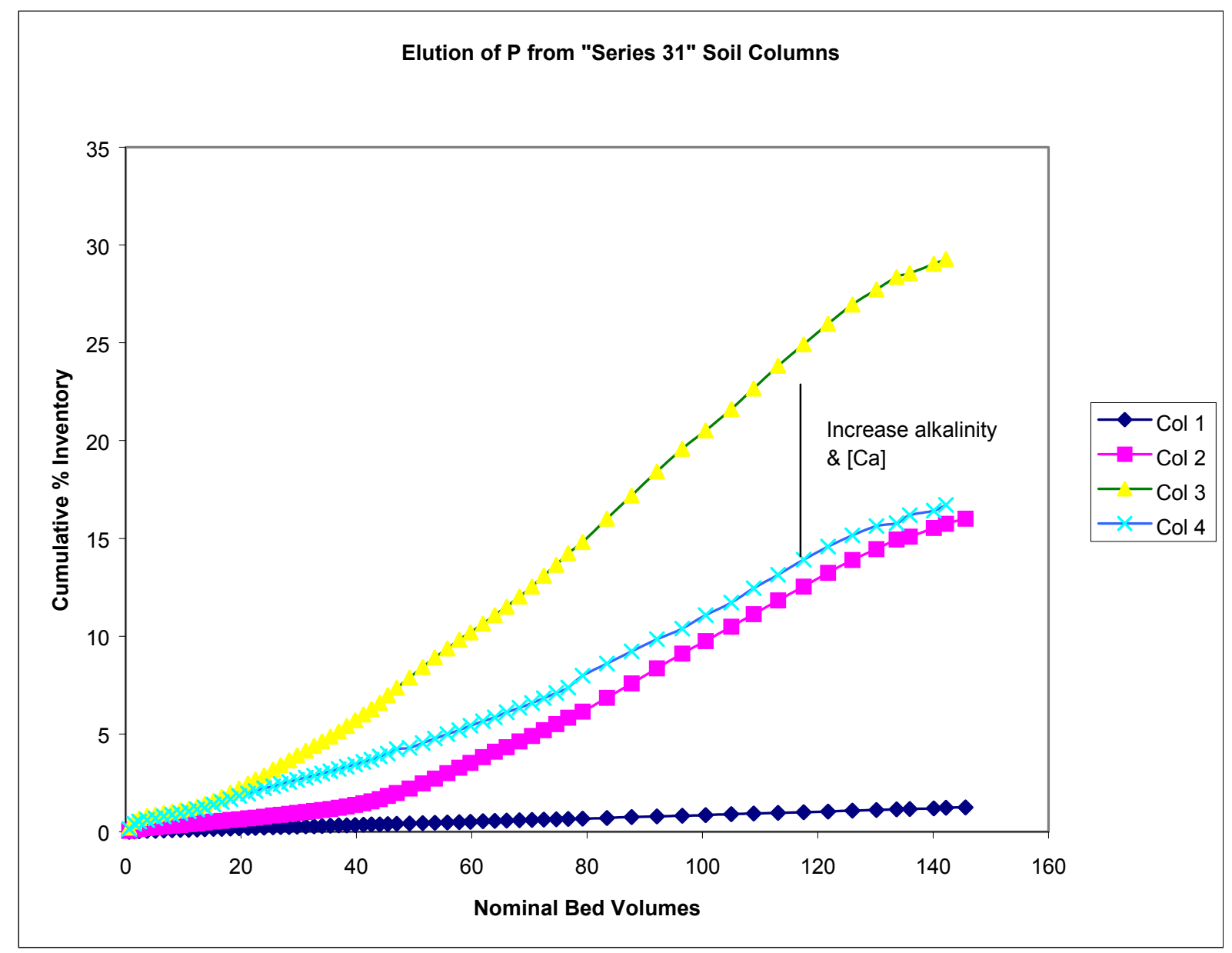

Figure 65. Elution of $P$ from "Series 31 " Soil Columns. Column \#1 (31-1) was a control, with no added APA. Column \#2 (31-2) was prepared with elutriated APA. Apatite product designation "00-0418", used in preparation of Column \#3 (31-3) is prepared with a very fine-grained ground biogenic apatite product. Apatite product designation "01-0380 fines," used in preparation of Column \#4 (31-4) is prepared with ground biogenic apatite that passed through a \#40 screen.

In Figure 66, we compare the cumulative elution of $\mathrm{P}$ from Columns 31-2 and 57-2. These soil columns have essentially equal inventories of total P $(\sim 0.295 \mathrm{~g})$, predominantly from amendment with APA sample 119-2S (see Table 40). Factors that contribute to the difference in the overall "attrition" of $\mathrm{P}$ (and hence the "longevity" of apatite in soil) may include the facts that Column 57-2 (1) did not appear to develop anaerobic conditions during the testing interval, (2) 57-2 was exposed to a higher flux of toxic metal ion (to inhibit microbial activity, and possibly to also react with soluble P), 
and (3) the eluate from Column 57-2 contained a higher total Ca concentration $(\geq 100$ $\mathrm{mg} / \mathrm{L}$ for $\mathrm{Ca}$ in $57-2$ eluate, vs. $60-80 \mathrm{mg} / \mathrm{L}$ for Ca in 31-2 eluate), which may suppress the dissolution of apatite by the common ion effect.

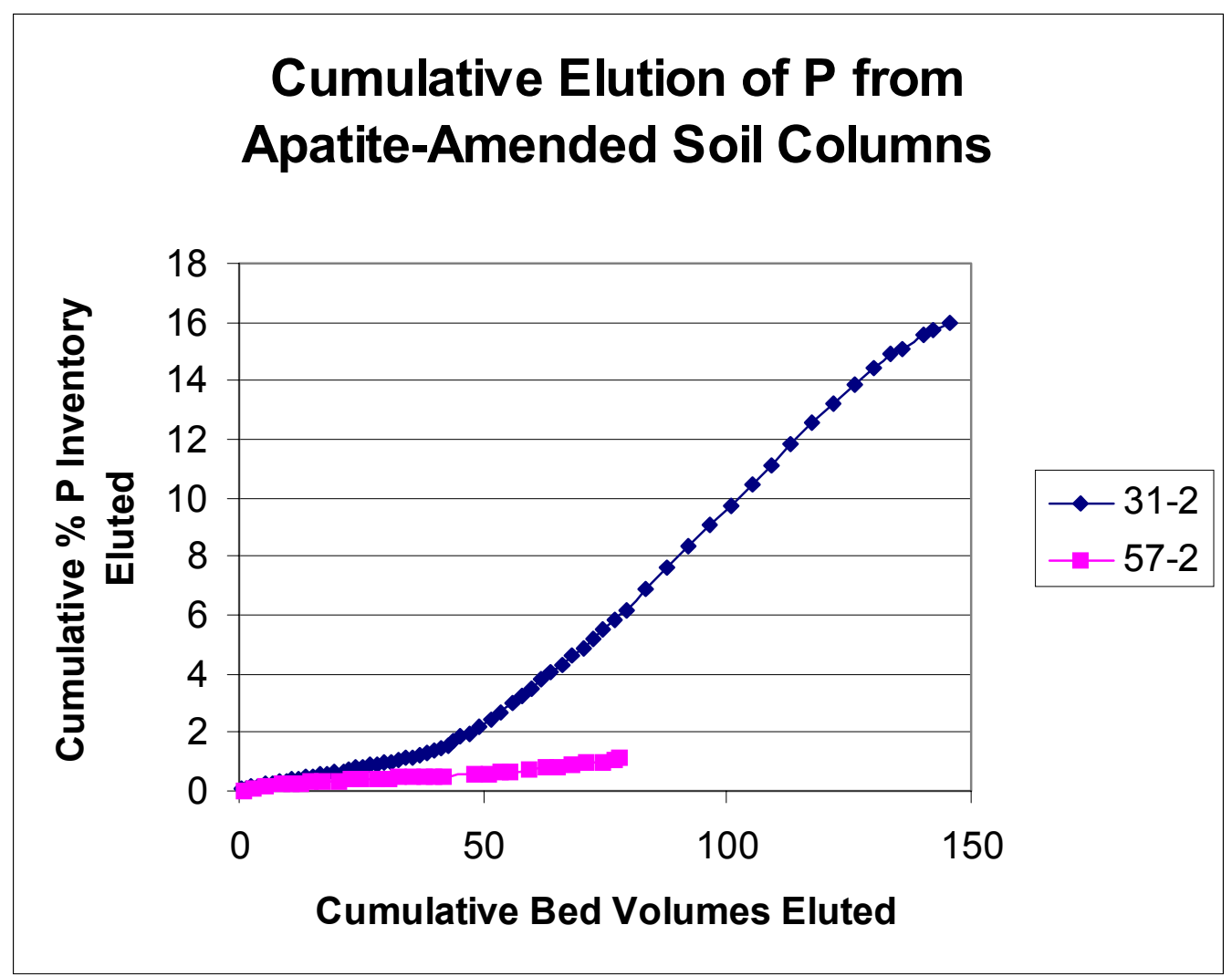

Figure 66. Cumulative Elution of Total Phosphorous (P) from Soil Columns Amended with $\sim 5 \mathrm{wt} \%$ Apatite (Material 119-2S). Total Inventory: Column 31-2 =0.298 g-P and Column 57-2 =0.293 g-P.

However, a major difference between the Series 31 and Series 57 experiments may be related to the turbidity observed in the eluate from the Series 31 columns amended with raw apatite. We isolated samples of the atmosphere-exposed fine solids found in the turbid latter eluate fractions of Columns $31-3$ and $31-4$ by using filtration $(0.45-\mu \mathrm{m}$ pore Versapor membrane syringe filter, Gelman PN 4497T) and by centrifugation (20 min at 4400 RPM). The observed turbidity in the eluents from Series 31 apatite-amended soil columns is similar to the turbidity formed due to the formation of fine grain apatite, as described in Section 4.18 (apatite dissolution experiments).

Scanning electron microscopy with energy-dispersive X-ray spectroscopy (SEM-EDS) was used to examine the morphology and elemental composition of the solids isolated from Series 31 soil column eluate. Figure 67 illustrates the average elemental composition of solids from Column 31-4, eluate fraction 58, as collected on a filter membrane (Sample 31-4-58F). 


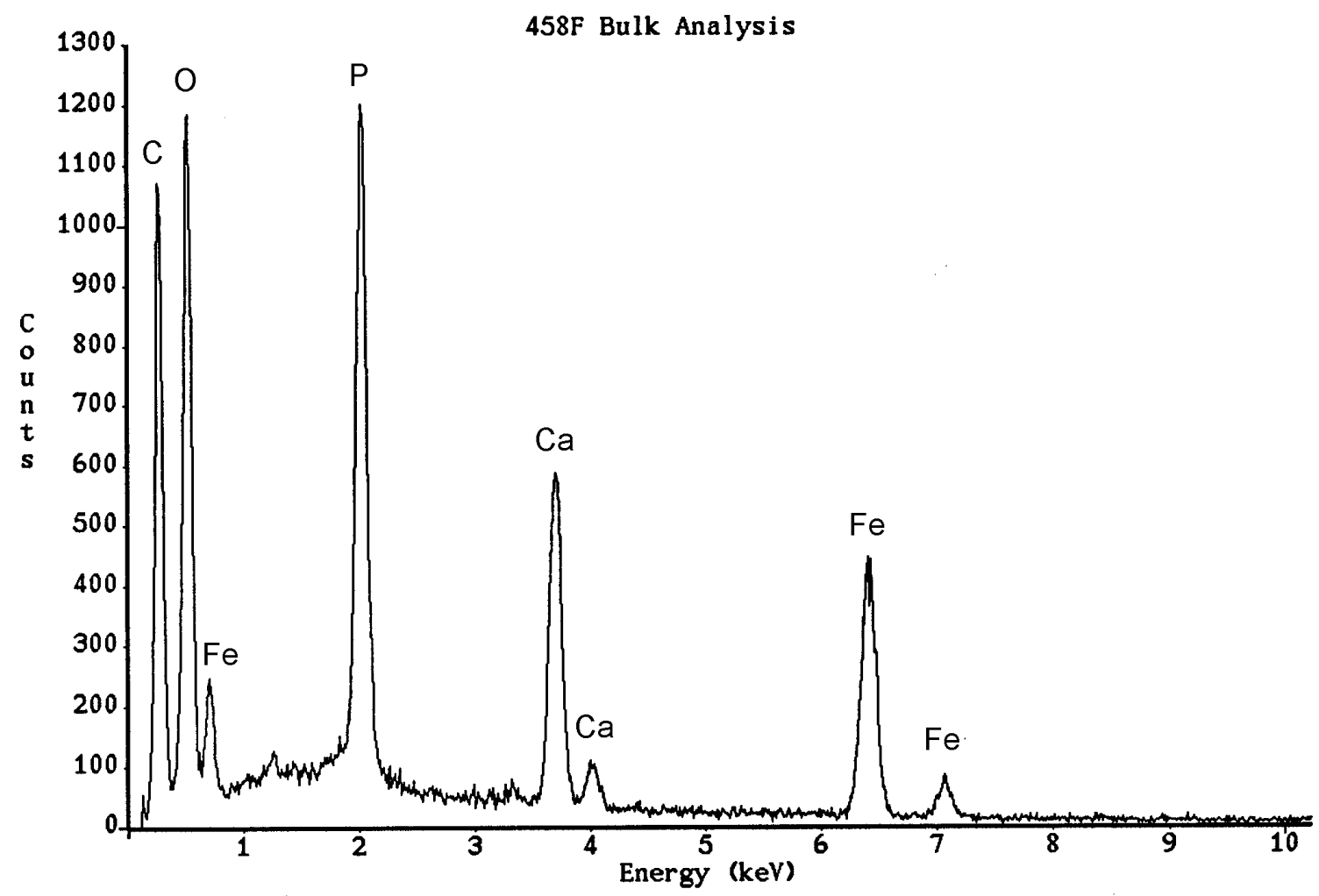

Figure 67. Elemental composition of solids from Column 31-4, eluate fraction 58, as determined with use of scanning electron microscopy with energy-dispersive X-ray spectroscopy (SEM-EDS).

A small aliquot of concentrated slurry of fine particulate (from Column 31-4, eluate fraction 56) was sonicated and placed on a transmission electron microscope (TEM) grid. As shown in Figure 68, the solids are agglomerates of individual particles with dimensions in the range of $\sim 200 \mathrm{~nm}$. 


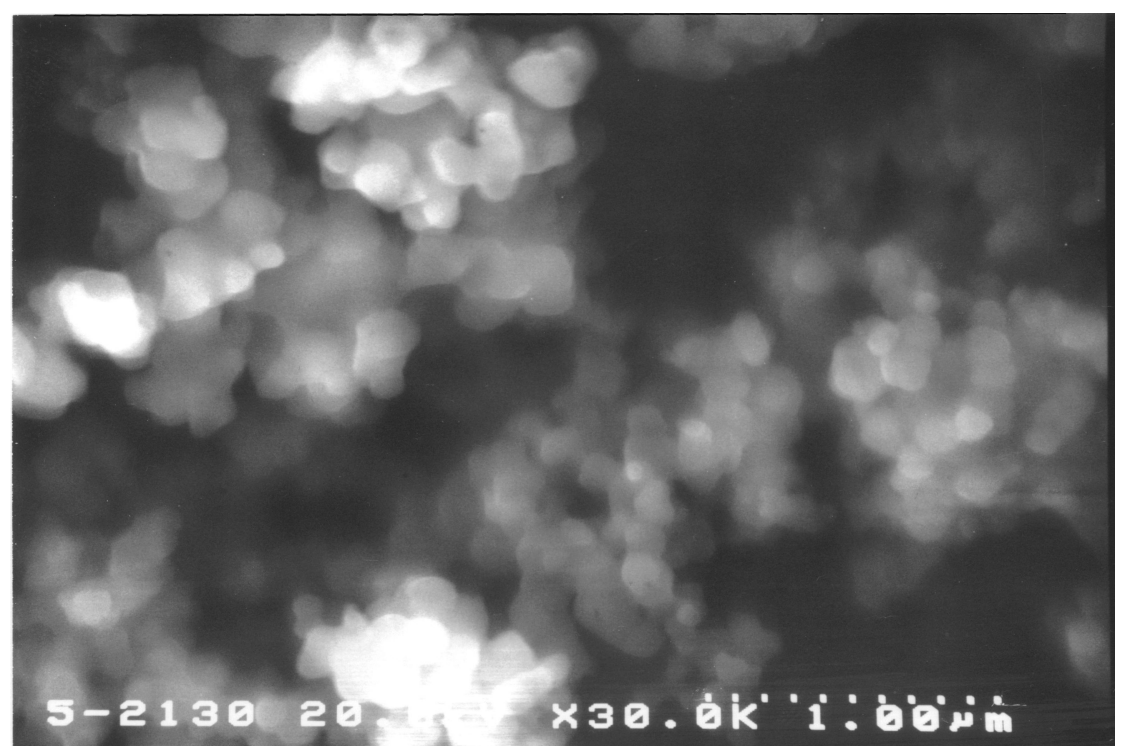

Figure 68. Morphology of fine solids that had been previously concentrated by centrifugation of Column 31-4, eluate fraction 56C. The solids are agglomerates of individual particles with dimensions in the range of $\sim 200 \mathrm{~nm}$ (median $\sim 0.17 \pm 0.04 \mu \mathrm{m})$.

We note that similar sized agglomerated particles were formed in the homogeneous precipitation of synthetic calcium and iron phosphate phases from soluble precursors. Thus it is possible that the fine particulate found in the soil column eluate represent a scavenging of ferrous iron (produced by the action of anaerobic bacteria on soil minerals) by phosphate ion (produced by the equilibrium dissolution of apatite phase). Both ferrous and ferric iron form insoluble phosphate salts. However, at near-neutral $\mathrm{pH}$ values, iron is more soluble under reducing conditions, and the homogeneous precipitation of phosphate ion by ferrous ion is optimum at $\mathrm{pH}$ values between 7 and 8 (EPA 625/1-76-001a). Note that extensive removal of phosphate ion by the formation of iron phosphate would shift the equilibrium by mass action to enhance the further dissolution of apatite phase (and thus increasing the total $\mathrm{P}$, soluble and colloidal forms, in the eluate, as suggested by the data in Figure 67).

Gschwend et al. (1987) have reported on the in-situ subsurface formation of colloidal $(\sim 100 \mathrm{~nm})$ iron phosphate solids, attributed to sewage-derived phosphate combining with ferrous iron released from aquifer solids. From chemical and thermodynamic inferences, Gschwend et al. (1987) suggest that the solids are consistent with a vivianite (ferrous phosphate hydrate) colloidal phase. Buesseler et al. (2003) remark on the observed loss of soluble phosphorous from groundwater that had been anoxic in situ upon the subsequent exposure of the solution to the ambient atmosphere. This phenomenon is attributed to the oxidation of ferrous iron with subsequent scavenging of $\mathrm{P}$, and possibly trace metals, by association with the newly formed oxidized metal colloidal solids (by sorption and coprecipitation). 
Synthetic colloidal iron phosphates (prepared in-house by homogeneous precipitation from soluble precursor solutions) did demonstrate a strong affinity to remove soluble uranium (data not shown), posing the possibility of facilitated transport of sorbed priority metals (see EPA/540/S-92/018). However, the testing performed in our investigation indicates that the small mass quantity of fine solids isolated from the anoxic soil column eluates have little or no association with priority metals (e.g., U, Mn, etc.; see Figure 68). Wet chemical analysis of solids isolated from Series 31 soil column eluate suggests that $\mathrm{Fe}$ had substituted mole for mole with $\mathrm{Ca}$ in an apatite-like structure (similar to $\mathrm{Ca}_{5}$ $\left.{ }_{x} \mathrm{Fe}_{\mathrm{x}}\left(\mathrm{PO}_{4}\right)_{3} \mathrm{OH}\right)$. The fine particles in the eluate demonstrate a tendency to further agglomerate and sediment (flocculate) with storage time, perhaps influenced by sorbed microbes that may change the net surface charge or provide a means to bridge between particles.

At the end of the testing interval, a sample of the soil from column 31-3 was submitted for identification of the associated microbial consortium; the results of this testing are described in Section 4.7.4.1. 


\subsubsection{Characterization of Soil Samples from Column Studies}

\subsubsection{Characterization of the Microbial Populations Induced in Apatite-Amended Soil Column 31-3}

The fate of phosphate ion from the dissolution of apatite soil amendment is controlled by many factors, including the composition of soil solid phases and the aqueous medium and also the microbial activity in the soil. Phosphate anion may sorb to charged surfaces in the soil matrix (especially iron and aluminum oxide phases; see Petticrew and Arocenia, 2001); may be metabolized by microbes or taken up by plant root systems; or may form insoluble precipitate phases with dissolved iron, aluminum or toxic heavy metals.

The dissolution of hydroxyapatite is $\mathrm{pH}$-dependent (Equation 10), and may be accelerated by microbes that excrete extracellular acidic metabolites. The potential utilization of microbes to accelerate the bioavailability of phosphorous (a limiting agricultural nutrient) is the subject of a recent International Symposium on Microbial Phosphate Solubilization (see abstracts of research posted at the URL: http://webcd.usal.es/psm). A range of soil microorganisms have the ability to solubilize precipitated forms of $\mathrm{P}$, with species of Pseudomonas and Bacillus bacteria and Aspergillis and Penicillium fungi being predominant in the rhizosphere.

$$
\mathrm{Ca}_{5}\left(\mathrm{PO}_{4}\right)_{3} \mathrm{OH}(\mathrm{s})+7 \mathrm{H}^{+}=5 \mathrm{Ca}^{2+}+3 \mathrm{H}_{2} \mathrm{PO}_{4}{ }^{-}+\mathrm{H}_{2} \mathrm{O}
$$

In soil column experiment Series 31, the eluate from soils amended with ground raw biogenic apatite (fish bone product) was noted to become septic, inferring a proliferation of anaerobic bacteria. At the end of the testing period, a sample of soil from Column Column 31-3 was submitted to Microbial Insights (Rockford, TN 37853) for characterization of the dominant microbial population. Denaturing gradient gel electrophoresis (DGGE) was used to detect differences in ribosomal DNA gene sequence, which were compared to a database of results for reference micro- organisms. Three dominant types of organisms were identified in the 31-3 soil.

1. Uncultivated soil bacterium associated with flexibacterial species.

These are anaeorbic or facultatively anaerobic Gram negative bacteria which can use complex organic nitrogen sources, such as peptones and aminoacids (e.g., from the raw flesh residual of ground fish bones). These are widely distributed and common to soils (Kuske et al., 1997).

\section{Pseudomonas sp.}

These are Gram-negative, preferably anaerobic beta proteobacteria, widely distributed and common to soils. Many members of this species are known to degrade complex organic compounds, including heterocyclic and aromatic compounds (e.g., chlorobenzene, etc.). These bacteria can effectively metabolize nitrate ion, many producing hydroxide ion and dintrogen $\left(\mathrm{N}_{2}\right)$ gas as byproducts. 


\section{Clostridium sp.}

These are anaerobic bacteria, common to soils, sewage, and decaying vegetation. As a group, they have a wide $\mathrm{pH}$ tolerance range (4.5 to 8.5), can use a variety of organic compounds as energy sources, and form drought- and oxygen-resistant spores.

The specific consortia of microorganisms formed in amended soil will of course be influenced primarily by the species already present in the native soil. The apatite provides the nutrients to allow these native soil microorganisms to proliferate. The biogenic apatite product is sterilized during processing, but may pick up adventitious bacteria during storage. But as this characterization indicates, the dominant bacteria in amended soil are expected to be common, nonpathogenic species that may have the ability to metabolize select co-contaminants.

\subsubsection{Examination of Soil Samples from "Series 57" Soil Columns}

The apatite-amended soil column (57-2) strongly retained the metals of interest, with the exception of As. In order to estimate the relative retention of metals, we performed a battery of tests on the exposed soil samples. The metal-exposed soil columns ("Series 57') were allowed to drain, and then the contents were extruded by gentle application of air pressure to the drain port. The wet soil from each of the columns was divided longitudinally into four approximately equal fractions, labeled A, B, C, and D. Fraction designated " $A$ " was at the water influent end of the column, and the other fractions progressed in distance along the column to fraction " $\mathrm{D}$," located at the drain (effluent) end of the column. The labeled fractions were dried under a heat lamp, the net dry weight recorded. The equivalent length of each column segment was estimated from the segment net dry weight, referenced to the dry soil bulk density and total volume and column length data for the original packed column. The individual fractions of dried soil were separately blended, and $\sim 5$-g from each fraction was taken to form a composite sample for analysis. Analysis of metal inventory within the individual segments allows estimation of the progression of metal within the column, even if no breakthrough of metal was detected in the column eluate. The blended composite sample was subjected to a battery of ancillary tests (e.g., select extraction procedures), to assess the manner by which the metal is bound to the soil matrix.

\subsection{Exposed Soil Mineralogy (“Series 57")}

The native soil (02-0656) did not have detectable levels of the contaminants added to the soil column feed solution. Portions of contaminant-exposed soil near the aqueous influent (segment "A") were examined by x-ray diffraction (XRD), to determine the crystalline components of the exposed soil, and were also examined by x-ray photoelectron spectroscopy (XPS). The latter technique allows characterization of the elemental composition in the near-surface (e.g., first 10-100 angstroms) of the material.

By XRD, soil fraction 57-1A (without added APA) evidenced several crystalline phases including quartz, calcite, dolomite, illite, and probable otavite $\left(\mathrm{CdCO}_{3}\right)$ and feldspar. 
[Note: by chemical analysis, soil fraction 57-1A (without added APA) contains $\sim 12.5$ wt $\% \mathrm{Ca}$, which would be equivalent to $\sim 30 \mathrm{wt} \%$ calcite $\left(\mathrm{CaCO}_{3}\right)$ or nearly $60 \mathrm{wt} \%$ dolomite $\left(\mathrm{CaMg}\left(\mathrm{CO}_{3}\right)_{2}\right)$ mineral phase]. In addition, there are several lines from the diffractogram that have not been assigned to a specific phase. Material 57-2A (with added APA) demonstrated similar phases, but with weaker lines for otavite and a possible additional phase representative of poorly crystalline apatite.

XPS for these materials were also very similar, except that photoelectron peaks for Cd were more intense for material 57-1A, and weak $\mathrm{P}$ peaks were present in material 57-2A (the latter consistent with the presence of apatite, nominally $\left.\mathrm{Ca}_{5}\left(\mathrm{PO}_{4}\right)_{3} \mathrm{OH}\right)$. Otherwise the near-surface elemental composition was nearly identical, comprised of the typical soil components $\mathrm{Si}, \mathrm{Al}, \mathrm{Ca}, \mathrm{Mg}, \mathrm{K}, \mathrm{C}, \mathrm{O}$, and $\mathrm{Fe}$. Curve fitting of the carbon peak reveals a carbonate component in both samples (consistent with calcite or dolomite). There is the possibility that $\mathrm{Hg}$ may also be present at very low concentrations (e.g., $\simeq 100 \mathrm{mg} / \mathrm{kg}$ ). [Since the photoelectron peaks for $\mathrm{Si}$ and $\mathrm{Hg}$ have very similar binding energies, it is difficult to differentiate $\mathrm{Hg}$ at low levels in the presence of silicate-rich materials].

\subsection{Spatial Distribution of Select Metals Within Exposed Soil (“Series 57")}

\section{$\underline{\operatorname{Arsenic}(\text { As) }}$}

The average loading of As on exposed soil (as estimated by EPA 3050 digestion of composite sample) is: $~ 17.4 \mathrm{mg} / \mathrm{kg}$ (57-1-comp) and $15.4 \mathrm{mg} / \mathrm{kg}$ (57-2-comp). The distribution of As along the exposed soil columns is illustrated in Figure 69. The slightly reduced retention of As in soil 57-2 is consistent with the observed low level of As in the eluate from the soil (cf. Figure 60), and may be related to the fact that phosphate (released in small amounts from dissolution of APA soil amendment) is similar in structure to arsenate ion, and may compete for soil binding sites. Thus, for the soil column equilibrated with phosphate ion, there is a slightly diminished binding capacity for arsenate ion. The distribution gradient for material 57-1 (no APA) is steeper that that of material 57-2 ( $\sim \mathrm{wt} \%$ APA), suggesting greater retardation in the soil matrix. 


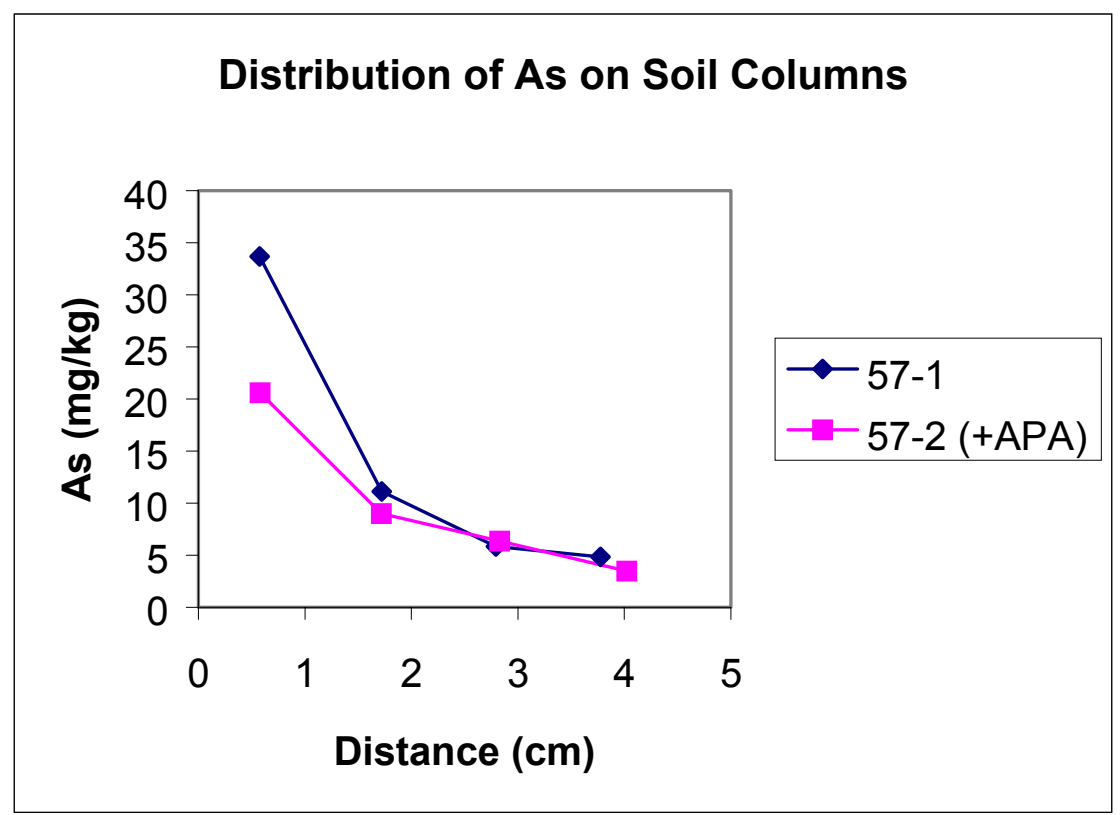

Figure 69. Spatial distribution of As in Segments from Exposed Soil Columns. 


\section{$\underline{\text { Cadmium }(\mathrm{Cd})}$}

The average loading of Cd on exposed soil (as estimated by EPA 3050 digestion of composite sample) is: $382 \mathrm{mg} / \mathrm{kg}$ (57-1-comp) and $\sim 366 \mathrm{mg} / \mathrm{kg}$ (57-2-comp). The spatial distribution for $\mathrm{Cd}$ in the soil segments is illustrated in Figure 70. Although the loading of $\mathrm{Cd}$ on soil is essentially equivalent (consistent with the elution of only $\sim 1 \%$ of Cd inventory from Column 57-1; see Figure 58), the distribution patterns are much different (see Figure 70). The preponderance of $\mathrm{Cd}$ in the APA-amended soil is concentrated at the influent end, whereas there is a near-linear gradient of $\mathrm{Cd}$ along the control column (57-1). The steeper gradient for $\mathrm{Cd}$ in the APA-amended soil suggests a greater retardation factor.

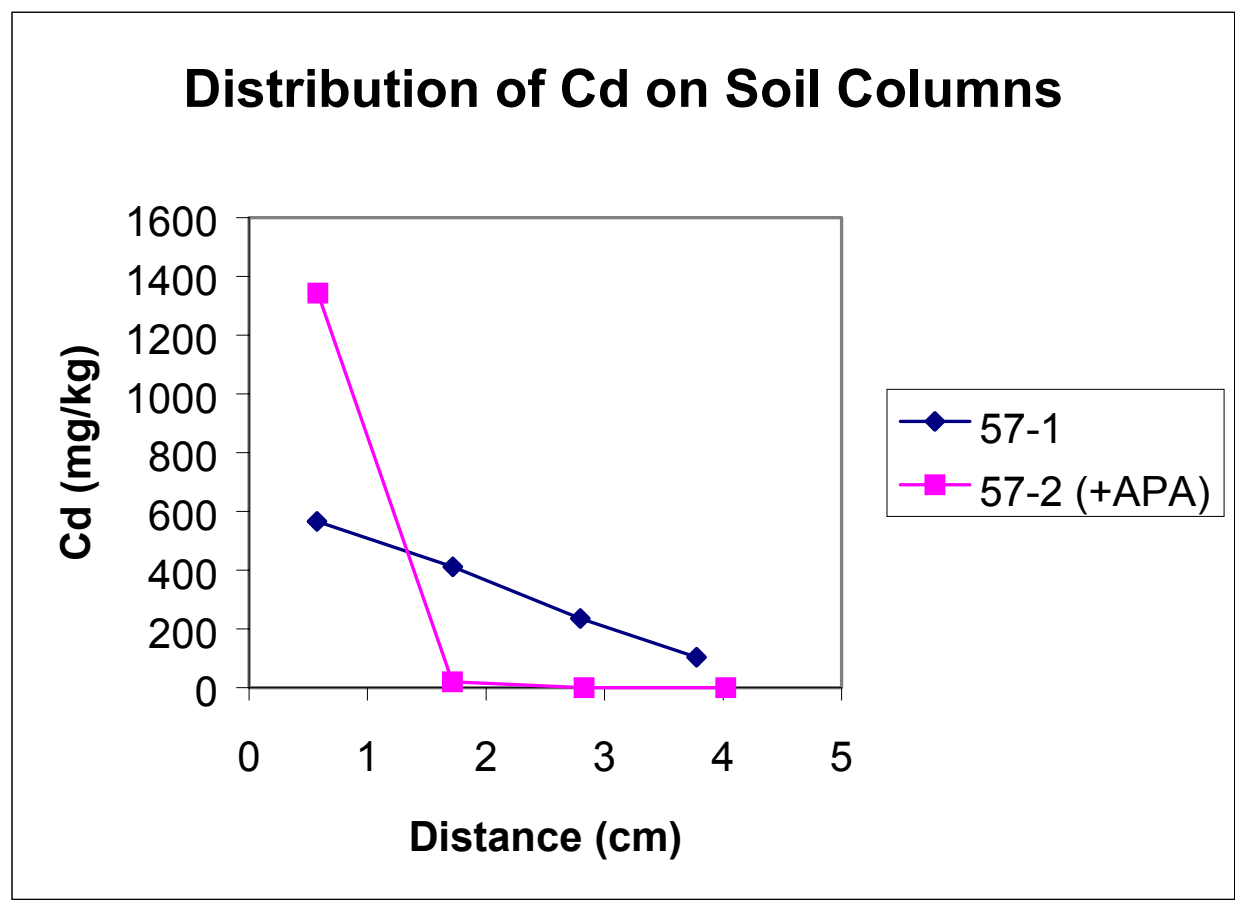

Figure 70. Spatial distribution of $\mathrm{Cd}$ in Segments from Exposed Soil Columns 


\section{Mercury $(\mathrm{Hg})$}

The average loading of $\mathrm{Hg}$ on exposed soil (as estimated by EPA 3050 digestion of composite sample) is: $739 \mathrm{mg} / \mathrm{kg}$ (57-1-comp) and $\sim 1050 \mathrm{mg} / \mathrm{kg}$ (57-2-comp). The spatial distribution for $\mathrm{Hg}$ in the soil segments is illustrated in Figure 71. Mercury in column $57-1$ is relatively low and the distribution gradient is relatively flat, suggesting that the soil is essentially saturated with respect to binding capacity for this metal (consistent with the elution of $\mathrm{Hg}$ from the control column; see Figure 59), whereas mercury in column 57-2 (APA-amended) is greatly concentrated near the influent end of the column.

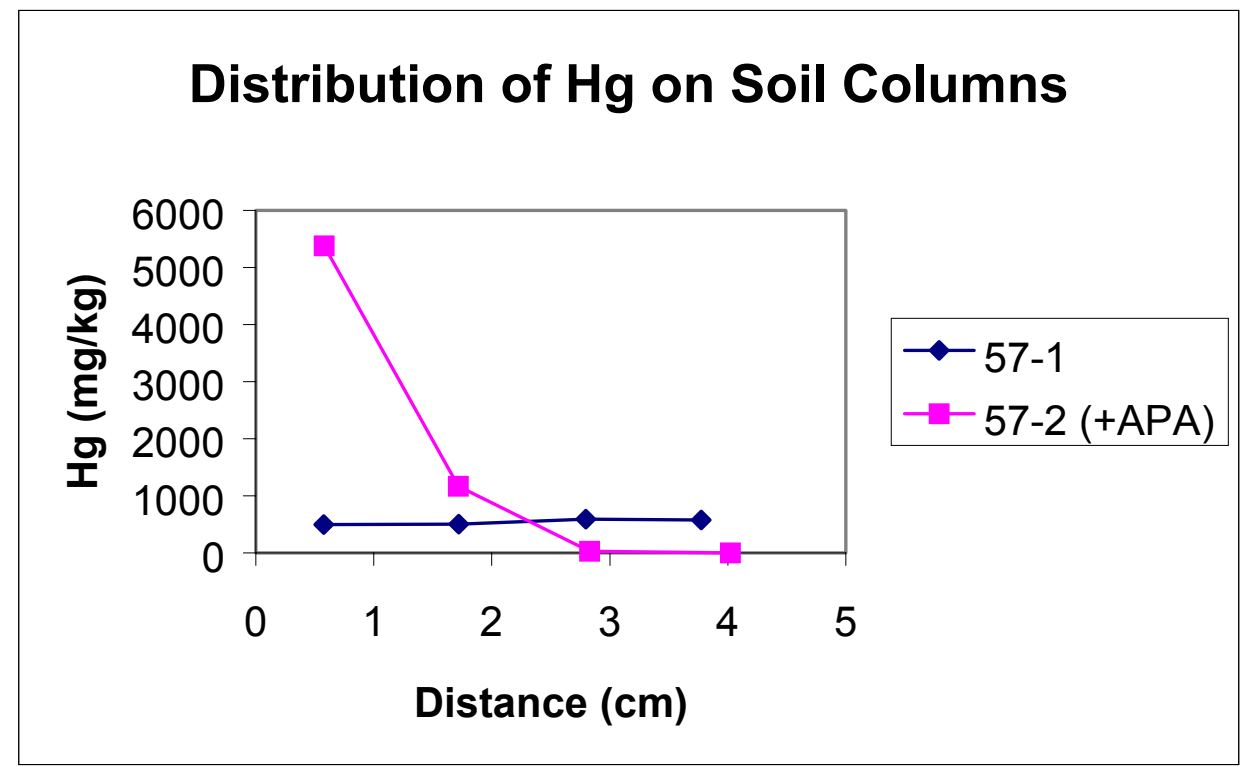

Figure 71. Spatial distribution of $\mathrm{Hg}$ in Segments from Exposed Soil Columns 


\section{$\underline{\operatorname{Uranium}(\mathrm{U})}$}

The average loading of $U$ on exposed soil (as estimated by EPA 3050 digestion of composite sample) is: $\sim 67 \mathrm{mg} / \mathrm{kg}(57-1$-comp) and $\sim 121 \mathrm{mg} / \mathrm{kg}$ (57-2-comp). The spatial distribution for $\mathrm{U}$ is illustrated in Figure 72. Similar to the cases for $\mathrm{Hg}$ and $\mathrm{Cd}$, $\mathrm{U}$ in column 57-2 (APA-amended) is greatly concentrated near the influent end of the column. In contrast, the gradient of $U$ along column 57-1 (control) is relatively flat, suggesting near-saturation binding with this contaminant, consistent with the breakthrough data shown in Figure 58.

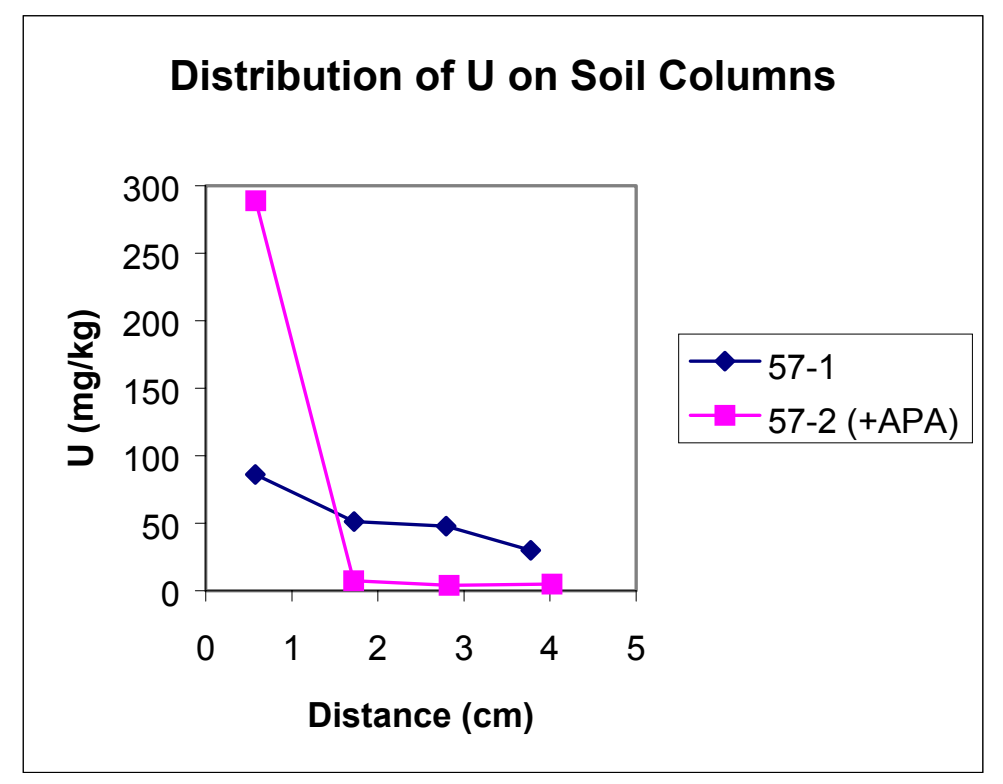

Figure 72. Spatial distribution of $U$ in Segments from Exposed Soil Columns

\subsection{Summary of data for migration of contaminants in soil}

Examining both the eluted aqueous phase and the residual soil components from soil column experiments allows a more detailed assessment of the relative metal binding capacity of the soils, with and without added APA. Analysis of the concentration of contaminants in the soil column eluate fractions as a function of total elution time and volume indicates that the soil without added APA has a lower retention of $\mathrm{Hg}, \mathrm{U}$, and $\mathrm{Cd}$ (i.e., these contaminants are incompletely retained in the soil phase), whereas the column with $\sim 5 \mathrm{wt} \%$ added APA has diminished binding capacity for As. These observations from the aqueous phase are supported by the direct analysis of the metals retained in the soils. 
For $\mathrm{U}$ and $\mathrm{Hg}$, the soil amended with APA phase (57-2) demonstrates both a greater total inventory of bound metal and a steeper gradient of metal concentration vs. distance, compared to the control soil, indicating a greater retardation of contaminant mobility. Cadmium is retained strongly in both the control and amended soil columns, but the gradient of metal concentration vs. distance is much steeper for the soil with added APA, suggesting a stronger retention factor.

These observations from the soil column experiments are consistent with the earlier batch test experiments (section 4.3), in which individual contaminants in aqueous phase were contacted with APA. The cationic contaminants $\mathrm{UO}_{2}{ }^{+2}, \mathrm{Cd}^{+2}$ and $\mathrm{Hg}^{+2}$ (and several others) all demonstrated strong partitioning to the solid (APA) phase. In contrast, oxyanions, such as arsenate $\left(\mathrm{AsO}_{4}{ }^{-}\right)$showed minimal sorption on APA. Since arsenate is similar in structure and charge to phosphate ion $\left(\mathrm{PO}_{4}^{-}\right)$, it had been postulated that perhaps arsenate would be co-precipitated along with phosphate salts of select metals, forming solid solutions. The unintended formation of an arsenate analog of autunite in the original as-formulated concentrated aqueous feed solution (see Section 4.7.3.1) suggests that this premise may be possible in some instances (although the resulting uranyl-arsenate complex is notably more soluble than the corresponding uranylphosphate complex). In the soil column experiments described above, the apatiteamended column (57-2) evidenced strong retention of $U$ and other cationic contaminants of interest, but somewhat diminished retention of As, relative to the control soil (57-1) without added APA. Thus there is little evidence from this study for any beneficial coprecipitation of arsenate ion within APA-amended soil.

\subsubsection{Selective extraction of metal contaminants in soil column composites}

\subsection{Introduction}

Knowing more about the nature of the interaction between a contaminant and the local geochemistry provides an insight to the potential mobility of the contaminant and may help identify possible means for its remediation. There have been many (nominally) selective extraction schemes, performed individually or in a defined sequence, intended to help define the manner in which select metals are bound to soil matrix. Most of these methods originate from agronomy protocols intended to assess the availability of select major metals (principally, $\mathrm{Fe}$ and $\mathrm{Mn}$ ) for uptake by plants. Compendia of standard test methods, with numerous variants, appear in sources such as Methods of Soil Analysis (published by the Amer. Soc. Agronomy). These methods recognize that total soil metal inventory is of limited use in understanding bioavailability or metal mobility, and that it is useful to estimate the amount of metal present in different solid-phase forms. For iron, principal fractions targeted for selective dissolution may include "total" vs. "free," "exchangeable" or readily soluble, "amorphous" or "active," organically bound, etc. (See, e.g., Olsen and Ellis, 1982; Jackson et al., 1986). Some of these selective extraction methods have also been adapted to assess the manner in which trace metal contaminants are bound to soil, since the environmentally available fraction of many contaminants of interest are principally associated with the dominant $\mathrm{Fe}$ or Mn oxide phases, which are frequently present in soil and sediments as surface coatings. Despite the fact that it is 
very difficult to estimate sorption site densities in heterogeneous systems (von Gunten \& Beneš, 1995), some published studies have used only the nominally selective extraction of "amorphous" oxide phases, and analyzed the extract for Fe, Mn, and select trace metals in order to predict the geologic and biological availability of the trace metals of interest (for model studies of uranium associations with "amorphous" iron oxides, see, e.g., Payne and Waite, 1991; Del Nero et al., 1999; Barnett et al, 2002).

Some recent studies published in the technical literature have alternately used a selected sequence of extractions from the soil matrix, with each successive lixivant solution increasing in its aggressiveness. The results of these sequential extractions (or "fractionation") often allow a comparison of how tenaciously different metal contaminants partition to different soil and sediment compositions. The partitioning of contaminants to different geochemical fractions is related to the contaminant speciation (or chemical form), as well as other physiochemical factors (Loyland et al., 2000). Metals deemed least mobile in soil have a relatively small proportion of the total associated with the most readily accessible (or "exchangeable") fraction whilst having the greatest proportion associated with the most refractory (or "residual") fraction. For example, based upon the results of sequential extractions, Hickey and Kittrick (1984) concluded that the relative mobility of select metals in the soils that they tested generally followed the order: $\mathrm{Cd}>\mathrm{Zn}>>\mathrm{Cu} \sim \mathrm{Ni}$. Similarly, Phillips and Chapple (1995) conclude that the potential mobility and biological availability of metals in the soils they tested generally followed the order $\mathrm{Zn}>\mathrm{Cr} \sim \mathrm{Cu} \sim \mathrm{Pb}$.

While these sequential extraction procedures cannot be used to identify the actual chemical or physical form of a given metal in soil (true "speciation"), they are useful in categorizing the metal partitioning into several operationally defined geochemical fractions (McLean and Bledsoe, 1992). However, there has been recent criticism of the various sequential extraction procedures (McLean and Bledsoe, 1992; von Gunten \& Beneš, 1995). The methods are not entirely specific for a geological fraction of the soil and the lixivant used may also remove metals associated with other fractions. Also, the extractions may significantly change the properties (e.g., surface charge) of insoluble components of the sample, and alter the oxidation state of various components. Readsorption of the extracted metals to the remaining solid phase of the soil may occur leading to artificially low concentrations of the metal being associated with that fraction. Therefore the sequentially extracted fractions are only operationally defined through the extraction process and may or may not represent chemical species (Scheinost et al., 2002).

McLean and Bledsoe (1992) have reviewed many of the various sequential extraction protocols that have been proposed. Chemical and methodological variations in the sequential extraction protocol make a comparison of results obtained by different methods and different authors difficult. The sequence of extractions originally recommended by Tessler et al. (1979), substantially equivalent to the modified recommendations of Phillips and Chapple (1995), appears to be the best documented and most frequently used protocol for estimating the partitioning of trace toxic metals in soil. (Recently, a somewhat modified sequential extraction scheme has been proposed to help 
elucidate the partitioning of actinides to contaminated soils and sediments; see Schultz et al., 1998; Loyland et al., 2000; Kurosaki et al., 2002). In this investigation, we have generally adapted the protocols recommended by Phillips and Chapple (1995). The extraction procedures used for defined fractions are described below. (Note that the amount of metal liberated by a given lixivant is referenced back to the original soil mass taken, in order to estimate the equivalent metal content for that fraction as $\mathrm{mg} / \mathrm{kg}$ ).

The sequence of extractions selected for use in this investigation has been briefly described in the "Experimental" section (Section 3).

\subsection{Results}

\subsection{Sequential Extraction of Calcium (Ca)}

Although calcium is not a contaminant of concern, it is of interest to observe how calcium in the soil responds to the extraction procedures. Calcium frequently partitions to relatively "mobile" sites or sediment phases (Loyland et al., 2000). However, a high proportion of total $\mathrm{Ca}$ in the native soil used for testing (sample 02-0608) is present as the relatively refractory compound dolomite, $\mathrm{CaMg}\left(\mathrm{CO}_{3}\right)_{2}$. The aqueous solubility of dolomite is less than that of calcium carbonate (Driessens, 1986). The total $\mathrm{Ca}$ in material $57-1$ composite is very high, $\sim 12.5 \mathrm{wt} \%$, consistent with the predominance of calcite and dolomite mineral phases (Section 2.2.1). (Note: $12.5 \mathrm{wt} \% \mathrm{Ca}$ is equivalent to $\sim 57 \mathrm{wt} \%$ dolomite mineral phase). Figure 73 illustrates the partition of $\mathrm{Ca}$ in sequential extracts from material 57-1 composite. Interestingly, most of the $\mathrm{Ca}$ is highly refractory; $\mathrm{Ca}$ in the so-called "carbonate" fraction is only $\sim 0.05 \%$ of the total inventory estimated by EPA 3050 methodology. The partitioning for $\mathrm{Ca}$ in material 57-2 composite, amended with APA (nominally calcium hydroxyapatite) is very similar (see Figure 73), except a higher portion is in the so-called "oxide-associated" fraction. 


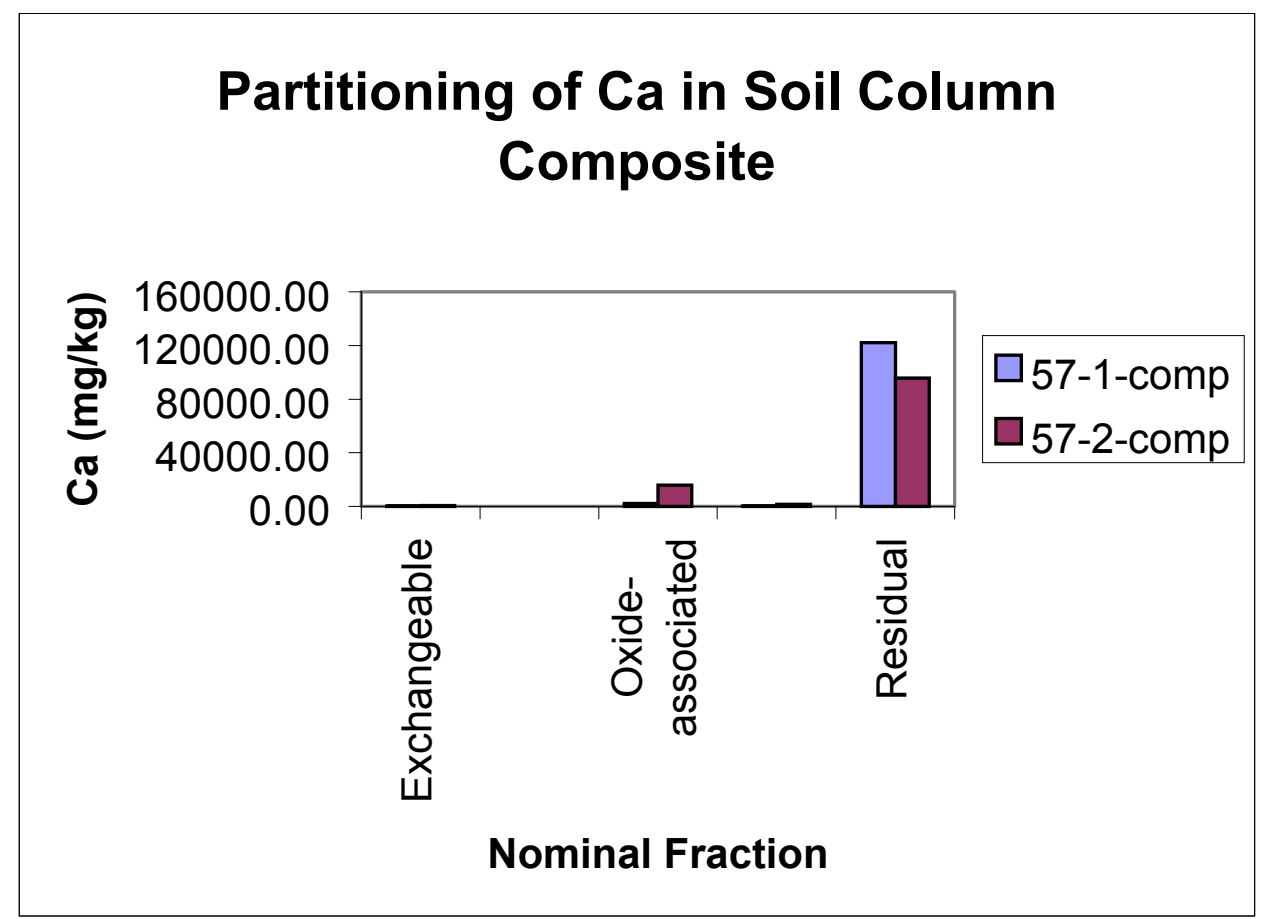

Figure 73. Partitioning of Extractable Ca in Exposed Soil Composites. Material 57-1 composite is a control (no APA), whereas material 57-2 contains $\sim 5 \mathrm{wt} \%$ APA.

Other major soil constituents were also noted to partition predominantly to the "Residual" fraction for both Series 57 composite soil samples: $\mathrm{Fe}(\geq 92 \%), \mathrm{Al}(\geq 94 \%)$ and $\mathrm{Mn}(\geq 84$ $\%$ ). Loyland et al. (2000) similarly note that partitioning of Fe and Al from sandy lake sediment indicates that they are predominantly refractory. 


\subsection{Sequential Extraction of Phosphorous (P)}

Composite exposed soil 57-1 (no added APA) does contain a small amount of $\mathrm{P}(\sim 387$ $\mathrm{mg} / \mathrm{kg})$, compared to composite exposed soil 57-2 ( $5 \mathrm{wt} \%$ APA, or total P $\sim 6030$ $\mathrm{mg} / \mathrm{kg}$ ). Although the inventory of total $\mathrm{P}$ is very different for the two samples (as estimated by the EPA 3050 extraction procedure), the proportions of extractable $\mathrm{P}$ within geochemical fractions are very similar, with $>90 \%$ being in the refractory "residual" fraction; see Figure 74. This suggests that $\mathrm{P}$ in the 57-1 material is also in the form or a relatively refractory solid phase, similar to apatite. Mineral P in sedimentary phosphorites is predominantly carbonate fluorapatite (Chen et al., 1997); however, this form of apatite is notably less effective than the biogenic apatite for metal sorption (Conca et al., 2000). For comparison purposes, Figure 74 also includes sequential extraction data for $\mathrm{P}$ in sample 31-2. Material 31-2 is a sample of contaminated soil (00-0656), originally amended with $\sim 5 \mathrm{wt} \%$ APA, and subsequently eluted with clean synthetic groundwater. The total P inventory for sample $31-2$ is $2020 \mathrm{mg} / \mathrm{kg}$. Compared to the Series 57 soils, a greater proportion of residual $\mathrm{P}$ in material $31-2$ is in the "oxide-associated" fraction. 


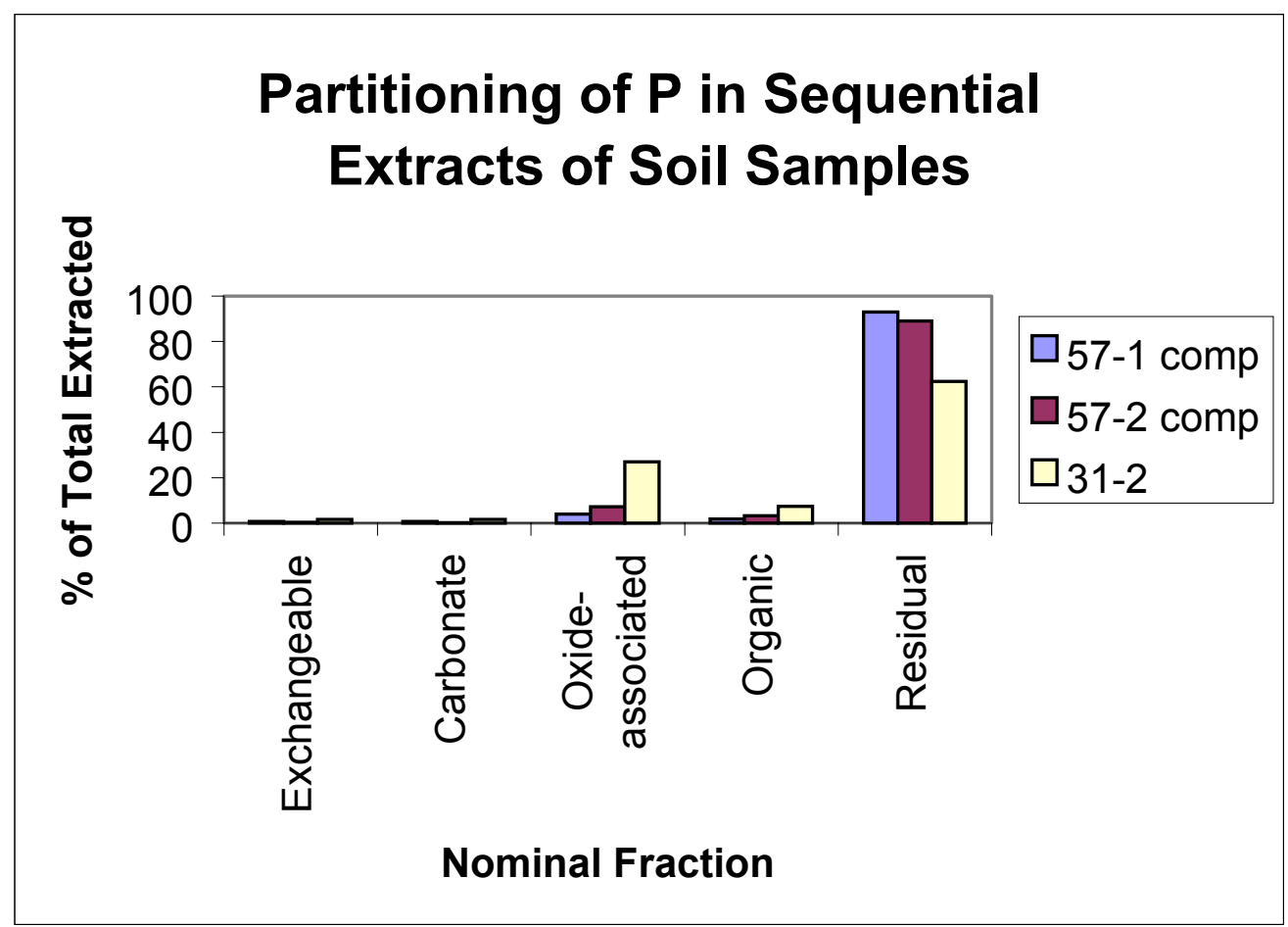

Figure 74. Partitioning of Extractable $\mathrm{P}$ in Soil Composites. Series 57 materials represent samples of "clean" soil (02-0608) that have exposed to contaminantsupplemented synthetic groundwater. Material 57-1 composite is a control (no APA), whereas material 57-2 contains $\sim 5 \mathrm{wt} \%$ APA. Results are normalized to the total $\mathrm{P}$ inventory in the sample (as determined with use of the EPA 3050 extraction procedure): $387 \mathrm{mg} / \mathrm{kg}$ for material 57-1-comp, and $6030 \mathrm{mg} / \mathrm{kg}$ for material 57-2-comp. Material $31-2$ is a sample of contaminated soil (00-0656), originally amended with $\sim 5 \mathrm{wt} \%$ APA, and subsequently eluted with clean synthetic groundwater. The total P inventory for sample $31-2$ is $2020 \mathrm{mg} / \mathrm{kg}$. 


\subsection{Sequential Extraction of Arsenic (As)}

Many arsenic compounds sorb strongly to hydrous oxides in soils and therefore are not very mobile. However, a small portion of the As in the feed solution did elute from the apatite-amended soil column (57-2). Arsenate and phosphate ions have similar structure and ionic charge, and may compete for similar binding sites within the soil matrix. Note the similar partitioning patterns for $\mathrm{P}$ (Figure 74) and As (Figure 75).

The partitioning of As within exposed soil was very similar for the control soil (57-1) and soil amended with $\sim 5 \mathrm{wt} \%$ apatite (57-2); see Figure 2.2.4. The percentage of total environmentally available As (from EPA Method 3050) that is found in the "Residual" fraction is $\sim 75 \%$ for the control and $\sim 89 \%$ for the amended soil.

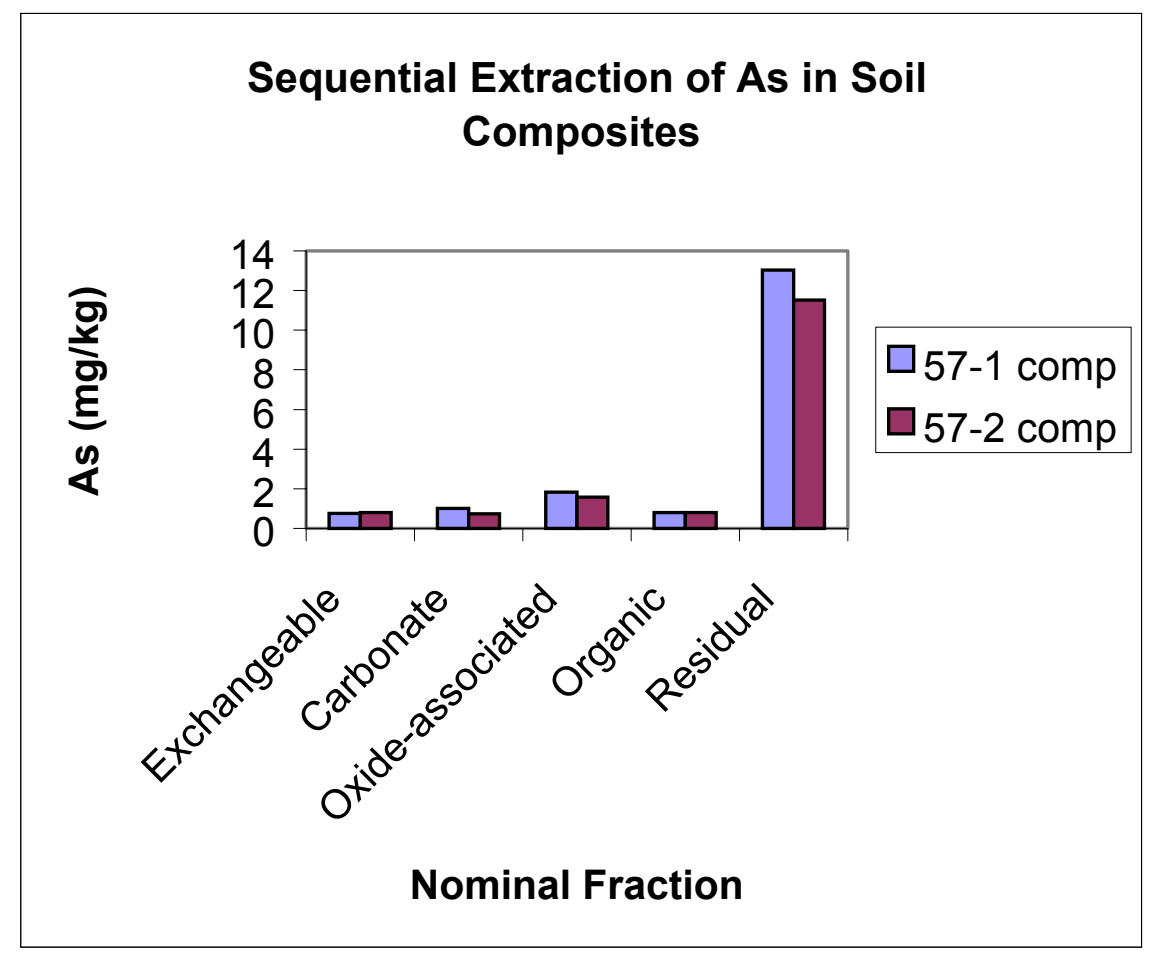

Figure 75. Partitioning of Extractable As in Exposed Soil Composites. Material 57-1 composite is a control (no APA), whereas material $57-2$ contains $\sim 5 \mathrm{wt} \%$ APA. 


\subsection{Sequential Extraction of Uranium (U)}

Unlike the slowly declining concentration of arsenate ion, the residual level of soluble uranyl ion in the feed solution remained fairly constant at an average of $\sim 1.5 \times 10^{-5}$ $\mathrm{mol} / \mathrm{L}$. Uranium was noted to breakthrough the control column (57-1) fairly rapidly (i.e., $50 \%$ breakthrough $(\mathrm{C} / \mathrm{Co}=0.5)$ occurred at about 60 nominal bed volumes, or $\sim 200$ pore volumes), whereas it was strongly retained near the solution influent for the apatiteamended column (57-2). The average loading of $\mathrm{U}$ was $67.3 \mathrm{mg} / \mathrm{kg}$ for column $57-1$ composite and $121.4 \mathrm{mg} / \mathrm{kg}$ for column $57-2$ composite.

The partitioning of uranium within the various fractions of exposed soil is illustrated in Figure 76. For the Series 57 control soil without added APA, the U was predominantly associated with the "metal oxide" fraction, presumably by sorption to Fe and Mn hydrous oxides (see, e.g., Hsi and Langmuir, 1985; Ho and Miller, 1986; Payne and Waite, 1991; Moyes et al., 2000; Giammer and Hering, 2001; Barnett et al, 2002; etc.). However, there were also significant amounts of $U$ associated with the relatively mobile so-called "exchangeable" and "carbonate" fractions. Uranyl ion forms a moderately insoluble complex with carbonate ion (i.e., Rutherfordine, $\mathrm{UO}_{2} \mathrm{CO}_{3}$ ), but $\mathrm{U}$ may become highly soluble at higher carbonate ion concentrations, due to formation of anionic carbonate complexes (Giblin et al., 1981; Miyahara, 1993; Meinrath et al., 1996). By mass balance closure, there was no evidence for a strongly retained "residual" fraction in material 57-1.

In contrast, material 57-2-comp, admixed with APA, has a much higher average loading of U, with approximately equal portions of "oxide-associated" and refractory "residual" fractions. This is consistent with the strong affinity of uranyl ion for hydrous metal oxides and the apatite phase.

For comparison purposes, Figure 77 also presents sequential extraction data for soil sample 31-2. This sample, amended with APA in the same manner as material 57-2, represents an authentic $\mathrm{U}$ contaminated soil that originated from a soil column eluted with clean (non supplemented) synthetic groundwater in a previous series of experiments. The native soil was noted to contain a portion of $\mathrm{U}$ in a mixed-valent state (reduced forms of $\mathrm{U}$ are less soluble than the uranyl ion; see (e.g.) Kertes and Guillaumont, 1985; Murphy and Shock, 1999). However, the oxidative lixivant used for the "organic" fraction (2.1.4) should leach appreciable $U$ from reduced species. The apatite-amended sample 31-2 contains a greater proportion of refractory ("residual") U inventory, but otherwise demonstrates a distribution among geochemical fractions that is similar to material 57-2.

The relatively low proportion of labile U(VI) in soils amended with APA (Figure 2.2.5) is in distinct contrast to the observations reported by Fuller et al (2002) for the high degree of reversibility for $\mathrm{U}(\mathrm{VI})$ sorbed to phosphate rock and cow bone products. In the cited study, relatively large proportions of $U$ initially sorbed to cow bone products were subsequently released from test columns by simply passing U(VI)-free synthetic groundwater through the columns. In our Series 57 soil column experiments, no soluble U was detected $(<20 \mu \mathrm{g} / \mathrm{L})$ in the APA-amended soil column aqueous eluate upon 
loading the column with U-supplemented feed solution (total $\sim 250$ pore volumes) or a subsequent brief $(\sim 4.3$ pore volume) rinse with $\mathrm{U}(\mathrm{VI})$-free synthetic groundwater. Our sequential extraction results indicate that $\mathrm{U}$ is tightly bound to the fish bone apatite and/or the phosphate-equilibrated soil, as verified by the strong retention of $\mathrm{U}$ in soil near the column influent.

It is possible that the carbonate content of the aqueous phase, and the degree of calcite saturation, potentially may affect the reversibility of metal binding by apatite phase. Buck et al. (1996) report that autunite-like uranium phosphate mineral phases found in soil at the DOE Fernald Site are rather refractory toward the release of soluble $U$ by extraction with carbonate solution. In our testing for the removal of soluble U in DOE legacy waste with use of calcined apatite (section 4.5 ), we noted significantly diminished uptake of soluble $U$ when the influent water had alkalinity values $\geq 1,000 \mathrm{mg} / \mathrm{L}$ as $\mathrm{CaCO}_{3}$. Thus the exchange of $\mathrm{U}$ at the surface of apatite media upon exposure to elevated carbonate levels in the solution phase may be affected by the manner by which the $U$ is bound (surface sorption vs. chemical precipitation or mineralization). The synthetic groundwater ("AGW") used by Fuller et al. (2002) contained a relatively high alkalinity $\left(\sim 480 \mathrm{mg} / \mathrm{L}\right.$ as $\left.\mathrm{CaCO}_{3}\right)$, which may have facilitated leaching of surface-sorbed $\mathrm{U}(\mathrm{VI})$. At $\mathrm{pH} \sim 7$, the $\mathrm{AGW}$ is approximately saturated with respect to calcite phase. The synthetic groundwater feed (column influent) solution used in our investigation contained modest alkalinity $\left(\sim 93 \mathrm{mg} / \mathrm{L}\right.$ as $\left.\mathrm{CaCO}_{3}\right)$, and (at $\left.\mathrm{pH} \sim 5.7\right)$ is undersaturated with respect to calcite (Saturation Index (SI) -2.2). However, the column 57-2 effluent solution (after passing through the apatite-amended dolomite-rich soil) had a total alkalinity of $325 \mathrm{mg} / \mathrm{L}$ as $\mathrm{CaCO}_{3}$, and (at $\mathrm{pH} \sim 8.6$ ) was oversaturated with respect to calcite (SI 1.75). (See APHA, SMEWW (1992) Method 2330 for estimation of calcium carbonate saturation). 
Figure 76. Partitioning of Extractable U in Exposed Soil Composites. Material 57-1 composite is a control (no APA), whereas material 57-2 contains $\sim 5 \mathrm{wt} \%$ APA. Material 32-2 is a sample of apatite-amended soil from another soil column experiment (contaminated soil exposed to a flow of "clean" synthetic groundwater).

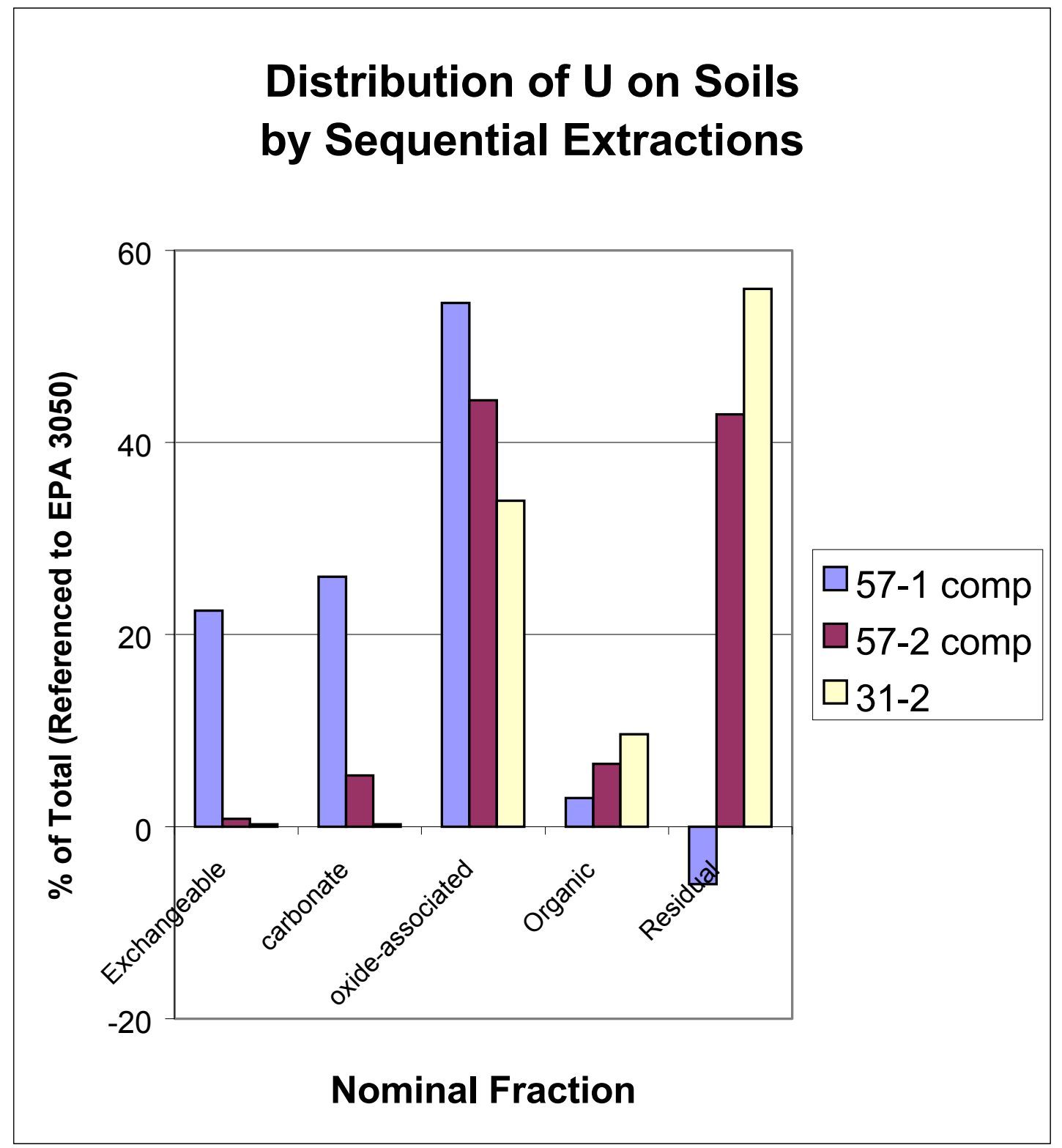




\subsection{Sequential Extraction of Cadmium (Cd)}

In soil, cadmium may be adsorbed by clay minerals (e.g., illite), carbonates or hydrous oxides of iron and manganese or it may be precipitated as cadmium carbonate, hydroxide, or phosphate phases. Evidence suggests that adsorption mechanisms may be dominant for the deposition of Cd in soil and sediment (Dudley et al., 1988, 1991). In sequential extraction of soils and sediments contaminated with metal wastes, the greatest proportion of the total Cd is typically associated with the exchangeable fraction (Hickey and Kittrick, 1984). Aqueous phase concentrations of $\mathrm{Cd}$ are limited by $\mathrm{CdCO}_{3}$ solubility in neutral and alkaline soils (Santillan-Medrano and Jurinak, 1975). This is consistent with the observations by Fuller (1978) that Cd typically has low mobility in many soil types. Under normal conditions, precipitation of $\mathrm{CdCO}_{3}$ and $\mathrm{Cd}(\mathrm{OH})_{3}$ can be expected to maintain $\mathrm{Cd}$ aqueous concentrations below the drinking water limit of $10 \mu \mathrm{g} / \mathrm{L}$, provided the $\mathrm{pH}$ value is $\geq 8$; however, at more acidic $\mathrm{pH}$ values, $\mathrm{Cd}$ solubility increases rapidly and sorption to common mineral phases generally decreases (EPRI RP2485-03). Under strongly reducing conditions, precipitation as CdS controls the mobility of cadmium (Smith et al., 1995).

Apatite is known to effectively remove soluble cadmium; see (e.g.): Jeanjean (1995); Wright (1995); Ma et al. (1994); Chen et al. (1997); Mandjiny (1998). From results for short-term contact studies with use of fossil apatite mineral, Ma et al. (1997) concluded that minor octavite $\left(\mathrm{CdCO}_{3}\right)$ precipitation does occur, but that sorption mechanisms (such as surface complexation, ion exchange, or the formation of amorphous solids) are primarily responsible for the removal of soluble $\mathrm{Zn}$ and Cd. Chen et al. (1997) similarly report that interaction of $\mathrm{Cd}$ and apatite phase induces the formation of $\mathrm{CdCO}_{3}$ and $\mathrm{Cd}(\mathrm{OH})_{3}$; these phases are highly insoluble in alkaline solution. Cadmium phosphate, if formed, should be more stable than otavite under acidic conditions (Bodek et al., 1988; Chen et al., 1997).

The partitioning of cadmium within the various fractions of exposed soil is illustrated in Figure 77. The distribution patterns are similar for soil with or without APA, with the exception that the proportion of "exchangeable" $\mathrm{Cd}$ is somewhat greater for the amended soil (57-2-comp). Spatial distribution of total Cd in segments of exposed soil columns revealed that $\mathrm{Cd}$ is more heavily deposited near the influent end of the soil column containing APA (Sample 57-2A) than in the control (Sample 57-1A); see Figure 70. This infers a stronger retardation factor for soil with APA. It is therefore somewhat surprising that the APA-amended soil composite (57-2-comp) has a higher proportion of relatively weakly bound exchangeable metal ion (Figure 77); this may reflect a diminished affinity between $\mathrm{Cd}^{+2}$ and a soil matrix that has equilibrated with phosphate ion to change the surface charge of the soil particles. 
As noted in Section 4.7.4.2.1, the influent end of the control sample (57-1A) had a somewhat greater prevalence of otavite mineral phase. One possible inference is that $\mathrm{Cd}$ in amended soil is bound to apatite or other phosphate phases by a moderate strength sorption mechanism, which competes with the formation of sparingly soluble carbonate phase. The high level of chloride ion in the lixivant used to define the "exchangeable" fraction should readily complex with cadmium (Hahne and Kroontje, 1973; Bodek et al., 1988), rendering it more soluble and less likely to re-sorb to the soil matrix. It is possible that $\mathrm{Cd}$ that is sorbed, rather than precipitated as otavite, is more easily displaced by the lixivant.

For the soil tested, as noted in Figure 77, the preponderance of soil-bound $\mathrm{Cd}$ is refractory to the sequential extraction protocols (i.e., by mass balance, it is largely accounted for by the "residual" fraction). This distribution pattern is significantly different than typical results reported by Hickey and Kittrick (1984), and may reflect the influence of high levels of calcium carbonate in the soil used for our column studies. Cadmium in soils containing calcite and/or phosphate salts of $\mathrm{Ca}$ and Fe typically displays low solubility (Bodek et al., 1988). 


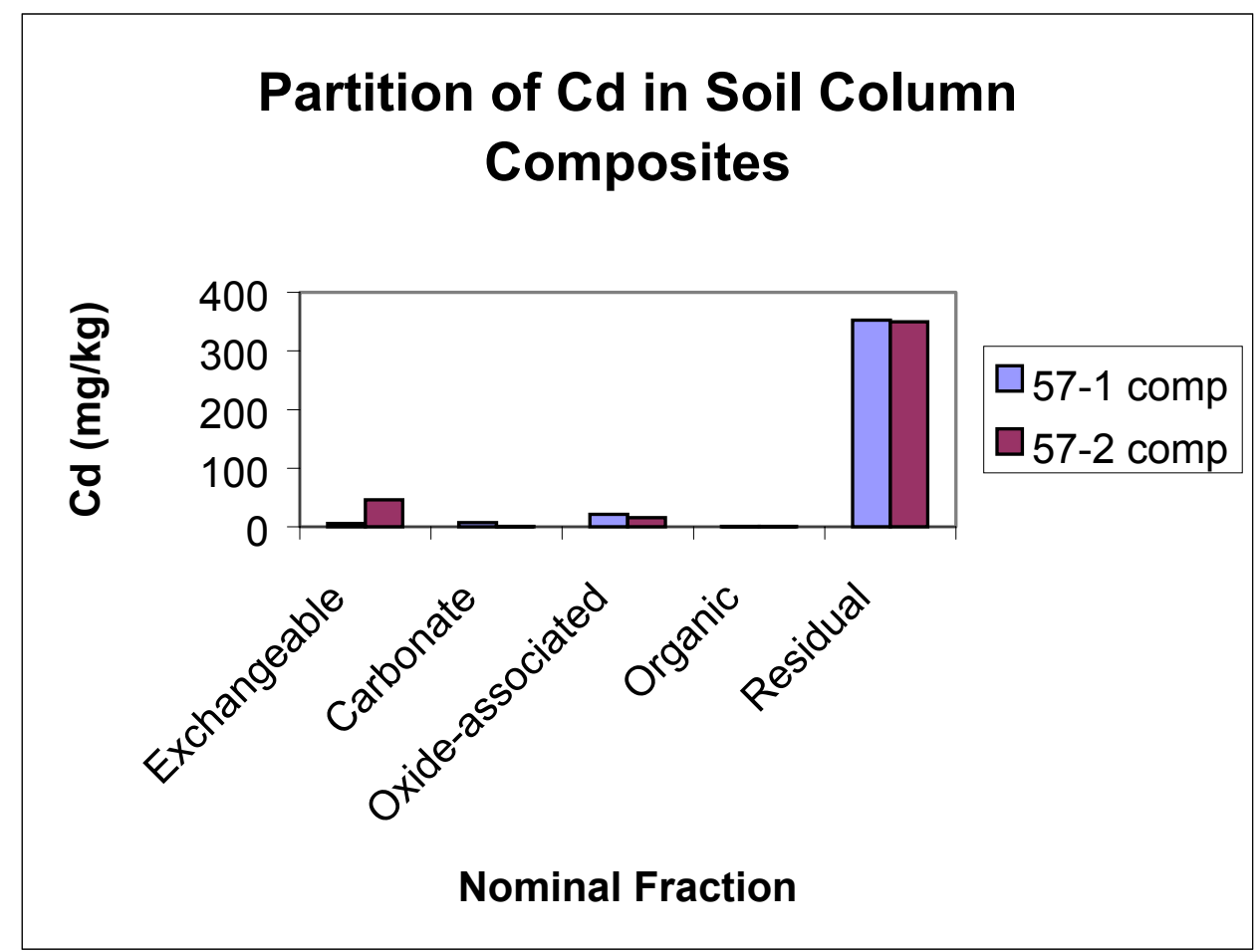

Figure 77. Partitioning of Extractable Cd in Exposed Soil Composites. Material 57-1 composite is a control (no APA), whereas material 57-2 contains $\sim 5 \mathrm{wt} \%$ APA. 


\subsection{Sequential Extraction of Mercury (Hg)}

As noted by Fuller (1978), Hg generally evidences moderate to high mobility in most soil types, but with reduced mobility noted for clayey soils. In the absence of elevated levels of chelating agents such as chloride ion, $\mathrm{Hg}$ (II) is strongly sorbed onto hydrous $\mathrm{Fe}$ and Mn oxides, clays and organics in soils and sediments. Inorganic phosphate ion sorbed to soil minerals enhances the retention of $\mathrm{Hg}(\mathrm{II})$; this effect is attributed by some investigators as being due to a change in the surface charge of the soil particles, rather than the formation of mercuric phosphate (Melamed and Bôas,1998, 2000). Binding of phosphate anions to iron oxyhydroxides can reverse the net surface charge from positive to negative (Appenzeller et al., 2002), enhancing the sorption of cations in general. Note, however, at elevated levels of chloride ion in groundwater, stable anionic complexes form with $\mathrm{Hg}(\mathrm{II})$, which may increase the mobility of mercury in soil (Melamed and Bôas, 1998, 2000).

In soil column tests, $\mathrm{Hg}$ was observed to break through on the control column (57-1, with no APA). The spatial distribution of Hg retained in exposed soil column segments indicates that the retardation of $\mathrm{Hg}$ is greatest in the APA-amended soil (57-2); see Figure 71. Figure 78 indicates that the overall retention (loading) of $\mathrm{Hg}$ is greater for the APA-amended soil; this soil composite also has a higher proportion of refractory "residual" fraction. In general, however, the distribution of $\mathrm{Hg}$ among geochemical fractions is rather similar for control and amended soil, despite the greater retardation of $\mathrm{Hg}$ observed in amended soil.

It is worth noting that the lixivant used to define the relatively mobile "exchangeable" fraction contains $\sim 2 \mathrm{~mol} / \mathrm{L}$ chloride ion, a strong complexing ligand for mercury (Hahne and Kroontje, 1973; Bodek et al., 1988). Yet only a small proportion of total Hg is liberated from the soil matrix with this lixivant, in contrast to the expectations of Melamed and Bôas (1998, 2000). 


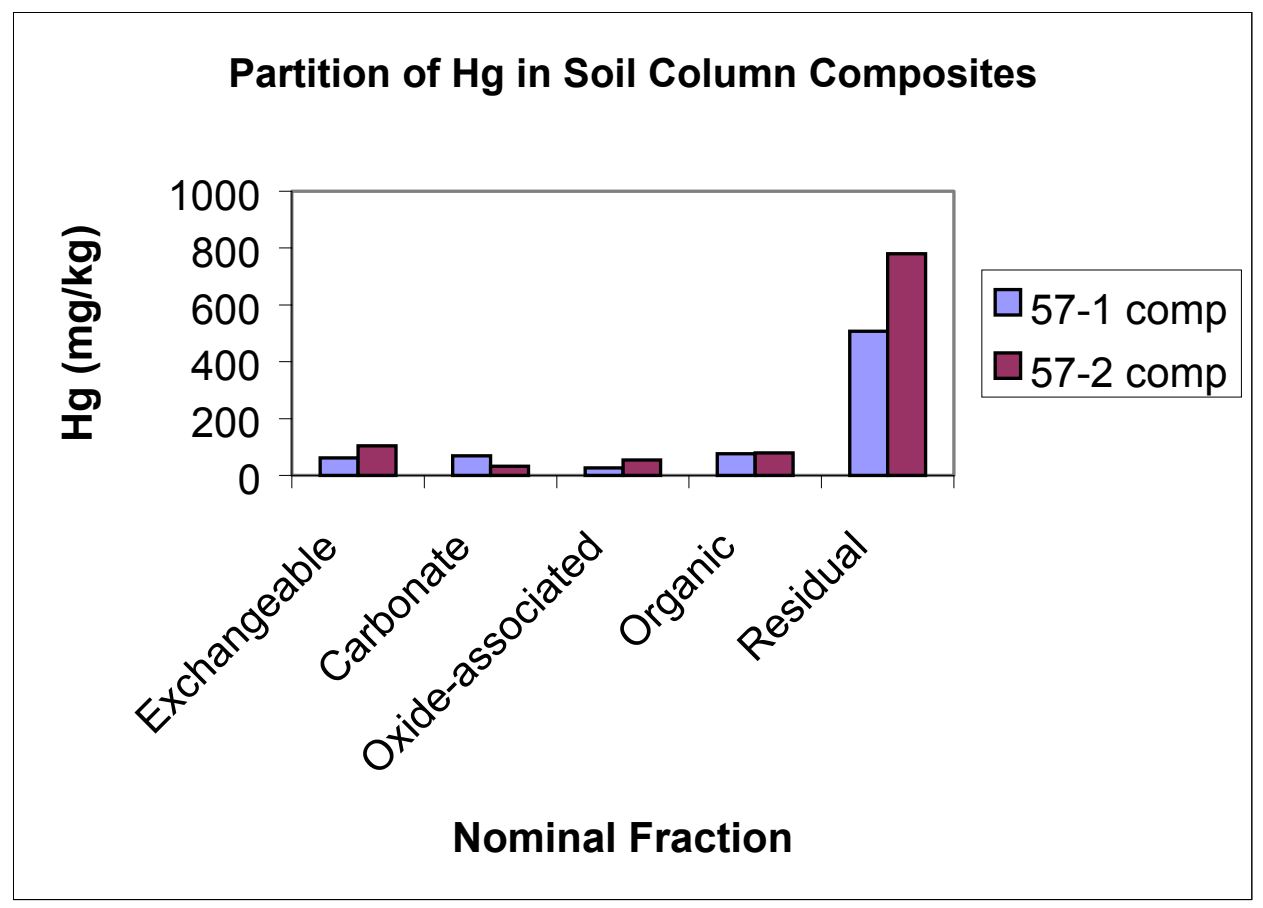

Figure 78. Partitioning of Extractable $\mathrm{Hg}$ in Exposed Soil Composites. Material 57-1 composite is a control (no APA), whereas material 57-2 contains $\sim 5 \mathrm{wt} \%$ APA.

\subsubsection{Summary for Sequential Extraction Results}

For the "Series 57" soil column experiments, soluble contaminants were supplemented into synthetic groundwater and the solution slowly perfused into a calciferous soil, with and without amendment by biogenic apatite. After terminating the influx of solution phase, the soil within the columns was extruded, air-dried, and analyzed by a battery of procedures. The spatial distribution of select metals within the columns confirmed that retardation of contaminant migration was greatest for the apatite-amended soil (i.e., metals tend to be strongly concentrated near the amended soil column influent). An exception was arsenate, an oxyanion, which demonstrated slightly reduced retention within the apatite-amended soil. Phosphate ion is released during the dissolution of apatite (see also Section 4.1.8); the slightly diminished retention of arsenic in the apatiteamended soil is attributed to competition between arsenate and phosphate ions for the same or similar binding sites within the soil matrix. 
Selective sequential extraction of composites of exposed soil indicates that most of the contaminants introduced to the calciferous soil were subsequently relatively recalcitrant to the lixivants utilized. Even without added apatite, the preponderance of most of the contaminants distribute to the relatively refractory "residual" fraction. The most notable exception is uranium (as the uranyl ion), which is relatively mobile in the soil without added apatite. The soil used for this series of tests contained a great abundance of mineral carbonate, both as calcite and dolomite. Whereas carbonate in the soil may facilitate precipitation of many metals (e.g., cadmium forms insoluble otavite mineral phase), dissolved carbonate enhances the solubility and mobility of uranyl ion. Amendment of the soil with apatite retarded the mobility of $U$, and greatly increased its refractory nature within the soil matrix (as judged by the sequential extraction protocol).

Mercury (as mercuric ion) was also relatively mobile in the soil without apatite, with breakthrough to the column effluent. Mercury in the amended soil evidenced both a decrease in mobility and a greater proportional distribution to the "refractory" fraction for the sequential extractions.

Although cadmium is more strongly concentrated near the solution influent for the amended soil, relative to soil without apatite, cadmium displayed similar partitioning by the sequential extraction protocol for the amended and control soil samples. Thus, at least for the calciferous soil composition, amendment by apatite did not greatly alter the refractory nature of cadmium in the soil matrix. 


\subsection{CONCLUSIONS}

A battery of physical, chemical, and instrumental procedures are used to characterize biogenic and synthetic hydroxyapatite phases. Soluble uranium is used as a model contaminant to study the effects of material processing parameters (particle size, crystallinity, residual organic matter, etc.) on metal binding.

Raw biogenic apatite is shown to contain considerable residual organic matter, which may or may not be a disadvantage, depending upon the intended application. Dried "raw" bone product may be suitable for subsurface applications, where the soil overburden minimizes nuisance odor, and where the medium is a host to adventitious bacterial activity which may facilitate destruction of organic contaminants and nutrient contaminants such as nitrate ion, etc. The residual organic matter in raw Apatite II will leach and be degraded over time. Dr. James Conca of the Los Alamos National Laboratory wrote of his experience in the subsurface use of Apatite II to treat plutonium $(\mathrm{Pu})$ :

"At Los Alamos, the Apatite II established a healthy microbial population with denitrifying activity that reduced nitrate and perchlorate to below background which was advantageous for that site where these were also contaminants along with the Pu. This activity did not affect the biological activity in the surrounding soil. This activity continued for almost a year until the organics in the Apatite II had been used up, then the nitrate and perchlorate increased to the influent concentrations and microbial activity reduced to that in the surrounding soil." (Personal communication to W.D. Bostick, MCLinc, March 1, 2002. See also Conca et al., 2002).

Elutriation is the separation of finer lighter particles from coarser heavier particles in a mixture by means of an upward flow of fluid to carry away the lighter particles. Treatment of raw ground apatite in this manner (washing and decanting) is a relatively economical means to remove a great deal of the extraneous organic matter that otherwise tends to stimulate microbial activity. A typical elutriated apatite product is MCLinc sample 119-2S, which was used in some of the soil column tests. Compared to the performance of raw biogenic apatite precursor, the eluate from cleaned apatite in soil had minimal odor and turbidity (colloidal matter). However, at relatively long-term exposure to mildly acidic water, biogenic apatite tends to form some additional "fines", due to dissolution (see Section 4.1.8).

Thermal treatment may be used to decompose residual organic matter in biogenic apatite, but adds greater processing cost. Data presented in the text for the removal of soluble $\mathrm{U}$ (see, e.g., Table 9) indicate that this contaminant is removed more rapidly, and to a lower residual value, with use of the charred fish bone product. The possible reasons for this are subject to speculation. It may be that organic matter leached from the raw bone in a closed system builds up to the point where it may (1) bind with the metal in solution phase or (2) bind with the apatite surfaces in a manner to somewhat interfere with further sorption of the metal, or (3) that the slight increase in hydroxyapatite crystallinity in the charred material enhances the initial sorption of metal. 
The release of phosphate ion from apatite is controlled by the equilibrium dissolution of the biogenic apatite phase, and is influenced by the chemistry of the aqueous system (e.g., the solution $\mathrm{pH}$ value, and mass-action effects such as the activity of free calcium ion, etc.). In the subsurface, liberated phosphate may be further controlled by sorption of phosphate ion to soil minerals, metabolism by microbes, uptake by root systems, etc.

In the test plan for this project, we proposed a success criterion by which to judge the effectiveness of apatite to treat a given contaminant of interest. The figure of merit suggested is achieving a conditional distribution coefficient $\left(\mathrm{K}_{\mathrm{d}}\right)>1,000 \mathrm{~mL} / \mathrm{g}$ for the contaminant of interest. The single metal experiments presented in Section 4.3 (and the data summarized in Section 4.3.19) indicate that apatite is especially effective for the cationic metal series:

$$
\mathrm{UO}_{2}{ }^{+2}>\mathrm{Pb}^{+2} \geq \mathrm{Th}^{+4}>\mathrm{Cd}^{+2}>\mathrm{Mn}^{+2} \sim \mathrm{Zn}^{+2}>\mathrm{Cu}^{+2} \sim \mathrm{SbO}^{+} \sim \mathrm{Hg}^{+2}
$$

As shown in Section 4.3.7, Apatite II also has a modest affinity for ferrous ion $\left(\mathrm{Fe}^{2+}\right)$, which may be present in anoxic groundwater, due to the action of anaerobic bacteria on iron-bearing soil minerals. Removal of contaminant oxyanions (e.g., arsenate, chromate, vanadate, etc.) to pre-existing apatite surfaces was less successful. In a longer time sense, some isomorphous substitution of toxic oxyanions may occur, by exchange with phosphate ion, but the kinetics of this exchange may not be useful as a control mechanism.

The mechanisms for metal removal by apatite minerals might include ion exchange, adsorption, complexation, coprecipitation, or precipitation of crystalline or amorphous phases (Chen et al., 1997). Many of these mechanisms may be surface-mediated, and thus may be affected by the particle size (and specific surface area) distribution for the treatment media. Batch testing indicates that soluble uranium is indeed removed more rapidly by smaller grain particulate (e.g., $\leq 425-\mu \mathrm{m}$ ) than by larger grains of the same material (see Section 4.2.2 and Figure 7).

The formation of crystalline phases, or solid solutions within the apatite host, would be favorable to the long-term stabilization of contaminant, since such phases are typically less soluble than the corresponding amorphous precipitate phase. Short-term phase contact, as used in the batch test procedures, may be dominated by initial surface sorption phenomena; whereas subsequent crystal growth and/or diffusion of contaminant into the solid phase pore structure or host crystal lattice to form a solid solution is comparatively slow (Narasaraju and Phebe, 1996; Hongshao and Stanforth, 2001).

Raw fish bone apatite contacted short-term $(\leq 20-\mathrm{h})$ with solutions of natural isotopic uranium $(\leq 150 \mathrm{mg} / \mathrm{L})$ demonstrated excellent removal of soluble $\mathrm{U}$, but the dried solid residue (containing $\leq 0.6 \mathrm{wt} \% \mathrm{U}$ ) did not yield identifiable new crystalline phase(s). In a separate series of experiments, with exposures to much higher concentrations of uranyl ion, solids were formed having weak diffraction lines matching ICDD Reference 350194, uranyl phosphate hydrate, $\left(\mathrm{UO}_{2}\right)_{3}\left(\mathrm{PO}_{4}\right)_{2} \bullet \mathrm{H}_{2} \mathrm{O}$. This phase may have been formed by homogeneous precipitation (uranyl ion plus soluble orthophosphate). According to Sandino and Bruno (1992), uranyl orthophosphate is a highly insoluble solid. 
Bostick et al. (2000) have shown that contact of biogenic apatite with yet higher levels of soluble uranium results in formation of autunite (calcium uranyl phosphate hydrate) crystalline phase. In contrast, apatite in a column array continuously exposed to a flow of low level of $\mathrm{U}(\sim 5 \mathrm{mg} / \mathrm{L})$ for several months was noted to have well-formed crystals such as chernikovite [or hydrogen autunite, $\left(\mathrm{H}_{3} \mathrm{O}\right)_{2}\left(\mathrm{UO}_{2}\right)\left(\mathrm{PO}_{4}\right)_{2} \cdot 6 \mathrm{H}_{2} \mathrm{O}$ ] at the surface of the apatite, with average loading of uranium on apatite phase (based upon mass-balance estimates) of $\geq 10 \mathrm{wt} \%$ without breakthrough (Matheson et al., 2001).

Recently, Fuller et al. (2002A) published a paper on the mechanisms of U(VI) removal by (reagent grade synthetic) apatite (HA). Their data indicated that at relatively low loading (e.g., $<0.5 \mathrm{wt} \%$ loading on $\mathrm{HA}$ ), $\mathrm{U}(\mathrm{VI})$ adsorbs to the HA surfaces as an innersphere complex, without the formation of an identifiable new phase. When loadings exceed $\sim 0.7 \mathrm{wt} \% \mathrm{U}$ on $\mathrm{HA}$, a crystalline $\mathrm{U}$ phosphate (chernikovite or hydrogen autunite) precipitates. At still higher loading, a second phase (autunite) appears. These findings are completely consistent with our previous observations (cited above).

Batch testing was also performed for a series of solutions that contained cadmium, mercury and lead as well as uranium. Testing was performed in an experimental design intended to identify any interactions among the metals tested, e.g., any competition for binding sites on the apatite surface or possible synergistic effects such as co-precipitation of mixed-metal phosphates. Under the conditions of testing, $\mathrm{U}$ and $\mathrm{Pb}$ were consistently reduced to solution values below their detection limits, and $\mathrm{Cd}$ and $\mathrm{Hg}$ demonstrated removals greater than had been observed in their respective single metal experiments.

A product designated "Exposed Dry Apatite" (EDA) was prepared by contacting raw apatite with a solution phase supplemented with the metals $\mathrm{U}, \mathrm{Cd}$. $\mathrm{Hg}$, and $\mathrm{Pb}$ (see Section 4.6). These metals were efficiently removed from solution, and the isolated solid phase was subsequently examined by select leaching procedures. Application of the TCLP indicated that all regulated metals were below their defined toxicity criteria, although a significant portion of the $\mathrm{Pb}$ inventory was leached, contrary to literature expectations for the formation of pyromorphite phase (see, e.g., Rabinowitz, 1993; Ruby, 1994; Chen, 1997). Testing by the aggressive ( $\mathrm{pH} 1.5$ ) bioaccessibility leaching protocol [SBRC SOP 110499 (Rev. 8)] indicated that the bulk ( $\geq 96 \mathrm{wt} \%$ ) of the apatite medium dissolved under the test conditions, liberating the majority of metals that had been sorbed to the substrate. Similar results were observed for an apatite char product that had been used in a series of treatability tests, reflecting the instability of biogenic apatite in strongly acid medium.

A series of soil column tests were initiated, comparing the performance of native soil to soil that had been amended by admixture with $5 \mathrm{wt} \%$ apatite. In the absence of apatite, uranyl ion from solution phase demonstrates only modest retardation on soil (i.e., it breaks through the column rapidly, appearing in the column eluate solution). Mercury also shows moderate retention on native soils tested, whereas cadmium is relatively strongly retained on soil. Apatite amendment improves the retention of these metals, as evidenced by minimal concentration in the column eluate solution, and enhanced deposition of metal near the influent end of the column. Testing of metal-exposed soil by 
a sequential extraction procedure indicates that apatite amendment generally increases the proportion of metal found in the more refractory "residual" fraction. An exception was noted for As, where apatite-amended soil demonstrated slightly less retention for arsenate than did the native soil. Batch testing results indicate that sorption of As by apatite is minimal. Also, phosphate ion (from the dissolution of apatite phase) is isomorphous with arsenate ion, and is expected to compete for the similar binding sites on soil.

Under conditions where the amended soil becomes anoxic (especially saturated soil containing relatively large amounts of extraneous organic matter, where septic conditions may develop), anaerobic microbes can proliferate, and these microbes can reduce iron minerals in soil to liberate soluble ferrous iron $\left(\mathrm{Fe}^{2+}\right)$. Ferrous iron can combine with soluble phosphate ion (from the dissolution of apatite) or (more likely) with apatite fines (see Section 4.3.7) to produce colloidal-sized iron-phosphate particulate phase. These colloidal solids may themselves have sorptive properties, and thus they have the potential for facilitated transport of contaminants. Facilitated transport of contaminants of concern was not observed in our soil column studies, but this remains a potential concern. Some trace only amounts of $\mathrm{Mn}$, which is also liberated from soil more readily under reductive conditions, was associated with the filtered solid phase isolated from the eluate from septic soil columns, where it had apparently partially substituted for ferrous ion. Note, however, that soil columns amended with elutriated apatite, having less extraneous matter than the raw crushed apatite, did not appear to produce colloidal solids under the conditions that such solids were found in the eluate from soil amended with raw apatite. This suggests that anaerobic bacterial activity may hasten the dissolution of apatite, and hence the formation of apatite "fines."

In summary, biogenic apatite shows great promise as a means to minimize the mobility of a large number of priority metals, especially uranium. As a soil amendment, apatite removes many priority metals from solution phase, thus reducing the toxicity to microbes and plant systems. Thus, apatite amendment may be beneficially combined with bioremediation and/or phytoremediation. Many times phytoremediation is not used as the sole treatment option, but rather as a final "polishing step", since it is important that salts or metabolites which may accumulate in the vegetation be non-toxic or at least less toxic than the parent compound (Schnoor, 1997). Where phytoremediation is utilized to treat trace organic contaminants, it is speculated that phosphate-induced metal stabilization will be beneficial in minimizing the osmotic transport of soluble metal contaminants and their subsequent deposition within the edible tissue portions (leaves, stalks) of the plants. Biogenic apatite provides nutrients (especially orthophosphate) to stimulate biological activity. In some instances, for example areas that may become flooded for an extensive period of time, it may be advantageous to use a cleaned apatite product (with reduced extraneous organic matter) to minimize the potential formation of ferrous phosphate. 


\subsection{REFERENCES AND BIBLIOGRAPHY}

Abdelouas, A; Lutze, W.; Nuttall, H.E. (1999). "Uranium Concentration in the Subsurface: Characterization and Remediation," Chapt. 9 in Burns, P.C.; Finch, R. (eds.) Reviews in Mineralogy, Vol. 38, Uranium: Mineralogy, Geochemistry and the Environment, Mineralogy Soc. of America.

American Public Health Association (1992), Method 2330: Calcium Carbonate Saturation (Proposed), in Standard Methods for the Examination of Water and Wastewater, $18^{\text {th }}$ Ed., Washington, DC.

American Soc. for Testing and Materials (ASTM) (1993), "Standard Test Method for Distribution Ratios by the Short-Term Batch Method," ASTM D 4319-93.

Anderson, C.L.; Thomson, B.M.; Busch, R.D.; Siegel, M.D.; Baldwin, C. (1998), "Removal of Metals and Radionuclides using Apatite and Other Natural Products," WERC Report, Oct. 1998.

Appenzeller, B.M.R.; Duval, Y.B.; Thomas, F.; Block, J.-C. (2002). "Influence of Phosphate on Bacterial Adhesion onto Iron Oxyhydroxide in Drinking Water," Environ. Sci. Technol., 36, 646-652.

Arey, J.S.; Seaman, J.C.; and Bertsch, P.M. (1999 ). "Immobilization of Uranium in Contaminated Sediments by Hydroxyapatite Addition," Environ. Sci. Technol., 33, 337342.

Barnett, M.O., Jardine, P.M., \& Brooks, S.C. (2002). U (VI) adsorption to heterogeneous subsurface media: Application of a surface complexation model. Environ. Sci. Technol., 36(5), 937-942.

Barton, L.L.; Fekete, F.A.; Marietta, E.V.; Nuttall, H.E., Jr.; Jain, R. (1992). Potential for Bacterial Remediation of Waste Sites Containing Selenium or Lead, Chap. 8 in Sabatini, D.A. and Knox, R.C. (eds.) Transport and Remediation of Subsurface Contaminants, ACS Symp. Series 491, Amer. Chem. Soc., Washington DC.

Ben-Dor, E.; Banin, A. (1989), "Determination of Organic Matter Content in Arid-Zone Soils Using a Simple "Loss-On-Ignition" Method," Commun. Soil Sci. Plant Anal., 20, 1675-1695.

Bodek, I.; Lyman, W.J.; Reehl, W.F.; Rosenblatt, D.H. (editors) (1988), Environmental Inorganic Chemistry, Properties, Processes, and Estimation Methods, Pergamon Press, New York. 
Bostick, William D.; Stevenson, Robert J.; Jarabek, Robert J.; Conca, James L. "Use of Apatite and Bone Char for the Removal of Soluble Radionuclides in Authentic and Simulated DOE Groundwater," Advances in Environmental Research, 3(4) 2000, 488498.

Bostick, W.D.; Jarabek, R.J.; Slover, W.A.; Fiedor, J.N.; Farrell, J. Helferich, R. (1996), "Zero-Valent Iron and Metal Oxides for the Removal of Soluble Regulated Metals in Contaminated Groundwater at a DOE Site," K/TSO-35P. [Included as Appendix D to "Phase I Report on the Bear Creek Valley Treatability Study, Oak Ridge Y-12 Plant, Oak Ridge, Tennessee," LMES Report Y/ER-185, April 1997].

Buck, E.C.; Brown, N.R.; Dietz, N.L. (1996), "Contaminant Uranium Phases and Leaching at the Fernald Site in Ohio," Environ. Sci. Technol., 30(1), 81.

Buesseler, K.O.; Hassellov, M; Dai, M. (2003). "Comment on "Trace Metal Levels in Uncontaminated Groundwater of a Coastal Watershed: Importance of Colloidal Forms," Environ. Sci. \& Technol., 37, 657-658.

Buffle, J. ; De Vitre, R.R. ; Perret, D.; Leppard, G.G. (1989), "Physico-Chemical Characteristics of a Colloidal Iron Phosphate Species Formed at the Oxic-Anoxic Interface of a Eutrophic Lake," Geochim. Cosmochim. Acta, 53:2, 399-408.

Butler, J.N. (1964), Ionic Equilibrium: A Mathematical Approach, Addison-Wesley Publishing Co., Inc., Reading, MA.

Chen, X.-B.; Wright, J.V.; Conca, J.L.; and Peurrung, L.M., 1997, "Effects of pH on Heavy Metal Sorption on Mineral Apatite," Environ. Sci. Technol., 32(3), 624-631.

Chen, X., J.V. Wright, J.L. Conca, and L.M. Peurrung (1997a), "Effects of pH on Heavy Metal Sorption on Mineral Apatite”, Environ. Sci. \& Technol., 31, 624-631.

Cheung, C.W.; Chan, C.K.; Porter, J.F.; McKay, G. (2001), "Combined Diffusion Model for the Sorption of Cadmium, Copper, and Zinc Ions onto Bone Char," Environ. Sci. Technol., 35, 1511-1522.

Conca, J.L., N. Lu, G. Parker, B. Moore, A. Adams, J.V. Wright and P. Heller (2000) "PIMS - Remediation of Metal Contaminated Waters and Soils", in Remediation of Chlorinated and Recalcitrant Compounds, (Wickramanayake, Gavaskar, Gibbs and Means, eds.) Battelle Memorial Institute, Columbus, Ohio, vol. 7, p. 319-326.

Conca, J.; Strietelmeier, E.; Lu, N.; Ware, S.D.; Taylor, T.P.; John Kaszuba, and Wright, J. (2002) "Treatability Study of Reactive Materials to Remediate Groundwater Contaminated with Radionuclides, Metals and Nitrates in a Four-Component Permeable Reactive," Chapter 8, in Groundwater Remediation of Trace Metals, Radionuclides, and Nutrients, with Permeable Reactive Barriers (eds. Naftz, Morrison, Davis, and Fuller), Academic Press, pp. 221-252. 
Craver, C.D. (1982), The Coblentz Society Desk book of Infrared Spectra, $2^{\text {nd }}$. Ed. Reference Spectrum No. 9792 "Calcium Phosphate Hydroxide (Hydroxyapatite)"

Cui, D.; Spahiu, K. (1992), "The reduction of U(VI) on corroded iron under anoxic conditions," Radiochim. Acta, 90, 623-628.

Dambies, L., Guimon, C., Yiacoumi, S., Guibal, E. (2000),'Characterization of metal ion interactions with chitosan by X-ray photoelectron spectroscopy". Colloids and Surfaces A : Physicochemical and Engineering Aspects, 177, p 203-214.

Dana, J.D.; Dana, E.S. (1997) Dana's New Mineralogy, $8^{\text {th }}$ Ed., John Wiley \& Sons, Inc.

Davies, W.; Gray, W. (1964), “A Rapid and Specific Titrimetric Method for the Precise Determination of Uranium Using Iron(II) Sulfate as Reductant,” Talanta, 11, 1203.

Davis, J.A.; Leckie, J.O. (1978), "Surface Ionization and Complexation at the Oxide/Water Interface, J. Colloid Interface Sci., 67, 90-107.

Del Nero, M.; Salah, S.; Miura, T.; Clément, A; Gauthier-Lafaye, F. (1999), "Sorption/Desorption Processes of Uranium in Clayey Samples of the Bangombe Natural Reactor Zone, Gabon," Radiochim. Acta, 87, 135-149.

Driessens, F.C.M. (1986), "Ionic Solid Solutions in Contact with Aqueous Solutions," Chapt. 25 in J.A. Davis and K.F. Hayes (eds.) Geochemical Processes at Mineral Surfaces, American Chemical Society, Washington, DC.

Dudley, L.M, J.E. McLean, R.C. Sims, and J.J. Jurinak. 1988. "Sorption of Copper and Cadmium from the Water Soluble Fraction of an Acid Mine Waste by two Calcareous Soils," Soil Sci., 145:207-214.

Dudley, L.M, J. E. McLean, T.H. Furst, and J.J. Jurinak. 1991. "Sorption of Cd and Cu from Acid Mine Waste Extract by two Calcareous Soils: Column Studies," Soil Sci., 151:121-135.

Duff, M.C.; Amrhein, C. (1996), "Uranium(VI) adsorption on goethite and soil in Carbonate Solution,” Soil Sci. Soc. Am. J., 60, 1393-1400.

Eighmy, T.T., Crannell, B.S., Butler, L.G., Cartledge, F.K., Emery, E.F., Oblas, D., Krzanowski, J.E., Eusden, J.D. Jr., Shaw, E.L., and Francis, C.A. (1997) Heavy metal stabilization in municipal solid waste combustion dry scrubber residue using soluble phosphate. Environ. Sci. Technol. 31: 3330-3338.

Electric Power Research Institute (1992), Cadmium Reactions in Geologic Materials, RP2485-03. 
Farrell, J.; Bostick, W.D.; Jarabek, R.J.; and Fiedor, J.N., 1999, "Effects of Water Chemistry on Uranium Removal from Groundwater Using Zero-Valent Iron Media," Ground Water, 37(4), 618-624.

Fiedor, J.N.; Bostick, W.D.; Jarabek, R.J.; Farrell, J. (1998). "Understanding the Mechanism of Uranium Removal from Groundwater by Zero-Valent Iron using X-Ray Photoelectron Spectroscopy (XPS)," Environmental Science \& Technology, 32(10), 1466.

Flury, M.; Harsch, J.B. (2000), "Remediation of Uranium Contaminated Mine Waste," U.S.G.S. Grant No. 1434-HQ96GR02704, Progress Report for the period March 1999 to February 2000 (Nww.swwrc.wsu.edu).

Fuller, C.C.; Bargar, J.R.; Davis, J.A.; Piana, M.J. (2002A), "Mechanisms of Uranium Interactions with Hydroxyapatite: Implications for Groundwater Remediation," Environ. Sci. Technol. 36: 158-165.

Fuller, C.C.; Piana, M.J.; Bargar, J.R.; Davis, J.A.; Kohler, M. (2002B), Evaluation of Apatite Materials for Use in Permeable Reactive Barriers for the Remediation of Uranium-Contaminated Groundwater, Chapter 9 (pp. 255-280) in in Naftz, D.L.; Morrison, S.J.; Davis, J.A.; Fuller, C.C. (eds), Handbook of Groundwater Remediation Using Permeable Reactive Barriers, Academic Press.

Fuller, W.H. (1978). Investigations of Landfill Leachate Pollutant Attenuation by Soils, EPA-600/2-78-158.

Gauglitz, R.; Holterdorf, M.; Frank, W.; Marx, G. (1992), Immobilization of Actinides by Hydroxyapatite," Mat. Res. Symp. Proc. 257, 567-573.

Geelhoed, J.S.; Van Riemsdijk, W. H.; Findenegg, G.R. (1997), "Effects of Sulphate and $\mathrm{pH}$ on the Plant-Availability of Phosphate Adsorbed on Goethite," Plant and Soil, 197, 241-249.

Giammer, D.E.; Hering, J.G. (2001). "Time scales for sorption-desorption and surface precipitation of uranyl on goethite," Environ. Sci. Technol., 35, 3332-3337.

Giblin, A.M.; Batts, B.D.; Swaine, D.J. (1981), Laboratory Simulation Studies of Uranium Mobility in Natural Waters, Geochim. Cosmochim. Acta, 45, 699-709.

Gambrell, R.P.; Partick, W.H., Jr. (1982), "Manganese,” Chapt. 18 in A.L. Page (Ed.) Methods of Soil Analysis, Part 2, $2^{\text {nd }}$ Edition, American Soc. Agronomy.

Greenberg, A.E.; Clesceri, L.S.; Eaton, A.D. (Eds.) (1992), Standard Methods for the Examination of Water and Wastewater, $18^{\text {th }}$ Ed., American Public Health Assoc., Washington, DC. 
Gschwend, P.M.; Reynolds, M.D. (1987), Monodisperse Ferrous Phosphate Colloids in an Anoxic Groundwater Plume, J. Contam. Hydrol., 1, 309-327.

Gu, B.; Dowlen, K.E.(1996), “An investigation of groundwater organics, soil minerals, and activated carbon on the complexation, adsorption, and separation of technetium-99," ORNL/TM-13154.

Guibal, E., Dambies, L., Milot, C., Roussy, J. (1999). "Influence of polymer structural parameters and experimental conditions on metal anion sorption by chitosan". Polymer International, 48, p 671-680.

Hahne, H.C.H.; Kroontje, W. (1973). "Significance of pH and Chloride Concentration on Behavior of Heavy Metal Pollutants - Mercury(II), Cadmium(II), Zinc(II), and Lead(II)," J. Environ. Qual., 2. 444-450

Harwell, J.H. (1992), "Factors Affecting Surfactant Performance in Groundwater Remediation Applications," Chap. 10 in Sabatini, D.A. and Knox, R.C. (Eds.) Transport and Remediation of Subsurface Contaminants, ACS Symposium Series 491, American Chemical Society, Washington, DC., pp. 124-132.

Herdon, G. (1953). Small Particle Statistics, Elsevier Publishing Company, Amsterdam.

Hickey, M. G. and J. A. Kittrick. 1984. "Chemical Partitioning of Cadmium, Copper, Nickle, and Zinc in Soils and Sediments Containing High Levels of Heavy Metals," $J$. Environ. Qual., 13:372-376.

Ho, C.H. and Miller, N.H. (1986), Adsorption of Uranyl Species onto Hematite Particles, J. Colloid Interface Sci., 110(1), 165-171.

Hodson, M.E.; Valsami-Jones, E.; Cotter-Howells, J.D. (2000), "Bonemeal Additions as a Remediation Treatment for Metal Contaminated Soil," Environ. Sci. Technol., 34, 3501-3507.

Hongshao, Z; Stanforth, R. (2001), "Competitive Adsorption of Phosphate and Arsenate on Goethite," Environ. Sci. Technol., 35, 4753-4757.

Hsi, C.-K. D., and Langmuir, D. (1985), Adsorption of Uranyl onto Ferric Oxyhydroxides: application of the Surface Complexation Site-Binding Model, Geochim. Cosmochim. Acta, 49, 1931.

International Centre for Diffraction Data (1993), Mineral Powder Diffraction File, ICDD, Swarthmore, PA.

James, B.R. (1996), "The Challenge of Remediating Chromium-Contaminated Soil," Environ. Sci. Technol., 30, 248A-251A. 
Jackson, Lim \& Zelazny (1986), Oxides, Hydroxides, and Aluminosilicates, in Methods for Soil Analysis, Pt. 1, 2nd Edition (1986), p. 122.

Jeanjean, J.; Rouchard, J.C. (1995), "Sorption of uranium and other heavy metals on hydroxyapatite," J. Radioanalyt. Nucl. Chem-Letters, 201(6), 529.

Kertes, A.S.; Guillaumont, R. (1985). "Solubility of UO2: A Comparative Review," Nucl. Chem. Waste Mgt., 5, 215-219.

Ko, D.C.; Porter, J.F.; McKay, G. (2001), "Determination of Solid-Phase Loading for the Removal of Metal Ion from Effluents Using Fixed-Bed Adsorbers," Environ. Sci.

Technol., 35, 2797-2803.

Kurosaki, H.; Asbury, S.M.L.; Navratil, J.D.; Clark, S.B. (2002), "Flow-through Sequential Extraction Approach Developed from a Batch Extraction Method," Environ. Sci. Technol., 36, 4880-4885.

Kuske, C.R.; Barnes, S.M.; Busch, J.D. (1997), "Diverse uncultivated bacterial groups from soils of the arid southwestern United States that are present in many geographic regions," Appl. Environ. Microbiol., 63(9), 3614-3621.

Leyva, A. G., Marrero, J., Smichowski, P., Cicerone, D. (2001), "Sorption of Antimony onto Hydroxyapatite," Environ. Sci. Technol. 35, 3669-3675.

Leiser, K.H.; Bauscher, C. (1987), "Technetium in the Hydrosphere and in the Geosphere," Radiochim. Acta, 44/45, 125-128.

Lindsay, W.L. (1979), Chemical Equilibria in Soils, John Wiley \& Sons, New York.

Loyland, S.M.; LaMont, S.P.; Herbison, S.E.; Clark, S.B. (2000). "Actinide Partitioning to an Acidic, Sandy Lake Sediment," Radiochim. Acta, 88, 793-798.

Ma, Q.Y., T.J. Logan, S.J. Traina and J.A. Ryan, 1994. Effect of aqueous A1, Cd, Fe(II), $\mathrm{Ni}$, and $\mathrm{Zn}$ on $\mathrm{Pb}$ immobilization by hydroxyapatite. Environ. Sci. Technology. 28:12191228.

Ma, Q.Y., T.J. Logan, S.J. Traina and J.A. Ryan, 1994. Effect of aqueous Al, Cd, Fe(II), $\mathrm{Ni}$, and $\mathrm{Zn}$ on $\mathrm{Pb}$ immobilization by hydroxyapatite. Environ. Sci. Technology. 28:12191228.

Mackay, D.; Paterson, S. (1984), "Spatial Concentration Distributions," Environ. Sci. Technol., 18, 207A.

Manahan, S.E. (1994), Environmental Chemistry, $6^{\text {th }}$ Ed., Lewis Publishers, New York. 
Manecki, M.; Maurice, P.A.; Traina, S.J. (2000), "Uptake of aqueous Pb by Cl-, F-, and $\mathrm{OH}$ - apatites: Mineralogic evidence for nucleation mechanisms," American Mineralogist, $85,932-942$.

Mandjiny, S.; Matis, K.A.; Fedoroff, M; Jeanjean, J.; Rouchard, J.C.; Toulhoat, N.; Potocek, V.; Maireles-Torres, P.; Jones, D. (1998), "Calcium hydroxyapaties: evaluation of sorption properties for cadmium ions in aqueous solution," J. Mater. Sci., 33(22), 5433.

Mantell, C.L. (1951), "Bone Char," Chapt. 6 in Chemical Engineering Series: Adsorption, $2^{\text {nd }}$ Ed., McGraw-Hill Book Company, New York.

Matheson, L.J.; Goldberg, W.C.; Bostick, W.D. (2001), "Laboratory Batch and Column Studies to Evaluate Apatite II ${ }^{\mathrm{TM}}$ Removal of Soluble Uranium from Contaminated Groundwater,"Abstr. Paper, Amer. Chem. Soc. 222: 147-ENVL Part 1.

Matheson, L.J.; Goldberg, W.C.; Huddleston, G.J.; Bostick, W.D. (2002), "Remediation of Metal-Contaminated Soil and Groundwater Using Apatite," Proceedings of the Third International Conference on Remediation of Chlorinated and Recalcitrant Compounds, Monterey, CA, May 20-23, 2002, World Meeting Number 0005952.

McGeehan, S.L. (1996), “Arsenic Sorption and Redox Reactions: Relevance to Transport and Remediation,” J. Environ. Sci. Health, A31(9), 2319-2336.

McLean, J.E.; Bledsoe, B.E. (1992), Ground Water Issue: Behavior of Metals in Soil, EPA/540/S-92/018 (archived at URL: www.epa.gov/swertio1/tsp/download/issue14.pdf)

MCLinc, "Test Plan for Use of Apatite for Chemical Stabilization of Subsurface Contaminants," MCL-614-TP (Rev. 1, November 2001).

MCLinc, “Operation Guide: X-Ray Diffraction," Standard Operating Procedure MCL7712.

MCLinc, "Determination of Uranium by a Modified Davies-Gray Titration," Standard Operating Procedure MCL-7737.

MCLinc, "Toxicity Characteristic Leaching Procedure," Standard Operating Procedure MCL-7743.

MCLinc, "Acid Digestion for Metals Based on EPA 3050B," Standard Operating Procedure MCL-7746.

Mehra, O.P.; Jackson, M.L. (1960), "Iron Oxide Removal from Soils and Clays by a Dithionite-Citrate System Buffered with Sodium Bicarbonate," in Proc. Seventh National Conf. Clays and Clay Minerals, pp. 317-327. 
Meinrath, G.; Kato, Y.; Kimura, T.; Yoshida, Z. (1996). "Solid-Aqueous Phase Equilibria of Uranium (VI) Under Ambient Conditions,” Radiochim. Acta, 75, 159-167.

Melamed, R.; Bôas, R.C.V. (1998), "Phosphate-Background Electrolyte Interaction Affecting The Transport of Mercury Through a Braziian Oxisol," Sci. Total Environ, 213, $151-156$.

Melamed, R.; Bôas, R.C.V. (2000), “Application of Physio-Chemical Amendments for the Counteraction of Mercury Pollution,” Sci. Total Environ, 261, 203-209.

Merck \& Co., "Bone Oil,” p. 1350 in Merck Index ( $9^{\text {th }}$ Ed.), Merck \& Co., Inc., Rathway NJ.

Merrill, D.T.; Maroney, P.M.; Parker, D.S. (1994), “Trace Element Removal by Coprecipitation," Report EPRI CS-4078S, Electric Power Research Institute, Palo Alto, CA.

Miyahara, K. (1993), "Sensitivity of Uranium Solubility to Variation of Ligand Concentrations in Groundwater," J. Nucl. Sci. Technol., 30(4), 314-332.

Monteil-Rivera, F.; Dumonceau, J.; Federoff, M.; Jeanjean, J.; Minel, L.; Barthes, M.G. (1999), "Sorpton of Se(IV) on Hydroxyapatite," Paper \# PB2-26, presented at "Migration '99,' Lake Tahoe, NV (UCRL-ID-13526).

Moody, T.E.; Wright; J. (1995). Adsorption Isotherms: North Carolina Apatite Induced Precipitation of Lead, Zinc, Manganese and Cadmium from Bunker Hill 4000 Soil, Technical Report BHI-00197, Bechtel Hanford, Richland, WA.

Moody, T.E.; Petersen, S.W.; Torne, E.G.; Vlcakova, J.; Higginbotham, J.F. (1996), "Laboratory Scale Stabilization of N-Springs Groundwater Strontium-90 using Phosphatic Materials,” Report BHI-00864.

Moody, T.E. (1997), "North Plateau Groundwater Sr-90 Phosphate Stabilization. Final Report for the West Valley Demonstration Project," CH2MHILL.

Morrison, S.J.; Metzler, D.R.; Carpenter, C.E. (2001). "Uranium Precipitation in a Permeable Reactive Barrier by Progressive Irreversible Dissolution of Zerovalent Iron," Environ. Sci. Technol. 35, 385.

Moyes, L.N.; Parkman, R.H/; Charnock, J.M.; Livens, F.R.; Hughes, C.R.; Braithwaite, A. (2000), "Uranium Uptake from Aqueous Solution by Interaction with Goethite, Lepidocrocite, Muscovite and Mackinawite: An X-Ray Absorption Spectroscopy Study," Environ. Sci. Technol., 34, 1062-1068.

MSE-TA (1998), "Final Report - Arsenic Removal Demonstration Project Mine Waste Technology Program Activity III, Project 9, Report MWTP-121. 
Murray, F.H.; Brown, J.R.; Fyfe, W.S.; and Kronberg, B.I., 1983, "Immobilization of UTh-Ra in Mine Wastes by Phosphate Mineralization," Canadian Mineralogist, 21(4), 607-610.

Murphy, W.M.; Shock, E.L. (1999). "Environmental Aqueous Geochemistry of Actinides," Chapt. 5 (pp. 221-253) in Burns, P.C.; Finch, R. (eds.) Reviews in Mineralogy, Vol. 38, Uranium: Mineralogy, Geochemistry and the Environment, Mineralogy Soc. of America, Washington, D.C.

Narasaraju, T.S.B.; Phebe, D.E. (1996), "Some Physico-Chemical Aspects of Hydroxyapatite," J. Mater. Sci., 31, 1-21.

Nelson, D.W., Sommers, L.E. (1996), "Total Carbon, Organic Carbon, and Organic Matter," Chapt. 34 in Bartels, J.M. (Ed.), Methods of Soil Analysis. Part 3. Chemical Methods, Soil Science Society of America, Inc., Madison, WI.

Neuman, W.F. (1953), "Deposition of Uranium in Bone," Chapt. 24 (pp. 1911-1990) in Voegtlin, C. and Hodge, H.C., Pharmacology and Toxicology of Uranium Compounds, Part III, McGraw-Hill Book Co., Ann Arbor, MI.

Nyer, E.K., et al. (Eds) (1996), In Situ Treatment Technology, Lewis Publishers.

Olsen; R.V.; Ellis, R., Jr. (1982), "Iron," Chapt. 17 in Methods of Soil Analysis, Pt. 2, 2 ${ }^{\text {nd }}$ Ed., Amer. Soc. Agronomy.

Parfitt, R.L.,; Atkinson, R.J. (1976), Nature, 264, 740-741.

Payne, T.E.; Waite, T.D. (1991), "Surface Complexation Modeling of Uranium Sorption Data Obtained by Isotope Exchange Techniques," Radiochim. Acta, 52/53, 487-493.

Peix, A.; Martinez-Molina, E. (2002), "Molecular Methods for Biodiversity Analysis of PSB," presented at Virtual International Meeting on Microbial Phosphate Solubilization.

Petticrew, E.L.; Arocena, J.M. (2001), "Evaluation of iron-phosphate as a source of internal lake phosphorous loadings," Sci. of the Total Environ., 266, 87-93.

Phillips, I.; Chapple, L. (1995), “Assessment of a Heavy Metals-Contaminated Site Using Sequential Extraction, TCLP, and Risk Assessment Techniques," J. Soil Contam., 4, 311325 .

Pourbaix, M. (1974), Atlas of Electrochemical Equilibria in Aqueous Solutions, NACE International. 
Puls, R.W.; Powell, R.M. (1992). "Surface-Charge Repulsive Effects on the Mobility of Inorganic Colloids in Subsurface Systems," Chap. 4 in Sabatini, D.A. and Knox, R.C. (Eds.) Transport and Remediation of Subsurface Contaminants, ACS Symposium Series 491, American Chemical Society, Washington, DC., pp. 40-54.

Rabinowitz, W.B. (1993), "Modifying soil lead bioavailability by phosphate addition," Environ. Contam. Toxicol., 51, 438-444.

Richardson, A.E. (2002), "Making Microorganisms Mobilize Soil Phosphorous," presented at Virtual International Meeting on Microbial Phosphate Solubilization.

Rietra, R.; Hiemstra, T.; Van Riemsdijk, W. (2001), "Interaction Between Calcium and Phosphate Adsorption on Goethite," Environ. Sci. Technol., 35, 3369-3374.

Ruby, M.V., Davis, A.; Schoof, R.; Eberle, S.; Sellstone, C.M. (1996), “Estimation of Lead and Arsenic Bioavailability Using a Physiologically Based Extraction Test," Environ. Sci. \& Technol., 30, 422-430.

Ruby, M.V., R. Schoof, W. Brattin, M. Goldade, G. Post, M. Harnois, D.E, Mosby, S.W. Casteel, W. Berti, M. Carpenter, D. Edwards, D. Cragin, and W. Chappel. 1999. Advances in evaluating the oral bioavailability of inorganics in soil for use in human health risk assessments. Environ Sci \& Tech. 33:3697-3705

Ryan, J.A. and P. Zhang (1995). Soil lead remediation: Is removal the only option? Twenty first Annual Risk Reduction Engineering Laboratory Research Symposia. EPA 600/R-95/012.

Sandino, A.; Bruno; J. "The Solubility of $\left.\mathrm{UO}_{2}\right)_{3}\left(\mathrm{PO}_{4}\right)_{2} \bullet 4 \mathrm{H}_{2} \mathrm{O}(\mathrm{s})$ and the Formation of U(VI) Phosphate Complexes: Their Influence in Uranium Speciation in Natural Waters," Geochim. Cosmochim. Acta, 56 (1992), 4135.

Santillan-Medrano, J. and J.J. Jurinak. 1975. "The Chemistry of Lead and Cadmium in Soils: Solid Phase Formation.” Soil Sci. Soc. Am. Proc., 29:851-856.

Scheinost, A.C.; Kretzschmar, R.; Pfister, S.; Roberts, D.R. (2002). "Combining Selective Sequential Extractions, X-ray Absorption Spectroscopy, and Principal Component Analysis for Quantitative Zinc Speciation in Soil," Environ. Sci. Technol., 36, 5021-5028.

Schultz, M.K.; Burnett, W.C.; Inn, K.G.W. (1998), J. Environ. Radioact., 40, 155-174.

Schwertmann, U.; Cornell, R.M. (1991), Iron Oxides in the Laboratory, VCH Verlag. $\mathrm{MbH}$, Weinheim, Germany. 
Sherwood, L.J; Qualls, R.G. (2001), "Stability of Phosphorous within a Wetland Soil following Ferric Chloride Treatment to control Eutrophication," Environ. Sci. Technol., $35,4126-4131$.

Schnoor, J.L. (1997). Phytoremediation, Technical Evaluation Report TE-98-01, prepared for Ground-Water Remediation Technologies Analysis Center (GWRTAC), Pittsburgh, PA.

Smith, L.A.; Means, J.L.; Chen, A.; Alleman, B.; Chapman, C.C.; Tixler, J.S.; Brauning, S.E.; Gavaskar, A.R.; Royer, M.D. (1995). Remedial Options for Metals-Contaminated Sites, Lewis Publishers, Boca Raton, FL.

Snoeyink, V.L.; Jenkins, D. ((1980). Water Chemistry. John Wiley and Sons, NY.

Solubilty/Bioavailability Research Consortium (SBRC), In Vitro Method for Determination of Lead and Arsenic Bioaccessibility, Draft Standard Operating Procedure 110499 (Rev. 8).

Sowder, A.G.; Khijniak, T.; Morris, P.J.; Bertsch, P.M. (1999), "Evaluating the Effect of Apatite Amendments on Uranium and Nickel Toxicity in Aged Contaminant Sediments," Paper \# PB7-05, presented at "Migration '99," Lake Tahoe, NV (UCRL-ID-13526).

Suzuki, T.; Ishigaki, K.; Miyake, M. (1984), "Synthetic Hydroxyapatites as Inorganic Cation Exchangers, Pt. 3. Exchange Characteristics of Lead Ions $\left(\mathrm{Pb}^{2+}\right)$," J. Chem. Soc. Faraday Trans. I. 80, 3157-3165.

Tessler, A.; Campbell, P.G.C.; Bisson, M. (1979), "Sequential Extraction Procedure for the Speciation of Particulate Trace Metals," Anal. Chem., 51, 844-851.

Traina, S.J.; Laperche, V. (1999). "Contaminant bioavailability in soils, sediments, and aquatic environments," Proc. Natl. Acad. Sci. USA, 96, 3365-3371.

U.S. Environmental Protection Agency (April 1976), "Process Design Manual for Phosphorous Removal," EPA 625/1-76-001a.

U.S. Environmental Protection Agency (1996), Methods for Evaluating Solid Waste, Physical/Chemical Methods, EPA-SW-846, Third Edition, Revision 2.

U.S. Environmental Protection Agency (1999), Understanding Variation in Partition Coefficient, Kd, Values Volume II: Review of Geochemistry and Available Kd Values for Cadmium, Cesium, Chromium, Lead, Plutonium, Radon, Strontium, Thorium, Tritium and Uranium, EPA 402-R-99-004B.

U.S. Environmental Protection Agency (2000), "Drinking Water Regulations and Health Advisories," EPA-822-B-00-001. 
U.S. Pat. No. 6,217,775, issued April 17, 2001, for "Treatment of Metal-Contaminated Leachates Utilizing Fish Bones and Fish Hard Parts."

U.S. Pat. Application Ser. No. 09/671,807, filed September 22, 2000, for "Stabilization and Remediation of Metal-Contaminated Soil Using Fish Bones."

Valsami-Jones, E.; Ragnarsdottir, K.V.; Putnis, A.; Bosbach, D.; Kemp, A.J.; Cressey, G. (1998). "The dissolution of apatite in the presence of aqueous metal cations at pH 2-7," Chemical Geology, 151, 215-233.

Van Haverbeke, Laurent; Vochten Renaud Van Springel, Karel. "Solubility and Spectrochemical Characteristics of Synthetic Chernikovite and Meta-Ankoleite," Mineralogical Magazine, 60 (1996), p. 759-766.

Villalobos, M.; Trotz, M.A.; Leckie, J.O. (2001), "Surface Complexation Modeling of Carbonate Effects on the Adsorption of $\mathrm{Cr}(\mathrm{VI}), \mathrm{Pb}(\mathrm{II})$ and U(VI) on Goethite," Environ. Sci. Technol., 35, 3849-3856.

Von Gunten, H.R.; Beneš, P. (1995), "Speciation of Radionuclides in the Environment,: Radiochim. Acta, 69, 1-29.

Wildung, R.E.; McFadden, K.M.; Garland, T.R. (1979). "Technetium Sources and Behavior in the Environment," J. Environ. Qual., 6, 156.

Wright, J.V., L.M. Peurrung, T.E. Moody, J.L. Conca, X. Chen, P.P. Didzerekis and E. Wyse (1995). In Situ Immobilization of Heavy metals it: Apatite Mineral Formulations, Technical Report to the Strategic Environmental Research and Development Program, Department of Defense, Pacific Northwest Laboratory, Richland, WA, 154 p.

Yanase, N., et al. (1991), "Uranium Distribution in Mineral Phases of Rock by Sequential Extraction Procedure," Radiochim. Acta, 52/53, 387-393.

Zachara, J.M.; Girvin, D.C.; Schmidt, R.L., Resch, C.T. (1987), “Chromate Adsorption on Amorphous Iron Oxyhydride in the Presence of Major Groundwater Ions," Environ. Sci. Technol., 21, 589-594.

Zachara, J.M.; Cowan, C.E.; Resch, C.T. (1993), "Metal Cation/Anion Adsorption on Calcium Carbonate: Implications to Metal Ion Concentrations in Groundwater," Chap. 2 in Allen, H.E.; Perdue, E.M.; Brown, D.S., Metals in Groundwater, Lewis Publ., Ann Arbor, MI.

Zhang, F., J.A. Ryan, and J. Yang (1998). "In Vitro Soil Pb Solubility in the Presence of Hydroxyapatite,” Environ. Sci. Technol., 32, 2763-2768. 
Zawacki, S.J.; Koutsoukos, P.B.; Salimi, M.H.; Nancollas, G.H. (1986), "The Growth of Calcium Phosphates," Chapt. 22 in J.A. Davis and K.H. Hayes (Eds.), Geochemical

Processes at Mineral Surfaces, American Chemical Society, Washington, DC.

Zhang, F., J.A. Ryan, and J. Yang (1998), "In Vitro Soil Pb Solubility in the Presence of Hydroxyapatite,” Environ. Sci. Technol. 32, 2763-2768. 


\subsection{LIST OF ACRONYMS AND ABBREVIATIONS}

APA

APA-C

Apatite II $^{\mathrm{TM}}$

AWC

BA

BYBY

$\mathrm{Cc}$

$\mathrm{C}_{\mathrm{e}}$

CFR

$\mathrm{Cg}$

DI-water

DOD

DOE

EDA

EPA

EPRI

FTIR

FRL
Apatite (generally used to represent raw biogenic material, e.g, fish bone meal).

Apatite char (APA that has been thermally processed to destroy excess organic matter; Apatite IIC).

The form of APA provided by PIMS-NW, Inc. for use in metals stabilization under U.S. Patent 6,217,775.

Acid washed coal

Bioaccessibility (as defined by Solubilty/Bioavailability Research Consortium (SBRC) SOP 110499, Rev \#8).

Burnyard-Boneyard area, located at the DOE Y-12 National Security Complex in Oak Ridge, TN.

Cubic centimeters (or milliliters)

Equilibrium concentration of soluble contaminant in the aqueous phase $(\mathrm{g} / \mathrm{mL})$. (Solute concentration in the Aqueous phse).

Consolidated Federal Register

Lognormal distribution median value.

De-ionized distilled water (Resistivity $\geq 18.2 \mathrm{M} \Omega$-cm, prepared with use of Milli-Q Plus Reagent Water System, Millipore Corp.)

U.S. Department of Defense

U.S. Department of Energy

Exposed Dry Apatite (metal-laden raw fishbone preparation).

U.S. Environmental Protection Agency

Electric Power Research Institute

Fourier Transform Infrared (spectroscopic method).

DOE Fernald Site Final Remediation Level

Hours 
HAP

ICDD

ICP-OES

$\mathrm{K}_{\mathrm{d}}$

$\mathrm{K}_{\mathrm{F}}$

$\mathrm{K}_{\mathrm{sp}}$

LSC

LOI

MCL

MCLinc

NETL

PGDP

$\mathrm{R}_{\mathrm{f}}$

RH

RPM

$S$

S

SDWR

SEM-EDS

SMEWW
Hydroxyapatite (nominally $\left.\mathrm{Ca}_{5}\left(\mathrm{PO}_{4}\right)_{3-\mathrm{x}}\left(\mathrm{CO}_{3}\right)_{\mathrm{x}}(\mathrm{OH})_{1+\mathrm{x}}\right)$. HAP is the principal mineral component in bone tissue.

International Centre for Diffraction Data

Inductively coupled plasma with optical emission spectroscopy (analytical technique).

Conditional contaminant distribution coefficient $(\mathrm{mL} / \mathrm{g})$, determined from the sorption isotherm.

Empirical Freundlich distribution coefficient $\left(\mathrm{K}_{\mathrm{F}}=\mathrm{S} / \mathrm{C}_{\mathrm{e}}{ }^{\mathrm{n}}\right)$.

Solubility product

Liquid scintillation counting

Loss on Ignition (a measure of organic matter).

Maximum Contaminant Level (U.S. EPA water quality criterion)

Materials and Chemistry Laboratory, Inc., Oak Ridge, TN.

National Energy Technology Laboratory

Paducah Gaseous Diffusion Plant

Retardation factor (Maximum number of bed pore volumes that can be treated before solute breakthrough).

Relative humidity

Revolutions per minute

Lognormal distribution spread factor (a statistical measure of variance)

Mass of contaminant "sorbed" at equilibrium per mass of sorbent (i.e., solute concentration in the solid phase).

U.S. EPA Secondary Drinking Water Regulation

Scanning Electron Spectrocopy with Energy Dispersive Spectroscopy (analytical technique).

Standard Methods for the Examination of Water and Wastewater 
Syn-BYBY Synthetic DOE Y-12 Boneyard-Burnyard (BYBY) groundwater composition.

Syn-HAP Synthetic hydroxyapatite (see HAP).

TCLP Toxicity Characteristic Leaching Procedure (EPA SW846 Method 1311).

U.S. United States of America

$\mathrm{Wt} \% \quad$ Weight percentage composition

XRD X-ray diffraction (analytical technique).

XPS X-ray photoelectron spectroscopy (analytical technique).

XRF X-ray fluorescence (analytical technique).

$\mu \mathrm{m} \quad$ micrometer $\left(1 \times 10^{-6}\right.$ meter $)$

$\rho_{\mathrm{b}} \quad$ Bulk density $\left(\mathrm{g} / \mathrm{cm}^{3}\right)$.

$\theta \quad$ Void fraction or gross porosity 


\section{Appendix A-1}

\section{NETL Batch Testing Individual Metals - Operational Instructions}

A. Prepare serial dilutions of metals from Metal Stock using syn-ByBy (synthetic groundwater described in test plan) for dilution $(50 \mathrm{ml}$ of stock metal solution $\sim 250 \mathrm{mg} / \mathrm{L}$ if all dissolved.) as:

M-A1 is metal stock $\sim 250 \mathrm{mg} / \mathrm{L}$ filtered through 0.45 um Nalge filter M-A2 is $50 \mathrm{~mL}$ of $\mathrm{A} 1$ plus $100 \mathrm{~mL}$ of syn-ByBy in a clean beaker to give nominal $1 / 3$ of 250 or 83 ppm solution*

$\mathrm{M}-\mathrm{A} 3$ is $50 \mathrm{~mL}$ of A2 plus $100 \mathrm{~mL}$ of syn-ByBy nominal 28ppm*

M-A4 is $50 \mathrm{~mL}$ of A3 plus $100 \mathrm{~mL}$ of syn-ByBy nominal $9.3 \mathrm{ppm} *$

*Note: actual concentrations will be determined by ICP

$\mathrm{M}$ is the symbol of metal being processed.

B. Equilibrate with with Apatite( material 01-0263; in B108)

To a series of $50 \mathrm{~mL}$ plastic centrifuge cones weigh out $\sim 0.8 \mathrm{~g}$ apatite (record actual weights used) to each tube with the Apatite add $40 \mathrm{~mL}$ of the appropriate solution and label as:

$\mathrm{M}-\mathrm{B} 1=0.8 \mathrm{~g}$ Apatite $+40 \mathrm{~mL}$ of $\mathrm{A} 1$

$\mathrm{M}-\mathrm{B} 2=0.8 \mathrm{~g}$ Apatite $+40 \mathrm{~mL}$ of $\mathrm{A} 2$

$\mathrm{M}-\mathrm{B} 3=0.8 \mathrm{~g}$ Apatite $+40 \mathrm{~mL}$ of A3

$\mathrm{M}-\mathrm{B} 4=0.8 \mathrm{~g}$ Apatite $+40 \mathrm{~mL}$ of $\mathrm{A} 4$

C. Mount tubes/cones - all of the A and B series ( 8 tubes per metal at $40 \mathrm{~mL}$ each) on TCLP apparatus for phase contact and use strong rubber bands or other means to secure to apparatus. Record start of tumble.

C1 Tumble for 50 hours then stop!

C2 Remove tubes from the tumbler, place in rack and then measure and record

$\mathrm{pH}$. ( Wash the electrode thoroughly with DI water between samples)

C3 Centrifuge at 4600rpm for 2 minutes. Centrifuge is in E-104 on right as you enter.

C4 Then filter through 0.2um Nalge filter.

C5 Add filtrate to labeled $60 \mathrm{~mL}$ plastic bottles and preserve the $40 \mathrm{~mL}$ with $4 \mathrm{~mL}$ of metals grade Nitric Acid used for ICP. To give a 10\% acid solution**

C6 Submit samples to ICP for analysis of the metal of interest and $\mathrm{Ca}$ and P.

C7 Review results with JRH and then submit to WDB to calculate $\mathrm{Kd}$.

** WDB to make volume adjustments in final spreadsheet calculations.

J.R. Hall 


\section{Appendix A-2}

Date: $\quad$ March 18, 2002

To: W. D. Bostick

From: $\quad$ J. W. Zolyniak

Subject: Experimental Design for Multi-Factor NETL Study

The attached table gives the experimental conditions and running order for the four metal NETL study. The experimental design is called a four-factor central composite design run in three blocks. Each factor will be run at five different levels. There are six center replicates, two in each experimental block. There are thirty total experiments, ten per block. The running order of the experiments was randomized within each block.

According to our previous discussions, you need to do the following before starting the experiments.

Identify the four metals and their five concentration levels. The table codes the five levels as -2 , $-1,0,1$ and 2 for each metal. The actual concentration levels and ranges can be different for each metal. For example, the concentration levels for metal 1 may be 100, 150, 200, 250, and 300, while metal 2 may be 15, 20, 25, 30, and 35 .

Be sure that all of the all of the combinations of experimental conditions listed in the table will produce the required measurements. The highest and lowest concentration levels of a metal (+/-2) will only be run in combination with the middle concentration levels ( 0 ) of the other three metals. It may be beneficial to test some of the combinations before starting the experiments. The statistical analysis of experimental data and the conclusions of the study will be messy if any of the experiments fail to run.

Establish levels or values for all of the variables that are not part of study and control them at these levels for length of the study.

Plan the experimental schedule so that unavoidable interruptions or changes in general experimental conditions occur between the blocks of experiments. For example, plan so the weekend falls between blocks or make changes in batches of materials between blocks of experiments. All of the experiments that share the effects of common setup or preparation step should be in the same block.

Please call me if you have any questions or problems with the design. 
Randomized Running Order of the 30 Experiments of the Central Composite Design

\begin{tabular}{|c|c|c|c|c|c|}
\hline $\begin{array}{l}\text { Block } \\
\text { No. }\end{array}$ & $\begin{array}{l}\text { Running } \\
\text { Order }\end{array}$ & $\begin{array}{l}\text { Metal } \\
1 \\
\end{array}$ & $\begin{array}{c}\text { Metal } \\
2 \\
\end{array}$ & $\begin{array}{c}\text { Metal } \\
3 \\
\end{array}$ & $\begin{array}{l}\text { Metal } \\
4 \\
\end{array}$ \\
\hline 1 & 1 & 1 & -1 & -1 & 1 \\
\hline 1 & 2 & 1 & 1 & 1 & 1 \\
\hline 1 & 3 & 1 & -1 & 1 & -1 \\
\hline 1 & 4 & 0 & 0 & 0 & 0 \\
\hline 1 & 5 & -1 & -1 & -1 & -1 \\
\hline 1 & 6 & -1 & -1 & 1 & 1 \\
\hline 1 & 7 & -1 & 1 & -1 & 1 \\
\hline 1 & 8 & 1 & 1 & -1 & -1 \\
\hline 1 & 9 & 0 & 0 & 0 & 0 \\
\hline 1 & 10 & -1 & 1 & 1 & -1 \\
\hline 2 & 1 & 1 & -1 & 1 & 1 \\
\hline 2 & 2 & 1 & 1 & -1 & 1 \\
\hline 2 & 3 & -1 & 1 & -1 & -1 \\
\hline 2 & 4 & 0 & 0 & 0 & 0 \\
\hline 2 & 5 & -1 & 1 & 1 & 1 \\
\hline 2 & 6 & -1 & -1 & -1 & 1 \\
\hline 2 & 7 & 1 & -1 & -1 & -1 \\
\hline 2 & 8 & 0 & 0 & 0 & 0 \\
\hline 2 & 9 & -1 & -1 & 1 & -1 \\
\hline 2 & 10 & 1 & 1 & 1 & -1 \\
\hline 3 & 1 & 0 & 0 & 0 & -2 \\
\hline 3 & 2 & 0 & 0 & 0 & 0 \\
\hline 3 & 3 & 0 & 0 & 2 & 0 \\
\hline 3 & 4 & 0 & 0 & 0 & 2 \\
\hline 3 & 5 & 0 & -2 & 0 & 0 \\
\hline 3 & 6 & 0 & 0 & 0 & 0 \\
\hline 3 & 7 & 0 & 2 & 0 & 0 \\
\hline 3 & 8 & 2 & 0 & 0 & 0 \\
\hline 3 & 9 & -2 & 0 & 0 & 0 \\
\hline 3 & 10 & 0 & 0 & -2 & 0 \\
\hline
\end{tabular}

The tabled values for the metals denote the actual concentration levels to be used. Each of the four metals can have different concentration levels and different ranges.

\begin{tabular}{c} 
Design Value \\
\hline-2 \\
-1 \\
0 \\
1 \\
2
\end{tabular}

Actual Concentration Level for a Metal
The lowest concentration level used in the study (Axial)
The average of the central and lowest (Factorial Level)
The average of the lowest and highest (Central Level)
The average of the central and highest (Factorial Level)
The highest concentration level used in the study (Axial)




\section{Appendix A-3}

Summary of Regression Analysis of Ce and Kd Measurements from the Four-Metal Experimental Design

\begin{tabular}{|l|l|c|c|c|}
\hline & \multicolumn{4}{|l|}{$\begin{array}{l}\text { Regression Results Using the Calculated Values } \\
\left(\mathrm{C}_{0}\right) \text { for the Initial Levels of the Four Metals }\end{array}$} \\
\hline \multicolumn{1}{|c|}{ Measurement } & Terms in the Model & $\mathrm{R}^{2}$ & $\begin{array}{c}\text { Coef. of } \\
\text { Var. (\%) }\end{array}$ & $\begin{array}{c}\text { Root Mean } \\
\text { Square Error }\end{array}$ \\
\hline $\mathrm{Hg} \mathrm{Kd}$ & Intercept, $\mathrm{Hg}, \mathrm{Hg}^{2}$ & 0.58 & 39.9 & 722.0 \\
\hline $\begin{array}{l}\mathrm{Hg} \mathrm{Kd} \text { using half of the } \\
\text { Ce detection limit }\end{array}$ & Intercept, $\mathrm{Hg}, \mathrm{Hg}^{2}$ & 0.80 & 37.3 & 867.5 \\
\hline $\mathrm{Hg} \mathrm{Ce}$ & Intercept, $\mathrm{Hg}$ & 0.70 & 35.2 & 68.0 \\
\hline $\begin{array}{l}\mathrm{Hg} \mathrm{Ce} \text { using half of the } \\
\text { detection limit }\end{array}$ & Intercept, $\mathrm{Hg}$ & 0.72 & 37.6 & 70.2 \\
\hline $\mathrm{Cd} \mathrm{Kd}$ & Block, $\mathrm{Cd}, \mathrm{Hg}, \mathrm{Cd}^{2}$ & 0.56 & 13.3 & 4577.2 \\
\hline $\mathrm{Cd} \mathrm{Ce}$ & Cd, $\mathrm{U}, \mathrm{U}^{2}$ & 0.81 & 20.6 & 3.83 \\
\hline
\end{tabular}

Six of the $30 \mathrm{Hg}$ Ce measurements were nondetections. None of the $\mathrm{Cd}$ measurements were nondetections. Using half of the Ce detection value increased the amount of variation in the $\mathrm{Ce}$ and $\mathrm{Kd}$ data.

$\mathrm{Pb}$ and $\mathrm{U}$ measurements were not modeled because of the large number of $\mathrm{Ce}$ nondetections: all $30 \mathrm{~Pb}$ measurements and 20 of the $30 \mathrm{U}$ measurements.

The full model used was

$(\mathrm{Ce}, \mathrm{Kd})=\quad($ Intercept and/or Block Effect $)+\mathrm{b}_{1} \mathrm{Hg}+\mathrm{b}_{2} \mathrm{~Pb}+\mathrm{b}_{3} \mathrm{Cd}+\mathrm{b}_{4} \mathrm{U}+$

$b_{12} \mathrm{HgPb}+b_{13} \mathrm{HgCd}+b_{14} \mathrm{HgU}+\mathrm{b}_{23} \mathrm{PbCd}+\mathrm{b}_{24} \mathrm{PbU}+\mathrm{b}_{34} \mathrm{CdU}$

$$
+b_{11} \mathrm{Hg}^{2}+b_{22} \mathrm{~Pb}^{2}+b_{33} \mathrm{Cd}^{2}+\mathrm{b}_{44} \mathrm{U}^{2}+\text { measurement error. }
$$

The root mean square error is an estimate of the standard deviation of the error term. It is model dependent. It has the same units as $\mathrm{Ce}$ or $\mathrm{Kd}$.

The coefficient of variation is 100 times the root mean square error divided by the overall mean of the dependent variable (either $\mathrm{Ce}$ of $\mathrm{Kd}$ ).

$\mathrm{R}^{2}$ is the proportion of total variation in the measurements that is explained by the model. 


\section{Appendix A-4}

Summary of Comparison of Single Metal Estimate (SME) with Four-Metal Design Kd $(4 \mathrm{M} \mathrm{Kd})$ Measurements

\begin{tabular}{|c|c|c|c|}
\hline Measurement & Mean & $\begin{array}{c}\text { Number of } \\
4 \mathrm{M} \mathrm{Kds}>\text { SMEs }\end{array}$ & $\begin{array}{c}\text { Correlation of } \\
4 \mathrm{M} \mathrm{Kd} \& \mathrm{SME}\end{array}$ \\
\hline $\mathrm{Hg} 4 \mathrm{M} \mathrm{Kd}$ & 1808.1 & \multirow{2}{*}{28 of 30} & \multirow{2}{*}{0.91} \\
\hline $\mathrm{Hg} \mathrm{SME}$ & 876.5 & & \\
\hline $\begin{array}{l}\text { Hg Difference: } \\
\text { 4M Kd - SME }\end{array}$ & 931.6 & & \\
\hline $\mathrm{Cd} 4 \mathrm{M} \mathrm{Kd}$ & 34419.7 & \multirow{2}{*}{30 of 30} & \multirow{2}{*}{-0.68} \\
\hline Cd SME & 261.6 & & \\
\hline $\begin{array}{l}\text { Cd Difference: } \\
\text { 4M Kd - SME }\end{array}$ & 34158.1 & & \\
\hline
\end{tabular}

The $\mathrm{Hg}$ and $\mathrm{Cd}$ differences (Kd - SME) are statistically significantly greater than zero.

A positive correlation coefficient of 0.91 means that larger $\mathrm{Hg} \mathrm{Kds}$ are associated with larger $\mathrm{Hg}$ SMEs and the relationship is fairly strong. A negative correlation of -0.68 means that larger $\mathrm{Cd} \mathrm{Kds} \mathrm{are} \mathrm{associated} \mathrm{with} \mathrm{smaller} \mathrm{Cd} \mathrm{SMEs.} \mathrm{The} \mathrm{relationship} \mathrm{is}$ weaker than $\mathrm{Hg}$. 